\title{
Fusion Materials Research at Oak Ridge National Laboratory in Fiscal Year 2016
}

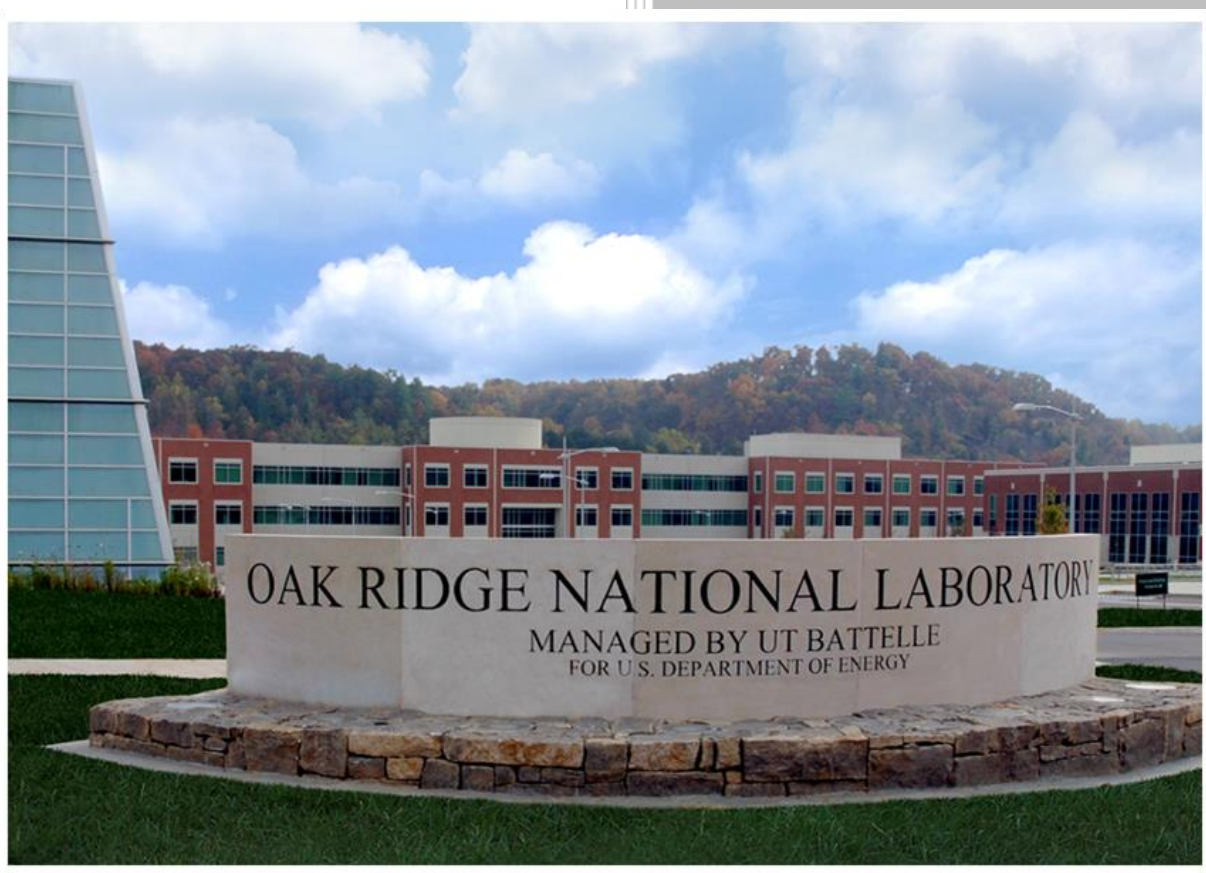

Compiled by:

F.W. Wiffen

Y. Katoh

S. Melton 


\title{
DOCUMENT AVAILABILITY
}

Reports produced after January 1, 1996, are generally available free via US Department of Energy (DOE) SciTech Connect.

Website http://www.osti.gov/scitech/

Reports produced before January 1, 1996, may be purchased by members of the public from the following source:

\author{
National Technical Information Service \\ 5285 Port Royal Road \\ Springfield, VA 22161 \\ Telephone 703-605-6000 (1-800-553-6847) \\ TDD 703-487-4639 \\ Fax 703-605-6900 \\ E-mail info@ntis.gov \\ Website http://www.ntis.gov/help/ordermethods.aspx
}

Reports are available to DOE employees, DOE contractors, Energy Technology Data Exchange representatives, and International Nuclear Information System representatives from the following source:

Office of Scientific and Technical Information

PO Box 62

Oak Ridge, TN 37831

Telephone 865-576-8401

Fax 865-576-5728

E-mail reports@osti.gov

Website http://www.osti.gov/contact.html

This report was prepared as an account of work sponsored by an agency of the United States Government. Neither the United States Government nor any agency thereof, nor any of their employees, makes any warranty, express or implied, or assumes any legal liability or responsibility for the accuracy, completeness, or usefulness of any information, apparatus, product, or process disclosed, or represents that its use would not infringe privately owned rights. Reference herein to any specific commercial product, process, or service by trade name, trademark, manufacturer, or otherwise, does not necessarily constitute or imply its endorsement, recommendation, or favoring by the United States Government or any agency thereof. The views and opinions of authors expressed herein do not necessarily state or reflect those of the United States Government or any agency thereof. 
Materials Science and Technology Division

FUSION MATERIALS RESEARCH AT OAK RIDGE NATIONAL LABORATORY IN FISCAL YEAR 2016

Compiled by:

F.W. Wiffen

Y. Katoh

S. Melton

Date Published: November 2016

Prepared by

OAK RIDGE NATIONAL LABORATORY

Oak Ridge, TN 37831-6283

managed by

UT-BATTELLE, LLC

for the

US DEPARTMENT OF ENERGY

under contract DE-AC05-00OR22725 


\section{CONTENTS}

CONTENTS iii

LIST OF FIGURES v

LIST OF TABLES.. ix

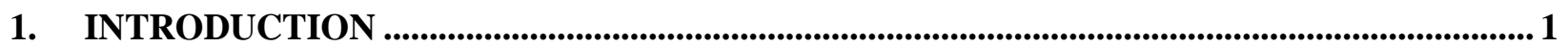

2. FUSION MATERIAL IRRADIATION TEST STATION (FMITS) AT SNS ........................... 3

3. ADVANCED STEELS

3.1 DEVELOPMENT OF HIGH-Cr ODS ALLOYS WITH Zr ADDITIONS FOR FUSION REACTOR APPLICATIONS .

3.2 DEVELOPMENT OF TRANSFORMATION ENHANCED ODS Fe-Cr ALLOYS ......... 8

3.3 DEVELOPMENT OF ADVANCED RAFM STEELS - CASTABLE NANOSTRUCTURED ALLOYS 9

3.4 BAINITIC STEEL DEVELOPMENT FOR FUSION APPLICATIONS ........................ 11

3.5 IRRADIATION EFFECTS IN 9Cr RAFM STEELS USING ${ }^{54}$ Fe ISOTOPE.................. 14

3.6 IMPACT OF NEUTRON IRRADIATION ON THERMAL HELIUM DESORPTION FROM IRON . 16

3.7 LIQUID METAL COMPATIBILITY IN FLOWING Pb-Li SYSTEMS........................... 19

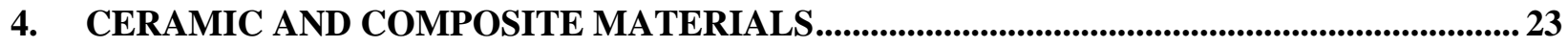

4.1 DEVELOPMENT OF SiC JOINING TECHNOLOGIES FOR FUSION .......................23

4.2 HIGH DOSE NEUTRON IRRADIATION EFFECTS ON MECHANICAL PROPERTIES OF SIC MATERIALS AND COMPOSITES ............................................... 25

4.3 PROPERTIES OF NEUTRON IRRADIATED NITE SiC MATERIALS........................ 28

4.4 ADVANCED CHARACTERIZATION OF IRRADIATION DEFECTS IN SiC............. 31

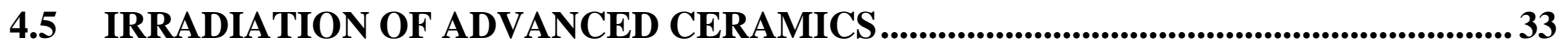

5. HIGH HEAT FLUX AND PLASMA FACING MATERIALS ................................................35

5.1 FABRICATION OF FUNCTIONALLY GRADED TUNGSTEN STEEL

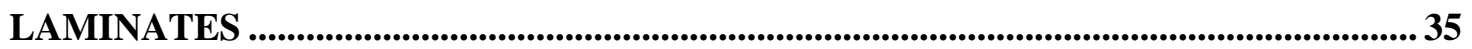

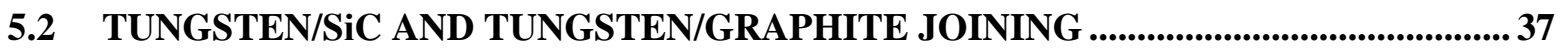

5.3 DETERMINATION OF PRECIPITATE COMPOSITION IN IRRADIATED TUNGSTEN USING NEUTRON INVENTORY CALCULATIONS AND ATOM

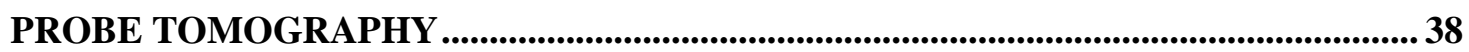

5.4 NEUTRON IRRADIATION EFFECTS IN TUNGSTEN .................................................. 40

5.5 NEUTRON IRRADIATION EFFECTS IN TUNGSTEN-COPPER COMPOSITES ..... 43

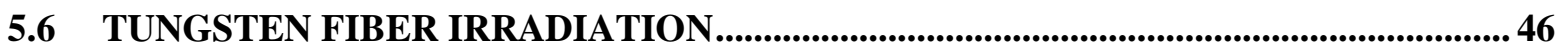

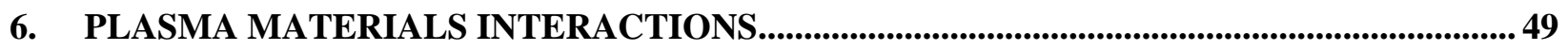

6.1 DAMAGE MECHANISM INTERACTIONS AT THE PLASMA-MATERIALS INTERFACE

6.2 IMPACT OF HELIUM BUBBLES ON DEUTERIUM DESORPTION KINETICS

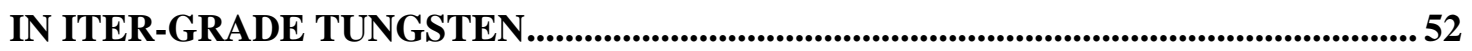

6.3 HIGH-HEAT FLUX TESTING OF FUSION MATERIALS.............................................55

7. EXPLORATORY, UNIQUE AND INNOVATIVE MATERIALS................................................59

7.1 DESIGN AND DEVELOPMENT OF NOVEL CU ALLOYS FOR FUSION ENERGY APPLICATIONS

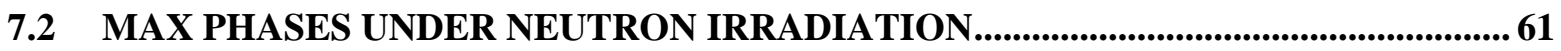

7.3 PRELIMINARY ASSESSMENT OF THE IRRADIATION BEHAVIOUR OF THE FeCrMnNi HIGH-ENTROPY ALLOY FOR NUCLEAR APPLICATIONS ......... 63

8. COMPUTATIONAL MATERIALS SCIENCE

8.1 STRENGTHENING MECHANISMS IN IRRADIATED ALLOYS 


\subsection{PROPERTIES OF VACANCY-HELIUM-HYDROGEN COMPLEXES IN}

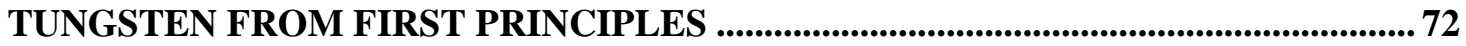

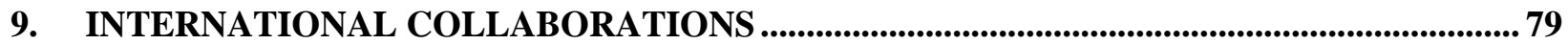

9.1 US-JAPAN COLLABORATIONS ON STRUCTURAL MATERIALS .......................... 79

9.2 US-JAPAN PHENIX PROGRAM .......................................................................................... 83

10. MATERIALS ENGINEERING SUPPORTING THE FNSF STUDY ........................................85

11. EXPERIMENTAL TECHNIQUES AND LABORATORY SYSTEMS ..................................... 87

11.1 IAEA ACTIVITY FOR STANDARDIZATION OF SMALL SPECIMEN TEST TECHNIQUES FOR FUSION

11.2 MINIATURE TEST DEVELOPMENT FOR TUNGSTEN-BASED MATERIALS ....... 88

11.3 NEW AND UPGRADED TESTING CAPABILITIES FOR IRRADIATED MATERIALS 89

11.4 ORNL INVENTORY SYSTEM FOR MANAGEMENT OF RADIOACTIVE SPECIMENS 94

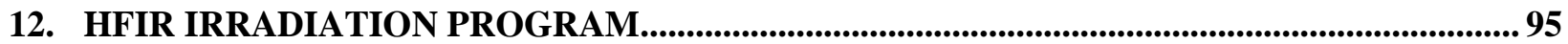

12.1 ARCHIVAL SAMPLES FOR THE FUSION MATERIALS COMMUNITY .................. 95

12.2 THE MFE-RB-19J HFIR IRRADIATION EXPERIMENT ................................................ 97

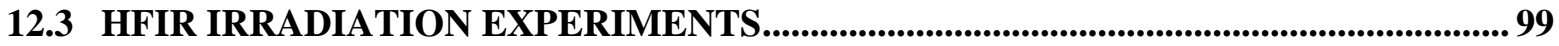

13. PUBLICATION AND PRESENTATION RECORD ..........................................................101

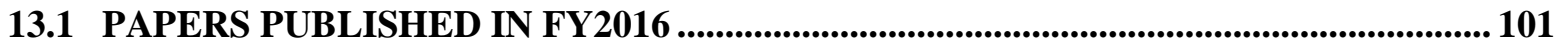

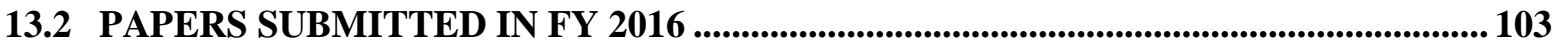

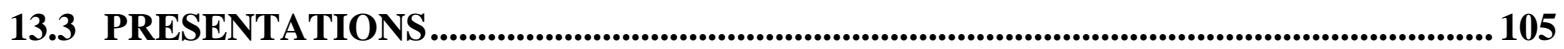




\section{LIST OF FIGURES}

Figure 1. a) High-resolution TEM image of $\mathrm{Zr}$-rich particle formed in $\mathrm{Fe}-12 \mathrm{Cr}-5 \mathrm{Al}-\mathrm{Zr}$ $\mathrm{Y}_{2} \mathrm{O}_{3}$ alloy identified as $\mathrm{Zr}(\mathrm{C}, \mathrm{N})$ with the space group $\mathrm{Fm} 3 \mathrm{~m}$ using b) FFT, and c) corresponding EDS Y, Zr, Al, and $\mathrm{O}$ elemental maps showing the special proximity between the $\mathrm{Zr}(\mathrm{C}, \mathrm{N})$ and $\mathrm{Y}$-Al-O particles.

Figure 2. Cross-section of the oxide formed on $125 \mathrm{YZ}$ after exposure for $1000 \mathrm{~h}$ at $700^{\circ} \mathrm{C}$ in static Pb-17Li, (a,c) BF-STEM images, b) HAADF-STEM images, d) EDS point spectrum generated from particle within the oxide.

Figure 3. Tensile properties of the $1^{\text {rst }}$ generation $125 \mathrm{YZ}$ alloy, and several $2^{\text {nd }}$ generation ODS Fe-10Cr-6Al-0.3Zr alloys extruded at temperature ranging from $900^{\circ} \mathrm{C}$ to $1050^{\circ} \mathrm{C}$, a) Ultimate tensile strength, b) Plastic deformation.

Figure 4. a) Comparison of the creep performance at $700^{\circ} \mathrm{C}$ of the $125 \mathrm{YZ}$ and $106 \mathrm{ZY} 9 \mathrm{C}$ alloys with the performance of new ODS FeCrAl alloys developed in Japan [2], b) Lifetimes of the $125 \mathrm{YZ}, 125 \mathrm{YT}, 125 \mathrm{YH}$ and $106 \mathrm{ZY9C}$ alloys tested at $800^{\circ} \mathrm{C}$ with an applied stress of $100 \mathrm{MPa}$.

Figure 5. Extruded bars of the ODS $10 \mathrm{WV}\left(\mathrm{Fe}-10 \mathrm{Cr}-1 \mathrm{~W}-0.3 \mathrm{Ti}-0.2 \mathrm{~V}+0.3 \mathrm{Y}_{2} \mathrm{O}_{3}\right)$ and $10 \mathrm{~V}$ (Fe-10Cr-0.3Ti-0.2 $+0^{0.3 Y_{2}} \mathrm{O}_{3}$ ) alloys.

Figure 6. SRIM-calculated depth profiles of dose (black) and implanted iron (red) after low (dashed) and high (solid) levels of irradiation damage. The experimentally characterized depth-dependent particle area fractions in three conditions are overlapped on the calculated profiles. Examples of particle shapes at $\sim 650 \mathrm{~nm}$ from surface are shown on right

Figure 7. Backscattered electron images (BEIs) of two heats of CNAs (05-3 and 06-3) compared to BEI and Ta-EDS of F82H-BA07.

Figure 8. Yield strength of the base and new 3Cr-3WVTa bainitic steels plotted as a function of test time, together with the data for Grade 91 (Mod. 9Cr-1Mo) F-M steels obtained from NIMS data sheets.

Figure 9. An example of cross-sectional micrograph of autogenous GTAW welds on a tempered bainitic steel (a), and the hardness contour maps (b, c, d); (a, b) base 3Cr-3WVTa, (c) LC, and (d) MSLC2.

Figure 10. (a) As-cast ingots of EUROFER97 (E97-54) and CNA (CNA-54) made of ${ }^{54} \mathrm{Fe}$ isotope, and (b) the rolled and annealed plates.

Figure 11. Machining plan of SS-J3 and M4 bend bar specimens.

Figure 12. High-angle annular dark field (HAADF) imaging of (a) as-irradiated polycrystalline Fe specimen, F02, irradiated in BOR-60 to 16.6 dpa at $386^{\circ} \mathrm{C}$; (b) as-irradiated single crystalline Fe specimen, A4, irradiated in HFIR to 5 dpa at $300^{\circ} \mathrm{C}$. The two enlargements on the right of (a) and (b) show the bright field TEM images of the marked region in the over focus and under focus conditions.

Figure 13. Comparison of He desorption spectra of the He-implanted samples before and after neutron irradiations: (a) polycrystalline $\mathrm{Fe}$; (b) single crystalline Fe.

Figure 14. Kanthal APMT thermal convection loop prepared for $600^{\circ} \mathrm{C}$ experiment. Furnaces are placed over the hot leg for operation and insulation is used as needed.

Figure 15. Room temperature yield strength of APMT specimens exposed to flowing Pb-Li eutectic for $1000 \mathrm{~h}$ at the indicated temperature. Indicated data are for specimens that did not receive the pre-oxidation heat treatment.

Figure 16. Post-exposure plan-view secondary electron SEM images of the APMT surfaces............ 21

Figure 17. Higher magnification post-exposure plan-view secondary electron SEM images of the APMT surfaces. 
Figure 18. SEM micrographs of unirradiated and irradiated TEP joints of SiC.

Figure 19. Comparison of typical creep coefficients among different nuclear materials.

Figure 20. STEM-HAADF micrographs of Hi-Nicalon Type $\mathrm{S}$ fiber and $\mathrm{SiC} / \mathrm{C}$ multi-layer interface irradiated to 100 dpa.

Figure 21. SiC materials after irradiation, adapted from Snead, Katoh, et al and other data. (Journal of Nuclear Materials, to be published) It shows that like CVD, NITE materials increase in strength.

Figure 22. Calculated Raman spectra of confined LO phonon line of $3 \mathrm{C} \mathrm{SiC}$ with various size of correlation diameters: an indication of defect-defect distance (a). Raman spectra of irradiated $\mathrm{SiC}$ at $540^{\circ} \mathrm{C}$ to $0.01 \mathrm{dpa}(\mathrm{b})$ and to $0.11 \mathrm{dpa}(\mathrm{c})$ are compared with the calculated spectra considering change in lattice constant and phonon confinement effect. The experimental spectra are well described as the sum of the calculated spectra and a Gaussian peak known as Raman band of amorphous or disordered SiC.

Figure 23. Components of HFIR rabbit irradiation capsule and Advanced Ceramic specimens.

Figure 24. Stress-strain curves for composite material with three $W$ layers, one $W$ layer, and no $W$ layers.

Figure 25. Atom maps showing the nucleation and maturation of the second phase precipitates in the single crystal irradiated tungsten for the (a) $0.2 \mathrm{dpa}$ and (b) 2.2 dpa specimens. In both reconstructions, the black points represent $1 \%$ of all the $\mathrm{W}$ ions detected. Concentration isosurfaces are used to highlight the second phase precipitates, and these were constructed using (a) 5at.\% ReOs, and (b) 20at.\% ReOs.

Figure 26. Ternary phase diagrams for the (a) low and (b) high dose data. The neutron inventory predicted bulk composition is shown (FISPACT), along with the corrected atom probe bulk and precipitate compositions. Phase boundaries for $1000-1500$ and $1600^{\circ} \mathrm{C}$ are overlaid onto the ternary diagram to show possible phases in the material system. The $\sigma$-phase is highlighted.

Figure 27. Microstructural evolution in single crystalline and polycrystalline pure $W$ materials irradiated with neutrons.

Figure 28. Microhardness of irradiated single crystal tungsten before and after HFIR irradiation.

Figure 29. Radiation-induced hardening contributions due to various defects identified from TEM observations based on linear superposition of the dispersed barrier hardening model.

Figure 30. Summary tensile behavior of tungsten-copper laminate after neutron irradiation.

Test temperature is approximately equal to the irradiation temperature. The zone boundaries are estimates, intended to help group points with similar behavior. [From L.M. Garrison, et al J Nucl Mater 481 (2016) 134-146].

Figure 31. The tungsten-copper laminate material was analyzed with EBSD in the unirradiated and irradiated state. Each sample is shown with band contrast, detail view of a tungsten-copper interface, and a larger view of multiple layers of the composite.

Figure 32. SEM image of the powder sintered tungsten copper composite.

Figure 33. Tensile curves of the tungsten-copper sintered composite at room temperature..............45

Figure 34. Tungsten fiber assembly in graphite tube. a) distant view, b) close in view, c) tilted view. 
Figure 35. Left: Approximate loading location of fibers. Because fibers could move around the $\mathrm{SiC}$ piece and because of the difficulty of loading these very small fibers, the cartoon loading locations are not exactly the same as the actual loading, but effort was made to keep the Type 1 and Type 2 fibers on opposite sides of the $\mathrm{SiC}$ piece to help identify them after irradiation. Right: Fibers in tube before end cap was inserted.

Figure 36. One of the graphite tubes is shown after the fibers were loaded with the end cap in place.

Figure 37. (a) SEM image of an isolated nanotendril. (b) Transmission Kikuchi diffraction (tKD) image quality map of the tendril. (c) Inverse-pole-figure image of the grain orientations, colored in the $Z$ (out-of-page) orientation, colored according to the unit triangle shown. Reprinted from [1].

Figure 38. (a) Tendril grain long-axis directions. (b) Tendril grain boundary character. (c) Tendril grain boundary misorientation histogram. $\mathbf{N}$ is the number of data, all measured via tKD. Reprinted from [1].

Figure 39. Typical bright field TEM images of the four conditions labeled.

Figure 40. Cumulative distribution functions of the bubbles sizes in the different conditions for the three different depths regimes. The values $p$ are the results of the twosample Kolmogorov-Smirnov test; smaller values (neared zero) indicate more statistically different distributions.

Figure 41. TEM imaging of FIB-prepared cross-section of He-ion exposed ALMT ITERGrade W shows a dense bubble layer within the first $100 \mathrm{~nm}$ of the surface. (1) Highly faceted bubbles; (2) Large $(90 \times 50 \mathrm{~nm})$ grain boundary bubble; (3) Bubbles visible on dislocation loop; (4) Small ( $<10 \mathrm{~nm})$ bubbles penetrating deep (>250 $\mathrm{nm}$ ) below surface.

Figure 42. Deuterium desorption spectrum from as-received $W$ and He-exposed $W$ implanted with $2 \mathrm{keV} \mathrm{D}^{+}$at room temperature.

Figure 43. Calculated temperature evolution during a HHF cycle for several thermal contact conduction values between the $\mathrm{SiC}$ and $\mathrm{Cu}$ washer.

Figure 44. Von Mises stress results for clamped S1 specimen at high temperature (Hot), i.e., right at the end of the HHF, and at room temperature (Cold). The SiC-Cu TCC was $5,000\left[\mathrm{~W} / \mathrm{m}^{2} \mathrm{~K}\right]$

Figure 45. Von Mises stress results for an unclamped $\mathrm{S1}$ specimen at high temperature (Hot), i.e., right at the end of the HHF, and at room temperature (Cold). The SiC$\mathrm{Cu}$ TCC was 5,000 [W/m $\left./ \mathrm{m}^{2} \mathrm{~K}\right]$..

Figure 46. Phase fractions vs temperature in CCNZ1 and CCNZ2 alloys.

Figure 47. Optical images of CCNZ1 and CCNZ2 in high and low magnification.

Figure 48. Change in lattice parameters of $\mathrm{TiC}$ (green) impurities in $\mathrm{Ti}_{3} \mathrm{SiC}_{2}$ at 0.1 (Tallman et al) and 2 dpa at (a) $\mathrm{T}_{\text {irr }} \sim 400^{\circ} \mathrm{C}$ and (b) $\mathrm{T}_{\text {irr }} \sim 700^{\circ} \mathrm{C}$. SiC lattice parameter (linear $\Delta \mathrm{a} / \mathrm{a}$ ) is shown as a comparison with the blue markers. (J Nucl Mater, unpublished).

Figure 49. $6 \mathrm{keV} \mathrm{He}+$ in-situ TEM irradiation showing (a) bright-field (BF) TEM image of the unirradiated sample, (b) BF of the microstructure at $298 \mathrm{~K}$ after $6.4 \times 10^{16}$ ions.cm ${ }^{-2}(\sim 4 \mathrm{dpa}),(\mathrm{c}) \mathrm{BF}$ image at $298 \mathrm{~K}$ after $1.3 \times 10^{17}$ ions.cm ${ }^{-2}(\sim 9 \mathrm{dpa})$ and (d) $\mathrm{BF}$ image at $673 \mathrm{~K}$ after annealing. Note all images taken in underfocus condition of $-32(24 \mathrm{~nm})$.

Figure 50. BFTEM images showing (a) massive bubble accumulation at $298 \mathrm{~K}$ and $6.4 \times 10^{16}$ ions.cm ${ }^{-2}$ of $6 \mathrm{keV} \mathrm{He}+$ irradiation and (b) the final microstructure at $673 \mathrm{~K}$ with fluence of $1.3 \times 10^{17}$ ions. $\mathrm{cm}^{-2}$. 
Figure $51.30 \mathrm{keV} \mathrm{Xe+} \mathrm{in-situ} \mathrm{TEM} \mathrm{irradiation} \mathrm{at} 298 \mathrm{~K}$ of the FeCrMnNi HEA system showing (a) the unirradiated microstructure, (b) BFTEM image after $4.7 \times 10^{16}$ ions.cm ${ }^{-2}(\sim 32 \mathrm{dpa})$ of irradiation and (c) BFTEM image after $9.3 \times 10^{16}$ ions.cm $^{-2}$ ( 65 dpa). Figure (d) shows in detail Xe bubbles in the microstructure.

Figure 52. Critical resolved shear stress for different obstacles of different size obtained by molecular dynamics modeling at $300 \mathrm{~K}$.

Figure 53. Critical resolved shear stress in reduced units as a function of harmonic mean of an obstacle diameter, $D$, and spacing between them along the dislocation line. Symbols present modeling results in current work, lines are dependences obtained in dislocation dynamic modeling for Orowan mechanism (black line) and void (red line) in [1,2].

Figure 54. Examples of microstructures created in dislocation interactions with a rigid inclusion $6 \mathrm{~nm}$ in diameter: a) The dislocation slip plane intersects inclusion exactly along the equator. b) The dislocation slip plane is $1 / 2$ obstacle radius above the equator.

Figure 55. Stress-strain dependences obtain in dislocation interaction with rigid inclusion of $8 \mathrm{~nm}$ in diameter at different strain rates.

Figure 56. The total pressure (a) and vacancy formation energy (b) as a function of modeling cell size. The constant lattice parameter was used. The notation $\mathbf{N x N x N}$ corresponds to the size of the modeling cell, where $\mathrm{N}$ is the number of repetitions of the original cubic cell.

Figure 57. High temperature tensile test results for several versions of F82H [1] .............................80

Figure 58. Fracture surface of F-82H, IEA heat tested at 573 K [2] ...............................................8 80

Figure 59. Neutron irradiation effect on the proportional limit stress (PLS) of SiC/SiC composites with either pyrolytic carbon $(\mathrm{PyC})$ monolayer interface or multilayered $\mathrm{PyC} / \mathrm{SiC}$ interface.

Figure 60. 5 kN Tensile Testing Module for FEI Versa 3D Dual Beam Microscope. Images show grips, the placement of the shoulder loaded specimen relative to heater and,

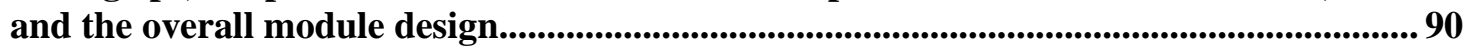

Figure 61. The FEI Versa 3D FIB-SEM, which will house the Tensile Testing Module....................90

Figure 62. Uncrated GD-OES system in LAMDA. Installation anticipated by December 2016.

Figure 63. HFIR irradiation capsule disassembly by remote manipulation in the IMET Hot Cells in ORNL Building 3025E.

Figure 64. Front and Rear Views of Oxy-Gon Custom Vacuum Chamber on an Instron Load Frame Ready for NRTL Inspection and Factory Acceptance Test in October 2016.

Figure 65. Interior View of the Chamber including Tungsten Mesh Resistance Heated Furnace.

Figure 66. Cycle comparison for Control Plate Position as a function of Reactor Power Days in the cycle. 


\section{LIST OF TABLES}

Table 1. Alloy chemical compositions (mass\% or ppmw for $\mathrm{O}, \mathrm{C}, \mathrm{N}$ and $\mathrm{S}$ ) determined by inductively coupled plasma analysis and combustion analysis.............................................. 6

Table 2. Nominal compositions of the steels in the present study .....................................................11

Table 3. Target and analyzed compositions of ORNL melted reference EUROFER97 heats.......... 14

Table 4. Summary of test materials, irradiation conditions, and strengths of $\mathrm{SiC}$ joints. The parenthesis indicates the standard deviation. .............................................................................23

Table 5. NITE-SiC feedstock composition in wt \% including additives and dispersants .................... 28

Table 6. NITE-SiC compositions in wt\% after sintering..................................................................29

Table 7. The fitted long positron lifetimes of irradiated $\mathrm{SiC}$ and the examples of possible vacancy clusters that have positron lifetimes comparable to the measured values. The concentrations of the example defects are also listed.

Table 8. Status of the Advanced Ceramics irradiation experiment .................................................33

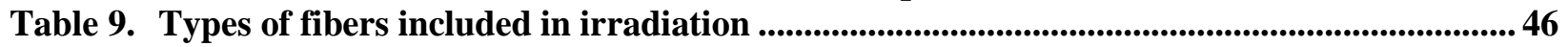

Table 10. Planned activities per tasks for a material science study..........................................................55

Table 11. High-heat flux test results for W/SiC specimens ..........................................................................56

Table 12. Single vacancy formation energy, in $\mathrm{eV}$, presented as a function of modeling cell size, $\mathbf{N}_{\mathrm{at}}$, together with previous results

Table 13. Di-vacancy binding energy, in $\mathrm{eV}$, presented as a function of modeling cell size, $\mathrm{N}_{\mathrm{at}}$, together with existing results. For notations see text.

Table 14. Di-vacancy binding energy in presence of $\mathrm{H}$ or $\mathrm{He}$ atom, in $\mathrm{eV}$, presented as a function of modeling cell size, $\mathbf{N}_{\mathrm{at}}$, together with existing results. For notations see text. The second column specifies the decay of $2 \mathrm{~V} / \mathrm{H}$ of $2 \mathrm{~V} / \mathrm{He}$ clusters.

Table 15. Small vacancy cluster formation and binding energies. For notations see text. The modeling cell contains $4 \times 4 \times 4$ primitive cubic cells ( 250 atoms).

Table 16. Binding energy of $6-\mathrm{V}$ cluster with $\mathrm{H}$ or $\mathrm{He}$ atom. For notations see text. The second column specifies the decay reaction. Modeling cell contains 250 sites $(5 \times 5 \times 5$ unit cells).

Table 17. Status of Testing and Shipment of Archival Samples for FUSMAT Community................96

Table 18. Fusion materials program capsules that completed HFIR irradiation in FY2016. These were all target zone rabbit capsules.

Table 19. HFIR fusion materials program rabbit capsules continuing irradiation beyond FY2016.

Table 20. Fusion materials program capsules removed from HFIR at the end of Cycle 465 for damage inspection 


\section{INTRODUCTION}

\section{Yutai Katoh (katohy@ornl.gov) and Bill Wiffen}

The realization of fusion energy is a formidable challenge, with significant achievements resulting from close integration of the plasma physics and applied technology disciplines. Presently, the most significant technological challenge for planned fusion power systems is the inability of current materials and components to withstand the harsh fusion nuclear environment. The overarching goal of the ORNL Fusion Materials Program is to provide the applied materials science support and materials understanding to underpin the ongoing DOE Office of Science Fusion Energy Program while developing materials for fusion power systems. In doing so the program continues to be integrated both with the larger U.S. and international fusion materials communities and with the international fusion design and technology communities.

This long-running ORNL program continues to pursue development of low activation structural materials such as the reduced activation ferritic/martensitic steels, higher strength/higher creep resistant/radiation resistant advanced steels, and silicon carbide composites. Focus tasks within the steels portfolio are development of castable nanostructured alloys, exploratory work on Bainitic steels and a helium-effects experiment using isotopically separated iron-54. Parallel to this is the increased emphasis on radiation effects, high heat flux testing and the development of refractory metals. This includes the use of an ORNL Plasma Arc Lamp Facility adapted for the thermal testing of irradiated materials, the development and evaluation of new tungsten materials, and the study and understanding of the irradiation performance of tungsten. In each case the materials are being developed in a design-informed fashion where properties improvements are led by fusion-relevant design studies and directed at advancing the Technology Readiness Level of the material systems.

New work supported by an Early Career Award is looking in depth at the materials side of the plasma materials interactions, characterizing the materials response to plasma impingement and determining the controlling mechanisms of the materials behavior.

A limited effort continues to examine functional and exploratory materials. In the area of diagnostics, ORNL supports basic irradiation materials science of ceramics that could be used in diagnostic systems. For high-temperature superconductors, ORNL has completed a limited program to quantify the irradiation sensitivity of the most recently developed tape materials. Studies of the MAX-phase ceramics, high entropy alloys, and bulk metallic glasses were continued as the materials that potentially possess exceptional or unique radiation tolerance.

Finally, this program integrates fundamental modeling into the development efforts as much as practicable.

This fusion materials program makes heavy reliance on neutron irradiation in HFIR, the High Flux Isotope Reactor at ORNL. This is complemented by use of the ORNL-University of Tennessee ion irradiation facility and other available accelerator facilities when these are better suited to explore fundamental aspects of materials behavior under irradiation.

This document summarizes FY2016 activities supporting the Office of Science, Office of Fusion Energy Sciences Materials Research for MFE carried out by ORNL. The organization of the report is mainly by material type, with sections on specific technical activities. 
A continuing activity initiated several years ago, "Materials Engineering in Support of the FNSF Program," is reported in Section 10.

The fusion materials effort consists of a wide array of tasks and collaborations both within the US and with international partners. The major continuing international collaborating partners are the Japan Agency for Quantum and Radiological Science and Technology (QST, reorganized and transferred from Japan Atomic Energy Agency, the US DOE-JAEA collaboration, focused on structural materials), the Japanese National Institute for Fusion Sciences (the PHENIX collaboration, emphasizing plasma facing materials and tritium fuel issues) and the Karlsruhe Institute of Technology in Germany (examining steel materials). Separately identified since FY2015 is a domestic collaboration, designed to provide specimens from the archive of HFIR-irradiated material to other OFES funded researchers to further their studies. Status of this work is reported in Section 12.1. 


\section{FUSION MATERIAL IRRADIATION TEST STATION (FMITS) AT SNS}

\section{MarkWendel (wendelmw@ornl.gov)}

The Fusion Materials Irradiation Test Station (FMITS) is a design concept for installation at the Spallation Neutron Source (SNS) Facility. The project developed the conceptual design, then flushed out design details in earlier years and in FY2015 looked in depth at several critical issues. The main goal of this final effort in FY2016 was to mitigate project technical risks.

The FMITS-type target seal, also called the double inflatable seal, was fabricated by KSM Corporation and is onsite at ORNL. The SNS target module seal test tank was modified and testing of the KSM part is being performed by SNS. Tests will be performed to verify robust function of the new double inflatable seal.

A specially designed containment tube with non-uniform wall thickness is required for the safety case of FMITS. The tube design biases the direction of any over-pressurization failure away from the SNS hydrogen moderators and mercury vessel. Destructive testing was completed at Fike, Inc. in Kansas City, Missouri on December 2, 2015. An ORNL engineer witnessed the testing and confirmed that the 20 tubes failed in the expected direction within the required range of burst pressure. This company is the same company that designed, fabricated, and tested the rupture discs that are used in HFIR irradiation experiment capsules.

All planned work on the FMITS project has been completed, and relevant documents and hardware are archived. The technical risks to the project have been greatly reduced due to the recent work. Any further activities to advance the FMITS await decisions and guidance from DOE. 


\title{
3. ADVANCED STEELS
}

\subsection{DEVELOPMENT OF HIGH-Cr ODS ALLOYS WITH Zr ADDITIONS FOR FUSION REACTOR APPLICATIONS}

\author{
S. Dryepondt (dryepondtsn@ornl.gov), C. Massey, D. T. Hoelzer, and K. A. Unocic
}

\section{OBJECTIVE}

The dual coolant lead-lithium (DCLL) blanket concept requires ferritic steels with sufficient $\mathrm{Pb}-\mathrm{Li}$ compatibility to demonstrate viable blanket operation in a DEMO-type fusion reactor. This project aims at developing oxide dispersion strengthened (ODS) FeCrAl alloy with excellent compatibility with $\mathrm{Pb}-\mathrm{Li}$ due to the formation of a protective Al-rich scale and superior creep resistance at temperature up to 700$800^{\circ} \mathrm{C}$

\section{BACKGROUND}

The first generation of ODS alloys was fabricated by ball milling $\mathrm{Fe}-12 \mathrm{wt}$.\% Cr-5Al powder with $\mathrm{Y}_{2} \mathrm{O}_{3}+$ $\mathrm{ZrO}_{2}, \mathrm{Y}_{2} \mathrm{O}_{3}+\mathrm{HfO}_{2}$ and $\mathrm{Y}_{2} \mathrm{O}_{3}+\mathrm{TiO}_{2}$ powder. All the alloys showed good tensile strength but limited ductility at temperature ranging from room to $800^{\circ} \mathrm{C}$, and good compatibility with $\mathrm{Pb}-\mathrm{Li}$ at $700^{\circ} \mathrm{C}$. In addition, the $\mathrm{Zr}$-containing alloy (125YZ alloy) exhibited superior creep resistance at 700 and $800^{\circ} \mathrm{C}$. A second generation of ODS FeCrAl alloys was therefore fabricated by ball milling $\mathrm{Fe}-10-12 \mathrm{Cr}-6 \mathrm{Al}-\mathrm{Zr}$ powders with $\mathrm{Y}_{2} \mathrm{O}_{3}$. The goal was to maintain the ODS FeCrAl mechanical strength but increase the alloy ductility to improve the alloy fabric ability.

\section{PROGRESS AND STATUS}

\section{First generation ODS FeCrAl}

Extensive characterization by transmission electron microscopy (TEM) of the first generation $125 \mathrm{YZ}$ alloy revealed the presence of $\mathrm{Y}_{3} \mathrm{Al}_{5} \mathrm{O}_{12}$ (YAG), $\mathrm{Al}_{2} \mathrm{O}_{3}$ and $\mathrm{Zr}(\mathrm{C}, \mathrm{N})$ precipitates, but no $\mathrm{Zr}$-rich oxides. The proximity of the YAG and $\mathrm{Zr}$-rich particles shown in Figure 1 indicates that co-precipitation of these two particles is likely taking place.
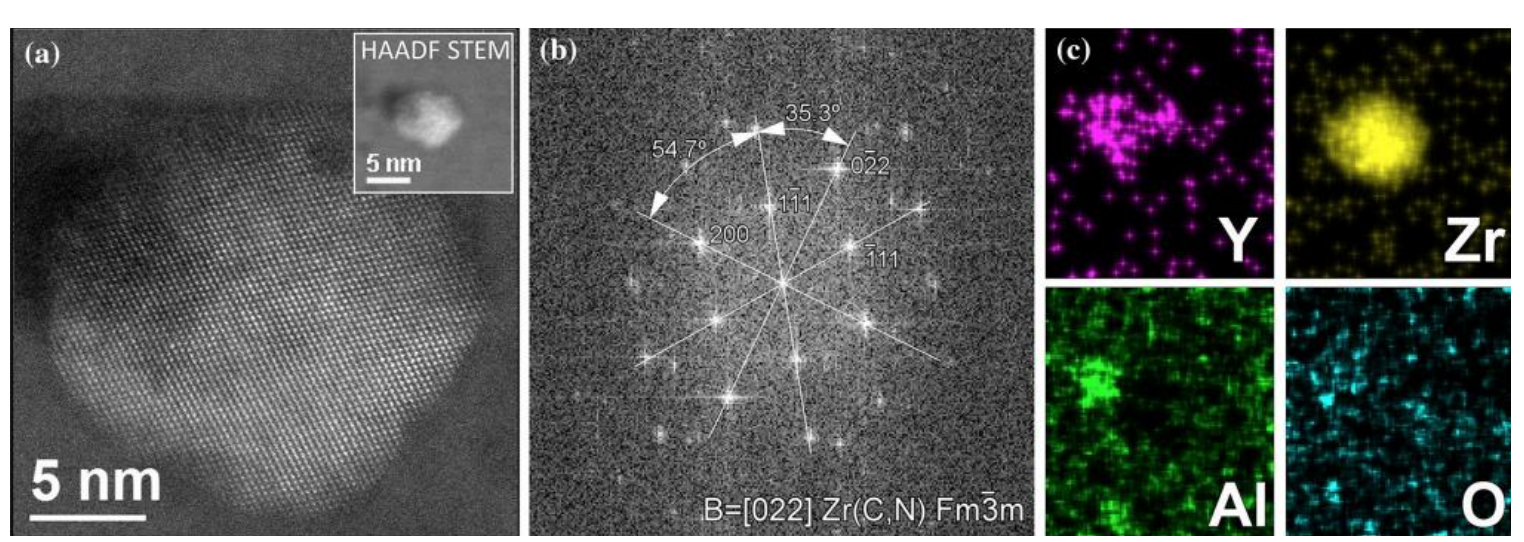

ure 1

Figure 1. a) High-resolution TEM image of $\mathrm{Zr}$-rich particle formed in $\mathrm{Fe}-12 \mathrm{Cr}-5 \mathrm{Al}-\mathrm{Zr}-\mathrm{Y}_{2} \mathrm{O}_{3}$ alloy identified as $\mathrm{Zr}(\mathrm{C}, \mathrm{N})$ with the space group $\mathrm{Fm} 3 \mathrm{~m}$ using b) FFT, and c) corresponding $\mathrm{EDS} \mathrm{Y,} \mathrm{Zr}$, Al, and $\mathrm{O}$ elemental maps showing the special proximity between the $\operatorname{Zr}(\mathrm{C}, \mathrm{N})$ and $\mathrm{Y}$-Al-O particles. 
As shown in Figure 2, TEM characterization was also conducted on the first generation ODS FeCrAl specimens exposed in static $\mathrm{Pb}-17 \mathrm{Li}$ for $1000 \mathrm{~h}$ at $700^{\circ} \mathrm{C}$. The thin oxide scales observed at the specimen surface, 0.5 to 1.5 um thick, were identified as $\mathrm{LiAlO}_{2}$ layers. Voids and $\mathrm{Zr}$, Hf or Ti-rich precipitates were noted in the $\mathrm{LiAlO}_{2}$ scale for the $125 \mathrm{YZ}$ (Figure 2), $125 \mathrm{YH}$ or $125 \mathrm{YT}$ alloys, respectively.
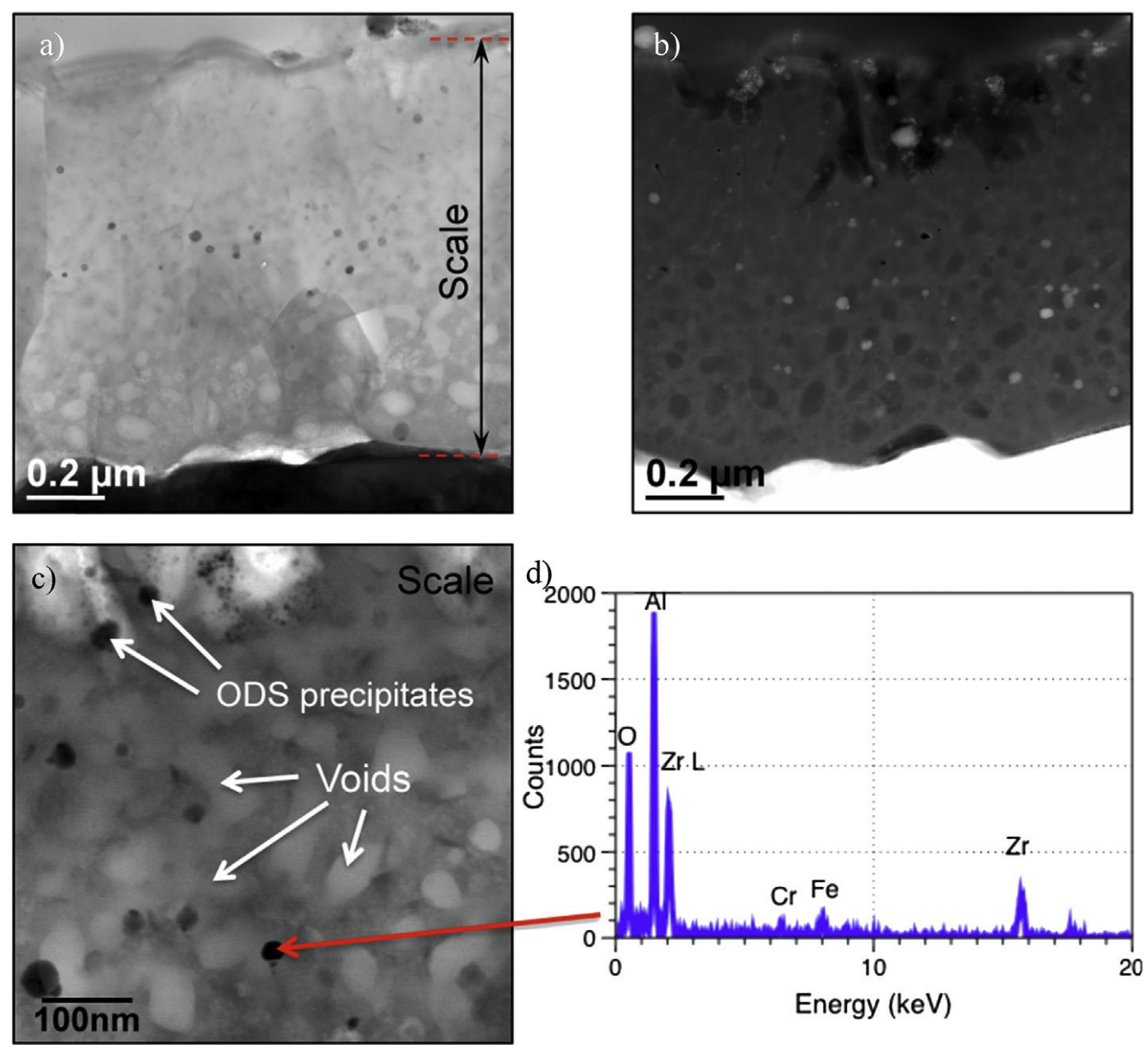

Figure 2. Cross-section of the oxide formed on $125 \mathrm{YZ}$ after exposure for $1000 \mathrm{~h}$ at $700^{\circ} \mathrm{C}$ in static $\mathrm{Pb}-17 \mathrm{Li}$, (a,c) BF-STEM images, b) HAADF-STEM images, d) EDS point spectrum generated from particle within the oxide.

\section{Second generation ODS FeCrAlZr}

The second generation ODS FeCrAlZr alloys were fabricated in collaboration with the FCRD-funded project on ODS FeCrAl alloys for accident tolerant fuel cladding, [1] and the compositions of some of the first and second generation ODS FeCrAl alloys are given in Table 1. To improve ODS FeCrAl alloy ductility, the effects of ball milling time and extrusion temperature were assessed. Figure 3 shows that increasing the extrusion temperature for Fe-10Cr-6Al-0.3Zr+ $\mathrm{Y}_{2} \mathrm{O}_{3}(106 \mathrm{ZY})$ alloys led to a decrease of alloy strength but an increase of alloy ductility. The ultimate goal of the FCRD project is to produce tubing with a wall thickness $<500 \mathrm{um}$. Extruding the powder at $1050^{\circ} \mathrm{C}$ or above is therefore recommended to decrease the alloy hardness and facilitate tube fabrication. For the fusion program, the $106 Z Y$ alloy extruded at $900^{\circ} \mathrm{C}(106 Z$ Y9C $)$ was particularly attractive due to superior tensile strength and ductility in the $20-800^{\circ} \mathrm{C}$ range compared to the strength and ductility of the first generation $125 \mathrm{YZ}$ alloy. 
This alloy was therefore selected for creep testing at $700^{\circ} \mathrm{C}$ and $800^{\circ} \mathrm{C}$, with applied loads of 100 and 140 $\mathrm{MPa}$, respectively. As can be seen in Figure 4a, the alloy is at least as creep resistant as the first generation Hf-containing $125 \mathrm{YH}$ alloy. Longer exposure times are required to evaluate the creep performance of the alloy at $700^{\circ} \mathrm{C}$, but it is worth noting that the $125 \mathrm{YZ}$ specimen tested at $700^{\circ} \mathrm{C}$ with an applied stress of $140 \mathrm{MPa}$ has now reached $18,000 \mathrm{~h}$, when the expected lifetime for the $\mathrm{Zr}$-containing alloy developed in Japan is $\sim 10,000 \mathrm{~h}$ with an applied stress of $120 \mathrm{MPa}$ at $700^{\circ} \mathrm{C}$ [2].

Table 1. Alloy chemical compositions (mass\% or ppmw for $\mathrm{O}, \mathrm{C}, \mathrm{N}$ and $\mathrm{S}$ ) determined by inductively coupled plasma analysis and combustion analysis.

\begin{tabular}{|c|c|c|c|c|c|c|c|c|c|c|c|}
\hline & Alloy & Extrusion & $\mathrm{Fe}$ & $\mathrm{Cr}$ & Al & $\mathrm{Zr} / \mathrm{HF} / \mathrm{Ti}$ & $Y$ & $C(\mathrm{ppm})$ & $N(p p m)$ & 0 (ppm) & $S$ (ppm) \\
\hline \multirow{3}{*}{ 1rst gen } & $125 Y Z$ & $950^{\circ} \mathrm{C}$ & 82.8 & 11.51 & 4.86 & $0.3 \mathrm{zr}$ & 0.18 & 250 & 161 & 1920 & 10 \\
\hline & 125YT & $950^{\circ} \mathrm{C}$ & 82.4 & 12 & 4.9 & $0.2 \mathrm{Ti}$ & 0.16 & 350 & 140 & 2220 & 30 \\
\hline & $125 \mathrm{YH}$ & $950^{\circ} \mathrm{C}$ & 82.3 & 11.68 & 4.82 & $0.68 \mathrm{Hf}$ & 0.17 & 220 & 110 & 2280 & 10 \\
\hline \multirow{4}{*}{ 2nd gen } & 1062Y_15C & $1050^{\circ} \mathrm{C}$ & 83.69 & 9.59 & 5.89 & $0.27 \mathrm{Zr}$ & 0.2 & 170 & 668 & 1890 & 30 \\
\hline & 1062Y_10C & $1000^{\circ} \mathrm{C}$ & 83.41 & 9.74 & 6.02 & $0.28 \mathrm{zr}$ & 0.22 & 190 & 580 & 1290 & 30 \\
\hline & 1062Y_950 & $950^{\circ} \mathrm{C}$ & 83.39 & 9.68 & 6.1 & $0.28 \mathrm{Zr}$ & 0.21 & 180 & 564 & 1400 & 30 \\
\hline & $106 Z Y 9 C$ & $900^{\circ} \mathrm{C}$ & 83.34 & 9.73 & 6.07 & $0.28 \mathrm{Zr}$ & 0.21 & 170 & 919 & 1300 & 30 \\
\hline
\end{tabular}
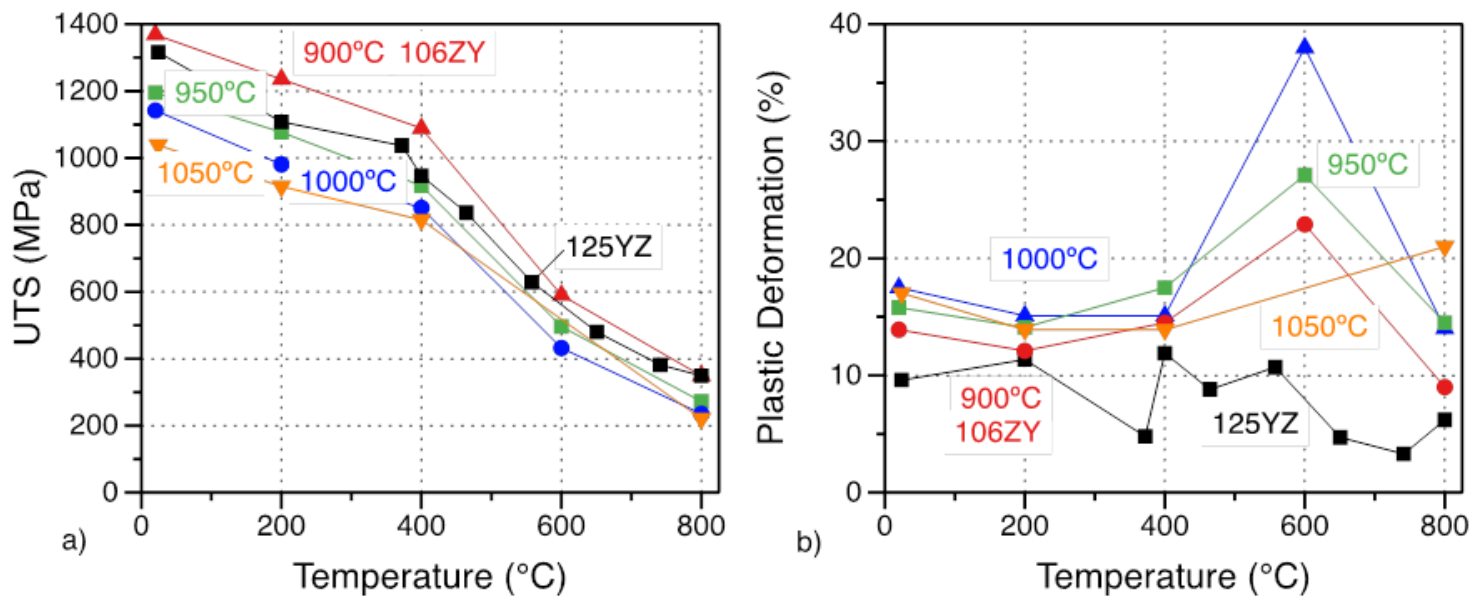

Figure 3. Tensile properties of the $1^{\text {rst }}$ generation $125 \mathrm{YZ}$ alloy, and several $2^{\text {nd }}$ generation $\mathrm{ODS} \mathrm{Fe}-10 \mathrm{Cr}$-6Al$0.3 \mathrm{Zr}$ alloys extruded at temperature ranging from $900^{\circ} \mathrm{C}$ to $1050^{\circ} \mathrm{C}$, a) Ultimate tensile strength, b) Plastic deformation. 

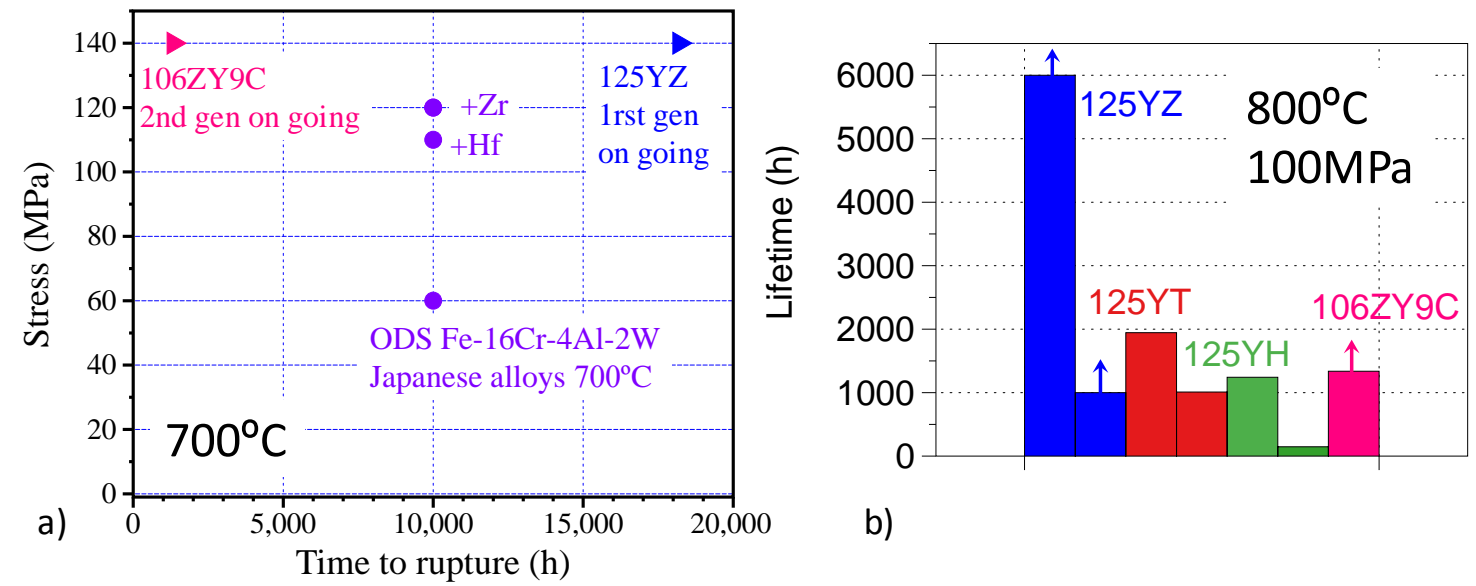

b)

Figure 4. a) Comparison of the creep performance at $700^{\circ} \mathrm{C}$ of the $125 \mathrm{YZ}$ and $106 \mathrm{ZY} 9 \mathrm{C}$ alloys with the performance of new ODS FeCrAl alloys developed in Japan [2], b) Lifetimes of the 125YZ, 125YT, 125YH and $106 \mathrm{ZY} 9 \mathrm{C}$ alloys tested at $800^{\circ} \mathrm{C}$ with an applied stress of $100 \mathrm{MPa}$.

\section{FUTURE PLANS}

Additional creep tests will be conducted at 700 and $800^{\circ} \mathrm{C}$ with higher applied stresses to fully assess the creep resistance of alloy 106YZ9C. Collaboration with other Fusion projects will also be initiated to perform compatibility and irradiation experiments. Finally, new ODS FeCrAlZr alloys will be fabricated using different ball milling and extrusion parameters to further improve the ODS $\mathrm{FeCrAl}$ alloy mechanical performance.

\section{REFERENCES}

[1] S. Dryepondt, C. Massey and P. Edmonson, ORNL-TM-2016/456 (2016).

[2] A. Kimura, R. Kasada, N. Iwata, H. Kishimoto, C.H. Zhang, J. Isselin, P. Dou, J.H. Lee, N. Muthukumar, T. Okuda, M. Inoue, S. Ukai, S. Ohnuki, T. Fujisawa, and T.F. Abe, J. Nucl. Mater., 417, $176(2011)$. 


\subsection{DEVELOPMENT OF TRANSFORMATION ENHANCED ODS Fe-Cr ALLOYS}

\section{D.T. Hoelzer(hoelzerd@ornl.gov)}

\section{OBJECTIVE}

The objective of this task is to develop transformation enhanced oxide dispersion strengthened (ODS) Fe$10 \mathrm{Cr}$ alloys for fusion reactor applications requiring high-temperature strength and toughness properties and microstructural stability during exposure to energetic neutrons and transmutated He concentrations.

\section{PROGRESS AND FUTURE DIRECTION}

Two ODS Fe-Cr alloys (10YWV and 10YV) were produced by mechanical alloying. The alloyed powders of compositions Fe-10Cr-1W-0.3Ti-0.2V and Fe-10Cr-0.3Ti-0.2V (weight percent) were produced by Ar gas atomization by ATI Powder Metals. These powders were mixed with $0.3 \mathrm{Y}_{2} \mathrm{O}_{3}$ and ball milled in the high kinetic energy CM08 Simoloyer for $40 \mathrm{~h}$ in an Ar gas atmosphere. Mild steel cans were filled with $\sim 1.3 \mathrm{~kg}$ of the $10 \mathrm{YWV}$ (Fe-10Cr- $1 \mathrm{~W}-0.3 \mathrm{Ti}-0.2 \mathrm{~V}+0.3 \mathrm{Y}_{2} \mathrm{O}_{3}$ ) powder and $1 \mathrm{~kg}$ of the $10 \mathrm{YV} \mathrm{Fe}-10 \mathrm{Cr}-0.3 \mathrm{Ti}-0.2 \mathrm{~V}+0.3 \mathrm{Y}_{2} \mathrm{O}_{3}$ ) powder followed by degassing in vacuum at $300^{\circ} \mathrm{C}$ and sealing. The sealed cans were heated to $850^{\circ} \mathrm{C}$ for $1 \mathrm{~h}$ followed by extrusion through a rectangular shaped die $(2.5$ inch wide and 1.25 inch high) into bars. Figure 5 shows the two extruded bars after the nose and tail sections were cut off to locate the ODS sections.

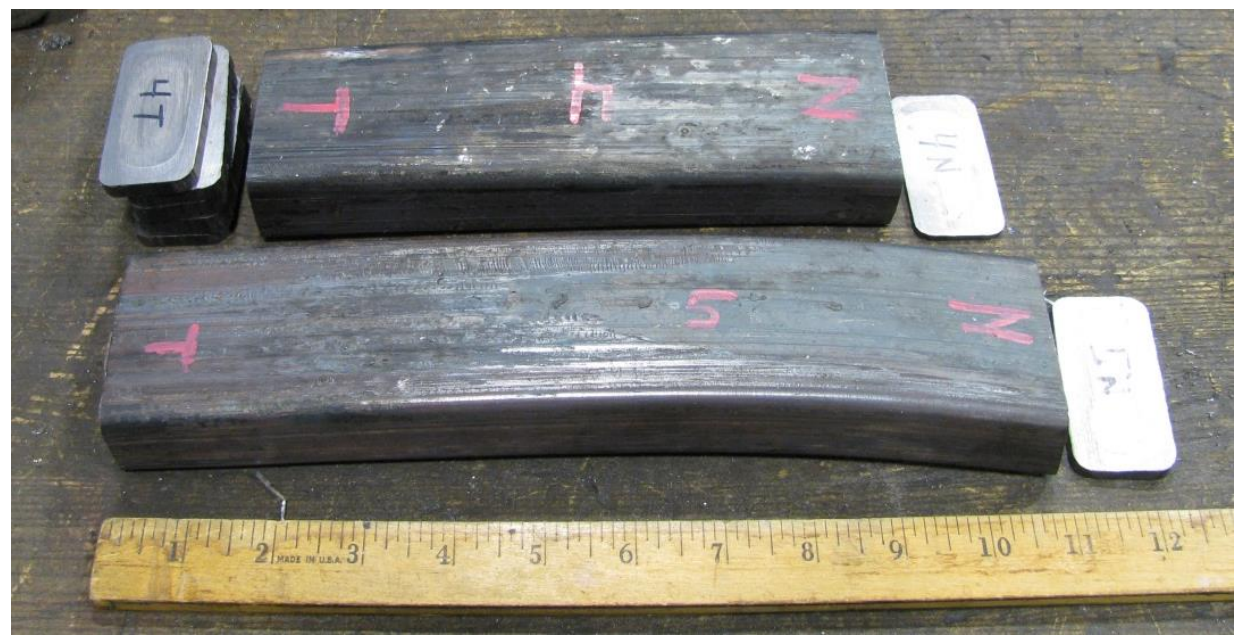

Figure 5. Extruded bars of the ODS 10WV (Fe-10Cr-1W-0.3Ti-0.2V $\left.+0.3 \mathrm{Y}_{2} \mathrm{O}_{3}\right)$ and $10 \mathrm{~V}(\mathrm{Fe}-10 \mathrm{Cr}-0.3 \mathrm{Ti}-0.2 \mathrm{~V}$ $+0.3 \mathrm{Y}_{2} \mathrm{O}_{3}$ ) alloys.

Samples 0.5 and 2 inches long were cut from the nose end of the extruded bars to evaluate the effects of annealing on the microstructure and tensile properties of the ODS $\mathrm{Fe}-\mathrm{Cr}$ alloys. The samples will be annealed for $8 \mathrm{~h}$ in vacuum at temperatures of $1000,1050,1100$ and $1150^{\circ} \mathrm{C}$. The microstructural characterization study will involve scanning electron microscopy and transmission electron microscopy to determine which annealing condition causes the optimum degree of partial transformation of fcc- $\gamma$ grains from the matrix of ultra-fine bcc- $\alpha$ grains in the two ODS Fe-Cr alloys. A similar study is planned to assess the effects of annealing on the tensile properties by fabricating and testing SS- 3 tensile specimens from the 2-inch length samples. 


\subsection{DEVELOPMENT OF ADVANCED RAFM STEELS - CASTABLE NANOSTRUCTURED ALLOYS}

\section{L.Tan(tanl@ornl.gov)}

\section{OBJECTIVE}

The current reduced activation ferritic-martensitic (RAFM) steels suffer noticeable strength reduction at temperatures above $\sim 500^{\circ} \mathrm{C}$, which limits their high temperature applications for future fusion reactors. This project is to develop castable nanostructured alloys (CNAs) that are manufacturable and affordable advanced RAFM steels, generating a high density of stable nanoprecipitates by optimizing alloy compositions and thermomechanical treatment (TMT) to achieve superior high temperature performance.

\section{SUMMARY}

The high-dose $\mathrm{Fe}^{2+}$-irradiated samples with dispersed vanadium nitride (VN) nanoprecipitates were characterized using transmission electron microscopy (TEM). The results showed that the particle shape was significantly influenced by the ion beam direction. Ion channeling effect may have occurred in one of the conditions. This study suggests that statistical quantitative analysis of the stability of ultrafine particles under heavy ion irradiation experiments may not adequately represent their stability under neutron reactor irradiation situation. Two new heats of CNAs were designed and procured; these exhibited much finer Ta-rich precipitates in higher densities than literature-reported $\mathrm{F} 82 \mathrm{H}$.

\section{PROGRESS AND STATUS}

The stability of $\mathrm{VN}$ nanoprecipitates dispersed in a ferritic alloy was determined by irradiating samples with $\mathrm{Fe}^{2+}$ ions to a peak dose of $\sim 246$ displacements per atom (dpa) at $500^{\circ} \mathrm{C}$. The focused ion beam technique was used to extract specimens from different grains for TEM microstructural characterization. The particle area fraction was analyzed using ImageJ with $200 \mathrm{~nm}$ depth bin size, which was normalized to $100 \mathrm{~nm}$ specimen thickness for each condition. The particle area fraction results are plotted in Figure 6 , together with the SRIM-calculated depth profiles of dose and implanted iron after two levels of irradiation damage. Two orientation conditions were characterized for the high-dpa sample, which have $20^{\circ}$ and $82^{\circ}$ angles between the ion beam direction and the length direction of the nanoprecipitates. The low-dpa sample with $12^{\circ}$ of such an angle was characterized before and reanalyzed here following this method for comparison. The remarkable distinction is the high-dpa case with implanted iron concentration $<0.055$ at. $\%$ resulted in a noticeable peak of particle area fraction. Furthermore, the particle area fraction evolution of the high-dpa with $82^{\circ}$ orientation angle shows a significantly deeper peak compared to the SRIM-calculated results, which may suggest an ion channeling effect in this configuration. High resolution TEM images taken from $\sim 650 \mathrm{~nm}$ of the samples in the three conditions are shown in Figure 6. The small angles with ion beam approximately parallel to the particle length did not much change the shape of the particles. In contrast, the large angle with ion beam approximately perpendicular to the particle length transformed the thin-lath-shaped particles into parallelograms.

Two new heats of CNAs, designed to have varied precipitate fractions of $\mathrm{M}_{23} \mathrm{C}_{6}$ and $\mathrm{MX}$ by controlling the ratio of $\mathrm{C} /(\mathrm{Ta}+\mathrm{Ti})$, were procured from Carpenter Technology. Figure 7 shows backscattered electron images (BEIs) of the two heats (bottom row), illustrating significantly finer Ta-rich particles (shown white) with higher densities than the literature data of F82H-BA07 (top row). 

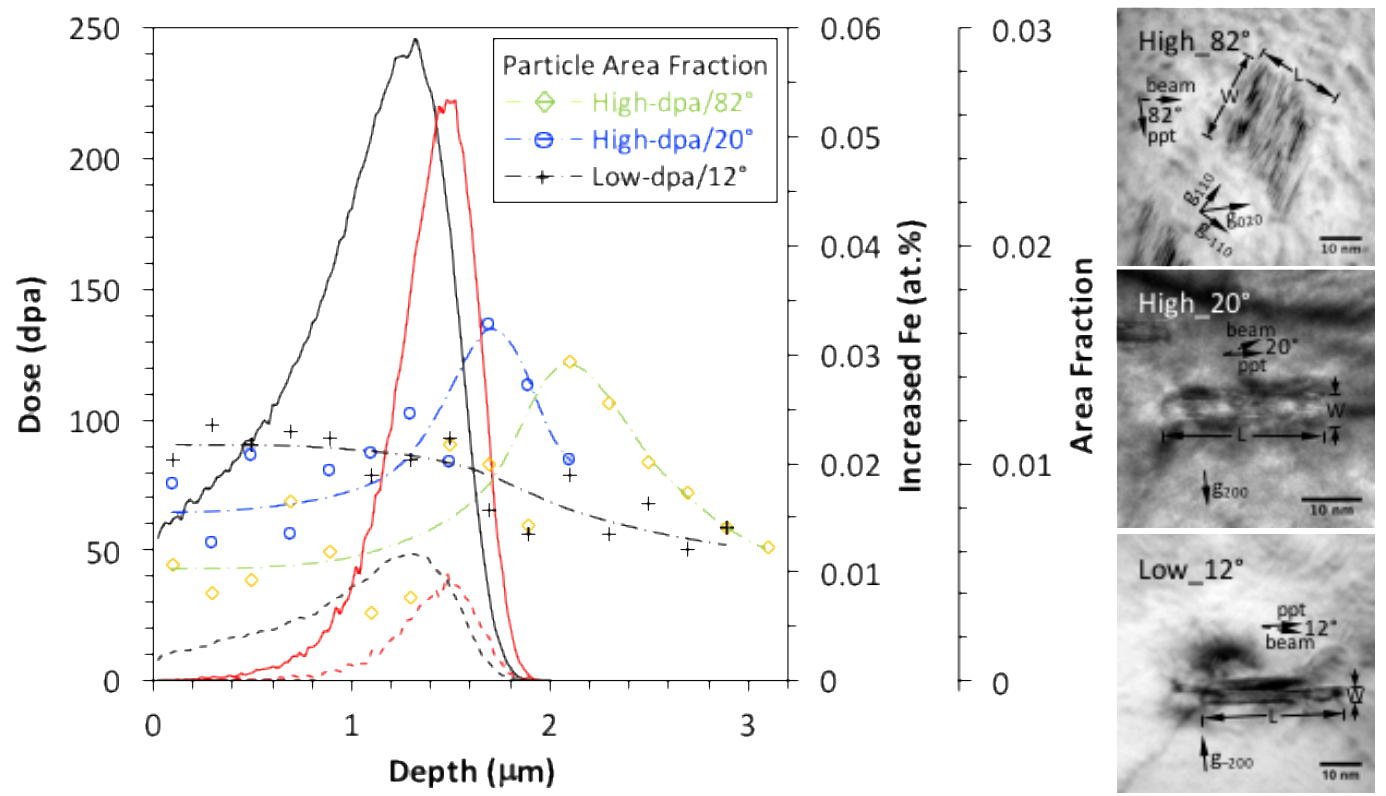

Figure 6. SRIM-calculated depth profiles of dose (black) and implanted iron (red) after low (dashed) and high (solid) levels of irradiation damage. The experimentally characterized depth-dependent particle area fractions in three conditions are overlapped on the calculated profiles. Examples of particle shapes at $\sim 650$ nm from surface are shown on right.
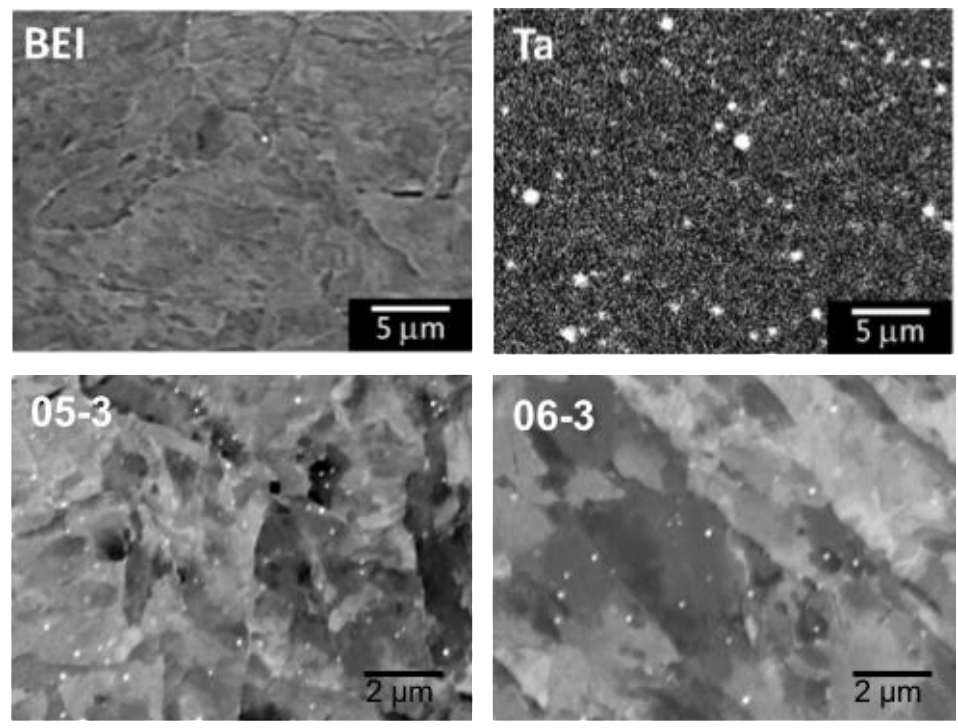

Figure 7. Backscattered electron images (BEIs) of two heats of CNAs (05-3 and 06-3) compared to BEI and Ta-EDS of F82H-BA07.

\section{FUTURE PLANS}

TMT exploration and mechanical property tests of the two new heats of CNAs are being pursued. This involves routine microstructural characterization to support the processes and observations. Neutron irradiation experiments of selected CNAs will be conducted in HFIR. 


\subsection{BAINITIC STEEL DEVELOPMENT FOR FUSION APPLICATIONS}

\section{Y.Yamamoto (yamamotoy@ornl.gov)}

\section{OBJECTIVE}

This work aims to develop a new bainitic steel, based on $3 \mathrm{Cr}-3 \mathrm{WV}$ (Ta) steel originally developed at ORNL, with mechanical properties of both base metal and weldments superior to those of existing commercial bainitic steels or ferritic-martensitic (F-M) steels. The target applications are high temperature structural components in fusion reactors such as the vacuum vessel, the structural ring which supports the blanket modules, and magnet shields, to be used at or above the $400-500^{\circ} \mathrm{C}$ temperature range. Improvement of long-term creep properties by introducing fine and stable second-phase dispersions, together with maintaining good weldability and no requirement of post-weld heat treatment (PWHT), is targeted via optimization of alloy composition and thermo-mechanical heat treatment.

\section{SUMMARY}

A new alloy design strategy for PWHT-free bainitic steel has been proposed; maintaining high hardenability during cooling combined with relatively low as-normalized hardness is the target to be achieved through optimization of alloy composition, in order to reduce property inhomogeneity across weldments. Four new heats of 3Cr-3WVTa base bainitic steels with low carbon combined with high Mn and $\mathrm{Si}$ additions were prepared, as guided by computational thermodynamics. The steels with the combination of $0.05 \% \mathrm{C}$ and 2 or $3 \% \mathrm{Mn}$ additions have successfully showed fully bainitic microstructure together with less hardness difference between as-normalized and tempered conditions. High temperature tensile properties also supported achieving the goal of improvement of mechanical properties at elevated temperatures. Evaluation of creep-rupture properties is currently in progress.

\section{PROGRESS AND STATUS}

Four lab-scale ingots $(13 \times 25 \times 125 \mathrm{~mm}$ size $)$ of new steels were prepared by arc-melting and drop casting at ORNL. Table 2 summarizes the nominal compositions of the steels in the present study, together with that of the reference base 3Cr-3WVTa steel prepared in the previous effort. The alloy compositions were selected based on the new alloy design strategy to expect relatively low as-normalized hardness (via 0.05C), high hardenability (high $\mathrm{Mn}$ additions), as well as supplemental oxidation resistance $(0.5 \mathrm{Si})$. The phase equilibrium and the CCT diagrams (not shown in this report) calculated by JMatPro version 9 with Fe database were used for the alloy selection.

Table 2. Nominal compositions of the steels in the present study

\begin{tabular}{lllllllll}
\hline \multirow{2}{*}{ Heat } & \multicolumn{8}{l}{ Composition, wt\% (balance Fe) } \\
\cline { 2 - 8 } & $\mathrm{C}$ & $\mathrm{Mn}$ & $\mathrm{Si}$ & $\mathrm{Cr}$ & $\mathrm{V}$ & $\mathrm{W}$ & $\mathrm{Ta}$ & \\
\hline 2751 & 0.10 & 0.4 & 0.14 & 3 & 0.2 & 3 & 0.1 & Base, reference \\
\hline LC & 0.05 & 0.4 & 0.16 & 3 & 0.2 & 3 & 0.1 & Low C \\
MSLC1 & 0.05 & 1.00 & 0.5 & 3 & 0.2 & 3 & 0.1 & Low C $+1 \mathrm{Mn}+0.5 \mathrm{Si}$ \\
MSLC2 & 0.05 & 2.00 & 0.5 & 3 & 0.2 & 3 & 0.1 & Low C $+2 \mathrm{Mn}+0.5 \mathrm{Si}$ \\
MSLC3 & 0.05 & 3.00 & 0.5 & 3 & 0.2 & 3 & 0.1 & Low C $+3 \mathrm{Mn}+0.5 \mathrm{Si}$ \\
\hline
\end{tabular}


Figure 8 illustrates the yield strengths (YS) of the new steels after tempering at $700^{\circ} \mathrm{C}$ for $1 \mathrm{~h}$, plotted as a function of test temperature. The YS of the base 3Cr-3WVTa steel and Gr 91 F-M steel are also plotted for comparison. All new steels showed lower YS than the base steel which could mainly be due to low C addition, although they still exhibited higher YS than Gr $91 \mathrm{~F}-\mathrm{M}$ steel up to $600^{\circ} \mathrm{C}$. The higher $\mathrm{Mn}$ addition resulted in the higher YS, but the effect of the Mn additions in the range studied was not so significant.

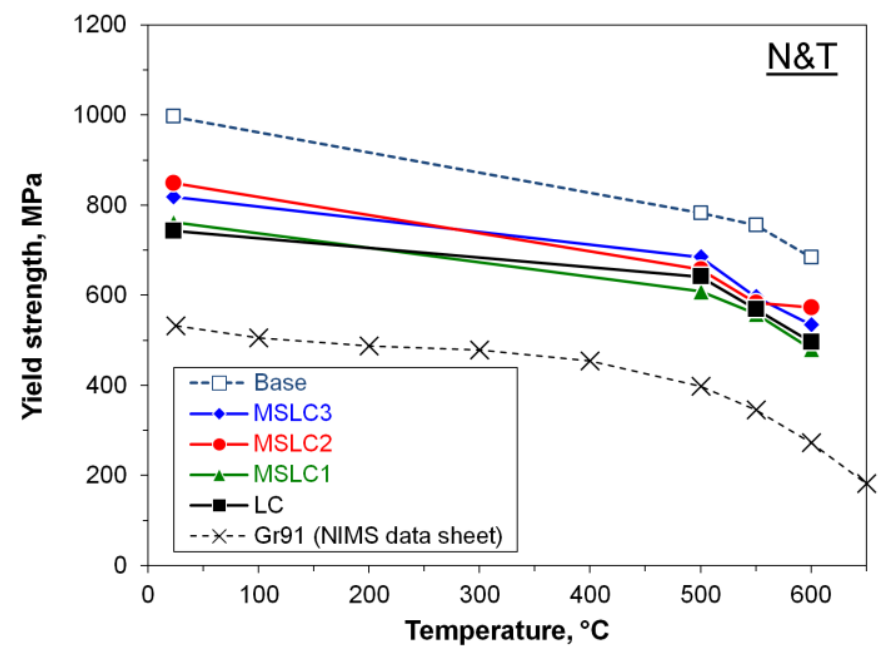

Figure 8. Yield strength of the base and new 3Cr-3WVTa bainitic steels plotted as a function of test time, together with the data for Grade 91 (Mod. 9Cr-1Mo) F-M steels obtained from NIMS data sheets.

The cross-weld microstructure was characterized using a map hardness analysis. Figure 9 shows an example of the cross-sectional micrograph of autogenous gas tungsten arc welds (GTAW) made on the tempered bainitic steel, together with the hardness contour maps measured from the base, LC, and MSLC2, after welding. All metals were tempered prior to welding. The weld metal on the base $3 \mathrm{Cr}-$ 3 WVTa steel showed hardness more than $400 \mathrm{HV}$ which was significantly higher than the base metal $(\sim 350 \mathrm{HV})$. The inter-critical heat affected zone (ICHAZ) showed lower hardness $(\sim 300 \mathrm{HV})$ than the base metal. Such hardness distribution could cause inhomogeneous properties across the weldments. The hardness map of the tempered LC showed very low hardness $(\sim 270 \mathrm{HV})$ in the base metal, and almost the same hardness as the weld metal hardness. The hardness at ICHAZ was $\sim 220 \mathrm{HV}$. The hardness gap between the base and the ICHAZ was similar to the base 3Cr-3WVTa steel. On the other hand, the MSLC2 showed slightly higher hardness at the weld metal than the base metal ( $300 \mathrm{HV}$ and $\sim 280 \mathrm{HV}$, respectively), together with the ICHAZ hardness of $\sim 260 \mathrm{HV}$. It was obvious that MSLC2 exhibited less hardness variation compared to the other steels, which satisfied the alloy design strategy to reduce the hardness variation across the weldments.

\section{FUTURE PLANS}

Two new steels will be down selected for a heat-size scale-up effort, and further property evaluation and detailed characterization will be conducted. Short- and intermediate-term creep-rupture properties of the base and the cross-weld specimens will be evaluated in the temperature range 550 to $600^{\circ} \mathrm{C}$. 

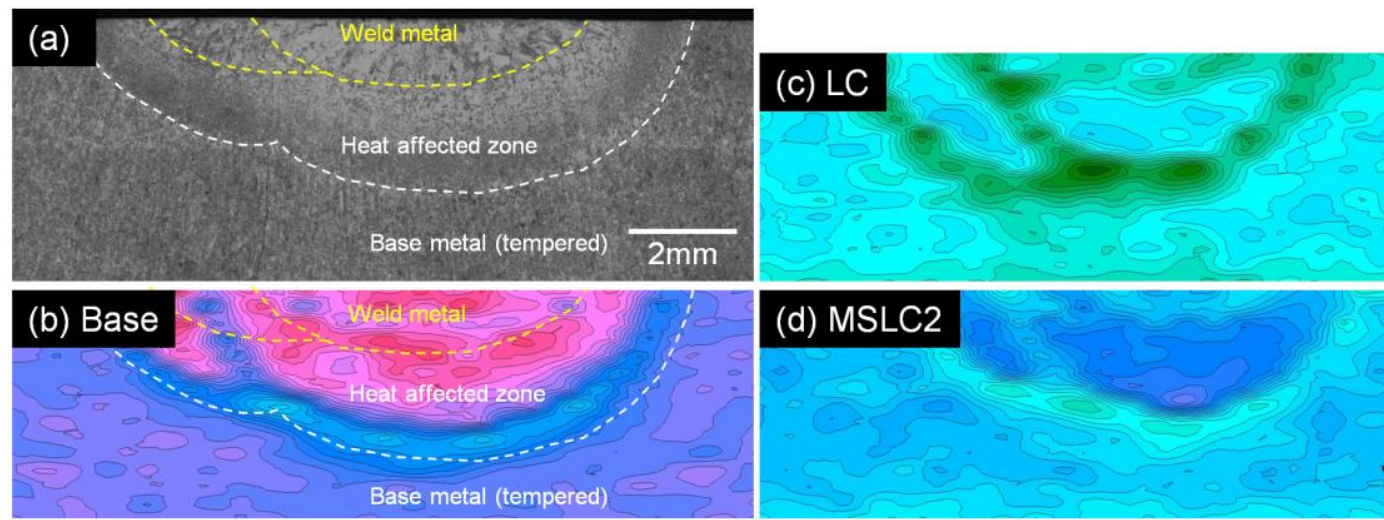

(d) MSLC2

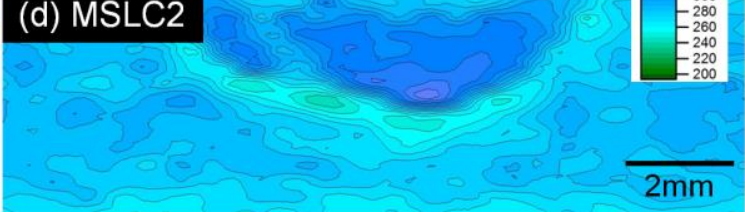

Figure 9. An example of cross-sectional micrograph of autogenous GTAW welds on a tempered bainitic steel (a), and the hardness contour maps (b, c, d); (a, b) base 3Cr-3WVTa, (c) LC, and (d) MSLC2. 


\subsection{IRRADIATION EFFECTS IN 9Cr RAFM STEELS USING ${ }^{54}$ Fe ISOTOPE}

\section{Y. Yamamoto(yamamotoy@ornl.gov1)}

\section{OBJECTIVE}

This primary goal is to evaluate the effect of irradiation on the microstructure and mechanical properties of 9Cr base reduced activation ferritic-martensitic (RAFM) steels, such as EUROFER 97 and cast nanostructured alloys (CNA), prepared using ${ }^{54} \mathrm{Fe}$ isotope reduced from the oxide powder that $\mathrm{KIH}$ provided. The ${ }^{54} \mathrm{Fe}$ isotope will accelerate helium production during neutron irradiation in HFIR which allows partially simulating fusion conditions within relatively short exposure times.

\section{SUMMARY}

Fabrication of four reference EUROFER97 steel plates was completed by arc-melting with natural Fe and hot-rolling with a steel guide. They were used to estimate the material yield after arc-melting and to establish the fabrication procedure for plate sample through hot-rolling. Based on the process parameters of the reference heats, two RAFM steel plates (targeting EUROFER97 and CNA) made of ${ }^{54} \mathrm{Fe}$ isotope powder, with size $\sim 0.25 \times 1.4 \times 2.5$ inch, were successfully fabricated. The machining of SS-J3 tensile specimens and M4 PCCVN bend bar specimens for irradiation in HFIR is in progress.

\section{PROGRESS AND STATUS}

Table 3 summarizes the analyzed chemical compositions of the trial EUROFER97 heats. The results indicated that two heats, E97-03 and E97-05, were out of the specification, and it was found that the W content of the heats was mistakenly selected lower than the target nominal content $(1.1 \mathrm{wt} . \%)$. It was also found that the other elements, especially $\mathrm{Mn}, \mathrm{C}$, and $\mathrm{N}$ were extremely lower than expected from the targets. The loss of the $\mathrm{N}$ content was due to the nitrogen gas bubbling during the arc-melting process, which was visually observed during the arc-melt operation. The number of arc-melting cycles (to ensure homogeneous mixing of the ingot) was also important to preserve the nitrogen content in the heat. The yields of these elements were calculated, and the calibrated amounts of the alloying additions were used for two newly arc-melted trial heats (\#22 and \#23). By minimizing the number of arc-melting cycles, the resultant alloy compositions mostly met the target specifications. Only the $\mathrm{C}$ content was higher than the target, so that re-calibration of the carbon was used for the next melt with the ${ }^{54} \mathrm{Fe}$ powder.

Table 3. Target and analyzed compositions of ORNL melted reference EUROFER97 heats

\begin{tabular}{lllllllllll} 
Name & \multicolumn{3}{l}{ Composition, wt.\% } & \multicolumn{2}{l}{ Remarks } \\
& $\mathrm{Fe}$ & $\mathrm{C}$ & $\mathrm{Mn}$ & $\mathrm{Cr}$ & $\mathrm{V}$ & $\mathrm{Ta}$ & $\mathrm{W}$ & $\mathrm{N}$ & \\
\hline $\begin{array}{l}\text { Target } \\
\text { (for E97-03/05) }\end{array}$ & 89.20 & 0.11 & 0.40 & 9.00 & 0.20 & 0.12 & 0.91 & 0.060 & $\begin{array}{l}\text { The target W content } \\
\text { was incorrect }\end{array}$ \\
\hline E97-03 & Bal. & 0.077 & 0.36 & 8.84 & 0.19 & 0.11 & 0.84 & 0.008 & Arc-melted x10 & \\
E97-05 & Bal. & 0.077 & 0.37 & 8.83 & 0.18 & 0.11 & 0.87 & 0.014 & Arc-melted x7 & \\
\hline $\begin{array}{l}\text { Target } \\
\text { (for new heats) }\end{array}$ & 88.94 & 0.11 & 0.50 & 9.00 & 0.20 & 0.12 & 1.10 & 0.030 & Nominal (revised) \\
\hline Heat \#22 & Bal. & 0.14 & 0.51 & 8.95 & 0.21 & 0.13 & 1.1 & 0.021 & Arc-melted x4 \\
Heat \#23 & Bal. & 0.13 & 0.51 & 8.94 & 0.21 & 0.13 & 1.11 & 0.022 & Arc-melted x4
\end{tabular}


Two new heats of EUROFER97 and CNA steels were arc-melted with ${ }^{54} \mathrm{Fe}$ isotope powder reduced from the oxide powders reported previously. The arc-melted ingots with size $0.5 \times 1.4$ x 1.4 inches (Figure 10a) were successfully rolled to plates $0.24 \times 1.42 \times 2.50 \mathrm{in}$., without formation of any edge cracks or side barreling (Figure 10b). They were homogenized, hot-rolled, and then normalized and tempered. There were no edge cracks or side barreling, the same as the trial EUROFER97 heat fabrication.

(a) As-cast ingots

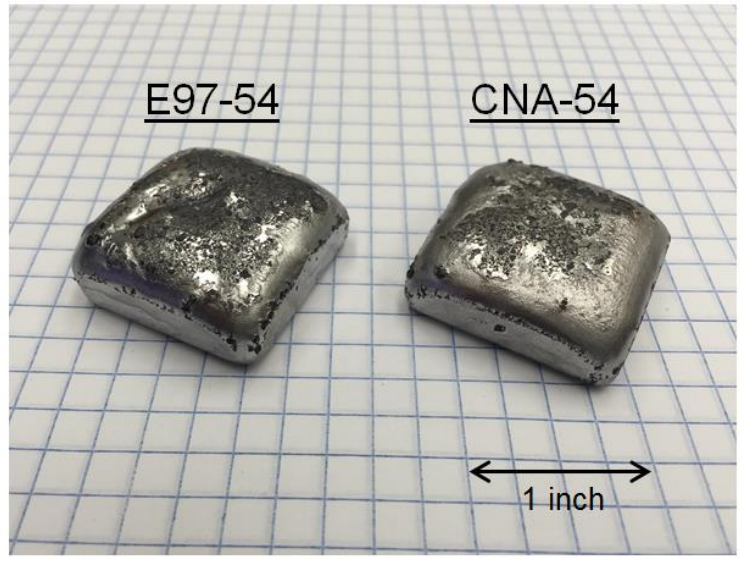

(b) Rolled and heat-treated

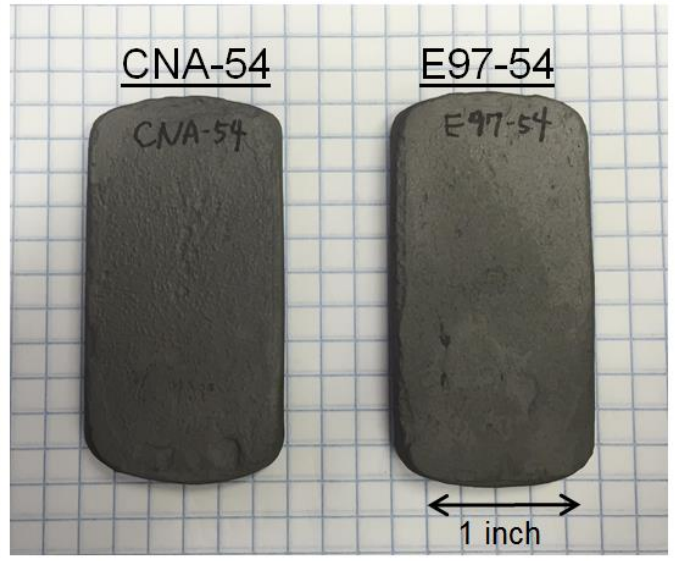

Figure 10. (a) As-cast ingots of EUROFER97 (E97-54) and CNA (CNA-54) made of ${ }^{54} \mathrm{Fe}$ isotope, and (b) the rolled and annealed plates.

Machining of SS-J3 tensile specimens and M4 PCCVN bend bar specimens from the reference material (heat \#22) following the plan shown in Figure 11a, has been completed (Figure 11b), and all specimens passed the ORNL size inspection. A total 72 SS-J3 specimens and 60 M4 PCCVN specimens are to be machined from the reference steels, E97-54, and CNA-57, with expected delivery in the middle of October, 2016.

(a) Machining plan

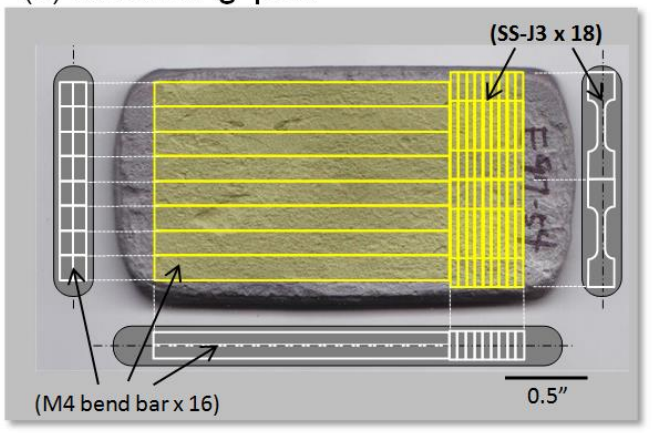

(b) Machined specimens

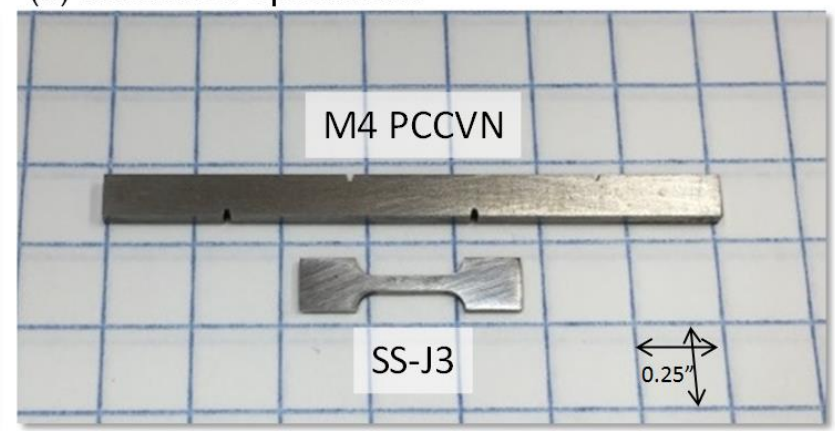

Figure 11. Machining plan of SS-J3 and M4 bend bar specimens.

\section{FUTURE PLANS}

Characterization and property evaluation of the as-fabricated plate specimens (including the reference steels, E97-54, and CNA-54) will be conducted. Detailed HFIR irradiation test plans are being developed. 


\subsection{IMPACT OF NEUTRON IRRADIATION ON THERMAL HELIUM DESORPTION FROM IRON}

Xunxiang Hu( $\underline{\text { huxl@ornl.gov) }}$

\section{OBJECTIVE}

The goal of this project is to investigate the impact of neutron irradiation on helium desorption from pure iron through a combination of thermal desorption spectrometry (TDS) and transmission electron microscope. This will provide insight into the underlying mechanisms of synergistic effects of neutron irradiation and tranmutant helium in iron-based structural materials used in fusion reactors.

\section{SUMMARY}

We have investigated the impact of neutron irradiation on thermal helium desorption behavior in high purity iron. Single crystalline and polycrystalline iron samples were neutron irradiated in HFIR to 5 dpa at $300^{\circ} \mathrm{C}$ and in BOR-60 to $16.6 \mathrm{dpa}$ at $386^{\circ} \mathrm{C}$. Following neutron irradiation, $10 \mathrm{keV}$ He ion implantation was performed on both samples to a fluence of $7 \times 10^{18} \mathrm{He} / \mathrm{m}^{2}$ at room temperature. TDS was conducted to obtain the helium desorption spectra. The comparison of He desorption spectra between unirradiated and neutron irradiated samples showed that the major He desorption peaks shifted to higher temperatures for the neutron-irradiated iron samples, implying that strong trapping sites for He were produced during neutron irradiation. TEM examination suggests that the trapping sites were likely voids. The underlying mechanisms controlling the helium trapping and desorption behavior were revealed through the detailed microstructure characterization of the neutron irradiated samples before and after TDS runs.

\section{PROGRESS AND STATUS}

Figure 12 shows the high angle annular dark field (HAADF) imaging of Fe sample F02, irradiated to 16.6 dpa at $386^{\circ} \mathrm{C}$ in BOR-60. It is evident that a high number density of cavities is dispersed within the grains, having an approximately continuous size distribution. No large dislocation loops were observed. A denuded zone with a width of $80 \sim 120 \mathrm{~nm}$ was observed in the vicinity of grain boundaries, indicating that grain boundaries are strong sinks for defects. For the A4 sample subjected to neutron irradiation in HFIR at $300^{\circ} \mathrm{C}$ to $5 \mathrm{dpa}$, the visible cavities are sparsely distributed within the grains with a very low number density of $\sim 8 \times 10^{19} \mathrm{~m}^{-3}$ and an average diameter of $9.0 \mathrm{~nm}$.

Figure 13 shows the comparison of the measured He desorption spectra of the Fe samples before and after neutron irradiation. The sharp $\mathrm{He}$ release peak at $912^{\circ} \mathrm{C}$, indicating the $\mathrm{BCC}$-FCC phase transformation, still appears in the He desorption spectra from both samples. The major He desorption group was observed in a higher temperature region while three major He release groups were observed in the $\mathrm{He}$ desorption spectra of neutron irradiated samples. The He desorption behavior in the FCC regime of the neutron irradiated samples is quite similar to those of unirradiated samples.

Significant He bubble evolution was expected in the thermal annealing processes. Most of the He bubbles in the bulk of the F02 were dissolved while the surviving bubbles existed near the free surface due to the implanted He stabilizing the bubbles in a shallow zone. In contrast, the pre-existing He bubbles in A4 were more stable in surviving the TDS measurement. The post-TDS microstructures of neutron-irradiated $\mathrm{Fe}$ were heavily dependent on the initial $\mathrm{He} / \mathrm{V}$ ratio of the He-V clusters or He bubbles contained in the as-irradiated samples. The surviving He bubbles in both neutron irradiated samples following TDS were predicted to have a $\mathrm{He} / \mathrm{V}$ ratio of $\sim 2.0$ through coordination with the theoretical study of the thermal stability of He-V clusters. 


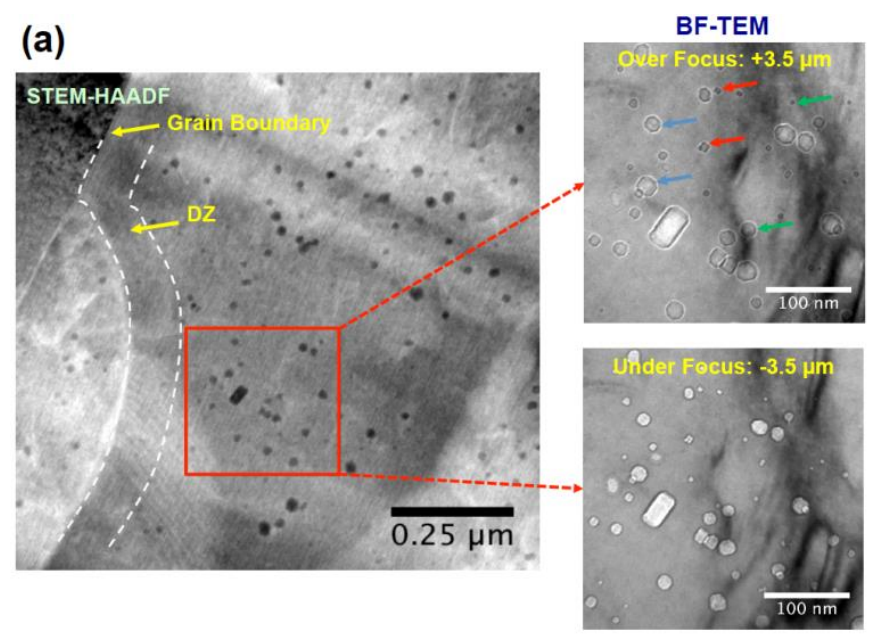

(b)

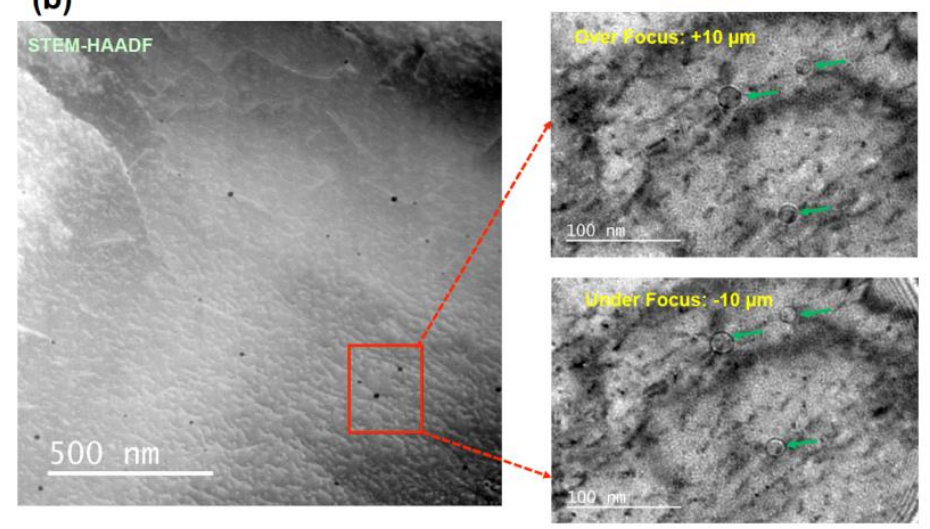

Figure 12. High-angle annular dark field (HAADF) imaging of (a) as-irradiated polycrystalline Fe specimen, F02, irradiated in BOR-60 to 16.6 dpa at $386^{\circ} \mathrm{C}$; (b) as-irradiated single crystalline Fe specimen, A4, irradiated in HFIR to $5 \mathrm{dpa}$ at $300^{\circ} \mathrm{C}$. The two enlargements on the right of (a) and (b) show the bright field TEM images of the marked region in the over focus and under focus conditions.

\section{FUTURE PLANS}

The present study only included two neutron irradiation conditions. In the future work, a systematic study of neutron irradiation impact on He behavior in Fe is necessary to capture the He-defect interactions, aiding the modeling predictions of $\mathrm{He}$ bubble nucleation and growth in $\mathrm{Fe}$-based alloys planned for use in fusion reactors. 

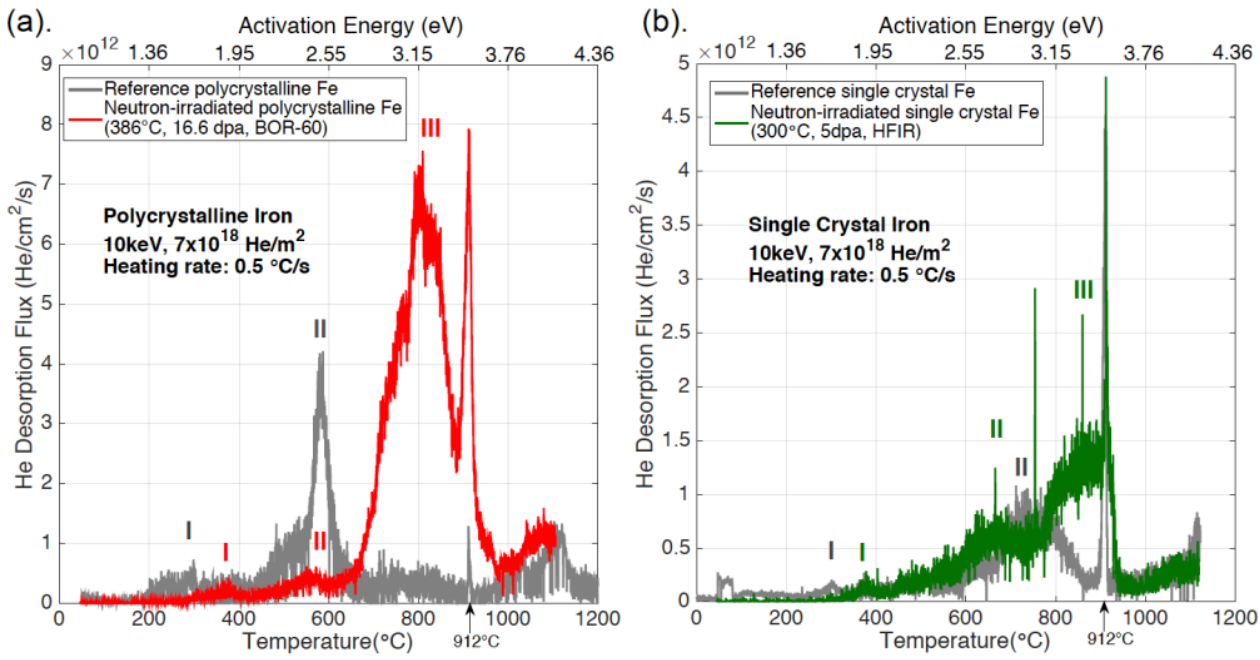

Figure 13. Comparison of He desorption spectra of the He-implanted samples before and after neutron irradiations: (a) polycrystalline Fe; (b) single crystalline Fe. 


\subsection{LIQUID METAL COMPATIBILITY IN FLOWING Pb-Li SYSTEMS}

\section{B. A. Pint (pintba@ornl.gov) and S. J.Pawel}

\section{OBJECTIVE}

The objective of this task is to identify potential structural materials having sufficient compatibility with flowing $\mathrm{Pb}$-Li eutectic that the maximum metal temperature for operation of the dual coolant $\mathrm{Pb}$-Li fusion reactor blanket can be increased to improve overall system efficiency.

\section{SUMMARY}

A thermal convection loop (TCL) fabricated using dispersion strengthened FeCrAl (Kanthal APMT, Fe$21 \mathrm{Cr}-5 \mathrm{Al}-3 \mathrm{Mo}$ ) tubing was operated for $1000 \mathrm{~h}$ at a peak temperature of $600 \pm 1.5^{\circ} \mathrm{C}$ and a temperature gradient of $\sim 85^{\circ} \mathrm{C}$. The liquid metal flow rate was $0.6-0.7 \mathrm{~m} / \mathrm{min}$. The TCL contained chains of APMT specimens in the hot and cold legs. Characterization of these specimens has just begun, and will be compared to the previously reported results from the similar $550^{\circ} \mathrm{C}$ TCL.

\section{PROGRESS AND STATUS}

Kanthal alloy APMT was selected for this work as it has excellent high temperature strength and oxidation resistance resulting from the $\mathrm{Al}_{2} \mathrm{O}_{3}$ surface film that readily forms at high temperature. However, it should be noted that this alloy does not possess the physical/mechanical/nuclear properties required for fusion materials duty and is not being considered as a candidate alloy for fusion service. Nevertheless, APMT is commercially available in tubing and several other forms necessary to fabricate a TCL. Thus, it was evaluated in the experiments described here as an acceptable surrogate for advanced alumina-forming oxide dispersion strengthened (ODS) alloys under development but not yet available in sufficient quantity for testing.

Figure 14 shows the TCL before testing. Both the hot and cold legs contained chains of 20 APMT SS-3 type tensile specimens. To avoid the complication of dissimilar materials interactions, all of the wire and specimens were APMT. The only other material was $\mathrm{W}$ weights on each chain used to prevent the chains from floating in the liquid metal. The approximate temperature of each specimen location was estimated by linear extrapolation as a function of position between thermowell locations at the top, middle and bottom of each leg. As with the $550^{\circ} \mathrm{C}$ loop, the loop surfaces and most of the specimens were preoxidized for $8 \mathrm{~h}$ in air at $1050^{\circ} \mathrm{C}$ and four had no pre-oxidation (i.e. bare metal when inserted). However, this time several specimens also were pre-oxidized for $2 \mathrm{~h}$ at $1000^{\circ} \mathrm{C}$ or $8 \mathrm{~h}$ at $1100^{\circ} \mathrm{C}$ in order to study possible effects of pre-oxidation temperature on performance.

Figure 15 shows the specimen mass change as a function of estimated exposure temperature for the $600^{\circ} \mathrm{C}$ loop as well as the $550^{\circ} \mathrm{C}$ loop. After exposure, specimens were cleaned before weighing in a 1:1:1 solution of acetic acid, hydrogen peroxide and ethanol. As with the previous loop experiment, most of the specimens showed a small mass loss and the specimens that were not pre-oxidized showed a larger mass loss than the pre-oxidized specimen. This temperature range is relatively low for the selective oxidation of $\mathrm{Al}$ to form a surface oxide because the diffusion rate of $\mathrm{Al}$ is slow. Thus, it is not surprising that some mass loss occurred before the alloy was able to form a protective reaction product to inhibit dissolution. The mass change of the specimens with $1000^{\circ}$ and $1100^{\circ} \mathrm{C}$ pre-oxidations was similar to the specimens pre-oxidized at $1050^{\circ} \mathrm{C}$. 


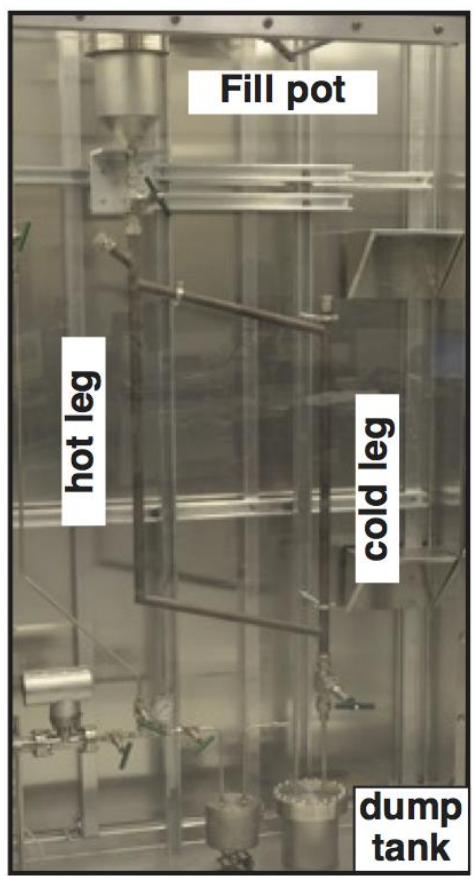

Figure 14. Kanthal APMT thermal convection loop prepared for $600^{\circ} \mathrm{C}$ experiment. Furnaces are placed over the hot leg for operation and insulation is used as needed.

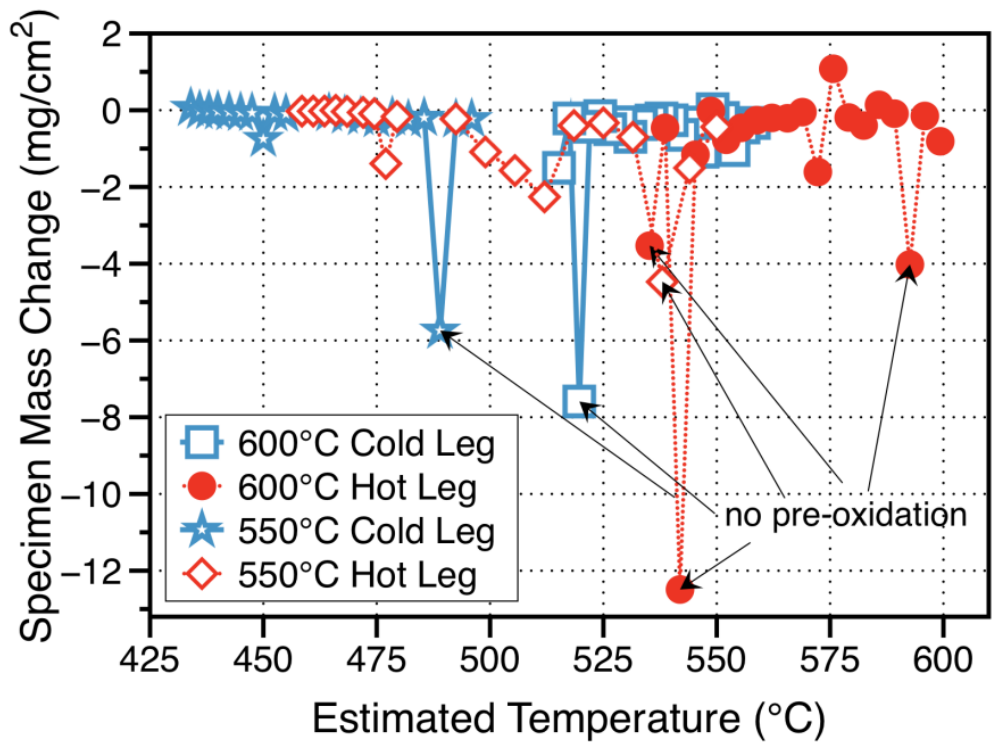

Figure 15. Room temperature yield strength of APMT specimens exposed to flowing Pb-Li eutectic for 1000 $h$ at the indicated temperature. Indicated data are for specimens that did not receive the pre-oxidation heat treatment.

Additional characterization of the exposed specimens is in progress. X-ray diffraction has initially not been able to detect a reaction product due to spallation of the oxide on some of the specimens. However, previously the reaction product was identified as $\mathrm{LiAlO}_{2}$. Figure 16 and Figure 17 show scanning electron microscopy (SEM) plan view images of specimens with different initial pre-oxidation treatments. While pre-oxidation reduced the specimen mass loss, the resulting oxide appeared to be poorly adherent after exposure and cleaning. In contrast, spallation was not observed for the specimens exposed as 
received (i.e. no pre-oxidation). One explanation for that difference is that the transformation from $\alpha$ $\mathrm{Al}_{2} \mathrm{O}_{3}$ to $\mathrm{LiAlO}_{2}$ during exposure led to the spallation. The as-received specimens that formed $\mathrm{LiAlO}_{2}$ directly formed a more adherent oxide. However, particularly at higher magnification in Figure 17, the oxide on the as-received specimen appears to be cracked similar to the other specimens. In general, the variations in the pre-oxidation temperature did not appear to significantly affect the scale adhesion after exposure.

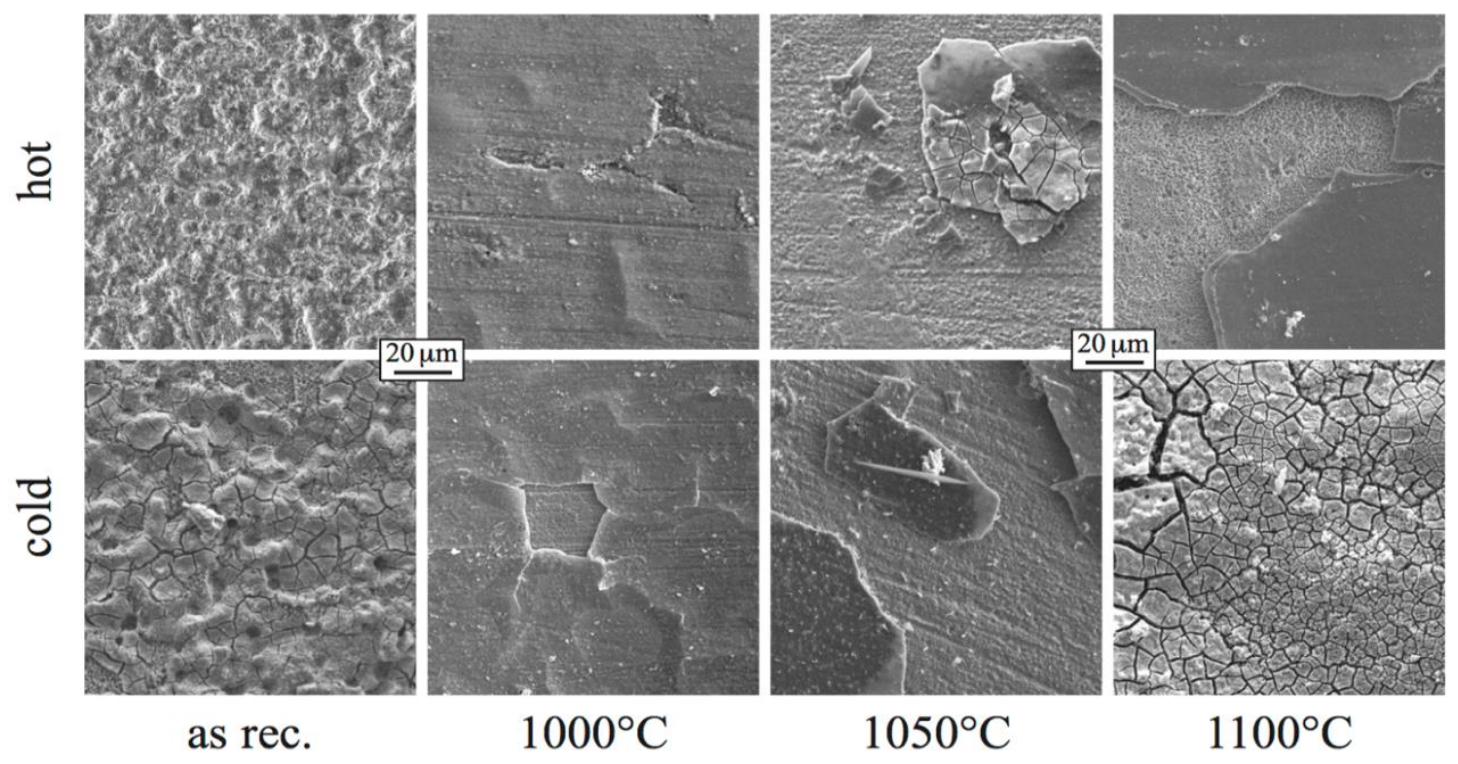

Figure 16. Post-exposure plan-view secondary electron SEM images of the APMT surfaces.

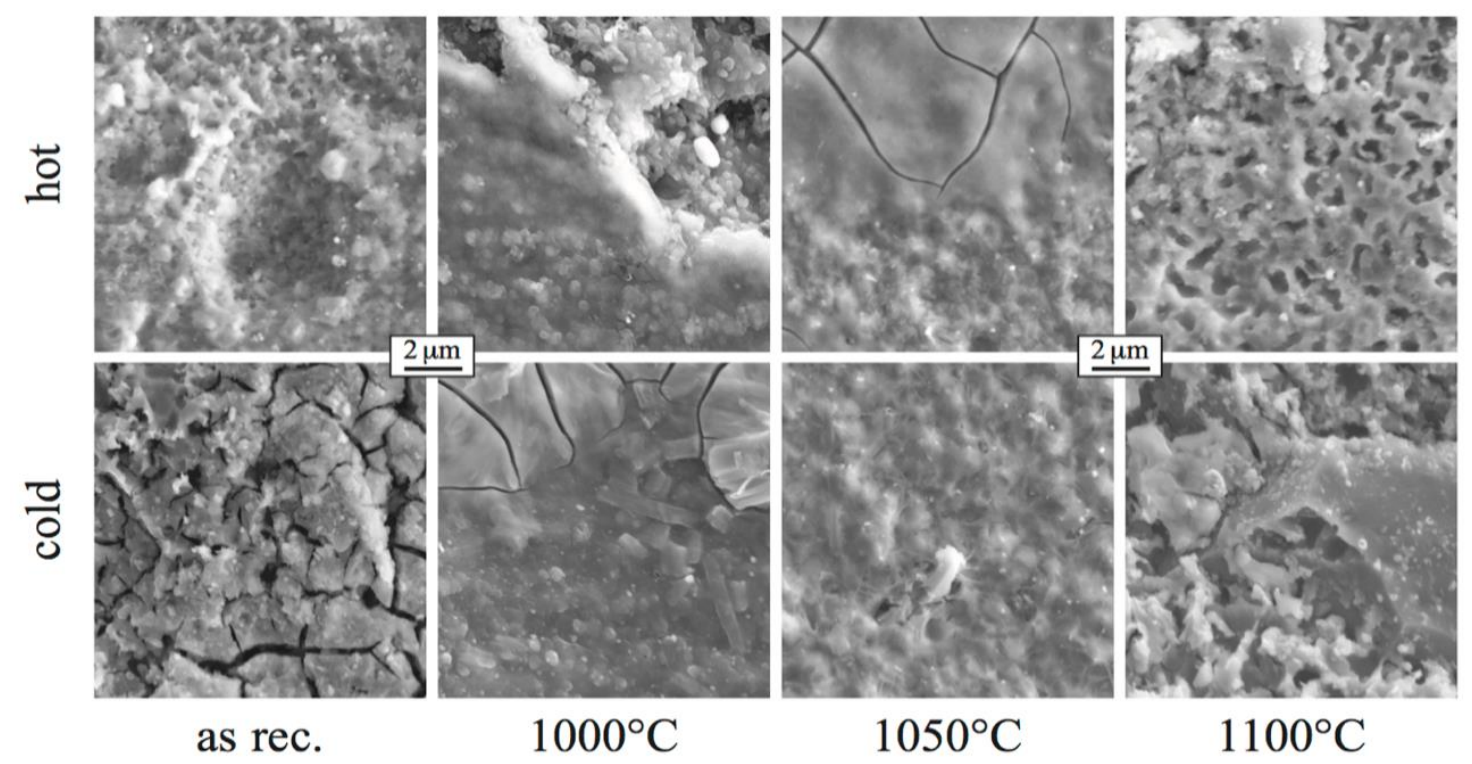

Figure 17. Higher magnification post-exposure plan-view secondary electron SEM images of the APMT surfaces. 


\section{FUTURE PLANS}

The characterization of the exposed APMT specimens will continue with measurement of the tensile properties at room temperature and more in-depth characterization of the reaction products. The third TCL is already fabricated and as soon as characterization is complete, it will be assembled for operation for $1000 \mathrm{~h}$ with a peak temperature of $650^{\circ} \mathrm{C}$ and APMT specimens similar to the previous experiments. Future TCL experiments will include multimaterial evaluations including SiC and ODS FeCrAl. 


\title{
4. CERAMIC AND COMPOSITE MATERIALS
}

\subsection{DEVELOPMENT OF SiC JOINING TECHNOLOGIES FOR FUSION}

\author{
T. Koyanagi (koyanagit@ornl.gov), Y. Katoh, J.O. Kiggans, M. Ferraris (Politecnico di Torino, Italy)
}

\section{OBJECTIVE}

The objective of this work is to develop irradiation tolerant silicon carbide joining technology for fusion applications. The work in this fiscal year focused on development of the pressureless joining methods.

\section{SUMMARY}

Joining is recognized as a key technology for development of $\mathrm{SiC}$ based materials for use as fusion structural materials. Decreasing applied stress during joining would be beneficial to join complex shaped materials. Significant reduction of the applied stress was achieved for transient eutectic phase (TEP) SiC sintering based joining. In addition, pressureless $\mathrm{Ti}_{3} \mathrm{SiC}_{2} \mathrm{MAX}$ phase forming joining was demonstrated, adapted from what was originally a pressurized joining method. There was no significant strength degradation due to the improved processing process. Neutron irradiation and post-irradiation experiments revealed that those two $\mathrm{SiC}$ joints in addition to a pressurelessly formed calcia-alumina (CA) glassceramics bonded $\mathrm{SiC}$ joint showed excellent irradiation resistance, retaining joint strength following irradiations at $290-780^{\circ} \mathrm{C}$ to $2.3-8.7 \mathrm{dpa}$ for $\mathrm{SiC}$.

\section{PROGRESS AND STATUS}

$\mathrm{SiC}$ joint specimens were neutron irradiated in the HFIR at $290,480-490$, and $730-780^{\circ} \mathrm{C}$ to $2.30-8.71 \mathrm{dpa}$ for SiC. The phases in the joints have been analyzed using XRD, SEM-EDS, and SEM-Electron Back Scatter Diffraction. The irradiation effects on the joint strength were determined by a torsional shear test. The microstructural stability of the bonding layers was evaluated by electron microscopy. The results are summarized in Table 4. In brief, there was no significant strength degradation of any joints following irradiation. Fractography also found no significant change in the fracture behavior as a result of the irradiation.

Table 4. Summary of test materials, irradiation conditions, and strengths of SiC joints. The parenthesis indicates the standard deviation.

\begin{tabular}{lllll}
\hline Joint materials & $\begin{array}{l}\text { Bonding } \\
\text { Layer }\end{array}$ & $\begin{array}{l}\text { Test } \\
\text { conditions }\end{array}$ & $\begin{array}{l}\text { Torsional shear } \\
\text { strength [MPa] }\end{array}$ & $\begin{array}{l}\text { Number of } \\
\text { torsion tests }\end{array}$ \\
\hline TEP & $\mathrm{SiC}$, & $\begin{array}{l}\text { Unirradiated } \\
480^{\circ} \mathrm{C} / 2.9 \mathrm{dpa}\end{array}$ & $114(21)$ & 9 \\
& $\mathrm{Y}-\mathrm{Al}$ oxides & $730^{\circ} \mathrm{C} / 2.3 \mathrm{dpa}$ & $126(32)$ & 4 \\
& & Unirradiated & $104(26)$ & 3 \\
CA glass & $\mathrm{Al}_{14} \mathrm{Ca}_{12} \mathrm{O}_{33}$, & $780^{\circ} \mathrm{C} / 2.3 \mathrm{dpa}$ & $110(10)$ & 3 \\
& $\mathrm{Al}_{2} \mathrm{Ca}_{3} \mathrm{O}_{6}, \mathrm{SiO}_{2}$ & & & 10 \\
& $\mathrm{Ti}_{3} \mathrm{SiC}_{2}$, & Unirradiated & $147(12)$ & 8 \\
& $\mathrm{SiC}_{2} \mathrm{TiC}^{2}$ & $290^{\circ} \mathrm{C} / 8.7 \mathrm{dpa}$ & $123(13)$ & 3 \\
& & $490^{\circ} \mathrm{C} / 2.9 \mathrm{dpa}$ & $110(19)$ & 4 \\
& & $780^{\circ} \mathrm{C} / 2.3 \mathrm{dpa}$ & $107(19)$ & 3 \\
\hline
\end{tabular}


The pressureless TEP SiC joint also showed stable microstructure following the irradiation (Figure 18), which was also reported in the pressurized TEP SiC joints. Regarding the CA glass joint, XRD analysis indicated that the oxide phases in the bonding layer exhibited phase instability under the irradiation, but this did not obviously affect the joint strength. The pressureless MAX phase joint exhibited irradiationinduced cracking, likely caused by strain from differential swelling between $\mathrm{SiC}$ phases and $\mathrm{Ti}_{3} \mathrm{SiC}_{2}$ phase, which was one of the reasons for the slight degradation of the strength.
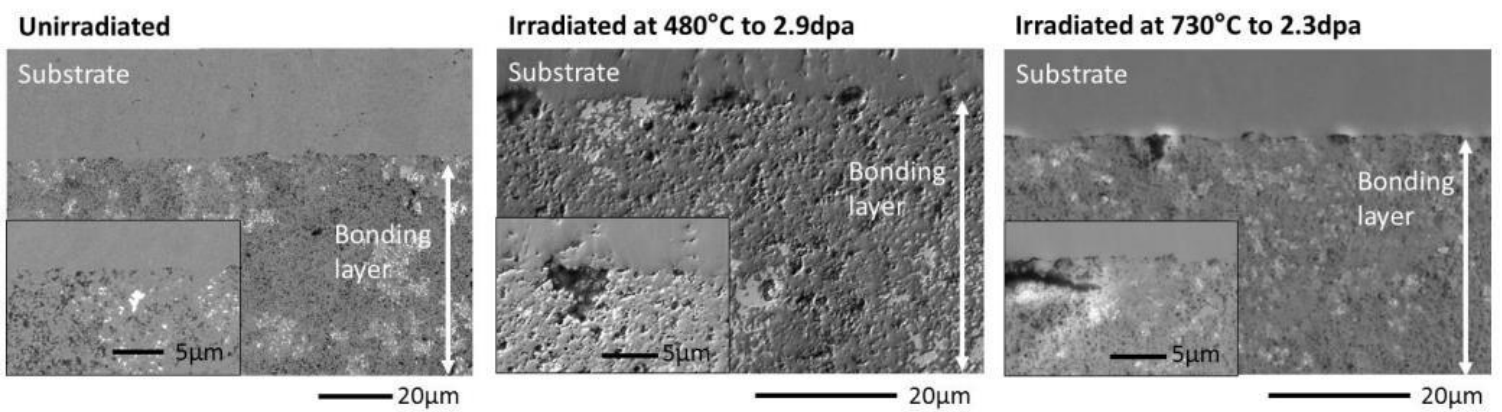

Figure 18. SEM micrographs of unirradiated and irradiated TEP joints of SiC.

\section{FUTURE PLANS}

A paper on the development of and irradiation effects on the pressureless $\mathrm{SiC}$ joints will be prepared. The post-irradiation examination of $\mathrm{SiC}$ joints with various carbides and/or silicide's is on-going. High-dose irradiation of the selected $\mathrm{SiC}$ joints up to > 20 dpa will be achieved within FY2017. 


\subsection{HIGH DOSE NEUTRON IRRADIATION EFFECTS ON MECHANICAL PROPERTIES OF SiC MATERIALS AND COMPOSITES}

T. Koyanagi (koyanagit@ornl.gov), Y. Katoh, L.L. Snead (Massachusetts Institute of Technology), T. Nozawa, K. Ozawa (National Institutes for Quantum and Radiological Science and Technology), $K$. Shimoda, T. Hinoki (Kyoto University)

\section{OBJECTIVE}

The objective of this task is to obtain a complete understanding of the effects of high neutron fluence irradiation on the mechanical properties and microstructures of silicon carbide ( $\mathrm{SiC})$ and $\mathrm{SiC}$ fiber reinforced $\mathrm{SiC}$ matrix ( $\mathrm{SiC} / \mathrm{SiC}$ ) composites to be used in fusion structural applications.

\section{SUMMARY}

The high-dose irradiation creep of various $\mathrm{SiC}$ materials was investigated, and the results have been published in the Journal of Nuclear Materials. The results showed that the dimensional stability of SiC under irradiation environments is superior to the stability of metallic nuclear alloys because of the smaller creep coefficient and the saturation of swelling. In addition, microstructural examination of the early nuclear grade $\mathrm{SiC} / \mathrm{SiC}$ composite irradiated to 100 dpa revealed the instability of carbon phases in the fiber and interphase under high dose radiation conditions, especially at lower temperatures.

\section{PROGRESS AND STATUS}

\section{High-dose irradiation creep}

Irradiation creep of various $\mathrm{SiC}$ materials was investigated using bend stress relaxation experiments. We found that the instantaneous creep coefficient was $\sim 1 \times 10^{-7}[\mathrm{MPa} \mathrm{dpa}]^{-1}$ at $\sim 400$ to $\sim 750^{\circ} \mathrm{C}$ for irradiations in the range $\sim 1-30 \mathrm{dpa}$ for all $\mathrm{SiC}$ materials except the coarse grain $\mathrm{SiC}$ at $\sim 750^{\circ} \mathrm{C}$. That creep coefficient is compared with those of several metals in Figure 19. The post-transient irradiation creep was reported for zirconium alloys, vanadium alloy (V-4Cr-4Ti), austenitic stainless steels (316 and 304), oxide-dispersion-strengthened (ODS) ferritic steels (MA957 and HT9), and ferritic/martensitic steels (F82H and JLF-1). The irradiation temperatures ranged from $\sim 300$ to $\sim 700^{\circ} \mathrm{C}$. Although the test methods, irradiation conditions, and stress exponents were different, the significant differences in the creep coefficient between $\mathrm{SiC}$ and the other materials can be discussed. The creep coefficient of the zirconium alloys was $\sim 1 \times 10^{-5}[\mathrm{MPa} \mathrm{dpa}]^{-1}$. A slightly smaller creep coefficient of $\sim 5 \times 10^{-6}[\mathrm{MPa} \mathrm{dpa}]^{-1}$ was obtained for the specific vanadium alloy. A much smaller creep coefficient of $\sim 1 \times 10^{-6}[\mathrm{MPa} \text { dpa }]^{-1}$ was typical of the austenitic stainless, ODS, and ferritic/martensitic steels. The creep coefficients of the $\mathrm{SiC}$ materials were approximately one order of magnitude smaller than the coefficients for those steels, making the creep coefficients of the SiC materials extremely small compared with those of the other nuclear materials. Although the smaller creep coefficient does not necessarily indicate a longer creep lifetime, it can be concluded that the smaller creep coefficient contributes to higher dimensional stability. In the case of the high-purity CVD SiC, the saturation of swelling above $\sim 1$ dpa along with the small creep coefficient makes the material more dimensionally stable in the irradiation environment than the metals. 


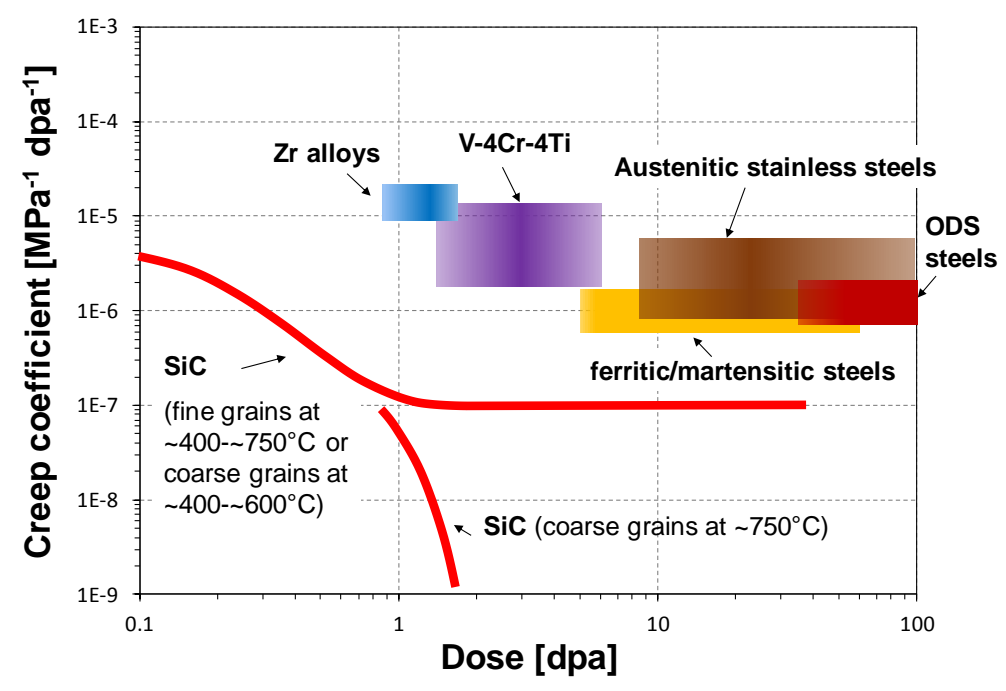

Figure 19. Comparison of typical creep coefficients among different nuclear materials.

\section{Microstructure of SiC composite irradiated to 100 dpa}

We have investigated the flexural behavior of multi-layer SiC/C coated Hi-Nicalon Type-S fiber reinforced CVI SiC/SiC composites irradiated to 100 dpa previously. The irradiated composites showed significant mechanical degradation for lower irradiation temperatures. The work in FY2016 included microstructural observations using TEM to understand the degradation mechanisms. Figure 20 shows STEM-HAADF images of the fiber and interphase following irradiations at 319 and $629^{\circ} \mathrm{C}$ to $100 \mathrm{dpa}$. The arrows in the image indicate relatively low-Z impurity phases in the as-fabricated fiber, which was reported to be carbon. The fraction of that phase significantly decreased during irradiation, especially at $319^{\circ} \mathrm{C}$. This may be a key to understanding the fiber degradation mechanism shown by the flexural test. The microstructural instability of the carbon phase was also observed at the fiber/matrix interface. The carbon phase seemed to disappear at $319^{\circ} \mathrm{C}$, but still exists after irradiation at $629^{\circ} \mathrm{C}$. The disappearance of the carbon phase is expected to cause brittle fracture of the composite, which is consistent with the flexural behavior. The mechanical properties of the composite may be improved by controlling these carbon or impurity phases.

\section{FUTURE PLANS}

High-dose irradiation creep: Advanced characterization of the irradiation produced defects in the creep specimen will be conducted using XRD to understand the underlying mechanisms and to develop a mechanistic creep model.

High-dose irradiation effects on the SiC/SiC composite: Further TEM characterization will be performed for a better understanding of the composite degradation mechanisms. A draft manuscript on this work will be prepared in FY2017. Newer generation SiC composites being irradiated in HFIR will be evaluated. 


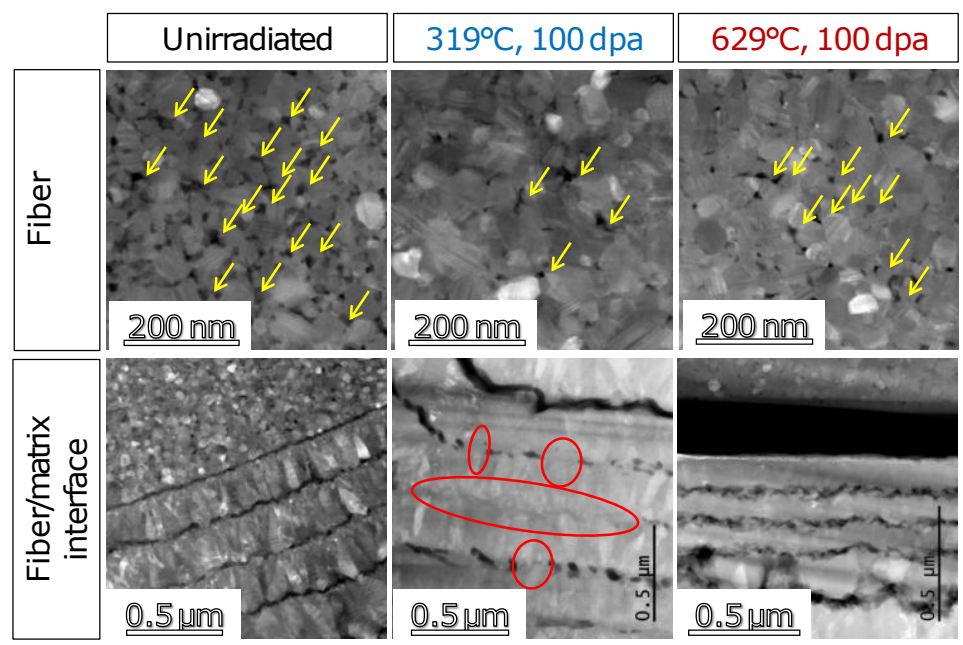

Figure 20. STEM-HAADF micrographs of Hi-Nicalon Type $\mathrm{S}$ fiber and SiC/C multi-layer interface irradiated to 100 dpa. 


\title{
4.3 PROPERTIES OF NEUTRON IRRADIATED NITE SiC MATERIALS
}

\author{
C. Ang (angck@ornl.gov), T. Koyanagi, J. Kiggans, K. Terrani, L. Snead*and Y. Katoh \\ *Currently at Massachusetts Institute of Technology, Cambridge, MA
}

\section{OBJECTIVE}

This work evaluates the effect of neutron irradiation on five NITE SiC materials. NITE is an alternative, economical process to obtain $\mathrm{SiC}_{\mathrm{f}}-\mathrm{SiC}$ composites, which may rival or compete with nuclear-grade $\mathrm{CVD}$ $\mathrm{SiC}$ materials in specific applications. The focus of this study is the radiation stability and increased strength of these $\mathrm{SiC}$ materials after irradiation.

\section{SUMMARY}

The current year focused on developing the understanding of the NITE SiC materials after irradiation. While CVD SiC materials are known to be radiation-resistant for fusion and fission conditions, less is known about NITE SiC. NITE (Nano-Infiltrated Transient Eutectic) SiC is made from conventional nanopowder of $\mathrm{SiC}$ with a $\sim 6-9 \mathrm{wt} \%$ oxide additives instead of using chemical decomposition of vaporized organic Si-C precursors. This yields a liquid phase during sintering and can densify SiC as a monolithic material or as matrix for fiber reinforced composites if rheology is controlled. Compared to CVD materials, NITE is a cost-effective production method for $\mathrm{SiC}_{\mathrm{f}}-\mathrm{SiC}$. Properties after irradiation were recently acquired. While thermal conductivity and thermal defect resistance was as predicted when compared to CVD SiC, the swelling of NITE SiC appeared to be lower than CVD SiC and the strength was significantly increased after irradiation. Detailed TEM investigations conducted by Koyanagi et al indicated that significant strain fields existed in SiC around triple points. It appeared that differential swelling of additives was associated with a strengthening mechanism. Investigations are continuing.

\section{PROGRESS AND STATUS}

Irradiation of 10 specimens of monolithic NITE materials was combined with the MAX phase FOA Unique Materials campaign, irradiated at $\sim 2$ and $\sim 10 \mathrm{dpa}$ at $\sim 400$ and $700^{\circ} \mathrm{C}$. There were four I-variants (using low-cost nanopowder) and $\mathrm{K}$ (Kyoto University material). The compositions are shown in Table 5 and Table 6.

Table 5. NITE-SiC feedstock composition in wt\% including additives and dispersants

\begin{tabular}{|l|l|l|l|l|l|l|l|l|}
\hline \multicolumn{2}{|c|}{ Design composition } \\
\hline $\mathrm{ID}$ & $\mathrm{SiC}$ & $\mathrm{PEI}^{*}$ & $\mathrm{Al}_{2} \mathrm{O}_{3}$ & $\mathrm{Y}_{2} \mathrm{O}_{3}$ & $\mathrm{Gd}_{2} \mathrm{O}_{3}$ & $\mathrm{Er}_{2} \mathrm{O}_{3}$ & $\mathrm{SiO}_{2}$ & PEG$^{*}$ \\
\hline $\mathrm{I}-1$ & 93 & 1 & 4 & 2 & 0 & 0 & & 0 \\
\hline $\mathrm{I}-2$ & 90 & 1 & 6 & 3 & 0 & 0 & & 0 \\
\hline $\mathrm{I}-3$ & 93 & 1 & 4 & 0 & 1 & 1 & & 0 \\
\hline $\mathrm{I}-4$ & 93 & 1 & 4 & 2 & 0 & 0 & & 2 \\
\hline $\mathrm{K}$ & 93 & 1 & 2 & 2 & & & 2 & \\
\hline
\end{tabular}

*Sintering additions. 
Table 6. NITE-SiC compositions in wt \% after sintering

\begin{tabular}{|l|l|l|l|l|l|l|l|l|l|}
\hline \multicolumn{1}{|l|}{ Chemical Analysis } \\
\hline ID & Si & C & Al & Y & Gd & Er & O & Fe & Cr \\
\hline I-1 & 65.97 & 27.62 & 2.14 & 1.06 & 0.00 & 0.05 & 2.95 & 0.12 & 0.10 \\
\hline I-2 & 66.25 & 27.74 & 1.56 & 1.40 & 0.00 & 0.19 & 2.55 & 0.23 & 0.09 \\
\hline I-3 & 66.49 & 27.84 & 1.95 & 0.33 & 0.25 & 0.32 & 2.66 & 0.08 & 0.07 \\
\hline I-4 & 66.36 & 27.79 & 2.02 & 0.76 & 0.00 & 0.07 & 2.77 & 0.16 & 0.07 \\
\hline K* & 67.09 & 28.09 & 1.60 & 0.58 & 0.02 & 0.13 & 2.37 & 0.11 & 0.01 \\
\hline
\end{tabular}

*K used a different powder (particle size, $80 \mathrm{~nm}>99 \%$ purity, Nanomakers, France, Lot\# 12-SiC-122) than the Iseries (particle size, $40 \mathrm{~nm}$, >98\% purity, Nanostructured \& Amorphous Materials, Inc., China, Lot\# 4620-123109).

Figure 21 shows the strength after irradiation to $\sim 2 \mathrm{dpa}$ and includes results from historical irradiated $\mathrm{SiC}$ ceramics. It can be seen that NITE and CVD variants were the only $\mathrm{SiC}$ ceramics that were able to maintain high strength after neutron irradiation - all pressureless sintered (PS), reaction bonded (RB), B-doped and hot pressed (HP) variants (in black) lose strength after irradiation (Snead et al).

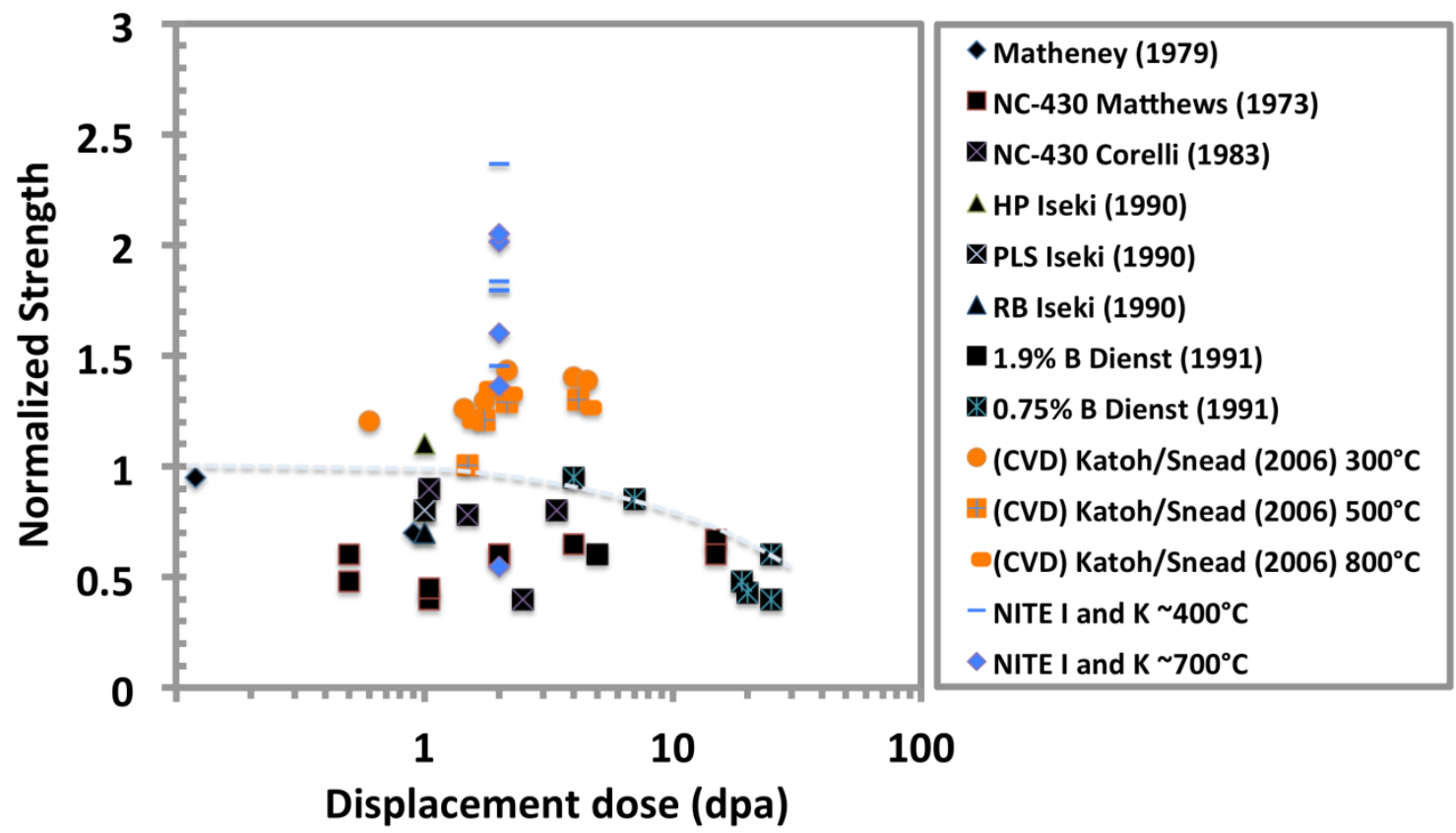

Figure 21. SiC materials after irradiation, adapted from Snead, Katoh, et al and other data. (Journal of Nuclear Materials, to be published) It shows that like CVD, NITE materials increase in strength.

The strengthening mechanism of CVD SiC was reportedly toughening from surface modification, relaxation of machining stresses on the surfaces and changes in elastic properties/fracture energy (Snead et al). The strengthening of TEP $\mathrm{SiC}$ (in blue) appeared to be a different mechanism, resulting in 1.4 to $2.4 \mathrm{x}$ normalized strength compared to unirradiated values. Investigations are continuing, but the strengthening appears to be the result of improved microstructure after irradiation. 


\section{FUTURE PLANS}

To further understand the strengthening of NITE $\mathrm{SiC}$ by irradiation, future work is focused on evaluation by electron microscopy and XRD. Retrieval of NITE SiC specimens irradiated at $~ 10 \mathrm{dpa}$ is currently underway for post irradiation examination. The results are needed to understand this unusual behavior of NITE SiC. 


\title{
4.4 ADVANCED CHARACTERIZATION OF IRRADIATION DEFECTS IN SiC
}

\author{
T. Koyanagi (koyanagit@ornl.gov), X. Hu, M.J. Lance and Y. Katoh
}

\section{OBJECTIVE}

This project is developing advanced characterization techniques for irradiation defects in SiC, including Raman spectroscopy and positron annihilation spectroscopy. This will help build mechanistic models of the material performance for fusion applications.

\section{SUMMARY}

Raman spectra from $\mathrm{SiC}$ were collected following neutron irradiation. The longitudinal optical (LO) peak shifted to a lower frequency and broadened as a result of the irradiation. The changes observed in the LO phonon line shape and position in neutron-irradiated $\mathrm{SiC}$ are explained by a combination of changes in the lattice constant and Young's modulus, and the phonon confinement effect. The phonon confinement model reasonably estimates the nano-scale defect-defect distances in the irradiated SiC, consistent with results from previous experiments and simulations. This work was published in Scripta Materialia.

Positron annihilation lifetime spectroscopy (PALS) was used to characterize the small vacancy clusters in $\mathrm{SiC}$ subject to various neutron irradiation conditions. The vacancy cluster distribution obtained from PALS investigation is critically important to complement the current understanding of the microstructural evolution in $\mathrm{SiC}$ under the irradiation conditions. A manuscript on this work has been prepared for journal publication.

\section{PROGRESS AND STATUS}

The LO lines of the Rama spectra of neutron irradiated SiC were quantitatively explained as the effect of change in lattice constant and effect of phonon confinement due to decreasing undistorted areas; change in lattice spacing affects the peak shift and the phonon confinement effect causes both peak shift and broadening. By fitting the Raman LO peak using a phonon confinement model (Figure 22), defect-defect distance (correlation diameter of undistorted crystal) can be estimated. The fitting well explains the Raman peaks of both low and high dose irradiated SiC. The estimated defect distances are $<3$ and $~ 15$ $\mathrm{nm}$ following irradiations at 380 to 790 and $1180^{\circ} \mathrm{C}$, respectively. The results are consistent with the results of previous experimental and simulation studies. Since Raman spectra are sensitive to atomistic defects, this provides an approach to quantitative evaluation of atomistic defects, which will help explain the behavior of $\mathrm{SiC}$ after neutron irradiation.

PALS has been used to investigate the vacancy defects in the neutron-irradiated SiC. The irradiation temperature and dose dependence of vacancy defects in $\mathrm{SiC}$ were captured by analyzing the measured positron lifetime spectra. The lifetime measurements indicate minimal effect of irradiation temperature on the vacancy defect evolution due to the thermal immobility of $\mathrm{Si}$ and $\mathrm{C}$ vacancies in the temperature regime $380 \sim 540^{\circ} \mathrm{C}$, while the irradiation enhanced diffusion or displacement cascade overlap contributes to the formation of detected vacancy clusters at higher radiation doses. For neutron irradiation temperatures of $\sim 750^{\circ} \mathrm{C}$, an obvious increase in the long lifetime component of the positron lifetime is observed, presumably due to the mobility of $\mathrm{Si}$ vacancies leading to the formation of larger, stoichiometric $\mathrm{V}_{\mathrm{Si}}+\mathrm{V}_{\mathrm{C}}$ clusters. Positron lifetime analysis excludes the possibility of generating large vacancy clusters in the specimens of interest in the studied temperature region of $380 \sim 790^{\circ} \mathrm{C}$. The largest vacancy cluster that could be identified is the stoichiometric defect, $\left(\mathrm{V}_{\mathrm{Si}}+\mathrm{V}_{\mathrm{C}}\right)_{4}$, in the sample irradiated to $29 \mathrm{dpa}$ at $750^{\circ} \mathrm{C}$, as shown in Table 7 . 

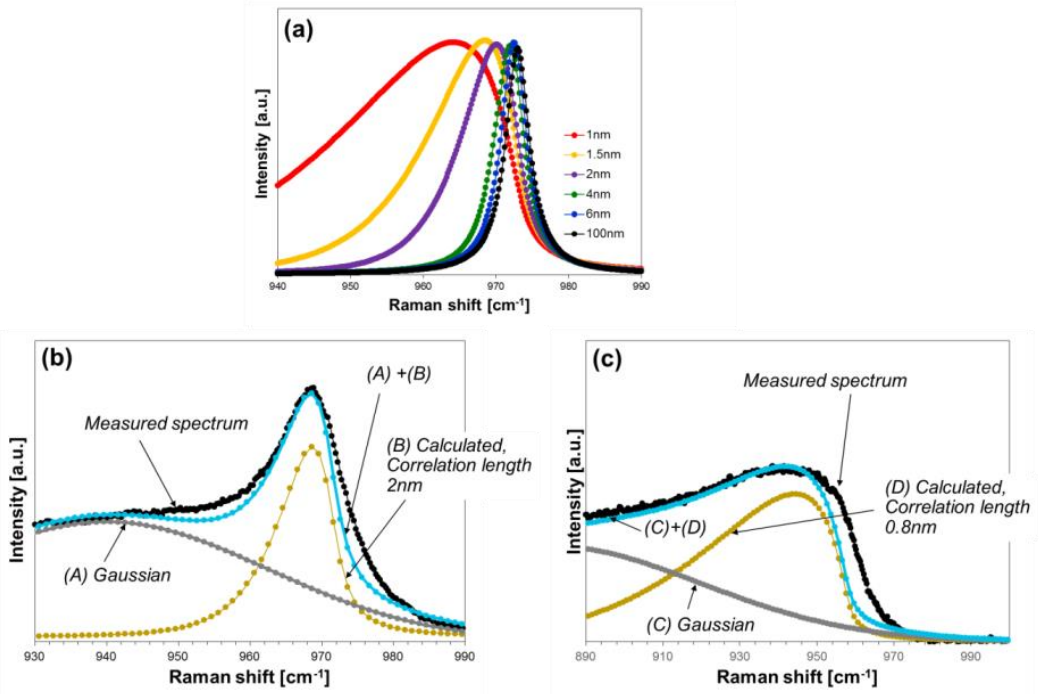

Figure 22. Calculated Raman spectra of confined LO phonon line of $3 \mathrm{C} \mathrm{SiC}$ with various size of correlation diameters: an indication of defect-defect distance (a). Raman spectra of irradiated $\mathrm{SiC}$ at $540^{\circ} \mathrm{C}$ to $0.01 \mathrm{dpa}$ (b) and to $0.11 \mathrm{dpa}(\mathrm{c})$ are compared with the calculated spectra considering change in lattice constant and phonon confinement effect. The experimental spectra are well described as the sum of the calculated spectra and a Gaussian peak known as Raman band of amorphous or disordered SiC.

Table 7. The fitted long positron lifetimes of irradiated $\mathrm{SiC}$ and the examples of possible vacancy clusters that have positron lifetimes comparable to the measured values. The concentrations of the example defects are also listed.

\begin{tabular}{|c|c|c|c|c|}
\hline $\begin{array}{c}\text { Irradiation } \\
\text { Temperature } \\
\left({ }^{\circ} \mathrm{C}\right)\end{array}$ & $\begin{array}{c}\text { Dose } \\
(\mathrm{dpa})\end{array}$ & $\begin{array}{c}\text { Fitted Long } \\
\text { lifetime, } \\
\tau_{2},(\mathrm{ps})\end{array}$ & Defect & $\begin{array}{c}\text { Concentration } \\
\text { (appm) }\end{array}$ \\
\hline As-received & As-received & 196 & $\mathrm{~V}_{\mathrm{Si}}{ }^{-}$ & 5.6 \\
\hline 380 & 0.01 & 239 & $\mathrm{~V}_{\mathrm{Si}}+\mathrm{V}_{\mathrm{C}}$ & 49.0 \\
\hline 380 & 0.11 & 253 & $\mathrm{~V}_{\mathrm{C}}+\mathrm{V}_{\mathrm{Si}_{\mathrm{C}}}+\mathrm{V}_{\mathrm{C}}$ & 44.4 \\
\hline 380 & 1.5 & 256 & $\mathrm{~V}_{\mathrm{C}}+\mathrm{V}_{\mathrm{Si}}+\mathrm{V}_{\mathrm{C}}$ & 49.6 \\
\hline 440 & 31 & 264 & $\left(\mathrm{~V}_{\mathrm{Si}}+\mathrm{V}_{\mathrm{C}}\right)_{2}$ & 64.4 \\
\hline 540 & 0.01 & 246 & $\mathrm{~V}_{\mathrm{Si}}+\mathrm{V}_{\mathrm{C}}$ & 69.4 \\
\hline 540 & 0.11 & 251 & $\mathrm{~V}_{\mathrm{C}}+\mathrm{V}_{\mathrm{Si}_{\mathrm{i}}}+\mathrm{V}_{\mathrm{C}}$ & 80.1 \\
\hline 500 & 29 & 274 & $\left(3 \mathrm{~V}_{\mathrm{Si}}+2 \mathrm{~V}_{\mathrm{C}}\right)^{-}$ & 24.6 \\
\hline 790 & 0.11 & 264 & $\left(\mathrm{~V}_{\mathrm{Si}}+\mathrm{V}_{\mathrm{C}}\right)_{2}$ & 53.9 \\
\hline 760 & 1.4 & 285 & $\left(\mathrm{~V}_{\mathrm{Si}}+\mathrm{V}_{\mathrm{C}}\right)_{3}$ & 32.0 \\
\hline 750 & 29 & 294 & $\left(\mathrm{~V}_{\mathrm{Si}}+\mathrm{V}_{\mathrm{C}}\right)_{4}$ & 60.0 \\
\hline
\end{tabular}

\section{FUTURE PLANS}

More work will be conducted to characterize the atomistic radiation defects, using Raman and Positron spectroscopies. In addition, a new experiment using synchrotron based $\mathrm{x}$-ray diffraction of the neutron irradiated $\mathrm{SiC}$ is ongoing for detailed determination of the lattice structure. 


\subsection{IRRADIATION OF ADVANCED CERAMICS}

\section{T. Koyanagi (koyanagit@ornl.gov), C.M. Petrie, N.O. Cetiner, Y. Katoh}

\section{OBJECTIVE}

The goal of this task is to evaluate the effects of neutron irradiation on the properties of advanced ceramics materials for potential use in fusion structural components.

\section{SUMMARY}

This report describes the technical planning and progress of HFIR neutron irradiation experiments on advanced ceramics. A total of eight rabbit capsules were designed and fabricated for irradiation of various advanced ceramics. The materials include isotopically-controlled ultra-high temperature ceramics such as $\mathrm{TiB}_{2}$ and $\mathrm{ZrB}_{2}, \mathrm{MAX}$ phases such as $\mathrm{Ti}_{2} \mathrm{AlC}, \mathrm{Ti}_{3} \mathrm{AlC}_{2}$, and $\mathrm{Ti}_{3} \mathrm{SiC}_{2}, \mathrm{SiC}$ of various qualities, AlN, TiC, YAG, glassy carbon, and Si. The irradiation of five rabbits has been completed during FY2016.

\section{PROGRESS AND STATUS}

The novel high-temperature ceramics including ultra-high-temperature ceramics (UHTC) and a family of layered ternary compounded are recently recognized as attractive materials for use in nuclear fusion applications. This task will generate experimental data needed to help in understanding the radiation resistance of the advanced ceramics, to rectify the significant lack of knowledge on these materials. Table 8 summarizes the materials included and the current status of the irradiation experiment.

Table 8. Status of the Advanced Ceramics irradiation experiment

\begin{tabular}{|c|c|c|c|c|}
\hline $\begin{array}{l}\text { Capsule } \\
\text { ID }\end{array}$ & $\begin{array}{l}\text { Target } \\
\text { Irradiation } \\
\text { Temperature } \\
{\left[{ }^{\circ} \mathrm{C}\right]}\end{array}$ & $\begin{array}{l}\text { Number } \\
\text { of } \\
\text { HFIR } \\
\text { Cycles }\end{array}$ & $\begin{array}{l}\text { Materials } \\
\text { Investigated }\end{array}$ & Status of irradiation \\
\hline IMR 3 & 200 & 1 & $\begin{array}{l}\text { SX } 3 \text { C SiC, SX } 6 \text { H SiC, Faulted } \mathrm{SiC} \text {, } \\
\text { Si, AIN, YAG, TiC, }\end{array}$ & $\begin{array}{l}\text { Irradiated in the cycle } 460 \text { and stored in the HFIR } \\
\text { pool. }\end{array}$ \\
\hline IMR 4 & 200 & 1 & $\begin{array}{l}\mathrm{TiB}_{2}, \mathrm{ZrB}_{2}, \mathrm{Ti}_{3} \mathrm{SiC}_{2}, \mathrm{Ti}_{3} \mathrm{AlC}_{2}, \mathrm{Ti}_{2} \mathrm{AlC}, \\
\text { Sintered } \mathrm{SiC} \text {, Glassy carbon }\end{array}$ & $\begin{array}{l}\text { Irradiated in the cycle } 466 \text { and stored in the HFIR } \\
\text { pool. }\end{array}$ \\
\hline IMR 6 & 600 & 1 & $\begin{array}{l}\mathrm{TiB}_{2}, \mathrm{ZrB}_{2}, \mathrm{Ti}_{3} \mathrm{SiC}_{2}, \mathrm{Ti}_{3} \mathrm{AlC}_{2}, \mathrm{Ti}_{2} \mathrm{AlC} \text {, } \\
\text { Sintered } \mathrm{SiC} \text {, Glassy carbon, } \mathrm{Si}, \mathrm{AlN} \text {, } \\
\text { YAG, TiC }\end{array}$ & $\begin{array}{l}\text { Irradiated in the cycle } 466 \text { and stored in the HFIR } \\
\text { pool. }\end{array}$ \\
\hline IMR 7 & 600 & 3 & $\begin{array}{l}\mathrm{TiB}_{2}, \mathrm{ZrB}_{2}, \mathrm{Ti}_{3} \mathrm{SiC}_{2}, \mathrm{Ti}_{3} \mathrm{AlC}_{2}, \mathrm{Ti}_{2} \mathrm{AlC} \text {, } \\
\text { Sintered } \mathrm{SiC} \text {, Glassy carbon, YAG, } \\
\text { TiC }\end{array}$ & $\begin{array}{l}\text { Irradiated in the cycle } 466-468 \text { and stored in the } \\
\text { HFIR pool. }\end{array}$ \\
\hline IMR 8 & 600 & 5 & $\begin{array}{l}\mathrm{TiB}_{2}, \mathrm{ZrB}_{2}, \mathrm{Ti}_{3} \mathrm{SiC}_{2}, \mathrm{Ti}_{3} \mathrm{AlC}_{2}, \mathrm{Ti}_{2} \mathrm{AlC}, \\
\text { Sintered } \mathrm{SiC} \text {, Glassy carbon, } \mathrm{Si} \text {, } \\
\text { YAG, TiC }\end{array}$ & $\begin{array}{l}\text { Under irradiation from the cycle 466-470, which } \\
\text { will plan to end within Jan. } 2017 \text {. }\end{array}$ \\
\hline IMR 9 & 1000 & 1 & $\begin{array}{l}\mathrm{Ti}_{3} \mathrm{SiC}_{2}, \mathrm{~T}_{3} \mathrm{AlC}_{2}, \mathrm{~T}_{2} \mathrm{AlC} \text {, Sintered } \\
\text { SiC, Glassy carbon, AIN, YAG, TiC }\end{array}$ & $\begin{array}{l}\text { Irradiated in the cycle } 466 \text { and stored in the HFIR } \\
\text { pool. }\end{array}$ \\
\hline IMR 10 & 1000 & 5 & $\begin{array}{l}\mathrm{Ti}_{3} \mathrm{SiC}_{2}, \mathrm{Ti}_{3} \mathrm{AlC}_{2}, \mathrm{Ti}_{2} \mathrm{AlC} \text {, Sintered } \\
\mathrm{SiC} \text {, Glassy carbon, YAG, TiC }\end{array}$ & $\begin{array}{l}\text { Under irradiation from the cycle } 466-470 \text {, which } \\
\text { will plan to end within Jan. } 2017 \text {. }\end{array}$ \\
\hline IMR 11 & 1000 & 5 & $\mathrm{TiB}_{2}, \mathrm{ZrB}_{2}$, Sintered $\mathrm{SiC}$ & $\begin{array}{l}\text { Under irradiation from the cycle } 466-470 \text {, which } \\
\text { will plan to end within Jan. } 2017 \text {. }\end{array}$ \\
\hline
\end{tabular}

A total of eight rabbit capsules have been designed, fabricated, and delivered to the HFIR in FY2016. The irradiation of five capsules has been completed. The target irradiation temperatures range from 200 to $1000^{\circ} \mathrm{C}$. The number of HFIR cycles is up to five, and the neutron fluence will be up to $\sim 1 \times 10^{26}\left(\mathrm{n} / \mathrm{m}^{2}, \mathrm{E}\right.$ $>0.1 \mathrm{MeV})$. The materials investigated are UHTCs such as $\mathrm{TiB}_{2}$ and $\mathrm{ZrB}_{2}, \mathrm{MAX}$ phases such as $\mathrm{Ti}_{2} \mathrm{AlC}_{\text {, }}$ 
$\mathrm{Ti}_{3} \mathrm{AlC}_{2}$, and $\mathrm{Ti}_{3} \mathrm{SiC}_{2}$, and additional high-temperature ceramics including $\mathrm{SiC}$ with various qualities, AlN, TiC, YAG, glassy carbon, and silicon. Note that the diboride samples were isotopically controlled; $>99 \mathrm{wt} \%$ purity ${ }^{11} \mathrm{~B}$ powder was used for fabrication instead of ${ }^{10} \mathrm{~B}$ or natural $\mathrm{B}$ powder to avoid producing transmutant helium during irradiation. These rabbit capsules contain 32 disk specimens that are nominally $0.5 \mathrm{~mm}$ thick and $6.0 \mathrm{~mm}$ diameter; the capsule components and specimens are shown in Figure 23. Post-irradiation examination will include investigations of swelling, thermal properties, electrical properties, equibiaxial flexural strength at room temperature and high temperature, microstructure, and positron annihilation lifetime. Dilatometry of $\mathrm{SiC}$ temperature monitors contained in the irradiation capsules will be conducted to determine actual irradiation temperatures.

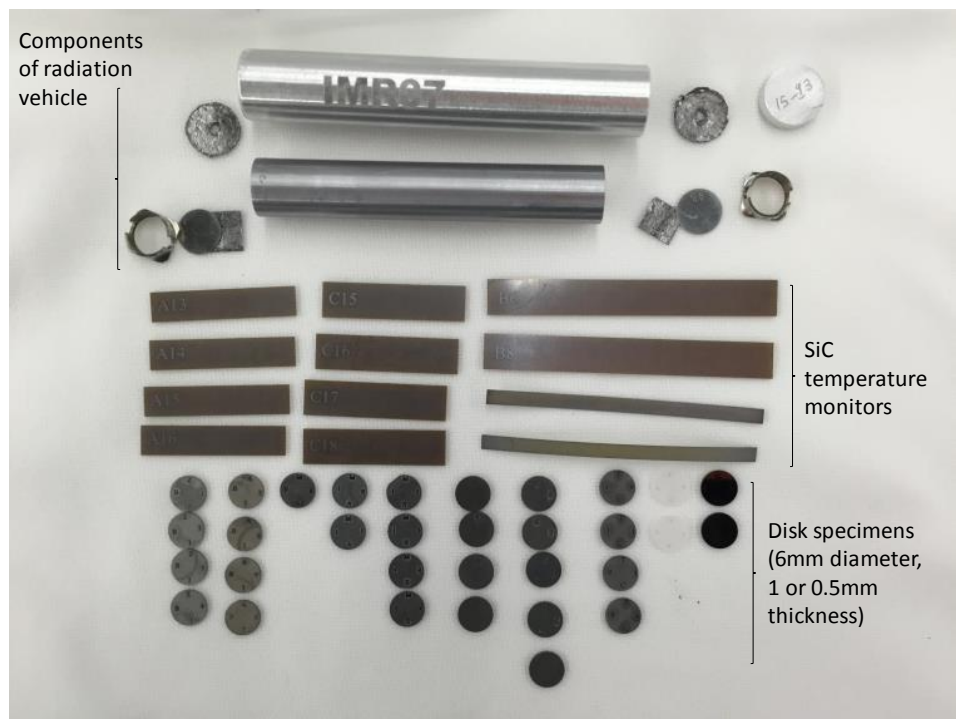

Figure 23. Components of HFIR rabbit irradiation capsule and Advanced Ceramic specimens.

\section{FUTURE PLANS}

Work next period will focus on evaluation of mechanical, physical and microstructural properties of unirradiated specimens. The experiments will include measurements of modulus and thermal properties, $\mathrm{X}$-ray diffraction analysis, and observations using electron microscopy. 


\section{HIGH HEAT FLUX AND PLASMA FACING MATERIALS}

\subsection{FABRICATION OF FUNCTIONALLY GRADED TUNGSTEN STEEL LAMINATES}

Lauren Garrison (garrisonlm@ornl.gov), M. Norfolk (Fabrisonic LLC.), J. Wenning (Fabrisonic LLC.), J. Moon (University of Nevada-Reno), Y. Katoh

\section{OBJECTIVE}

The objective of this project is to create a functionally graded tungsten to steel laminate composite for use in plasma facing components in fusion reactors.

\section{SUMMARY}

Two roll-bonded tungsten-steel composites have been fabricated. Tensile tests of the generation 2 composite were completed and showed increasing strength and decreasing ductility with increased W content. A feasibility study for ultrasonic welding tungsten to steel was completed. 34 trials were completed that varied the parameters of foil thickness, interlayer material, welding force, vibration amplitude, and other welding parameters. Promising results were obtained for joining tungsten to steel and tungsten to steel with an aluminum interlayer.

\section{PROGRESS AND STATUS}

\section{Roll bonded composite}

The generation 2 composite was fabricated using ten layers of $250 \mu \mathrm{m}$ Grade 92 steel alternating with ten layers of $25 \mu \mathrm{m}$ tungsten and was forged at $1000^{\circ} \mathrm{C}$ for only $20 \%$ thickness reduction. The goal of the generation 2 composite is to determine if the processing parameters can be optimized to create bonding between the layers without causing fragmentation of the tungsten layers, as was seen in the generation 1 composite.

Tensile bars were machined from the generation 2 composite. Because there was low visible contrast between the laminate composite and the surrounding stainless steel material, different samples had differing amounts of composite versus stainless steel. This allowed a comparison of the strengthening provided by varying the number of tungsten layers in the sample (Figure 24). The more tungsten layers that were present, the stronger and less ductile the material was. The generation 2 composite was also shear punch tested and those results are being analyzed to attempt to determine a correlation between the shear and tensile properties of the composite.

\section{Ultrasonic welded composite}

An initial investigation of the feasibility of producing composites using ultrasonic bonding was completed with the company Fabrisonic, which specializes in ultrasonic welding of dissimilar materials. The ultrasonic welding process utilizes a sonotrode (also called a horn) that provides normal force onto the material to be bonded as well as side-to-side ultrasonic vibration. The combination of pressure and ultrasonic vibrations create a solid state bond between the layers.

Tungsten foils with thickness $250 \mu \mathrm{m}, 100 \mu \mathrm{m}$, and $25 \mu \mathrm{m}$ were used in the trials. Interlayer materials of aluminum and copper were used, and two different baseplates were used in the trials, a C1020 carbon steel baseplate and an aluminum alloy $6061 \mathrm{~T} 6$ baseplate. The baseplate and interlayer materials were chosen based on Fabrisonics successful bonds in the past. If feasibility of bonding tungsten can be shown, the interlayer and baseplate materials could be expanded to include fusion specific alloys. 


\section{Engineering Stress vs. Strain Tungsten-Steel Layered Composite}

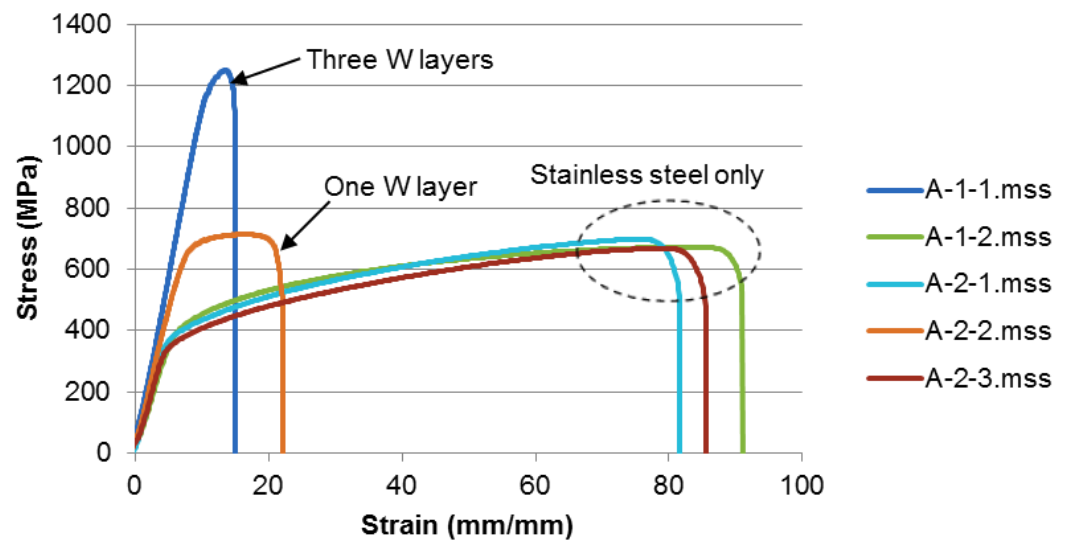

Figure 24. Stress-strain curves for composite material with three $W$ layers, one $W$ layer, and no $W$ layers.

Overall, 34 trials were completed that varied the parameters of foil thickness, interlayer material, welding force, vibration amplitude, and other welding parameters. Successful bonding was achieved by lowering the normal force and adjusting the other welding parameters compared to the initial tests. Tungsten foils both $100 \mu \mathrm{m}$ thick and $250 \mu \mathrm{m}$ thick were successfully welded with minimal to no cracking in the tungsten layers. Welding parameters were developed for bonding tungsten foil to steel using an aluminum interlayer as well as separate parameters for directly bonding the tungsten foil to the steel baseplate.

Six of the trials that showed at least partial bonding success were selected for more in depth interface analysis. Small sub-sections of the selected trial joints were machined by electro-discharge machining. Those that remained bonded after machining will be examined with optical and scanning electron microscopy.

\section{FUTURE PLANS}

The shear punch and tensile data for the roll-bonded composite is being analyzed in an attempt to develop a correlation. The next generation composite that is fabricated will be larger to provide miniature bend or fracture toughness specimens. For the ultrasonic welded material, the interface will be examined by optical and scanning electron microscopy. The focus will be on evaluating (1) the quality of the bond based on voids, cracks, or other imperfections observed at the interface and (2) any intermetallic phases at the interface. 


\subsection{TUNGSTEN/SiC AND TUNGSTEN/GRAPHITE JOINING}

Lauren Garrison (garrisonlm@ornl.gov), Jeremy Moon (University of Nevada-Reno), Jim Kiggans, Paul Menchhofer, Yutai Katoh

\section{OBJECTIVE}

The objective of this project is to fabricate thin tungsten layers bonded to graphite and $\mathrm{SiC}$ substrates that will provide a significant reduction in neutron activated volume as compared to standard $6 \mathrm{~mm}$ discs for rapid screening tests. Because there are still many unknowns in the tungsten response to neutron irradiation, there is a need to test a variety of microstructures and tungsten-based materials or alloys quickly to help steer the future development of tungsten plasma-facing materials and components.

\section{SUMMARY}

A first test of hot isostatic pressing tungsten foils, $0.25 \mu \mathrm{m}$ thick, to a $2 \mathrm{~mm}$ thick graphite substrate and a $2 \mathrm{~mm}$ thick $\mathrm{SiC}$ substrate was completed. The joined materials will be sectioned to evaluate the interlayer thickness and bond quality.

\section{PROGRESS AND STATUS}

Tungsten becomes highly activated after neutron irradiation in HFIR and takes an estimated three years cooling time before standard size samples are able to be transferred to LAMDA for post irradiation examination (PIE). Certain PIE activities such as microstructural analysis and permeation testing require only a very small volume of material. By joining a thin layer of tungsten onto a substrate of graphite or $\mathrm{SiC}$, the activated tungsten volume is significantly reduced, and the substrate provides the necessary structural support for handling and clamping the sample.

Graphite and SiC substrate material $2 \mathrm{~mm}$ thick has been machined. Tungsten foils of thicknesses $25 \mu \mathrm{m}$ were purchased from ESPI Metals. A first joining test was conducted with hot isostatic pressing (HIP). Based on previous work in the PHENIX collaboration, HIP parameters of $1300^{\circ} \mathrm{C}$ and $10 \mathrm{MPa}$ were chosen for the $\mathrm{W} / \mathrm{SiC}$ to minimize the interlayer thickness. Similar parameters were used for joining the W/graphite. Boron Nitride was used to prevent bonding between the top of the tungsten foil and the graphite used in the press, and the process was done in a vacuum furnace. The main concern is possible oxidation of the $\mathrm{W}$ and graphite layers, so after HIP the material will be cross-sectioned for elemental analysis.

\section{FUTURE PLANS}

The tungsten/SiC and tungsten/graphite joined specimens will be cross-sectioned to evaluate the interlayer thickness, bond quality, and extent of oxidation (if present). Based on the analysis of the first joined specimens, the process could be expanded to other tungsten-based materials, and the joined specimens would be cut into discs for inclusion in rabbit irradiation capsules. 


\title{
5.3 DETERMINATION OF PRECIPITATE COMPOSITION IN IRRADIATED TUNGSTEN USING NEUTRON INVENTORY CALCULATIONS AND ATOM PROBE TOMOGRAPHY
}

\author{
P. D. Edmondson (edmondsonpd@ornl.gov) and M. R. Gilbert (Culham Centre for Fusion Energy)
}

\section{OBJECTIVE}

The divertor of a commercial nuclear fusion power plant is currently proposed to be constructed from tungsten; however this material is subject to irradiation-induced embrittlement, partly due to the formation of second phase precipitates primarily composed of the transmutation products. The objective of this project is to determine the chemical composition of the second phase precipitates as a function of neutron dose in order to determine their phases, and begin to understand the formation mechanisms in order to begin to develop mitigation strategies.

\section{SUMMARY}

This project focused on using atom probe tomography data to determine the composition of precipitates formed in single crystal, pure tungsten irradiated to low ( $0.2 \mathrm{dpa})$ and high ( $2.2 \mathrm{dpa})$ damage levels. Atom probe tomography data, following reconstruction, consists of the $x, y$, and $z$ co-ordinates of the constituent atoms of the material, and their mass-to-charge state ratio. Normally isotopic peak overlaps in the massto-charge-state ratio are deconvolved using the relative natural abundances of the elements identified in the material. However, in the case of irradiated tungsten the neutron-induced transmutation and decay results in non-natural abundances translating to errors in the bulk and cluster compositions when using the natural abundances. To correct for this, neutron inventory calculations - in collaboration with Culham Centre for Fusion Energy - have been performed using the HFIR spectrum, and accounting for the decay time between end of irradiation and start of analysis to provide the highest quality neutron inventory data possible that can then be utilized to deconvolve the mass-to-charge-state ratio overlaps to provide accurate chemical compositions from the atom probe data.

\section{PROGRESS AND STATUS}

Atom probe reconstructions of the low and high dose samples are shown in Figure 25. In this figure, the precipitates are represented through the use of concentration isosurfaces and the differences in precipitate morphologies is stark with the low dose precipitates being approximately spherical; high dose precipitates appearing with a more ribbon-like morphology. The atom positions and mass spectrum from within these precipitates have been exported to be analyzed individually to obtain corrected compositional data based on the neutron inventory calculations.

The neutron inventory calculation outputs and exported atom position files from the atom probe datasets were then analyzed using a custom Matlab script that extracted the pertinent data, and then calculated the elemental compositions using a peak deconvolution method utilizing the isotopic abundances calculated in the neutron inventory calculations. This was performed for the bulk data, i.e. precipitates and matrix, and the individual precipitates. Ternary phase diagrams showing the predicted high temperature phases, and the neutron inventory bulk composition, and the corrected atom probe tomography compositions for both the bulk and the precipitates is shown in Figure 26. For the low dose precipitates, the accumulation of transmutation products is low, yet it is clear that the precipitates are beginning to enrich in $\mathrm{Re}$, but are still within the phase boundary corresponding to the $\alpha$-phase. The $\alpha$-phase is the same as the bulk material and is BCC. In the high dose specimen, transmutation has resulted in higher levels of Re and Os 
a)

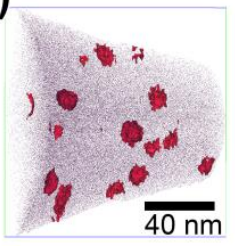

b)

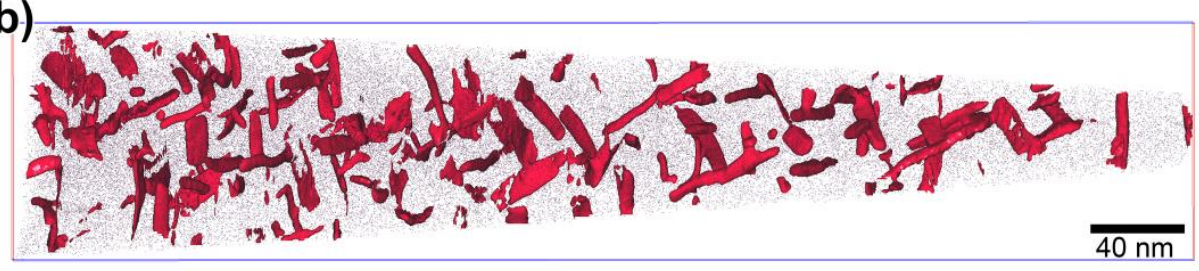

Figure 25. Atom maps showing the nucleation and maturation of the second phase precipitates in the single crystal irradiated tungsten for the (a) 0.2 dpa and (b) 2.2 dpa specimens. In both reconstructions, the black points represent $1 \%$ of all the $W$ ions detected. Concentration isosurfaces are used to highlight the second phase precipitates, and these were constructed using (a) 5at.\% ReOs, and (b) 20at.\% ReOs.

(the two primary transmutation products), and the precipitates appear to be significantly enriched in these elements. The precipitates are either in the $\sigma$-phase boundary or give the appearance that they are moving in that direction. It should be noted here that the phase diagrams (overlaid in Figure 26) are for high temperature phases, and that lower temperature ternary phase diagrams are not available for this system and that the precipitate may or may not yet be stabilized in the $\sigma$-phase under these irradiation conditions.

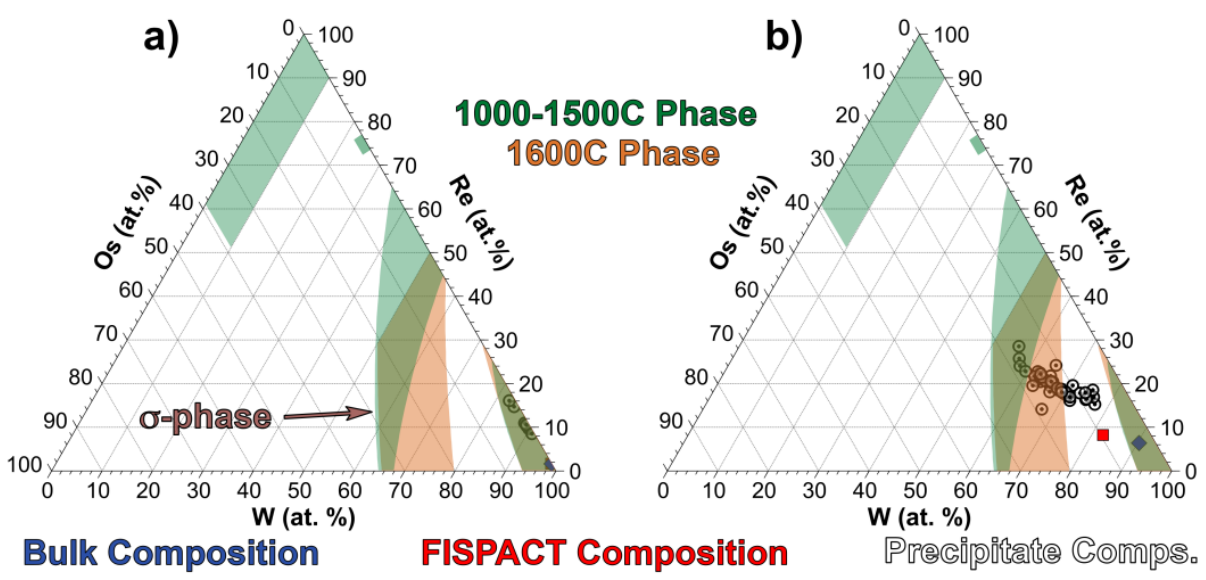

Figure 26. Ternary phase diagrams for the (a) low and (b) high dose data. The neutron inventory predicted bulk composition is shown (FISPACT), along with the corrected atom probe bulk and precipitate compositions. Phase boundaries for $1000-1500$ and $1600^{\circ} \mathrm{C}$ are overlaid onto the ternary diagram to show possible phases in the material system. The $\sigma$-phase is highlighted.

\section{FUTURE PLANS}

All analysis of this work has been completed and a manuscript for submission to a journal is being drafted. Future research could include examination of irradiated polycrystalline tungsten, focusing on the intragrain regions and areas close to grain boundaries where depletion of second phase precipitates has been observed in TEM data. Examination of specimens irradiated to intermediate doses and at lower temperatures is also desirable. 


\title{
5.4 NEUTRON IRRADIATION EFFECTS IN TUNGSTEN
}

\author{
X.Hu(huxl@ornl.gov), L. Garrison, T. Koyanagi
}

\section{OBJECTIVE}

This task examines the post irradiation response of pure tungsten subjected to neutron exposure in HFIR. The overarching objective is to capture the irradiation temperature and dose dependence of the microstructure and the resultant mechanical and physical properties of tungsten.

\section{SUMMARY}

Microstructures and properties of single crystal bulk tungsten (W) and polycrystalline $\mathrm{W}$ foil with a high degree of crystallographic texture were investigated using transmission electron microscopy, tensile tests, and hardness tests following neutron irradiations at 90 to $800^{\circ} \mathrm{C}$ to 0.03 to $4.6 \mathrm{dpa}$ in the HFIR mixed neutron energy spectrum. Dominant irradiation defects were dislocation loops and small clusters at $90^{\circ} \mathrm{C}$. Additional voids were formed in $\mathrm{W}$ irradiated above $460^{\circ} \mathrm{C}$. Voids and precipitates attributed to transmutation elements Re and Os were dominant defects at more than $\sim 1 \mathrm{dpa}$. Irradiation hardening of $\mathrm{W}$ was coordinated with the dispersed barrier hardening model informed by the available microstructural data, enabling the determination of dominant hardening source under various conditions.

\section{PROGRESS AND STATUS}

Figure 27 summarizes the dose and temperature dependence of microstructural evolution of pure W, including data on W irradiated in HFIR, JOYO, and JMTR. There are two boundary conditions characterizing the microstructure. First is at an irradiation temperature of $400^{\circ} \mathrm{C}$. Above this temperature, irradiations with both mixed and fast neutron spectra produced voids, in addition to loops and small defect clusters. The accurate boundary temperature for void formation is not available at this point due to the lack of the data for temperatures between 90 and $400^{\circ} \mathrm{C}$. Voids were observed even at the very low neutron fluence of $0.17 \mathrm{dpa}$, and this study also found voids at only $0.03 \mathrm{dpa}$. The second boundary condition is for a neutron dose of $\sim 1 \mathrm{dpa}$, enough to form precipitates visible by TEM in both single crystal and polycrystalline $\mathrm{W}$ after the HFIR irradiation. In this relatively high dose regime, voidprecipitate interactions were observed. On the other hand, the fast spectra (JOYO irradiation) did not produce precipitates up to $1.54 \mathrm{dpa}$, and a void lattice structure appeared at $600-800^{\circ} \mathrm{C}$ for $\sim 1 \mathrm{dpa}$. Therefore, at higher neutron doses, different neutron spectra strongly affected the microstructural development in pure W. Microstructural data is not currently available for W neutron irradiated at low temperature to high doses; such data may be needed to understand the temperature dependent precipitation behavior.

The last two capsules from the TITAN campaign, TB-650-4 and T9G-13, were opened and the specimens cataloged at the hot cells. The target irradiation conditions for these capsules were TB-650-4: $20 \times 10^{25}$ $\mathrm{n} / \mathrm{m}^{2}$ at $650^{\circ} \mathrm{C}$ and T9G-13: $12 \times 10^{25} \mathrm{n} / \mathrm{m}^{2}$ at $300^{\circ} \mathrm{C}$. The preliminary analysis of the $\mathrm{SiC}$ temperature monitors from capsule T9G-13 revealed the irradiation temperature was between 400 and $500^{\circ} \mathrm{C}$. Based on other capsules in this campaign, the irradiation temperature of TB-650-4 is expected to be in the range of $700-800^{\circ} \mathrm{C}$, and the $\mathrm{SiC}$ temperature monitors will be tested. Radioactivity of all specimens from T9G-13 was measured and specimens packaged in lead pigs for shipment to LAMDA. Several of these packages have been received, inspected, and cleaned in LAMDA. 
Previously, microhardness was measured on single crystal tungsten samples that had been irradiated up to approximately $1 \mathrm{dpa}$. The hardness was not sensitive to irradiation temperature and increased rapidly with increasing dose. To test if the hardness saturated, three higher dose samples were hardness tested (Figure 28), showing that up to 4.5 dpa the hardness has not yet saturated.

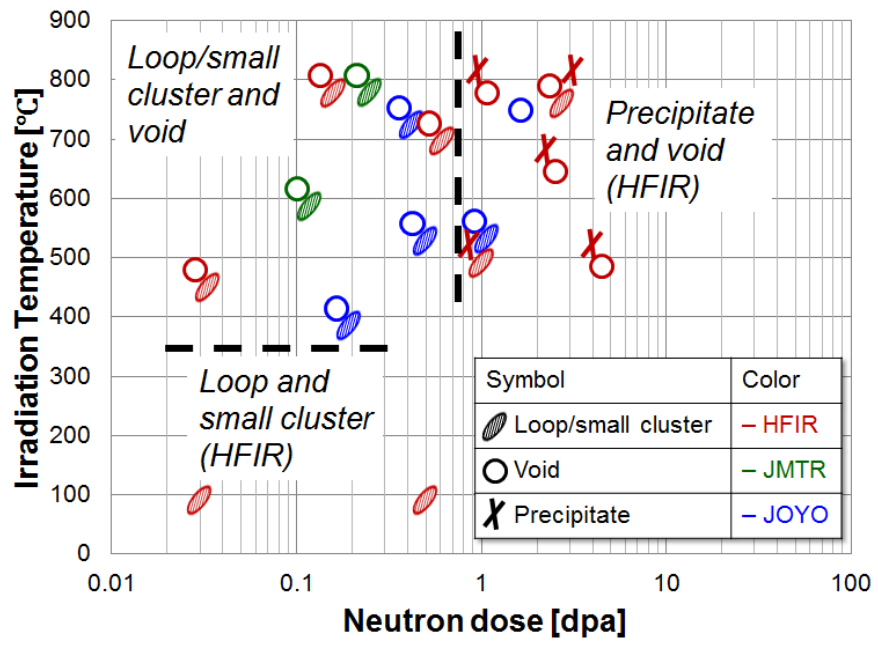

Figure 27. Microstructural evolution in single crystalline and polycrystalline pure $\mathbf{W}$ materials irradiated with neutrons.

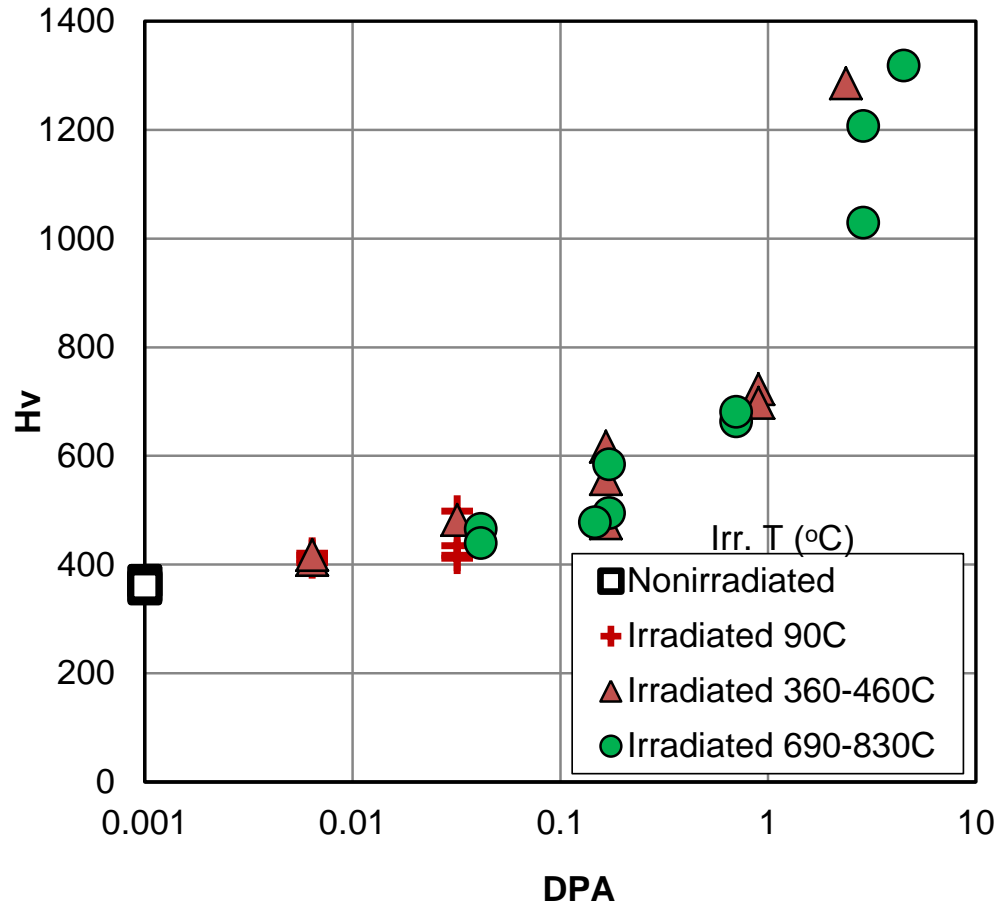

Figure 28. Microhardness of irradiated single crystal tungsten before and after HFIR irradiation. 
The underlying mechanism governing the irradiation hardening behavior of neutron-irradiated W was revealed by coordinating the dispersed barrier hardening model informed by the available microstructure information, as shown in Figure 29. For the samples irradiated in HFIR, dislocation loops and voids are the major contributor to the irradiation hardening at low dose levels, while intermetallic second phase precipitation dominate for doses greater than $0.6 \mathrm{dpa}$, leading to a tremendous hardness increase. The model fails to accurately predict hardness increase in the intermediate dose range, which we interpret to result from TEM-invisible precipitates or even super-saturated solid solutions of transmutant rhenium or osmium. Additionally, when applying the hardening model to the tungsten irradiated in JMTR, the model also under estimated the measured hardness increase. Since JMTR has a mixed neutron spectrum, there will be some production of transmutant elements. Thus, it is tempting to conclude that, just like the tungsten irradiated in HFIR to the intermediate dose range, a hardening contribution from small, TEM invisible precipitates was not captured, resulting in the underestimation of the hardness increase for JMTR. Moreover, for the samples irradiated in Joyo, which has a fast neutron energy spectrum, the model prediction and the experimental data have a relatively good agreement in comparison with the tungsten irradiated in HFIR and JMTR.

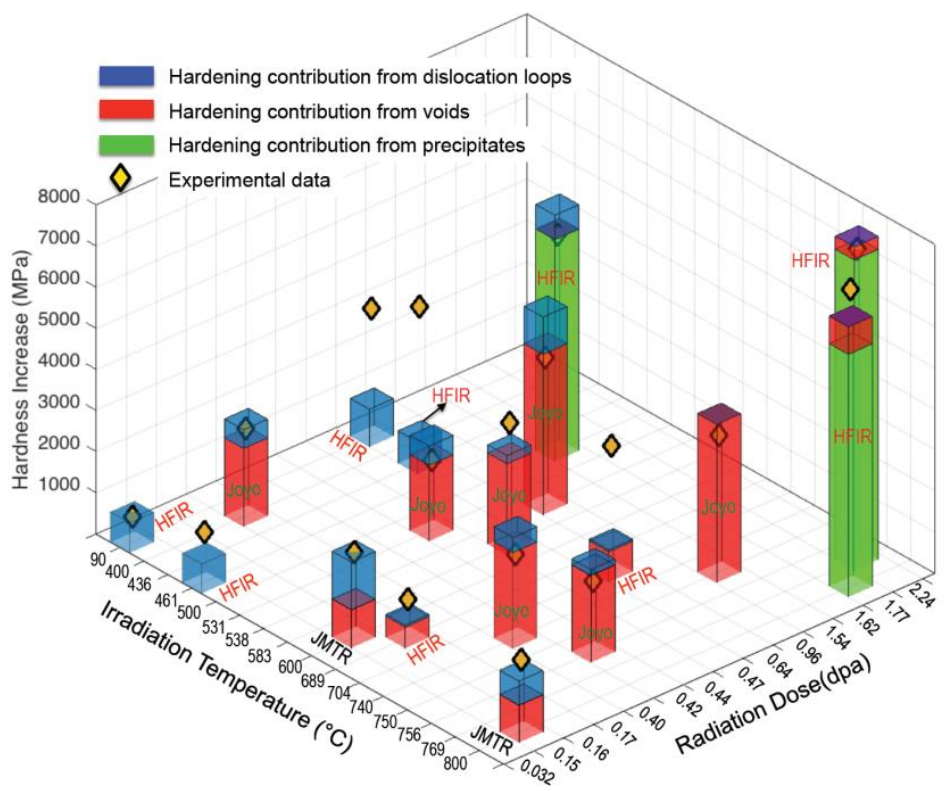

Figure 29. Radiation-induced hardening contributions due to various defects identified from TEM observations based on linear superposition of the dispersed barrier hardening model.

\section{FUTURE PLANS}

Future work will investigate the irradiation effects of $\mathrm{W}$ irradiated in larger irradiation temperature and dose ranges. The second phase W-Re-Os precipitate will be characterized in more details to help elucidate its hardening contribution. Further mechanical tests, including shear punch and 3-point bend, will be conducted on the TITAN samples. 


\subsection{NEUTRON IRRADIATION EFFECTS IN TUNGSTEN-COPPER COMPOSITES}

Lauren Garrison (garrisonlm@ornl.gov), Jeremy Moon (University of Nevada-Reno), Joseph Willenborg (University of Tennessee-Knoxville), Yutai Katoh

\section{OBJECTIVE}

The aim of this work is to evaluate tungsten-copper composites for potential use as part of plasma-facing components for future fusion reactors. Because tungsten is known to become more brittle after irradiation and also because the thermal expansion coefficients of tungsten and copper are substantially different, tungsten-copper laminate composites offer the potential for a more ductile and robust joint between the two materials.

\section{SUMMARY}

As part of the US-Japan TITAN program, two types of tungsten-copper composites were irradiated in HFIR at temperatures from 300 to $900^{\circ} \mathrm{C}$ and fast neutron fluences of 0.01 to $20 \times 10^{25} \mathrm{n} / \mathrm{m}^{2}(\mathrm{E}>0.1 \mathrm{MeV})$ (0.002 to $4 \mathrm{dpa}$ in tungsten). One tungsten-copper laminate composite was composed of $0.1 \mathrm{~mm}$ thick alternating layers of tungsten and copper. Tensile tests have previously been completed on the tungstencopper laminate and EDS and EBSD analysis of the material is underway. The other material was a tungsten-copper powder sintered composite, with $75 \% \mathrm{~W}$ and $25 \% \mathrm{Cu}$. Tensile tests of the unirradiated and irradiated tungsten-copper sintered composite have been completed and are being analyzed.

\section{PROGRESS AND STATUS}

The completed first campaign of tests of the tungsten-copper composite focused on tensile properties and fracture surface evaluation. The details of this investigation were published in FY16, and are summarized in Figure 30. The main conclusion of the work was that although the composite is more ductile than tungsten before neutron irradiation, after irradiation the ductility is severely reduced and the behavior of the composite is determined by the tungsten behavior. After neutron irradiation to $\sim 0.1 \mathrm{dpa}$ or higher and at test temperatures where the tungsten layers failed by delamination or ductile failure, the composite was ductile. However, after $\sim 0.1 \mathrm{dpa}$ irradiation and at test temperatures where the tungsten failed by brittle cleavage, the composite experienced brittle failure.

Three tungsten-copper samples were polished and analyzed with EBSD (Figure 31). Both before and after irradiation, the tungsten foil layers show elongated grains resulting from the hot rolling used to produce the tungsten foil. The grain size increases closer to the copper layers, which is believed to be a result of the $1100^{\circ} \mathrm{C}$ heating cycle used to produce the composite. The copper layers do not show distinct grains except near the boundaries with the tungsten layers. The bulk of the copper layers are nearly single crystalline. 


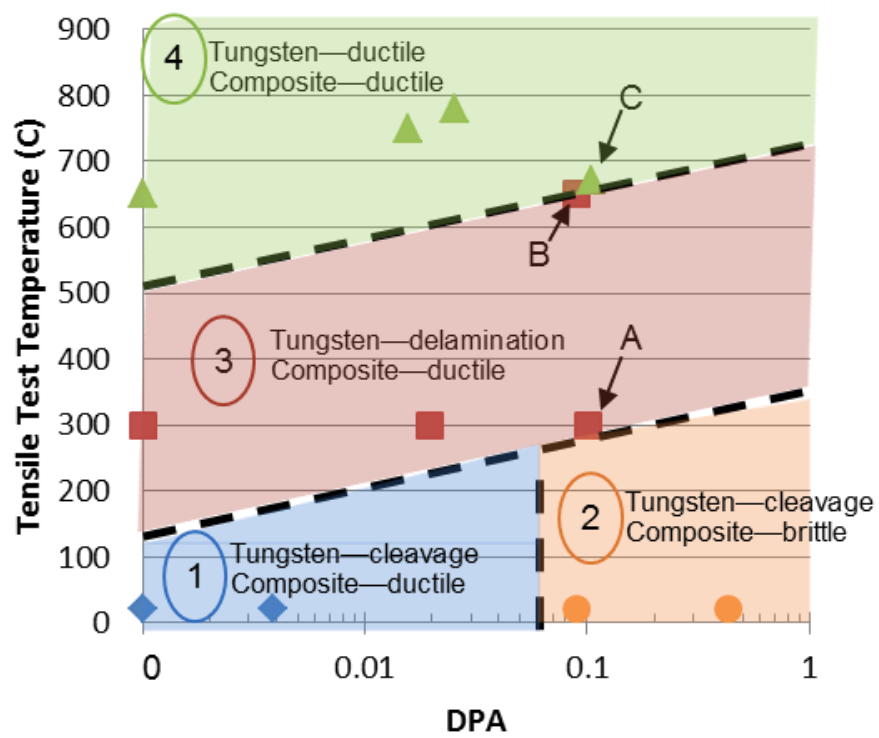

Figure 30. Summary tensile behavior of tungsten-copper laminate after neutron irradiation. Test temperature is approximately equal to the irradiation temperature. The zone boundaries are estimates, intended to help group points with similar behavior. [From L.M. Garrison, et al J Nucl Mater 481 (2016) 134146].

a) SW40, unirradiated

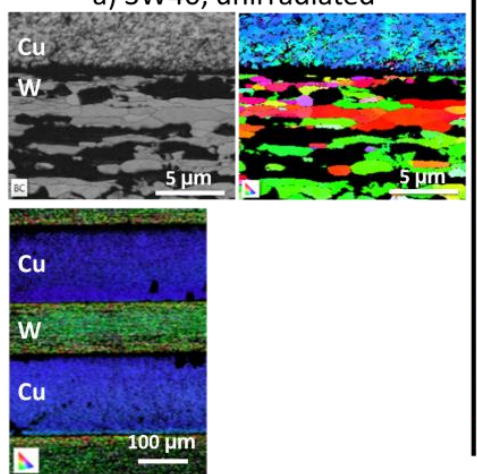

b) SW25, $0.09 \mathrm{dpa} 760^{\circ} \mathrm{C}$

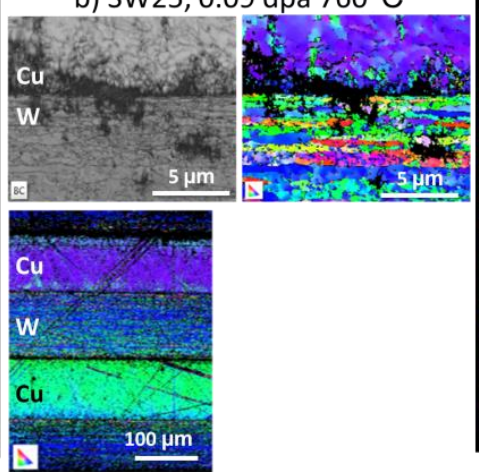

c) SW15, $0.43 \mathrm{dpa} 710^{\circ} \mathrm{C}$
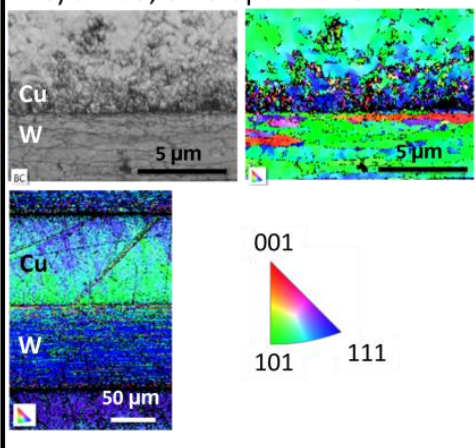

001

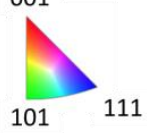

101

Figure 31. The tungsten-copper laminate material was analyzed with EBSD in the unirradiated and irradiated state. Each sample is shown with band contrast, detail view of a tungsten-copper interface, and a larger view of multiple layers of the composite.

As an alternative to the tungsten-copper laminate composite, a powder sintered tungsten copper composite with $75 \% \mathrm{~W}$ and $25 \% \mathrm{Cu}$ was investigated. A polished surface of one of the tungsten copper sintered composites is shown in Figure 32. A closer examination reveals that there are sharp boundaries between the rounded $\mathrm{W}$ particles and the $\mathrm{Cu}$. As expected, no interlayer or mixed phase formed between the elements. 


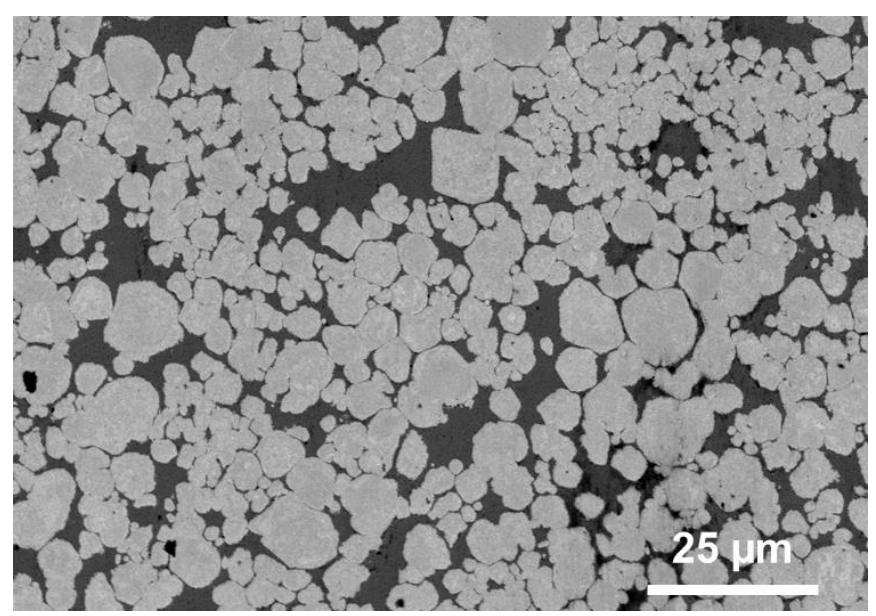

Figure 32. SEM image of the powder sintered tungsten copper composite.

Two identical tungsten-copper sintered composite samples were tensile tested at room temperature. The tensile data plotted in Figure 33 does not account for machine compliance, so the elastic region is not representative of the material properties. The material does show ductility at room temperature, which is a significant improvement compared to traditional sintered tungsten. Examining the fracture surface of one of the samples, limited reduction in area is detected near the fracture surface, and the fracture surface itself has a bright copper-color.

\section{Engineering Stress vs. Strain Tungsten-} Copper Composite

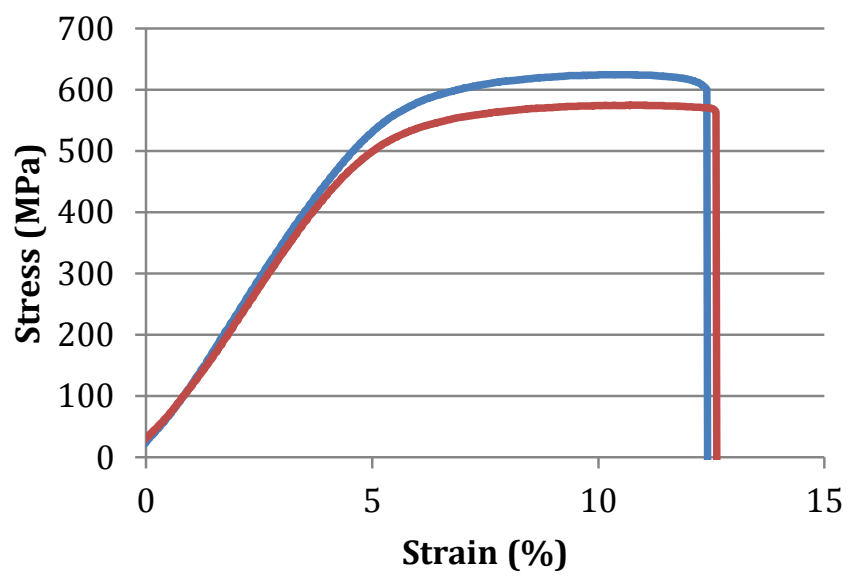

Figure 33. Tensile curves of the tungsten-copper sintered composite at room temperature.

\section{FUTURE PLANS}

Further analysis will be completed on the irradiated tungsten-copper laminate composite to characterize any changes in the interface after irradiation. A set of the neutron irradiated tungsten-copper sintered composite have been tensile tested. These data are being analyzed. 


\subsection{TUNGSTEN FIBER IRRADIATION}

Lauren Garrison (garrisonlm@ornl.gov), Johann Riesch (Max-Planck-Institute for Plasma Physics), Joel McDuffee, Yutai Katoh

\section{OBJECTIVE}

Tungsten fiber reinforced tungsten matrix composites are one of several tungsten-based composites being developed for possible application as plasma-facing materials. This task will evaluate the effects of neutron irradiation on the microstructure and mechanical properties of tungsten fibers.

\section{SUMMARY}

Three types of tungsten fibers with diameter $150 \mu \mathrm{m}$ were assembled in graphite tubes for irradiation. The graphite tubes containing the fibers were loaded in the 500,800 , and $1200^{\circ} \mathrm{C}$ zones of the $\mathrm{RB} * 19 \mathrm{~J}$ capsule, which began irradiation in June 2016.

\section{PROGRESS AND STATUS}

Irradiation of tungsten fibers will be completed as part of the $\mathrm{RB} * 19 \mathrm{~J}$ irradiation capsule, which is a collaboration between ORNL, the PHENIX US-Japan collaboration, and the JAEA. The 19J instrumented capsule is irradiated in the removable beryllium section of HFIR. The capsule contains gadolinium shielding to reduce the thermal neutron flux. This will limit the transmutation rate of tungsten to simulate fusion reactor conditions. The tungsten fiber samples are in the 500,800 , and $1200^{\circ} \mathrm{C}$ sections of the capsule.

Three fiber types (Table 9) were provided by Johann Riesch at the Max-Plank Institute for Plasma Physics in Germany. Previous work by Riesch et al. has shown the promise of tungsten fibers in a tungsten fiber reinforced tungsten matrix composite.

Table 9. Types of fibers included in irradiation

\begin{tabular}{|l|l|l|l|}
\hline & Type 1 & Type 2 & Type 3 \\
\hline Composition & W with 60 ppm K & W with 60 ppm K & W \\
\hline $\begin{array}{l}\text { Straightening } \\
\text { method }\end{array}$ & $\begin{array}{l}\text { straightened by plastic } \\
\text { deformation (1\%) at } \\
\text { room temperature }\end{array}$ & $\begin{array}{l}\text { straightened by } \\
\text { producer at high } \\
\text { temperature }\end{array}$ & $\begin{array}{l}\text { straightened by plastic } \\
\text { deformation (1\%) at } \\
\text { room temperature }\end{array}$ \\
\hline Lot & $\begin{array}{l}\text { Lot 1151-06-13, ID } \\
14337467\end{array}$ & $\begin{array}{l}\text { Lot 1223-02-02, ID } \\
22665182\end{array}$ & $\begin{array}{l}\text { Lot 2618-04-14, ID } \\
40215691\end{array}$ \\
\hline Length & $40 \mathrm{~mm}$ & $38.5 \mathrm{~mm}$ & $37 \mathrm{~mm}$ \\
\hline Diameter & $150 \mu \mathrm{m}$ & $150 \mu \mathrm{m}$ & $150 \mu \mathrm{m}^{3}$ \\
\hline Volume per fiber & $0.71 \mathrm{~mm}^{3}$ & $0.68 \mathrm{~mm}^{3}$ & $0.65 \mathrm{~mm}^{3}$ \\
\hline
\end{tabular}

The fibers were assembled for irradiation in small graphite tubes with a $\mathrm{SiC}$ temperature monitor at the center, Figure 34. Fibers were inserted approximately halfway into the graphite tube during assembly to ensure tight and even packing on each side of the $\mathrm{SiC}$ piece, then the fibers and $\mathrm{SiC}$ piece were slid into the graphite tube. The approximate loading pattern is shown in Figure 35. 

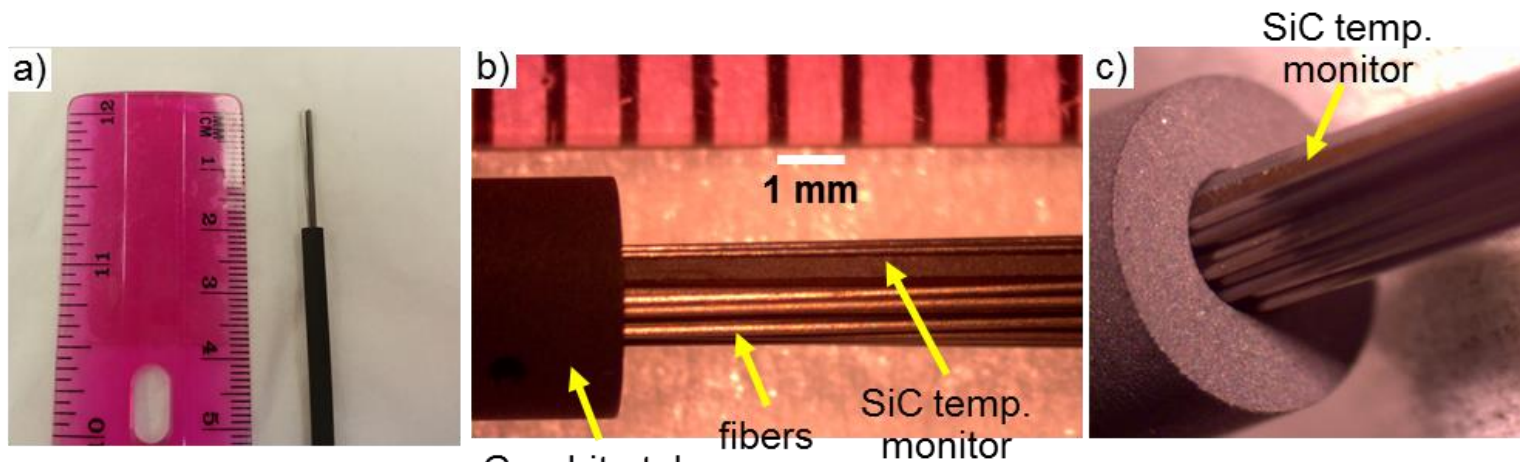

Graphite tube

Figure 34. Tungsten fiber assembly in graphite tube. a) distant view, b) close in view, c) tilted view.

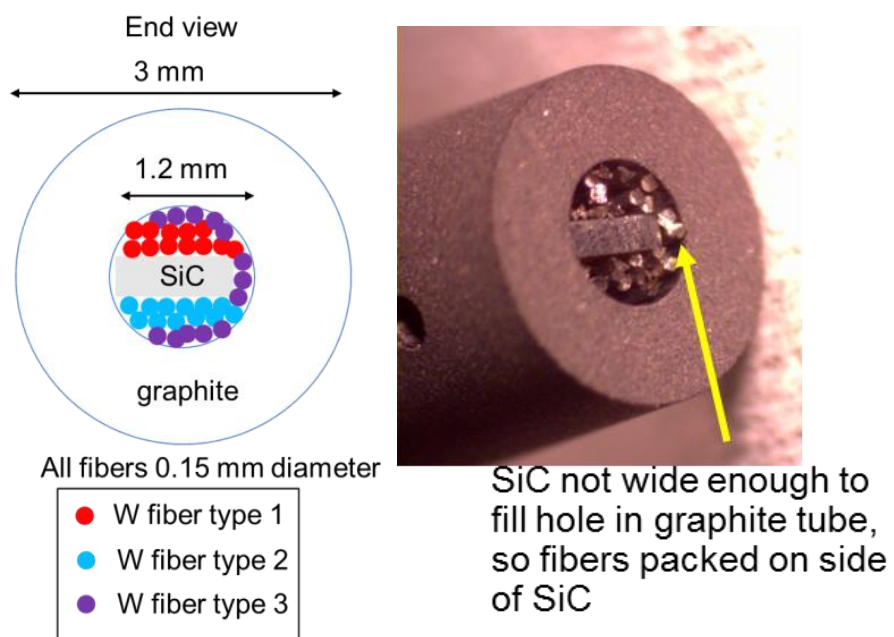

Figure 35. Left: Approximate loading location of fibers. Because fibers could move around the SiC piece and because of the difficulty of loading these very small fibers, the cartoon loading locations are not exactly the same as the actual loading, but effort was made to keep the Type 1 and Type 2 fibers on opposite sides of the $\mathrm{SiC}$ piece to help identify them after irradiation. Right: Fibers in tube before end cap was inserted.

One graphite tube of fibers will be included in each of the three higher temperature zones in the irradiation capsule. Each tube contains 12 or 13 of each of the three types of fibers. For comparison a typical SSJ2 tungsten sample has a mass of $\sim 0.4 \mathrm{~g}$, which is slightly less than the $\sim 0.48 \mathrm{~g}$ of tungsten within each tube.

To close the graphite tubes, the end cap was inserted such that the hole in the tube and cap were aligned and a pin could be inserted to keep the cap in place (Figure 36). The fibers, as part of the RB*19J capsule, began irradiation in the June, 2016 HFIR cycle. 


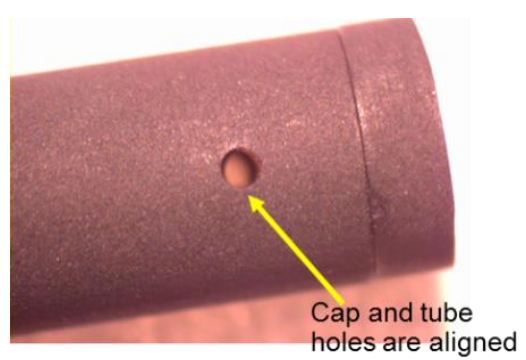

Figure 36. One of the graphite tubes is shown after the fibers were loaded with the end cap in place.

\section{FUTURE PLANS}

Fixtures and procedures for testing the fibers are under development. The irradiation of capsule 19J will be completed in early 2017. Once the tungsten materials have cooled to acceptable dose limits for the LAMDA Laboratory, samples will be shipped for testing and microstructural evaluation, likely in late 2017 or after. 


\title{
6. PLASMA MATERIALS INTERACTIONS
}

\subsection{DAMAGE MECHANISM INTERACTIONS AT THE PLASMA-MATERIALS INTERFACE}

\author{
C.M.Parish (parishcm@ornl.gov), K. Wang
}

\section{OBJECTIVE}

The overarching objective of this work is to bridge the gap between the atomistic knowledge and models and the phenomenological materials science underlying the design, fabrication, and service of divertors and other plasma-facing materials for magnetic confinement fusion. Specifically, the influence of intrinsic defects (dislocations, grain boundaries) and extrinsic defects (ion- and neutron-irradiation damage, impurities) interactions with $\mathrm{He}$ and bubbles, in terms of nucleation sites, growth, trapping, and surface degradation, will be measured.

\section{SUMMARY}

In this reporting period, a series of different aspects of the overarching question of plasma-materials interactions have been studied. First, the morphologies and growth structures of tungsten nanotendril "fuzz" have been explored in greater detail than any previous publications. Second, the influence of preexisting intrinsic defects on the evolution of the helium-induced microstructure has been systematically studied, with the intent of providing experimentally determined confirmation of the theoretical models being developed by other OFES efforts. Third, collaborations with other laboratories (specifically UC-San Diego, Drs. Tynan, Doerner, and Baldwin; and UT-Knoxville, Drs. Wirth and Donovan) have been undertaken to broaden the scope of this effort and provide expertise in microstructural characterization that complements the other laboratories' strengths in plasma physics and sample exposure. This effort has also collaborated within ORNL (MIRF experiment, Drs. Bannister and Meyer; proto-MPEX experiment, Dr. Rapp et al.).

\section{PROGRESS AND STATUS}

A tungsten nanotendril "fuzz" specimen from UC-San Diego (collaboration with R. Doerner and M. Baldwin) has been comprehensively analyzed. Unique results indicate that, contrary to possible hypotheses, the fuzz has a random long-axis orientation (rather than a preferential axis such as $<101>$ ) and the grain boundaries are near-random, with a slight preference to certain non-special grain boundaries; Figure 37 and Figure 38.
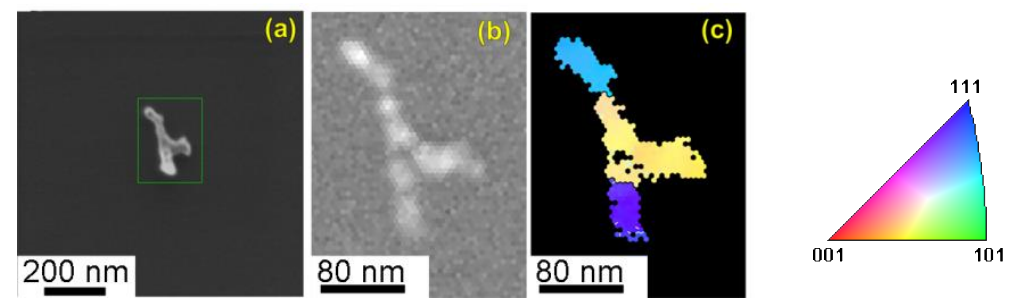

Figure 37. (a) SEM image of an isolated nanotendril. (b) Transmission Kikuchi diffraction (tKD) image quality map of the tendril. (c) Inverse-pole-figure image of the grain orientations, colored in the $Z$ (out-ofpage) orientation, colored according to the unit triangle shown. Reprinted from [1]. 
To study the influence of starting microstructure, samples of hot rolled (high dislocation density, small grain size) and recrystallized (low dislocation density, large grain size) tungsten were exposed to $2 \times 10^{23}$ and $20 \times 10^{23} \mathrm{He} / \mathrm{m}^{2}$ at $900^{\circ} \mathrm{C}$ in the ORNL MIRF facility (in collaboration with F. Meyer and M. Bannister). The helium bubble distributions underneath the surface were examined using FIB and TEM, Figure 39. Comparison of the bubble sizes was performed for three different regions (marked in Figure 39), $0-50 \mathrm{~nm}, 51-100 \mathrm{~nm}$, and 100+ nm below the surface. These comparisons (plotted as cumulative distribution functions) are given in Figure 40 and illustrate complex relationships, which we are still in the process of understanding. It appears that at lower fluence $\left(2 \times 10^{23} \mathrm{He} / \mathrm{m}^{2}\right)$ the near-surface region (where bubbles nucleate most copiously) there is little difference between the high- and low-defect density material, whereas deep in the sample the bubble populations are quite different. However, at higher fluence $\left(20 \times 10^{23} \mathrm{He} / \mathrm{m}^{2}\right)$ the bubble size distributions in the hot rolled and recrystallized material are relatively similar, perhaps indicating that further homogeneous nucleation of bubbles overwhelms the heterogeneous nucleation of the defects.

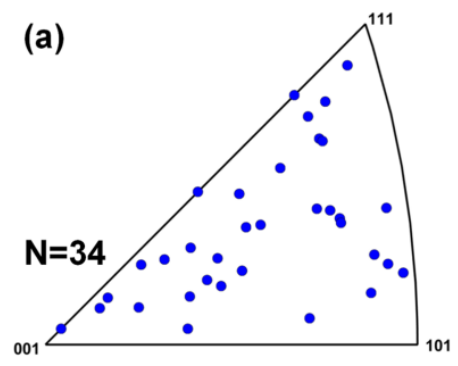

(c)

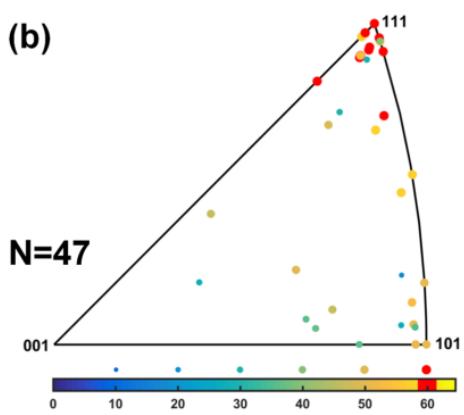

Misorientation, ${ }^{\circ}$

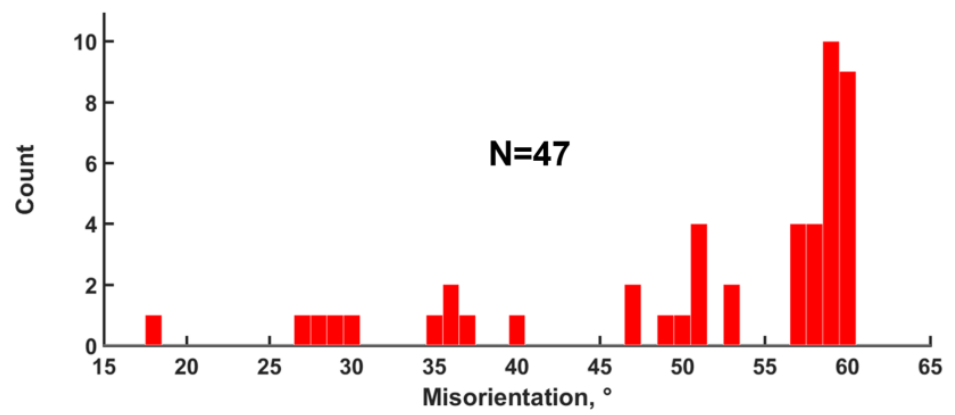

Figure 38. (a) Tendril grain long-axis directions. (b) Tendril grain boundary character. (c) Tendril grain boundary misorientation histogram. $N$ is the number of data, all measured via tKD. Reprinted from [1].

\section{FUTURE PLANS}

The examination of the nanotendril fuzz and the hot rolled and recrystallized tungsten samples continues, with an eye to elucidation of the underlying mechanisms rather than simply reporting microstructural observations. One tool we will be using is the newly acquired in situ heating holder for the LAMDA lab transmission electron microscope, where we intend to perform heating experiments to capture processes underway, such as bubble nucleation or coalescence. We also are continuing to collaborate with UCSD, UTK, and the proto-MPEX project, and hope to also build further non-ORNL collaborations. 


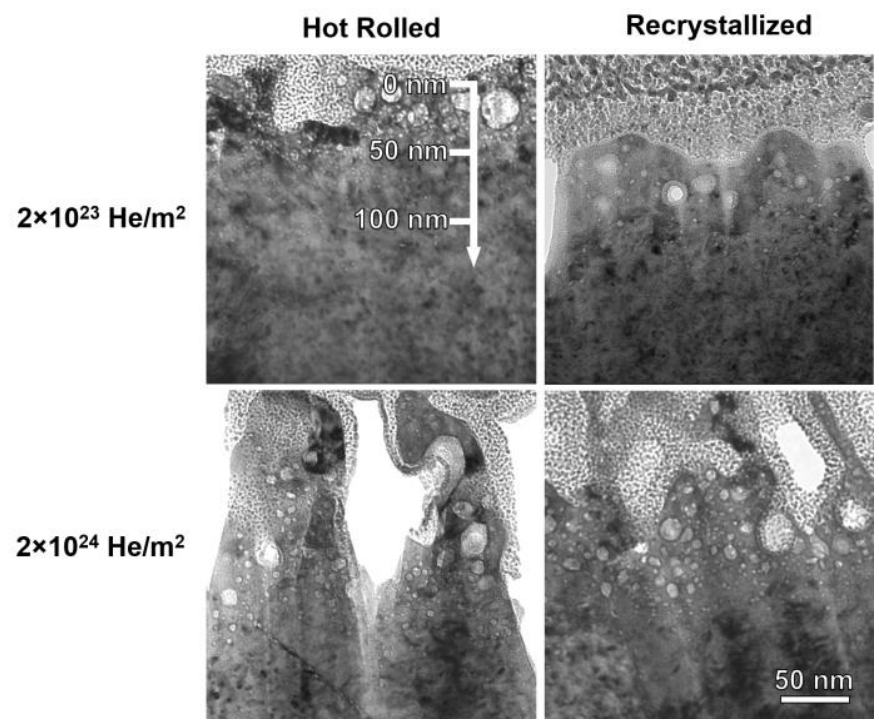

Figure 39. Typical bright field TEM images of the four conditions labeled.
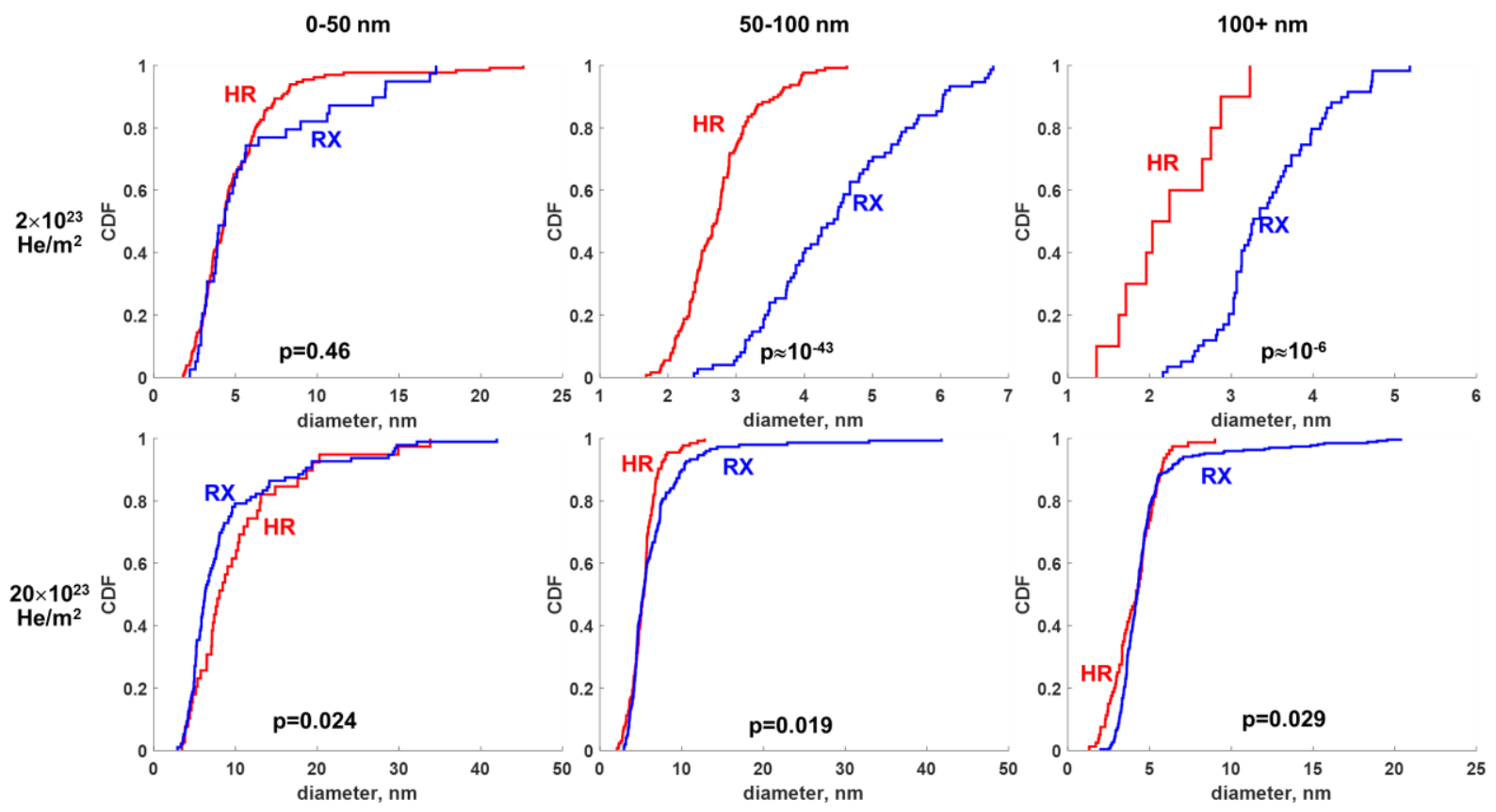

Figure 40. Cumulative distribution functions of the bubbles sizes in the different conditions for the three different depths regimes. The values $p$ are the results of the two-sample Kolmogorov-Smirnov test; smaller values (neared zero) indicate more statistically different distributions.

\section{REFERENCES}

[1] C.M. Parish, K. Wang, R.P. Doerner, M.J. Baldwin, "Grain orientations and grain boundaries in tungsten nonotendril fuzz grown under divertor-like conditions", Scripta Materialia, 127 (2017) 132135. 


\title{
6.2 IMPACT OF HELIUM BUBBLES ON DEUTERIUM DESORPTION KINETICS IN ITER- GRADE TUNGSTEN
}

\author{
X.Hu(huxl@ornl.gov), C.Parish
}

\section{OBJECTIVE}

The goal of this project is to investigate the impact of pre-existing helium bubbles produced in the Heplasma exposure process on the deuterium desorption behavior in ITER-grade tungsten by using the newly established gas implantation and thermal desorption spectrometry (TDS) system at ORNL.

\section{SUMMARY}

We have investigated the impact of pre-existing He bubbles on the D desorption behavior in ITER-grade $\mathrm{W}$. This addresses the question of whether He bubbles will increase the D retention in W. Transmission electron microscopy was used to characterize the He bubble distributions in the near surface region of $\mathrm{W}$ following He-plasma exposure. Then $\mathrm{D}$ was implanted in the plasma exposed $\mathrm{W}$ and reference samples at room temperature. The following TDS measurements enable the direct comparison of D desorption spectra. The results indicated that the $\mathrm{D}$ desorption peaks shift to higher temperature due to the strong trapping ability of pre-existing He bubbles.

\section{PROGRESS AND STATUS}

Tungsten samples were exposed to $75 \mathrm{eV} \mathrm{He}$ plasma at $1000^{\circ} \mathrm{C}$ to a fluence of $3.4 \times 10^{24} / \mathrm{m}^{2}$ at a flux of $2.3 \times 10^{19} / \mathrm{m}^{2} / \mathrm{s}$ in the SNL-Livermore plasma exposure experimental facility. TEM analysis was performed at the ORNL LAMDA Facility using a FEI Talos F200X S/TEM. Figure 41 shows highresolution TEM images of the first few hundred nanometers below the surface of the exposed region of the sample. The top image shows a densely packed bubble region within the first $100 \mathrm{~nm}$ of the surface, many of which are in the range of 10-30 nm diameters. These dense layers of small $(<10 \mathrm{~nm})$ bubbles have been documented on higher flux plasma exposure stages for a variety of fluence levels and have been asserted to have a strong influence on permeation of hydrogenic particles into the bulk $\mathrm{W}$. The lower image shows a higher magnification of the near surface region where quite a few unique features are recognized. Large faceted bubbles $(90 \times 50 \mathrm{~nm})$ are noted near grain boundaries and smaller faceted bubbles are scattered in the near-surface bubble layer. Bubbles are seen to grow along what appears to be a dislocation loop. Small bubbles $(<10 \mathrm{~nm})$ are also seen penetrating up to $250 \mathrm{~nm}$ below the surface. The formation of this dense bubble layer near the surface, as well as the more scattered bubbles forming deeper below the surface, are likely to have significant effects on retention and permeation of hydrogen. 


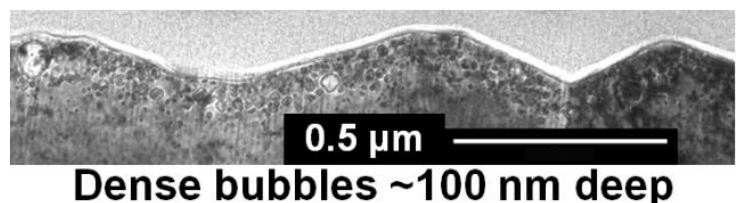

Dense bubbles $\sim 100 \mathrm{~nm}$ deep Sizes $\sim 10-30 \mathrm{~nm}$

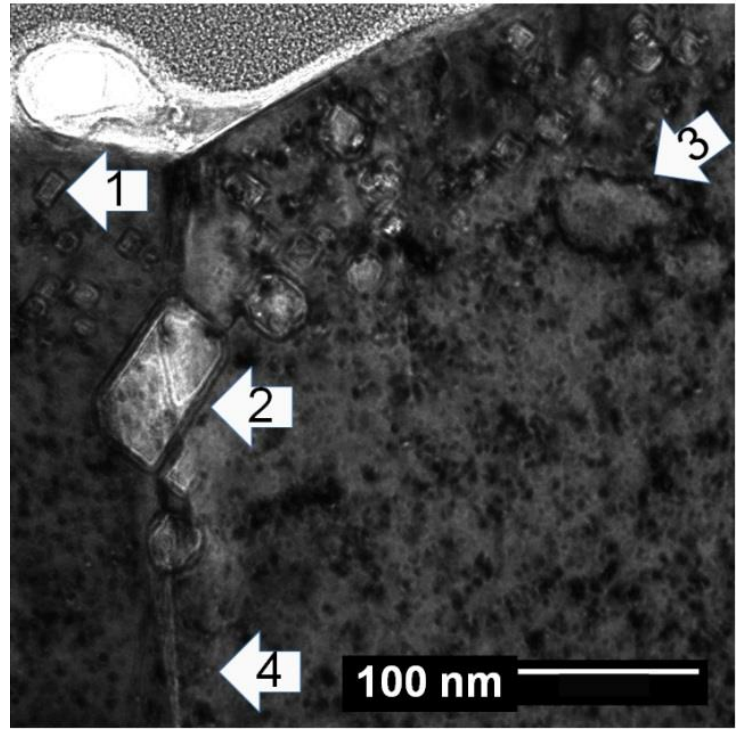

Figure 41. TEM imaging of FIB-prepared cross-section of He-ion exposed ALMT ITER-Grade W shows a dense bubble layer within the first $100 \mathrm{~nm}$ of the surface. (1) Highly faceted bubbles; (2) Large $(90 \times 50 \mathrm{~nm})$ grain boundary bubble; (3) Bubbles visible on dislocation loop; (4) Small $(<10 \mathrm{~nm})$ bubbles penetrating deep (>250 $\mathrm{nm}$ ) below surface.

In order to evaluate the impact of pre-exiting He bubbles on the $\mathrm{D}$ behavior in $\mathrm{W}$, thermal desorption spectrometry was used to measure the D desorption spectra from two different $\mathrm{W}$ samples, i.e., as-

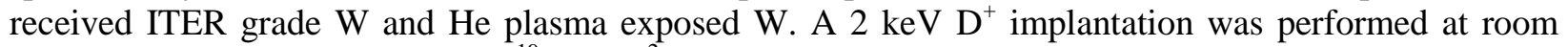
temperature to a fluence of $2.5 \times 10^{19}$ ions $/ \mathrm{m}^{2}$ for these two samples using the in situ $20 \mathrm{keV}$ ion gun of the ORNL Gas Implantation and Thermal Desorption System. Figure 42 shows the measured D desorption spectra from these two samples following the D implantation. Two major desorption peaks were observed for the D desorption spectrum of the reference W sample, which were centered at 550 and $678 \mathrm{~K}$. The lower temperature D desorption peak arises from the D binding with weak trapping sites, such as grain boundaries, or dislocations. The more significant higher temperature D release is ascribed to the relatively strong trapping capability of the single vacancies or small vacancy clusters produced during the $2 \mathrm{keV} D$ implantation. For the D spectrum of the $\mathrm{W}$ specimen subject to the He plasma exposure, there are also two major desorption peaks, at 605 and $720 \mathrm{~K}$. The D desorption peaks shifted to relatively higher temperatures, implying D binding with different trapping sites. TEM observation of this plasma exposed sample showed a large number of He bubbles existing in the near surface region. These are expected to serve as strong trapping sites for the implanted D, leading to the observed D desorption peak shift to higher temperature in Figure 42. The preliminary result demonstrates that the pre-existing He bubbles do alter the $\mathrm{D}$ trapping and desorbing behavior in $\mathrm{W}$. More work is needed to analyze the mutual interactions of $\mathrm{D}, \mathrm{He}$, and defects present in $\mathrm{W}$. 


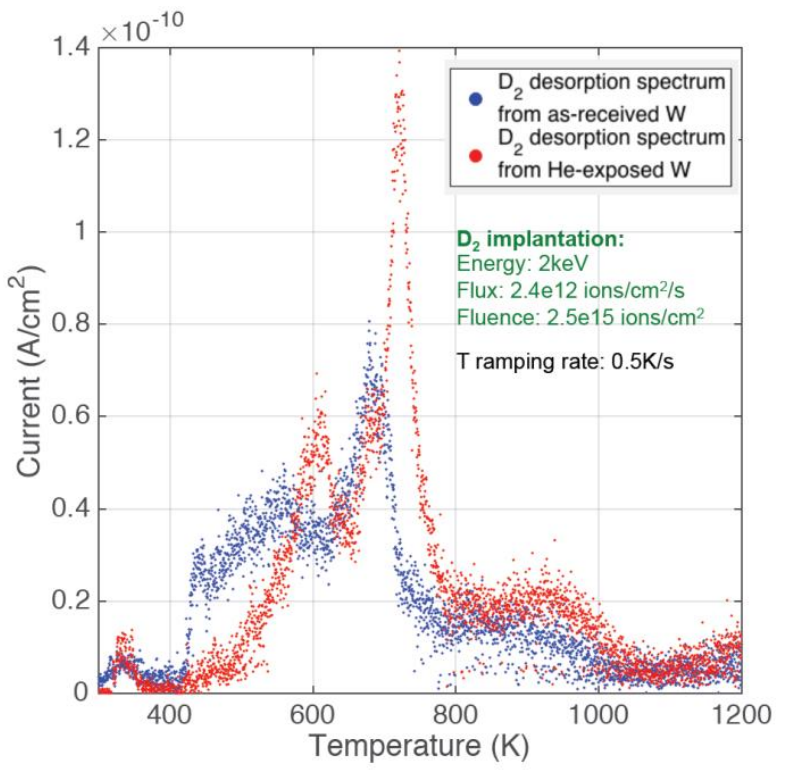

Figure 42. Deuterium desorption spectrum from as-received $\mathrm{W}$ and He-exposed $\mathrm{W}$ implanted with $2 \mathrm{keV} \mathrm{D}^{+}$ at room temperature.

\section{FUTURE PLANS}

The present study showed preliminary results of the impact of He bubbles on D desorption spectra by combining TEM and TDS observations. However, the repeatability of the experimental results has not been checked and the insights obtained from this single measurement are limited. We plan to investigate multiple samples with various He-plasma exposure conditions and perform the D implantation on these samples to elucidate the underlying mechanisms controlling D trapping and de-trapping with He bubbles. Experimental results will be coordinated with appropriate modeling work. 


\subsection{HIGH-HEAT FLUX TESTING OF FUSION MATERIALS}

\section{A.S. Sabau (abaua@ornl.gov), J. Kiggans, S. Gorti, Y. Katoh and K. Ibano (Osaka University)}

\section{OBJECTIVE}

High-heat flux testing (HHFT) of irradiated materials for plasma facing components and of mock-up divertor components using Plasma Arc Lamps (PAL) will provide basic materials property information and constitutive equations for materials behavior in the harsh fusion environment.

\section{SUMMARY}

A review of relevant physical phenomena that take place during HHFT was used to identify specific tasks in the ORNL program for materials characterization. Examination of activities in handling irradiated specimens in FY2017 was conducted to ensure close coordination between the elements of a multidisciplinary effort needed for a comprehensive material science study of irradiated effects during HHFT. Thermo-mechanical model simulations of the high-heat flux testing of W/SiC specimens were completed, taking into account actual HHF cycles and temperature-dependent thermophysical and elastic mechanical properties. Preliminary results from the numerical simulations of the HHFT of W/SiC specimens indicated that stresses experienced by the specimens during HHFT are relatively small compared to those expected for the W/F82H specimens.

\section{PROGRESS AND STATUS}

Effort was conducted in two main areas: (a) planning of activities for handling the neutron-irradiated specimens in FY2017 and (b) thermo-mechanical analysis of HHFT of W/SiC specimens.

Planning activities for handling irradiated specimens in FY2017 was started. A review was conducted of relevant physical phenomena that take place during HHFT in order to identify areas of concentration for specimen characterization. The following physical phenomena will be considered for understanding irradiation effects during HHFT of W-based materials: (1) Time to anneal irradiation defects, (2) Thermal conductivity degradation, (3) Changes in mechanical properties, (4) Changes in microstructure, and (5) Defect evolution during HHFT.

Basic materials property information and constitutive equations for materials behavior in the harsh fusion environment will be generated in materials science investigations. The tasks which are needed for this study were identified and are shown in Table 10. The modeling task will provide the temperature distribution within the specimen and ensuing specimen deformation, plastic deformation, and build-up of residual stresses during HHFT. The materials will be characterized before and after HHFT.

Table 10. Planned activities per tasks for a material science study

\begin{tabular}{|c|l|l|l|l|}
\hline Task & \multicolumn{1}{|c|}{$\begin{array}{c}\text { Modeling } \\
\text { HHFT }\end{array}$} & $\begin{array}{c}\text { PIE: } \\
\text { Microstructural } \\
\text { characterization }\end{array}$ & $\begin{array}{c}\text { PIE: } \\
\text { Defect } \\
\text { characterization }\end{array}$ & $\begin{array}{c}\text { PIE: } \\
\text { Property } \\
\text { measurement }\end{array}$ \\
\hline Activities & $\begin{array}{l}\text { Energy transport, } \\
\text { Stress analysis }\end{array}$ & $\begin{array}{l}\text { Surface SEM, } \\
\text { Profilometry }\end{array}$ & $\begin{array}{l}\text { STEM imaging, } \\
\text { TEM imaging, } \\
\text { Large-area high-speed } \\
\text { STEM-X-ray mapping }\end{array}$ & $\begin{array}{l}\text { Thermal conductivity } \\
\text { Micro-hardness }\end{array}$ \\
\hline
\end{tabular}


Data acquired during HHFT of W/SiC specimens as part of the joint US/Japan PHENIX program, was analyzed. Specimens were supplied by the Japanese collaborators in the PHENIX program. The main variables in the high-heat flux testing were the number of cycles at high heat flux and average cycle duration (Table 11). The diameter of the $\mathrm{W} / \mathrm{SiC}$ specimens was $10 \mathrm{~mm}$. The thickness of $\mathrm{SiC}$ was $1 \mathrm{~mm}$ while the $\mathrm{W}$ thickness was 1 or $2 \mathrm{~mm}$.

Table 11. High-heat flux test results for $\mathrm{W} / \mathrm{SiC}$ specimens

\begin{tabular}{|l|l|l|l|l|l|l|l|l|}
\hline No. & $\begin{array}{l}\text { W } \\
\text { thickness } \\
{[\mathrm{mm}]}\end{array}$ & $\begin{array}{l}\text { No. of } \\
\text { Cycles }\end{array}$ & $\begin{array}{l}\text { Average } \\
\text { cycle } \\
\text { time }[\mathrm{s}]\end{array}$ & $\begin{array}{l}\text { Cycle } \\
\text { duration } \\
{[\mathrm{s}]}\end{array}$ & $\begin{array}{l}\text { Max. } \\
\text { Heat } \\
\text { Flux } \\
{\left[\mathrm{W} / \mathrm{cm}^{2}\right]}\end{array}$ & $\begin{array}{l}\text { Average } \\
\text { Heat } \\
\text { Flux } \\
{\left[\mathrm{W} / \mathrm{cm}^{2}\right]}\end{array}$ & $\begin{array}{l}\text { Total heat } \\
\text { input } \\
{\left[\mathrm{MJ} / \mathrm{cm}^{2}\right]}\end{array}$ & $\begin{array}{l}\text { Total time } \\
\text { at high- } \\
\text { heat flux } \\
{[\mathrm{s}]}\end{array}$ \\
\hline 1 & 2 & 122 & 11.1 & $10-15$ & 288 & 264 & 0.361 & 1,356 \\
\hline 2 & 2 & 100 & 10.9 & $5-15$ & 300 & 274 & 0.301 & 1,094 \\
\hline 3 & 1 & 101 & 11.3 & $10-15$ & 288 & 272 & 0.311 & 1,146 \\
\hline 4 & 1 & 132 & 13 & $10-18$ & 288 & 274 & 0.478 & 1,731 \\
\hline
\end{tabular}

${ }^{1}$ Number of cycles at heat fluxes above $210 \mathrm{~W} / \mathrm{cm}^{2}$.

Thermo-mechanical models for the simulations of full HHFT tests were implemented in the ABAQUS ${ }^{\mathrm{TM}}$ software and numerical simulation results were conducted for $\mathrm{W} / \mathrm{SiC}$ samples $\mathrm{S} 1$ and $\mathrm{S} 3$, taking into account the specific parameters of actual high-heat flux cycles. Temperature-dependent thermophysical and elastic mechanical properties for the $\mathrm{SiC}$ were used as input in the numerical simulations of the HHFT. One of the main modeling assumptions is that the clamp is a rigid body, i.e., the distance from the clamp surface to the back-side of the $\mathrm{Cu}$ washer was held constant. For the last HHFT cycle, the calculated temperatures at the top surface of the $\mathrm{W}$ are shown in Figure 43 for thermal contact conduction (TCC) per unit area (between the $\mathrm{SiC}$ and $\mathrm{Cu}$ washer) of 4,000, 5,000, 6,000 and 7,000 $\left[\mathrm{W} / \mathrm{m}^{2} \mathrm{~K}\right]$. The calculated temperature data showed that the temperatures were relatively low. This data also indicate that the HHF cycle duration can be shortened to 7-8 s, as the surface temperatures approached the linear regime in this short time.
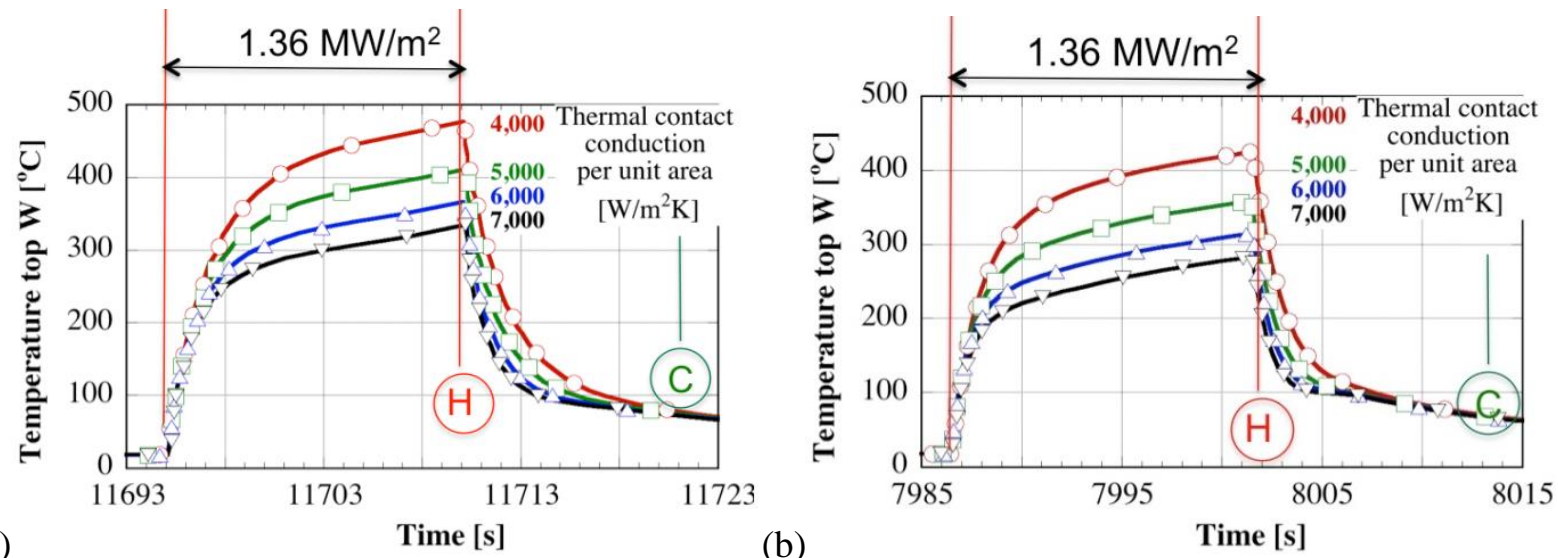

(a)

(b)

Figure 43. Calculated temperature evolution during a HHF cycle for several thermal contact conduction values between the $\mathrm{SiC}$ and $\mathrm{Cu}$ washer. 
The results for the Von Mises stress [Pa] in a clamped specimen with a TCC of 5,000 [W/m $\left./ \mathrm{m}^{2} \mathrm{~K}\right]$ are shown in Figure 44 and Figure 45 at high temperature (Hot), i.e., right at the end of the HHF, and at room temperature (Cold), respectively. The stresses are shown on a deformed mesh in order to illustrate the changes in the specimen geometry during HHFT, with the deformation scale of 50. The left-hand-side of each figure is the centerline of the specimen. In order to illustrate the mechanical effect of clamping, the results are shown in Figure 45 for an unclamped specimen, although at the same thermal contact conduction as the clamped specimen. The following observations can be made with respect to the stress and deformation results:

- At high temperatures, the specimen bulge upward at its center, resting on the clamp at its outer edges.

- At room temperature, before clamp removal, the specimen is undeformed as it underwent only elastic deformation. The stresses are highest in the $\mathrm{SiC}$ and are very low at approximately $7 \mathrm{MPa}$.

- For the clamped specimen (Figure 44), the predicted residual stresses are highest in W and are located around the edge of the specimen in the clamped region. However, the stresses are small, approximately $74 \mathrm{MPa}$ at a $\mathrm{W}$ temperature of $400^{\circ} \mathrm{C}$. The highest stress levels at the $\mathrm{W}$-SiC interface were approximately $50 \mathrm{MPa}$.

- For the unclamped condition (Figure 45), the predicted residual stresses are highest at the W/SiC interface and were approximately $50 \mathrm{MPa}$.

- For the unclamped condition, the stresses in W would be under-predicted, while the stresses in the $\mathrm{SiC}$ (actually, at the W-SiC interface) would be over-predicted.

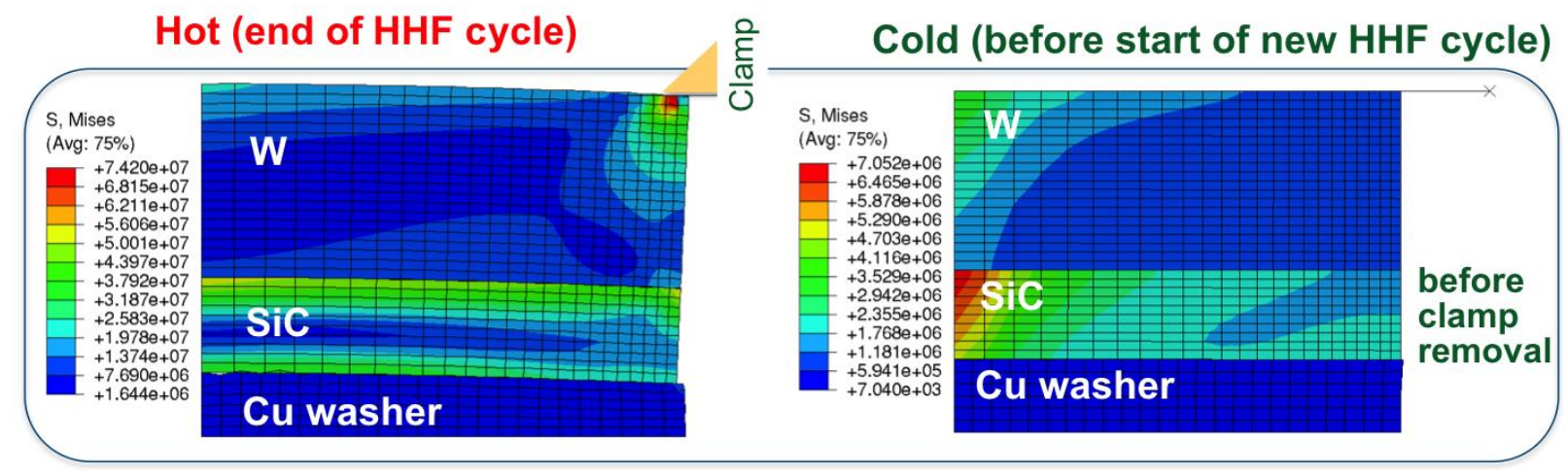

Figure 44. Von Mises stress results for clamped S1 specimen at high temperature (Hot), i.e., right at the end of the HHF, and at room temperature (Cold). The SiC-Cu TCC was $5,000\left[\mathrm{~W} / \mathrm{m}^{2} \mathrm{~K}\right]$.

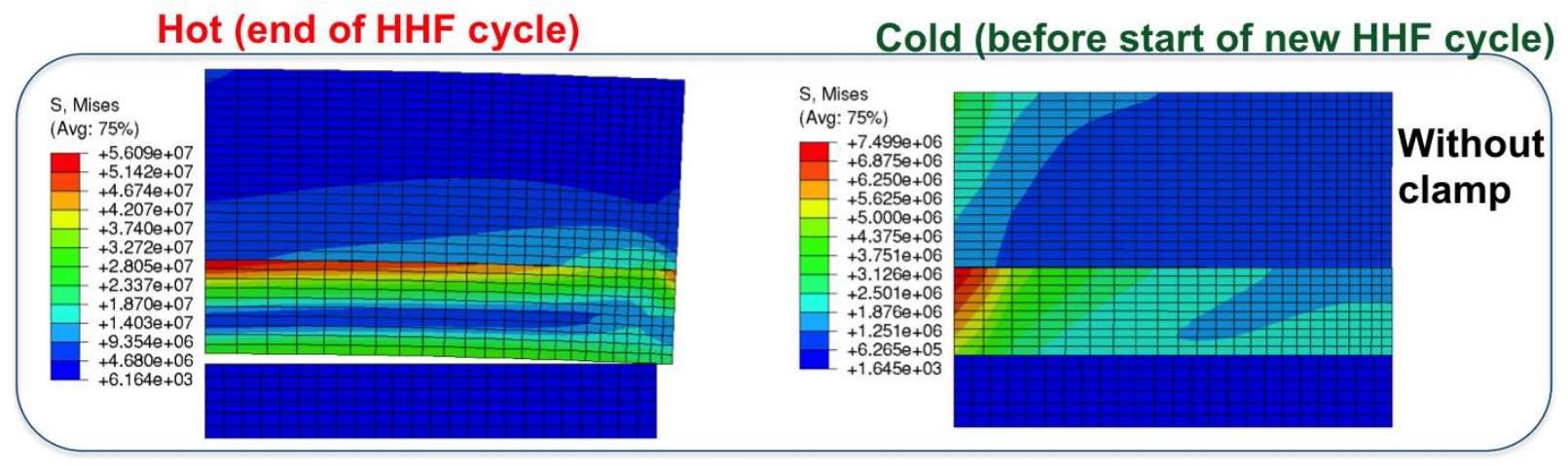

Figure 45. Von Mises stress results for an unclamped S1 specimen at high temperature (Hot), i.e., right at the end of the HHF, and at room temperature (Cold). The SiC-Cu TCC was $5,000\left[\mathrm{~W} / \mathrm{m}^{2} \mathrm{~K}\right]$. 


\section{FUTURE PLANS}

Efforts are now focused on: (1) conducting high-heat flux testing of non-irradiated specimens for the joint US/Japan PHENIX program and (2) understanding the deformation during HHFT using thermomechanical simulation of the high-heat flux test. 


\section{EXPLORATORY, UNIQUE AND INNOVATIVE MATERIALS}

\subsection{DESIGN AND DEVELOPMENT OF NOVEL Cu ALLOYS FOR FUSION ENERGY APPLICATIONS}

Ying Yang (yangying@ornl.gov) and Steven J. Zinkle

\section{OBJECTIVE}

This study aims to develop high strength, high conductivity copper alloys with improved thermal creep strength for high heat flux structures in long pulse fusion reactors. We are using an accelerated approach of computational thermodynamics guided alloy design.

\section{SUMMARY}

A computation thermodynamics tool for designing and developing $\mathrm{Cu}-\mathrm{Cr}-\mathrm{Nb}-\mathrm{Zr}$ alloys has been successfully developed. Thermodynamic modeling results based on this tool enabled the rapid development of novel $\mathrm{CuCrNbZr}$ alloys with targeted microstructures using economical conventional ingot making methods followed by simple heat treatment procedures. The new alloys display uniform grain structures with bimodal distribution of precipitates.

\section{PROGRESS AND STATUS}

During the first ten months of FY2016, we developed a thermodynamic database for the $\mathrm{Cu}-\mathrm{Cr}-\mathrm{Nb}-\mathrm{Zr}$ system. With the aid of this modelling tool, we designed a $\mathrm{Cu}-\mathrm{Cr}-\mathrm{Nb}-\mathrm{Zr}$ alloy and fabricated it using economical, conventional ingot processing technology followed by cold rolling, solutionizing and thermal aging. Optical imaging shows that the microstructure of this alloy displayed a well-defined recrystallized grain structure, with $\mathrm{Cr}_{2} \mathrm{Nb}$-Laves phase precipitates of submicron size decorating grain boundaries, dislocations and stacking faults. High magnification scanning electron microscopy (SEM) shows ultrafine matrix Cr precipitates with a size range of $5 \sim 10 \mathrm{~nm}$ in thermally aged samples. Vickers hardness of 60.5 $\mathrm{HV}$ is achieved in solutionized samples and $123.2 \mathrm{HV}$ was achieved in thermally aged samples. The significant enhancement of hardness during the thermal aging can be primarily attributed to the formation of the ultrafine $\mathrm{Cr}$ matrix precipitates.

During the last two months (Aug. Sep.) new CuCrNbZr alloys were designed and fabricated following this same procedure. The new alloys were designed with slightly higher $\mathrm{Cr}$ and $\mathrm{Zr}$ contents, to achieve a higher volume fraction and number density of $\mathrm{Cr}$ and $\mathrm{Cu}_{5} \mathrm{Zr}$ (or $\mathrm{Cu}_{51} \mathrm{Zr}_{14}$ ) matrix and grain boundary precipitates (thereby providing a useful comparison of the relative importance of matrix and grain boundary precipitates on properties). Figure 46 shows the calculated phase fraction vs temperature in the newly designed alloy (denoted by CCNZ2) compared to the previous one (denoted by CCNZ1). It shows the mole fraction of $\mathrm{Cr}$ and $\mathrm{Cu}_{5} \mathrm{Zr}\left(\mathrm{Cu}_{51} \mathrm{Zr}_{14}\right)$ precipitates in the $\mathrm{CCNZ2}$ alloy is greatly increased. Figure 47 shows optical microscope images of CCNZ2 compared to CCNZ1. A Vickers hardness of 107.2 HV was achieved in solutionized and aged CCNZ2, compared to $123.2 \mathrm{HV}$ for the CCNZ1. The GB precipitates are slightly coarser in the CCNZ2 alloy. Some precipitate phases of $1 \sim 5 \mu \mathrm{m}$ size with a square shape were observed in CCNZ2. These features might be associated with the reduced hardness in the new alloy. Additional microstructural analysis is ongoing for these alloys. 


\section{FUTURE WORK}

This task will continue with additional microstructural characterization and mechanical testing of the $\mathrm{CuCrNbZr}$ alloys. The thermodynamic modeling will be extended to the $\mathrm{Cu}-\mathrm{Cr}-\mathrm{Ta}-\mathrm{Zr}$ system, and will lead to design of CuCrTaZr alloys
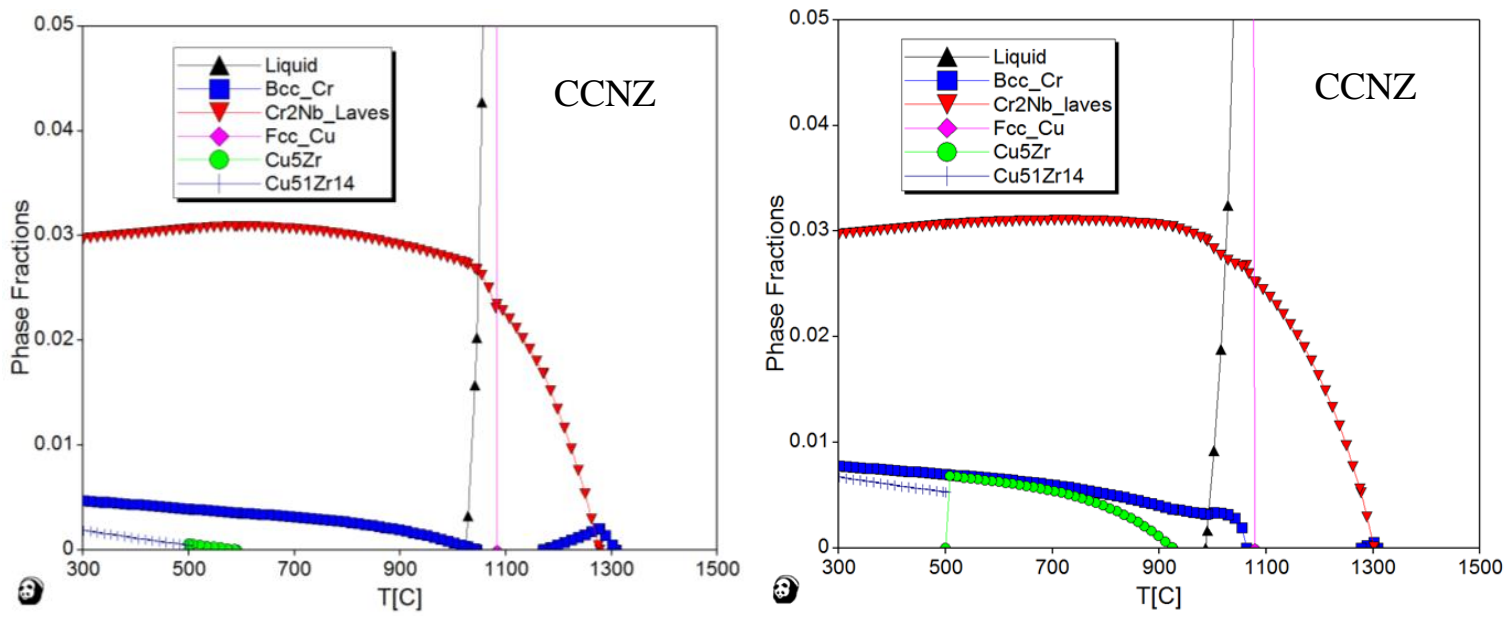

Figure 46. Phase fractions vs temperature in CCNZ1 and CCNZ2 alloys.
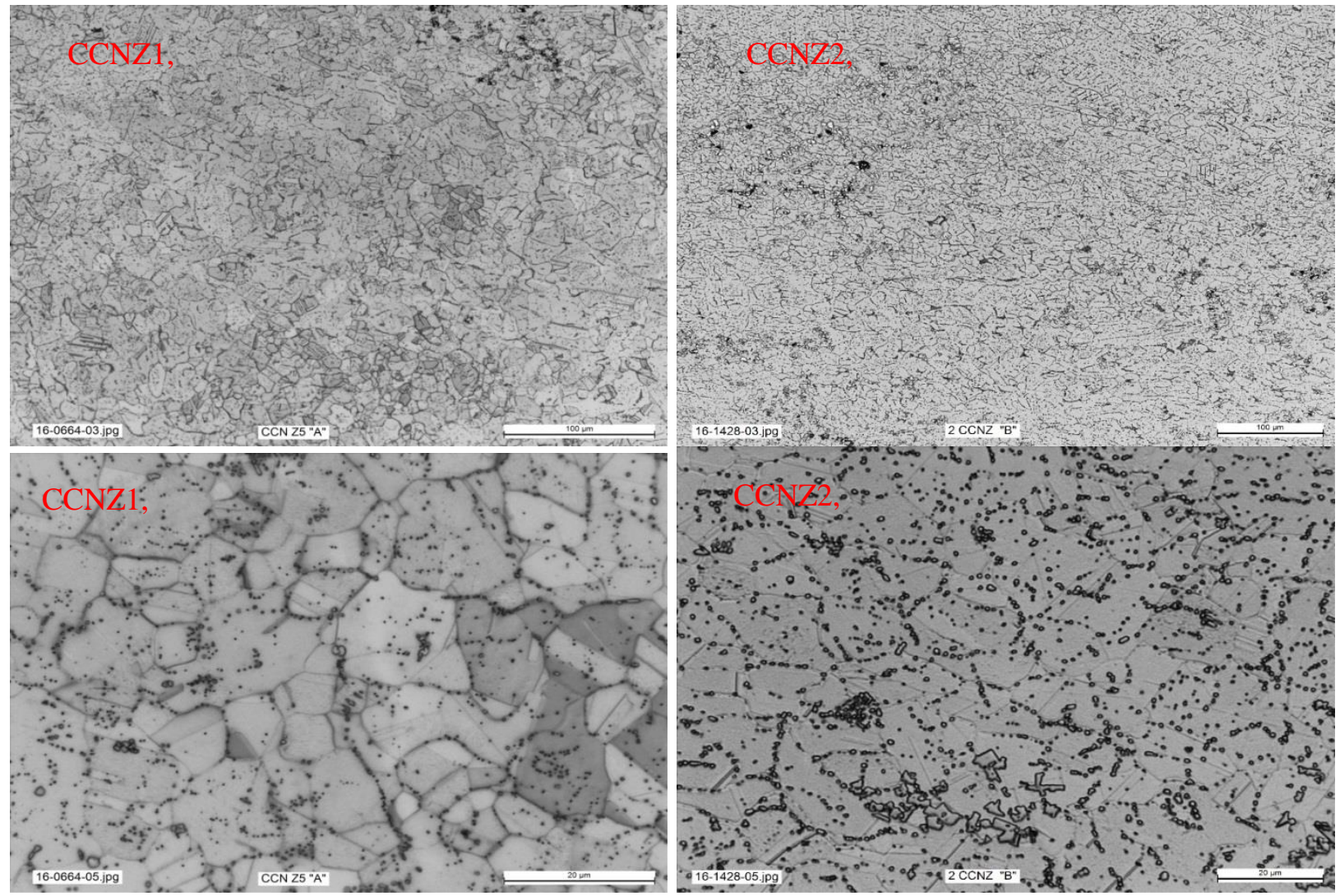

Figure 47. Optical images of CCNZ1 and CCNZ2 in high and low magnification. 


\title{
7.2 MAX PHASES UNDER NEUTRON IRRADIATION
}

\author{
C. Ang (angck@ornl.gov), C. Parish, C. Silva, N. Cetiner, S. Zinkle, P. Edmondson, Y. Katoh
}

\section{OBJECTIVE}

MAX phase materials are candidates for high temperature, high radiation environments due to their predicted radiation damage tolerance and unusually high fracture toughness. The minimum objectives of the MAX evaluation program have been completed on the $\mathrm{Ti}_{3}(\mathrm{Al} / \mathrm{Si}) \mathrm{C}_{2}$ materials purchased from 312, LLC. The subsequent objectives are to consolidate and publish the current data, and develop more fundamental understanding of the (1) defect migration and (2) fracture toughness of the irradiated material.

\section{SUMMARY}

The current year effort focused on coordinating results of SEM, XRD, elastic modulus, and swelling data for neutron irradiated $\mathrm{Ti}_{3}(\mathrm{Al} / \mathrm{Si}) \mathrm{C}_{2}$ materials. Two manuscripts on $\mathrm{Ti}_{3} \mathrm{SiC}_{2}$ and $\mathrm{Ti}-\mathrm{Al}-\mathrm{C}$ materials were recently accepted for publication. Limited additional analysis of fracture surfaces and transmission electron microscopy was also conducted. The thermal and electrical data have not yet been published in order to make full use of further fundamental studies such as annealing, which will be correlated to specific defect identification. An NSUF RTE was recently proposed and accepted. It is expected that electrical resistivity annealing, coupled with selected transmission electron microscopy, can begin early in the new fiscal year.

\section{PROGRESS AND STATUS}

Two investigations of irradiated materials are currently underway: a fundamental defect annealing study of MAX phases and the changes in fracture toughness caused by antisite defects. (The latter is not discussed here.) The annealing is of particular interest to fundamental studies of all MAX phases. Loss of the A-layer results in reduced thermal and electrical conductivity, but saturation of point defect swelling occurs due to the rapid migration of the atoms between the M-A layers. However, the fact that the loss of the $\mathrm{A}$ atoms also results in anisotropic swelling indicates a key role associated with the return of A-layer atoms. The argument is as follows: if interstitial migration is available at room temperature and above, and yet after irradiation at $\sim 400^{\circ} \mathrm{C}$ the A-atoms have not recovered to the A-layer by interstitial migration, this means that another mechanism is required. The thermal diffusivity data clearly indicates that a migration energy associated with $\sim 600-900^{\circ} \mathrm{C}$ annealing seems necessary to recover electronic thermal conductivity. This indicates the dynamic irradiation recovery begins at a slightly lower temperature. The focus on M-A layers being recombination zones for irradiation-produced defects does not appear to offer any further insights; at $\sim 400^{\circ} \mathrm{C}$, all defects calculated by ab initio methods (Middleburgh, Zhao et al) would seem to be mobile, except for $\mathrm{C}$ and $\mathrm{Ti}$ vacancies.

One aspect of the MAX phases that has been neglected in searching for explanation of annealing results is processes in the MX-region. While ab initio analyses indicate that defects are unlikely to form in the MX region, there are several interesting coincidences that cannot be explained by defects only occurring in the M-A layers. Furthermore, swelling of ceramics is only reduced, not eliminated by increasing irradiation temperature, and generally, defect clusters are annihilated by onset of vacancy migration (Zinkle et al).

This explanation converged with examination of TiC phase impurities at 0.1 and 2 dpa from work by Tallman et al and this work. TiC is the parent $\mathrm{MX}$ phase for these $\mathrm{Ti}_{3}(\mathrm{Al} / \mathrm{Si}) \mathrm{C}_{2} \mathrm{MAX}$ phases. Figure 48 shows the results, with the neutron fluence-to-dpa conversion for $\mathrm{ZrC}, \mathrm{TiC}$ and $\mathrm{SiC}$ taken as $1 \times 10^{25} \mathrm{n} / \mathrm{m}^{2}$ 
$\left(\mathrm{E}>0.1 \mathrm{MeV}\right.$ ) equals $1 \mathrm{dpa}$. It appeared that swelling is mitigated in both $\mathrm{TiC}$ and $\mathrm{Ti}_{3}(\mathrm{Al} / \mathrm{Si}) \mathrm{C}_{2}$ between 400 and $700^{\circ} \mathrm{C}$. $\mathrm{SiC}$ is also shown based on data by Snead et al.
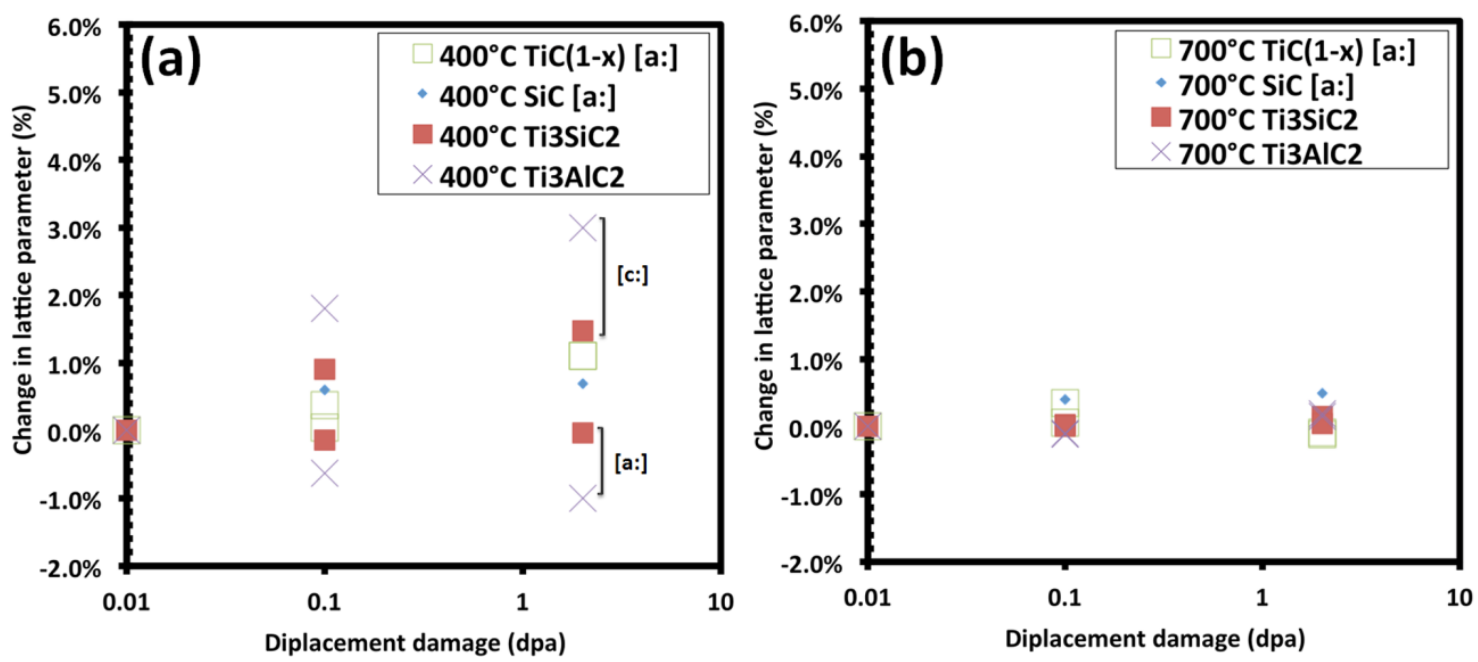

Figure 48. Change in lattice parameters of $\mathrm{TiC}$ (green) impurities in $\mathrm{Ti}_{3} \mathrm{SiC}_{2}$ at 0.1 (Tallman et al) and $2 \mathrm{dpa}$ at (a) $\mathrm{T}_{\text {irr }} \sim 400^{\circ} \mathrm{C}$ and $(\mathrm{b}) \mathrm{T}_{\mathrm{irr}} \sim 700^{\circ} \mathrm{C}$. SiC lattice parameter (linear $\Delta \mathrm{a} / \mathrm{a}$ ) is shown as a comparison with the blue markers. (J Nucl Mater, unpublished).

While TiC is not the Ti-C stoichiometry in MAX phases, the similarities in bond lengths and coordination chemistry result in similar values for migration energies (Råsander and Middleburgh et al). Vacancy migration has been observed after ion irradiations of $\mathrm{TiC}_{(1-\mathrm{x})}$ at $\sim 800^{\circ} \mathrm{C}$ (Dickerson et al), which is consistent with a migration energy near $\sim 3 \mathrm{eV}$.

In $\mathrm{Ti}_{3}(\mathrm{Al} / \mathrm{Si}) \mathrm{C}_{2}$, the anisotropic swelling under irradiation is only eliminated above $\sim 700^{\circ} \mathrm{C}$. Prior to this temperature, the lattice parameter swelling is only reduced. Coupled with a change in thermal and electrical resistivity between $400-700^{\circ} \mathrm{C}$, it indicates that the swelling dynamic recovery is accompanied by A-atom recovery. The only explanation is that A-atom recovery of $\mathrm{Ti}_{3}(\mathrm{Al} / \mathrm{Si}) \mathrm{C}_{2}$ is dependent on a higher defect migration energy (either vacancy migration, or thermal dissolution of small vacancy clusters). Since $\mathrm{Ti}$ and $\mathrm{C}$ vacancies are the only remaining immobile defects, the current investigation is attempting to determine the migration energy from electrical resistivity measurements after annealing.

It seems likely that there is a relationship between the temperature needed to remove defects from $\mathrm{TiC}$ and Ti-C based MAX phases. Speculatively, the published papers proposed either (1) A-atoms are trapped in Ti-C layers of MAX phase requiring a vacancy mediated recovery of A-atoms or (2) C-atom migration back into the Ti-C layers. Both energies are about $\sim 2.5-3 \mathrm{eV}$. It should follow an Arrhenius relationship near the temperature at which electrical conductivity begins to recover.

\section{FUTURE PLANS}

Annealing and electrical resistivity measurement will be conducted over the temperature range previously bracketed by thermal diffusivity annealing to evaluate the migration energy. An Arrhenius relationship has already been established. As noted, other investigations include the isolation of the effect of antisite defects on room temperature fracture toughness, since resulting post-irradiated microstructures show MM (as opposed to M-A) layers. Finally, plans are underway to begin examination of the MAX phase materials irradiated at $\sim 10 \mathrm{dpa}$ as resources become available. 


\subsection{PRELIMINARY ASSESSMENT OF THE IRRADIATION BEHAVIOUR OF THE FeCrMnNi HIGH-ENTROPY ALLOY FOR NUCLEAR APPLICATIONS}

P.D. Edmondson (edmondsonpd@ornl.gov), M.A. Tunes ${ }^{l}$, R.W. Harrison ${ }^{l}$, G. Greaves ${ }^{l}$, J.A.Hinks ${ }^{l}$ and S.E. Donnelly ${ }^{l}{ }^{1}$ University of Huddersfield, Huddersfield, UK)

\section{OBJECTIVE}

In the search for new nuclear materials with improved radiation tolerance and behavior, the high-entropy alloys (HEAs) have arisen as new candidates for structural components in nuclear reactors due to their suspected superior stability under irradiation. The metallurgical definition of HEAs is any alloy with multiple elements, five or more all in equiatomic compositions. The basic principle is the high mixing entropy of its solid solution lowers the Gibbs free energy giving a strong enhancement of the microstructural stability at low and high temperatures.

The objective of this project is to assess the irradiation behaviour of the FeCrMnNi HEA system in order to investigate whether the high entropy effect is responsible for a microstructure with better radiation resistance compared to conventional alloys. In this work transmission electron microscopy (TEM) with in-situ ion irradiation has been used at the MIAMI-1 facility at the University of Huddersfield, UK: a 100 $\mathrm{kV}$ ion accelerator coupled with a JEOL JEM-2000FX TEM. This methodology allows the evolution of the HEA microstructure to be studied on the nanoscale during the ion irradiation.

\section{SUMMARY OF EXPERIMENTS}

The preliminary aim of this project was focused on the characterization of the HEA sample as-cast at ORNL and the production of TEM samples using the Focused Ion Beam (FIB) technique. In addition, some preliminary in-situ TEM irradiation experiments were performed using two different ion beams at $298 \mathrm{~K}: 30 \mathrm{keV} \mathrm{Xe}{ }^{+}$and $6 \mathrm{keV} \mathrm{He}$.

Energy dispersive X-ray spectroscopy (EDX) was used to determine the composition of the alloy. The quantitative analysis from the EDX measurements in the as-received alloy showed that the composition in weight percent (\%-wt.) was: $25.08-\mathrm{Fe}, 20.48-\mathrm{Cr}, 27.34-\mathrm{Ni}$ and $20.89-\mathrm{Mn}$. The balance $(6.21 \%$-wt.) was due to the impurities of $\mathrm{C}, \mathrm{Si}$ and O. TEM diffraction patterns taken of this HEA revealed it to be a single phase solid solution with a BCC structure.

\section{PROGRESS AND STATUS}

To investigate the response of the alloy to low energy ion implantation, a first experiment was carried out at MIAMI-1 using a $6 \mathrm{keV} \mathrm{He}$ beam at $298 \mathrm{~K}$. Figure 49 shows bubble nucleation occurring at a fluence of $6.4 \times 10^{16}$ ions.cm ${ }^{-2}(\sim 4 \mathrm{dpa})$ and bubble size was observed to increase slightly with ion fluence. Details of bubble populations are shown in Figure 50, with migration to twin interfaces was observed during the irradiation (see Figure 50a). After $1.3 \times 10^{17}$ ions. $\mathrm{cm}^{-2}(\sim 9 \mathrm{dpa})$ at $298 \mathrm{~K}$, the temperature was increased to $673 \mathrm{~K}$ where bubble coalescence was observed for those bubbles situated on twin interfaces. Figure 50b is the microstructure after irradiation showing He bubbles throughout the alloy at $673 \mathrm{~K}$. The diffraction pattern remained unchanged (inset in Figure 49d) after the irradiation and the annealing.

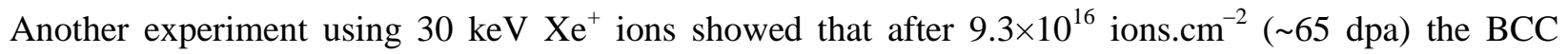
structure had changed as can be seen looking at the inset diffraction patterns in Figure 51 and it is attributed directly to the effects of the irradiation. Bending or curling were not observed during the experiment. Bubble nucleation was observed to occur at around $4.7 \times 10^{16}$ ions.cm ${ }^{-2}(\sim 32 \mathrm{dpa})$ of 
irradiation at $298 \mathrm{~K}$. Compared to the $6 \mathrm{keV} \mathrm{He}+$ irradiation, the accumulation of bubbles in the twin interfaces was observed, however, it was not significant when compared to the $6 \mathrm{keV} \mathrm{He}^{+}$irradiation.

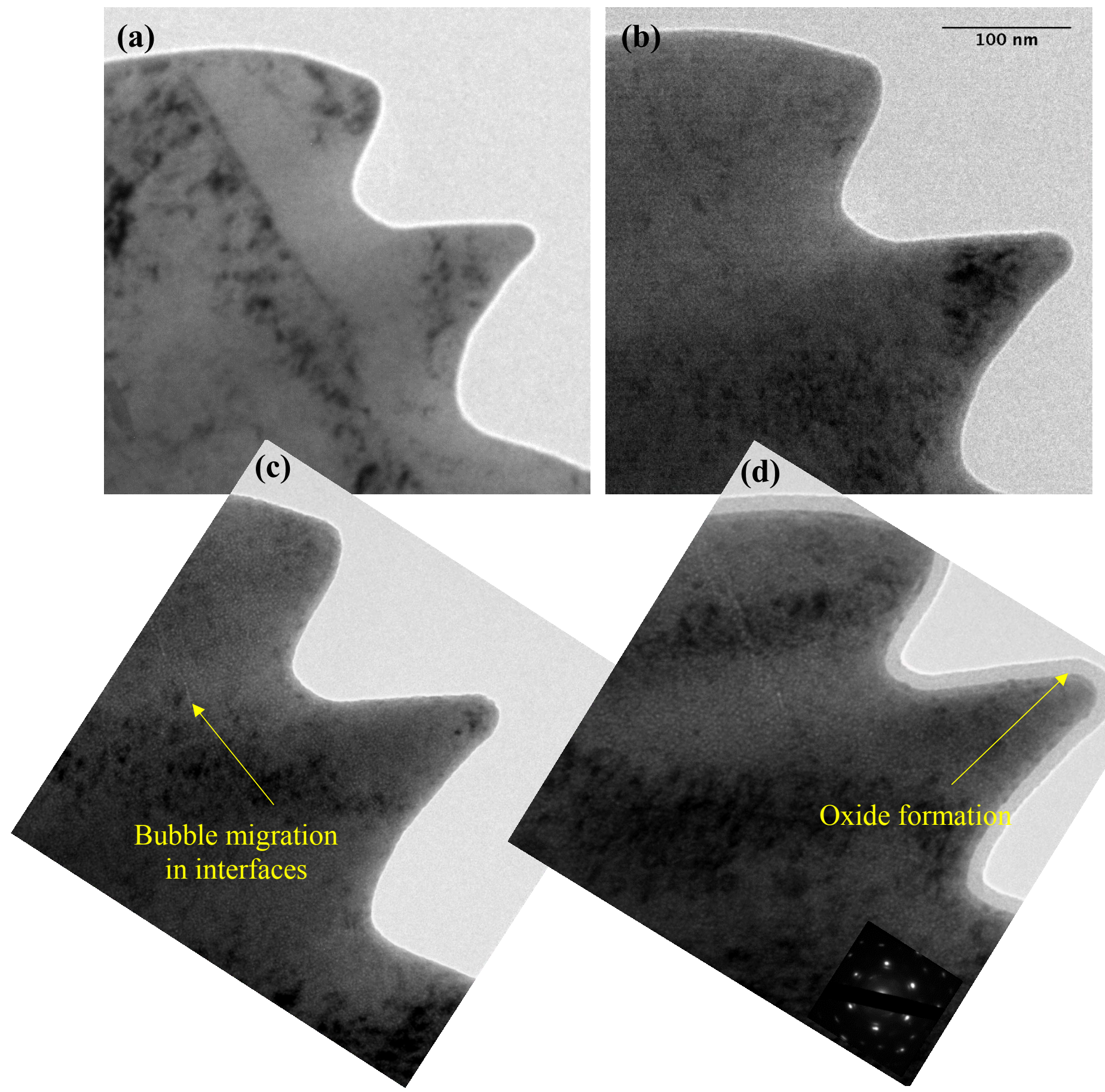

Figure 49. $6 \mathrm{keV} \mathrm{He}+$ in-situ TEM irradiation showing (a) bright-field (BF) TEM image of the unirradiated sample, (b) BF of the microstructure at $298 \mathrm{~K}$ after $6.4 \times 10^{16}$ ions.cm ${ }^{-2}(\sim \mathrm{dpa})$, (c) BF image at $298 \mathrm{~K}$ after $1.3 \times 10^{17}$ ions.cm ${ }^{-2}(\sim 9 \mathrm{dpa})$ and (d) BF image at $673 \mathrm{~K}$ after annealing. Note all images taken in underfocus condition of $-32(24 \mathrm{~nm})$. 
An interesting feature of this experiment was the notable degree of sputtering: Figure 51a shows a very sharp needle-like region in which the shape changed to a more rounded geometry (Figure 51c) as the fluence increased suggesting that the Xe ions were responsible for the removal of noticeable amounts of material from the sample. As reported before in the scientific literature, this sputtering might be due to the thermal spike from the individual impacts causing a localised melting so that flow processes driven by surface tension then changes the shape of the specimen.
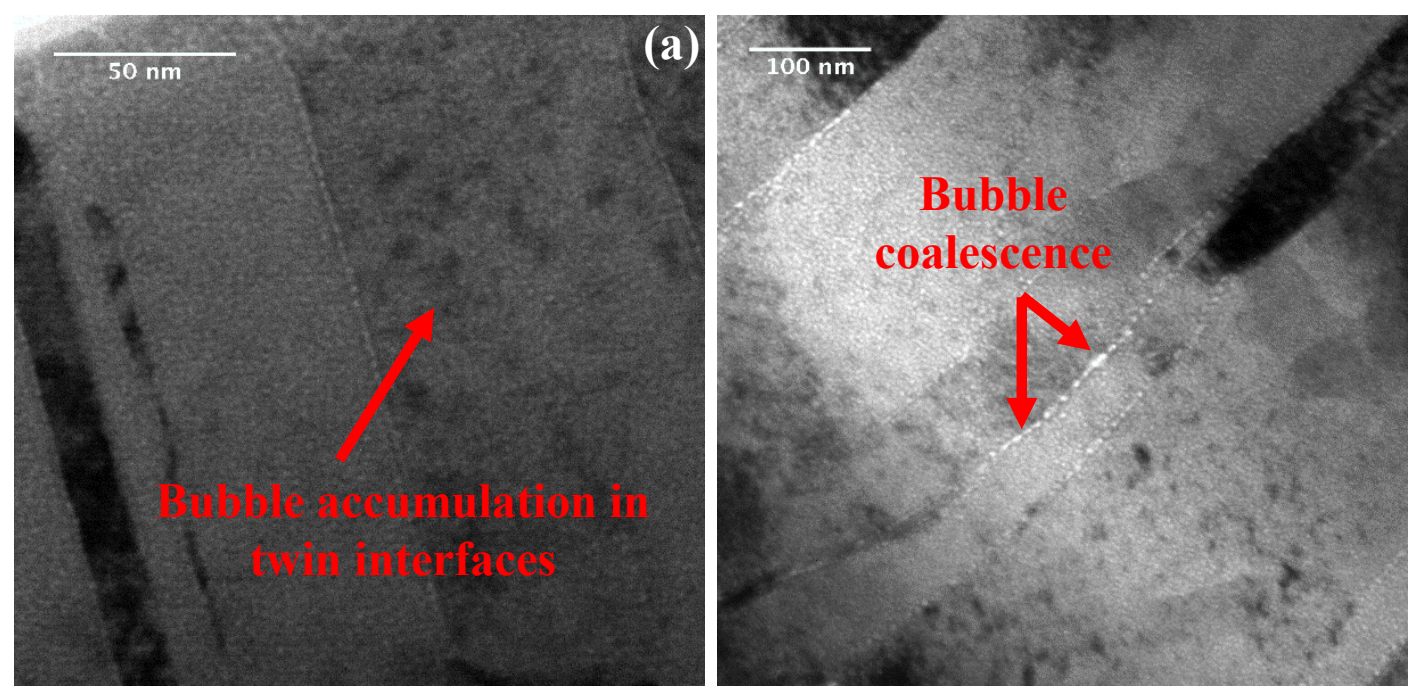

Figure 50. BFTEM images showing (a) massive bubble accumulation at $298 \mathrm{~K}$ and $6.4 \times 10^{16}$ ions.cm ${ }^{-2}$ of $6 \mathrm{keV}$ $\mathrm{He}+$ irradiation and (b) the final microstructure at $673 \mathrm{~K}$ with fluence of $1.3 \times 10^{17}$ ions.cm ${ }^{-2}$. 

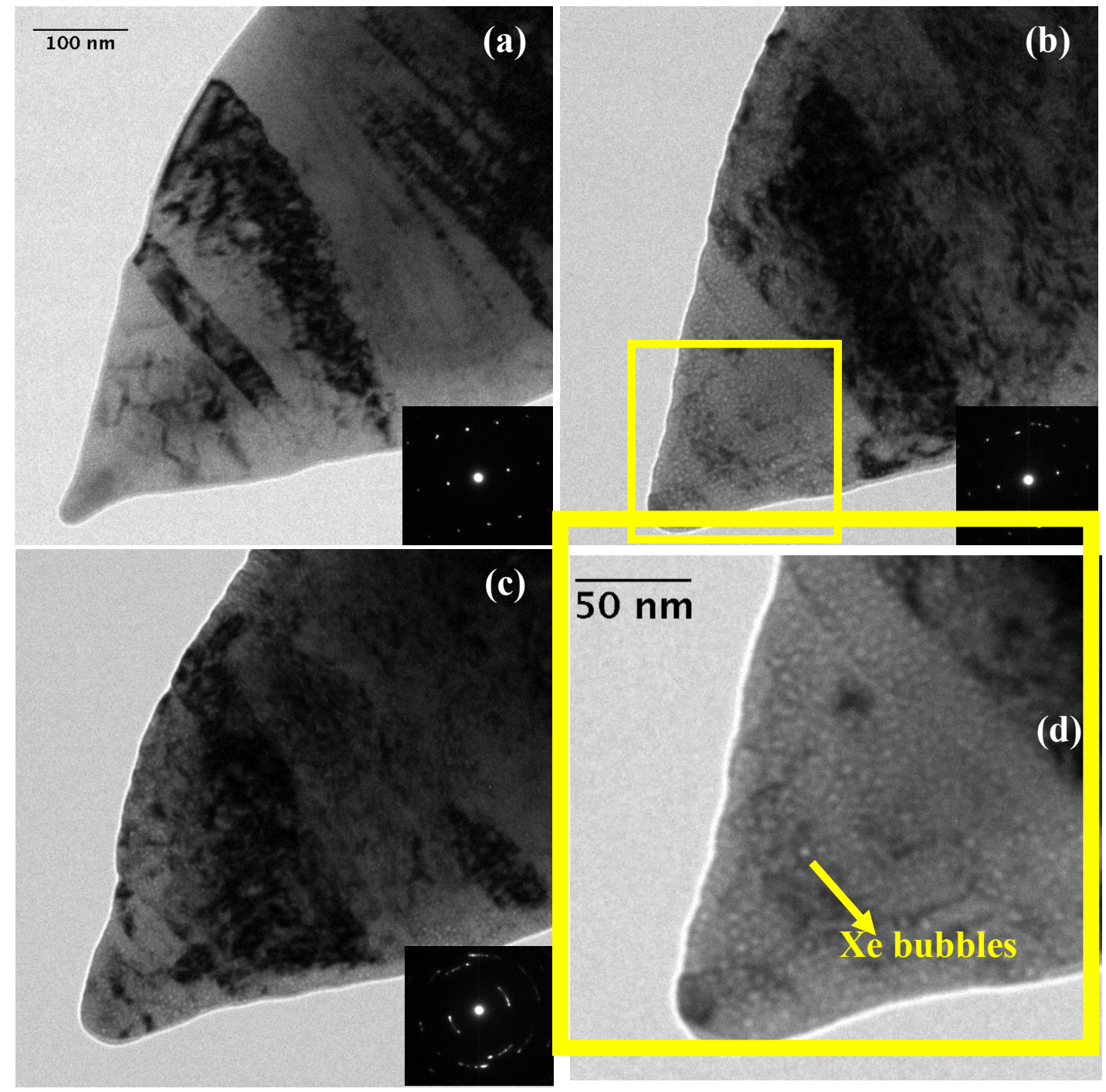

Figure 51. $30 \mathrm{keV} \mathrm{Xe}+$ in-situ TEM irradiation at $298 \mathrm{~K}$ of the FeCrMnNi HEA system showing (a) the unirradiated microstructure, (b) BFTEM image after $4.7 \times 10^{16}$ ions.cm ${ }^{-2}(\sim 32$ dpa) of irradiation and (c) BFTEM image after $9.3 \times 10^{16}$ ions.cm ${ }^{-2}(\sim 65 \mathrm{dpa})$. Figure (d) shows in detail Xe bubbles in the microstructure.

\section{FUTURE PLANS AND FURTHER WORK}

Some preliminary experiments have been performed in order to investigate the effects of low energy He (or higher energy Xe implantation) on the microstructure of the FeCrMnNi alloy at $298 \mathrm{~K}$. Bubble nucleation and coalescence were observed using $6 \mathrm{keV} \mathrm{He}^{+}$ions and changes in the microstructure were observed with $30 \mathrm{keV} \mathrm{Xe}^{+}$irradiation suggesting that the microstructural stability provided by the high entropy effect is sensitive to the energy and the mass of the ion. The observation of bubble accumulation in the twin interfaces may diminish the applicability of this alloy in the nuclear field as inert gas bubbles play key roles in embrittlement, swelling and degradation of mechanical properties in nuclear materials, but these phenomena should be studied further. For future work, new irradiations will be carried out at higher temperatures as well as comparative studies with similar non-high-entropy alloys-to better evaluate the influence of the high entropy effect upon irradiation. 


\title{
8. COMPUTATIONAL MATERIALS SCIENCE
}

\subsection{STRENGTHENING MECHANISMS IN IRRADIATED ALLOYS}

\author{
Yu.N. Osetskiy( osetskiyyn@ornl.gov)
}

\section{OBJECTIVE}

The purpose of this research is to understand atomic level strengthening mechanisms in materials with radiation induced microstructures such as voids, gas-filled bubbles, secondary phase precipitates and oxide particles. These microstructures serve as obstacles to dislocation motion and cause radiation induced hardening and embrittlement. Currently, we are investigating the map of mechanisms depending on the obstacle type and size. Understanding atomic scale features of strengthening mechanisms will improve both interpretation of experimental results and predictive capabilities of theoretical models for materials degradation under irradiation.

\section{SUMMARY}

Irradiation of structural alloys by neutrons and ions lead to formation of a high density of nanoscale objects such as secondary phase precipitates, voids and gas-filled bubbles. These objects are obstacles to dislocation motion and cause wanted or unwanted changes in mechanical properties. In order to predict materials behavior these obstacles must be characterized as well as their individual strength be estimated. The only technique that allows this at the scale of nanometers is classical molecular dynamics (MD). In this work we modeled vacancy voids, He-filled bubbles, $\mathrm{Cu}$ precipitates and rigid inclusions in a bcc-Fe matrix. At the current stage of the research we investigated $1 / 2<111>\{110\}$ edge dislocations. During its motion this dislocation cannot change its glide plane (cannot cross-slip) to avoid interaction with obstacles and therefore produces maximum effect on strengthening. The results obtained in this research will be used to improve theoretical prediction of mechanical properties changes.

\section{PROGRESS AND STATUS}

Strength of different obstacles. We now have finished modeling obstacles up to $8 \mathrm{~nm}$ in diameter. This type of modeling demands large modeling crystals, $>8 \times 10^{6}$ atoms and long physical time for dislocationobstacle interaction, up to a few ns. The results obtained for all studied obstacle are presented in Figure 52 as the critical resolved shear stress (CRSS) of different obstacles versus their size. The results obtained with obstacles up to $8 \mathrm{~nm}$ has demonstrated that according to the interaction mechanisms all obstacles can be divided in two groups. One group consists of only rigid inclusions that interact with dislocations by the classical Orowan interaction mechanism [1]. The other includes voids, bubbles and precipitates which can be cut by interacting dislocation.

The first group demonstrates much stronger strong size dependence of critical resolved shear stress (CRSS) versus obstacle size than the second one. Small rigid inclusions, $\leq 1 \mathrm{~nm}$, can be very weak obstacles comparable to soft precipitates. Larger rigid inclusions demonstrate maximum strength among all the studied obstacles

Small obstacles, $<4 \mathrm{~nm}$, of the second group, show individual mechanisms with different hardness. However, large obstacles, $\geq 4 \mathrm{~nm}$, are strong and have very similar interaction mechanism: before the obstacles are sheared the dislocation line shape adopts a long dipole of screw dislocations, and the mechanism is assumed to be the Orowan-type. However, as our modeling has demonstrated, the 
classical Orowan mechanism [1] i.e. with formation of a sheared dislocation loops around the obstacle is applicable only to rigid obstacles from the first group.

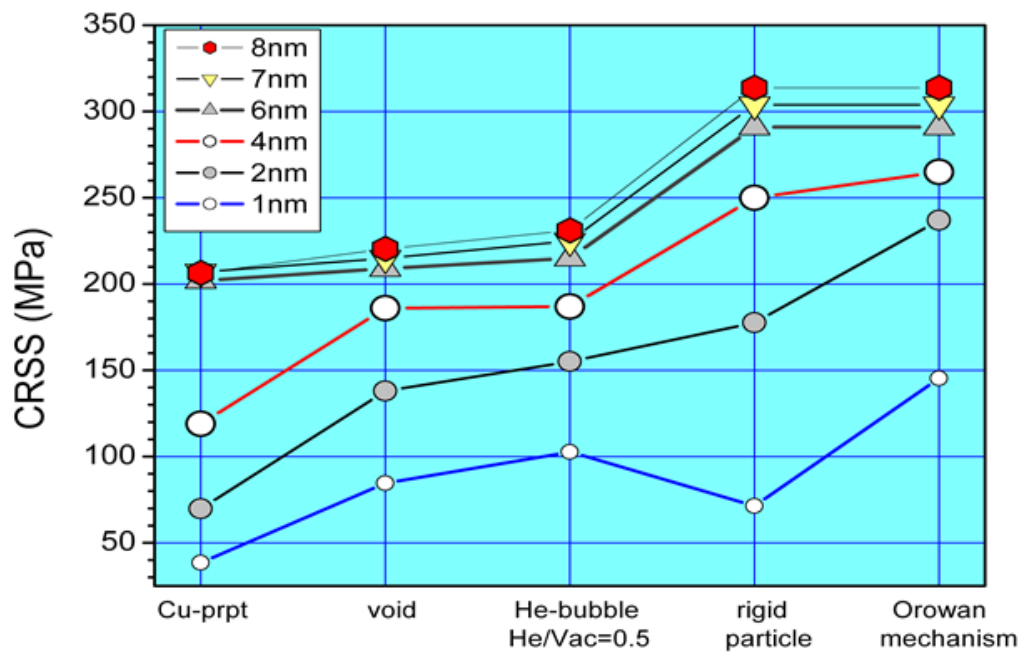

Figure 52. Critical resolved shear stress for different obstacles of different size obtained by molecular dynamics modeling at $300 \mathrm{~K}$.

Rigid obstacles are found to be the strongest. The dependence of their strength is also exceptionally strong within the range studied as can be seen in Figure 53 where the comparison of atomistic modeling of rigid obstacles from 1 to $8 \mathrm{~nm}$ in diameter at $300 \mathrm{~K}$ (circles) with theoretical estimation from [2,3] (lines) is presented.

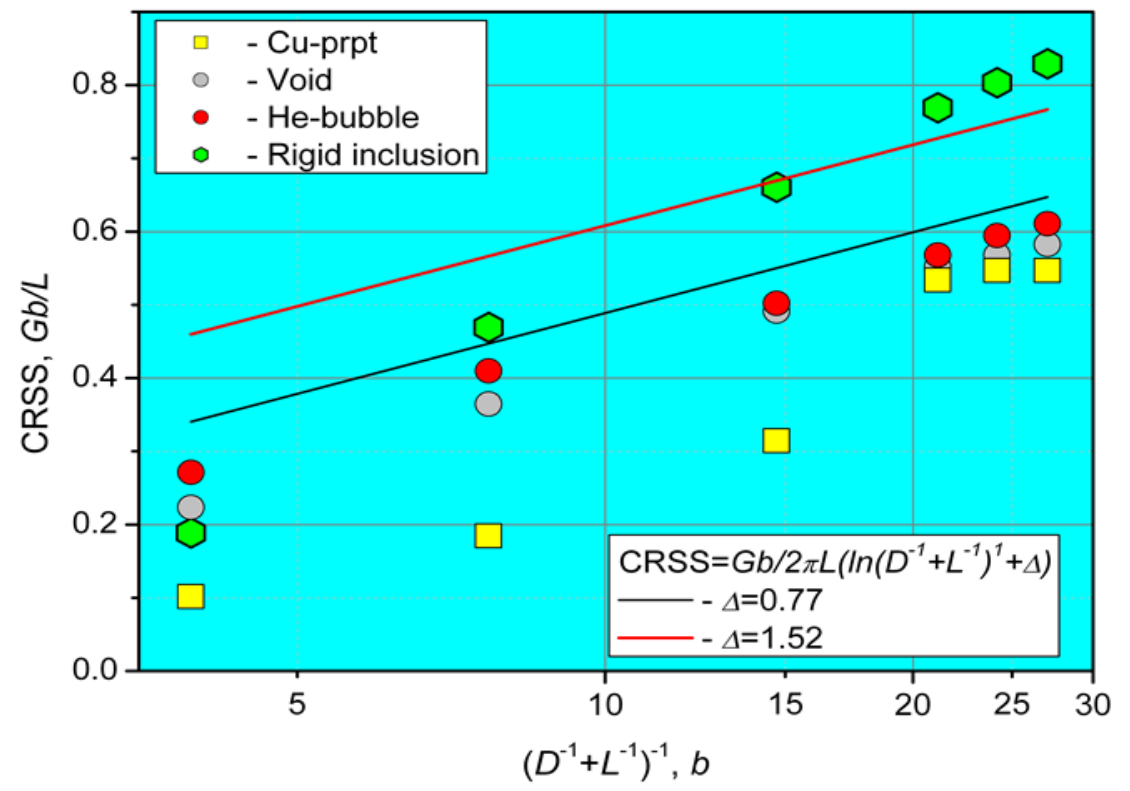

Figure 53. Critical resolved shear stress in reduced units as a function of harmonic mean of an obstacle diameter, $D$, and spacing between them along the dislocation line. Symbols present modeling results in current work, lines are dependences obtained in dislocation dynamic modeling for Orowan mechanism (black line) and void (red line) in [1,2]. 
Features of interaction mechanisms. As mentioned above all obstacles from the second group interact with gliding dislocation by cutting mechanisms. The dislocation line shape at the critical stress, i.e. just before the dislocation breaks away, depends on the obstacle size and for all large obstacles saturates at the screw dislocation dipole configuration. On the contrary, mechanisms of dislocation interaction with rigid inclusions depend on the inclusion size and interaction geometry, i.e. position of dislocation glide plane relatively to the obstacle equator.

Thus, very small inclusions, $\leq 1 \mathrm{~nm}$, are very weak obstacles and even edge dislocation can avoid a direct interaction at the atomic level. However, large inclusions are very strong. Their interaction with gliding dislocations produces new defects and such interaction involves high energy and stress. Some examples are presented in Figure 54 for the $6 \mathrm{~nm}$ inclusion and $300 \mathrm{~K}$ ambient temperature.

When the dislocation glide plane is close to the obstacle equator the interaction mechanism is the classical Orowan one as shown in Figure 54a. The Orowan shear loop is created when the screw dislocation dipole annihilates at the critical stress. Formation of the Orowan shear loop involves a lot of energy and therefore this mechanism demonstrates the maximum possible stress. The dislocation line is slightly modified by a small superjog as a few vacancies are created when the screw segments crossslipped before annihilation. A similar modification of the dislocation line was also observed for other obstacles.

If, however, the dislocation slip plane is far enough from the inclusion equator the interaction mechanism changes. At the critical stress, when the screw segments are of maximum length, they can cross-slip to surround the rigid inclusion and thus not produce the Orowan shear loop. Instead, the following dipole annihilation produces an edge dislocation loop with nature that depends on the cross-slip direction. Thus if the dislocation glide plane is close to the top of the inclusion the screw segments cross-slips up and an interstitial loop is left behind the inclusion and the corresponding superjog is created on the dislocation line. This case is shown in Figure 54b. If, however, the dislocation glide plane is close to the inclusion, the bottom screw segments cross-slip down and a vacancy type dislocation loop is left behind the inclusion with the corresponding modification of the dislocation line shape. This is the first time these mechanisms were observed directly in atomic scale modeling and thus confirm some mechanisms predicted earlier by Hirsch [4,5]. 

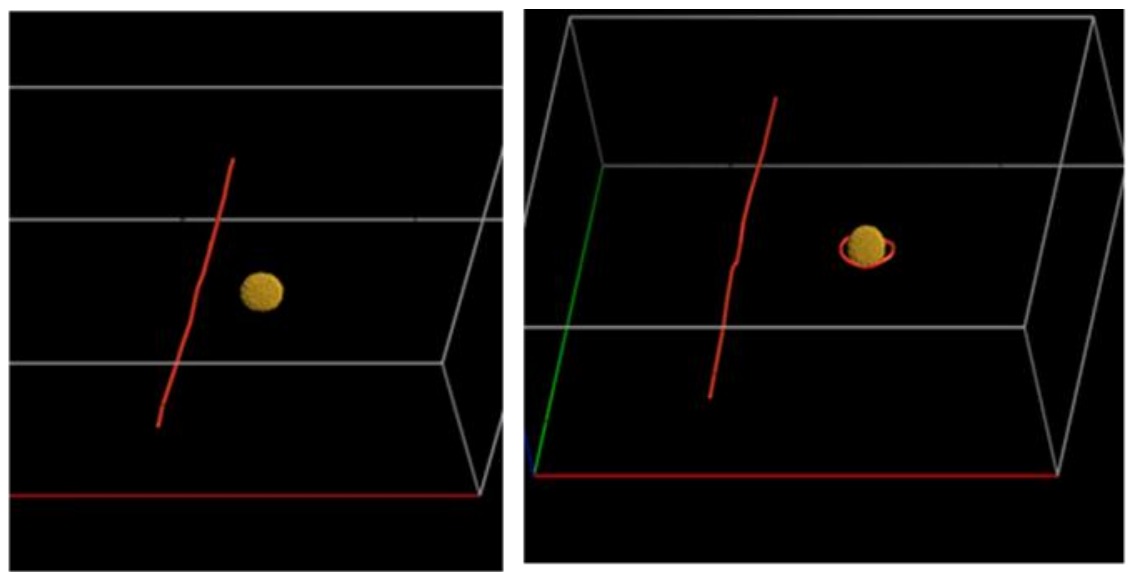

a
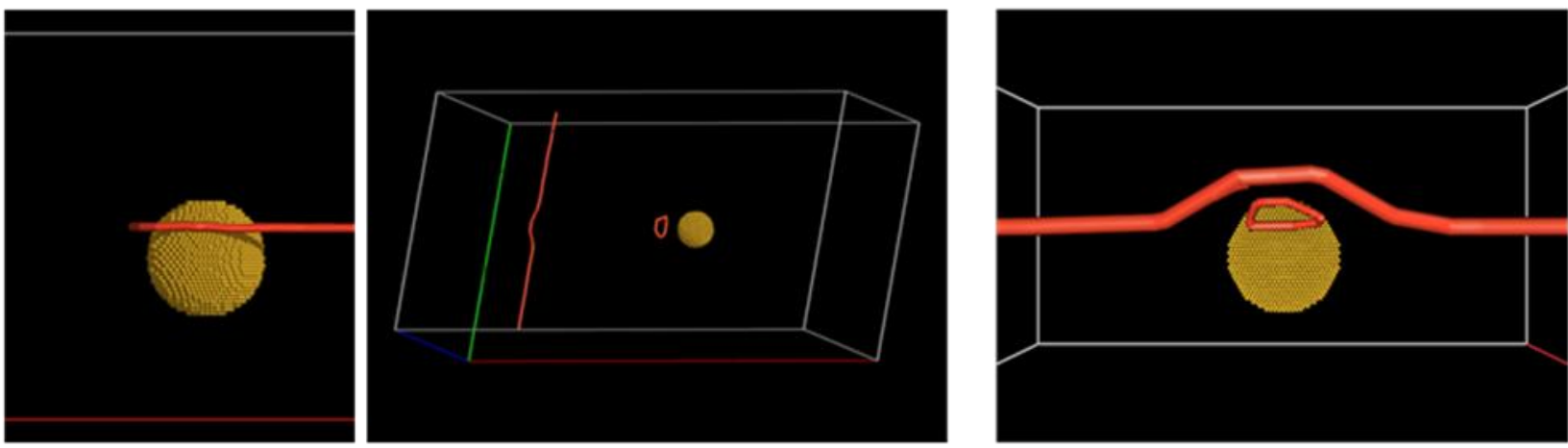

$b$

Figure 54. Examples of microstructures created in dislocation interactions with a rigid inclusion $6 \mathrm{~nm}$ in diameter: a) The dislocation slip plane intersects inclusion exactly along the equator. b) The dislocation slip plane is $1 / 2$ obstacle radius above the equator.

Predicting mechanical properties from elementary mechanisms. Our calculations provide parameters for the prediction of mechanical property changes due to irradiation. Within the current task we now are finalizing investigation of the interaction geometry effect for large obstacles. The main issue is if a simple usage of mean defect size is appropriate for strengthening estimation. We already have some evidences that interaction between an obstacle and a dislocation gliding above or below its equator can be strongly asymmetric for some obstacles. In this case a simple usage of the dispersed barrier hardening model [4] with a mean obstacle size can be inaccurate, especially for small obstacles. Also a combination of different obstacles in the materials microstructure requires knowledge of the strength of each obstacle type and our simulation provides the necessary information.

Strain rate and temperature effects. The ongoing activity includes investigation of temperature and stain rate effects in dislocation-obstacle interactions. This activity requires extended time for the low strain rate modeling. By now we have observed some strain rate effects for different obstacles. Preliminary results for room temperature were obtained. An example of interaction between a $1 / 2<111>\{110\}$ edge dislocation and a rigid precipitate $8 \mathrm{~nm}$ in diameter is shown in Figure 55 where the stress-strain curves are presented at different deformation rates of $10^{6} \mathrm{~s}^{-1}$ and $5 \times 10^{6} \mathrm{~s}^{-1}$. The maximum stress on both curves, that is the critical resolved shear stress (CRSS), is the same at $330 \pm 20 \mathrm{MPa}$ 
whereas the maximum strain is different. The slower deformation leads to higher plasticity. The analysis of deformation mechanisms as well as modeling of other temperatures and strain rates is in progress.

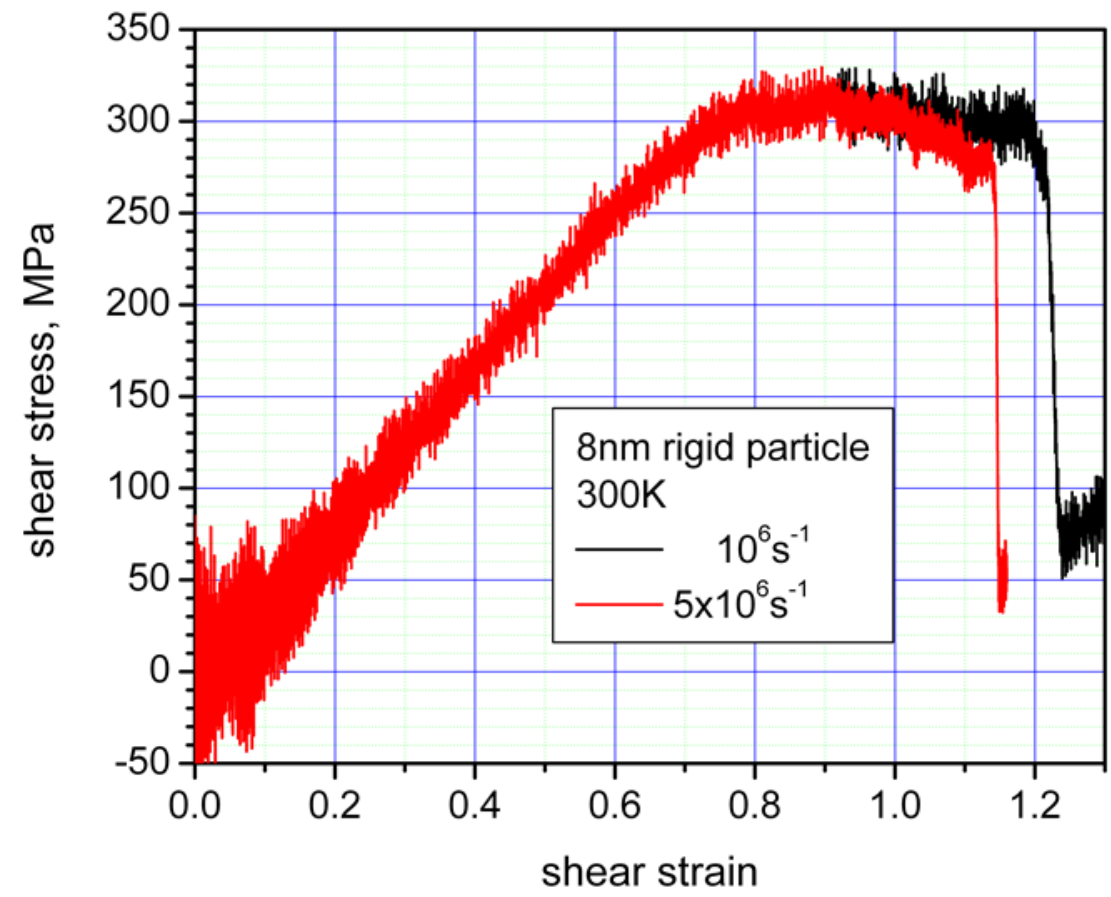

Figure 55. Stress-strain dependences obtain in dislocation interaction with rigid inclusion of $8 \mathbf{~ n m}$ in diameter at different strain rates.

\section{FUTURE STUDIES}

Future tasks within this continuing modeling effort will include:

1. Finalize modeling of edge dislocation interaction with He-filled bubbles up to $10 \mathrm{~nm}$ in diameter and different He-to-vacancy ratios.

2. Finalize modeling of temperature and strain rate effects.

3. Extend dislocation-obstacle interaction to $1 / 2<111>$ screw dislocations.

4. Modify the dispersed barrier hardening model by including dislocation obstacles interaction mechanisms revealed in atomic-scale modeling.

5. Extend the modeling program to dislocation-type obstacles such as dislocation loops. So far dislocation loops are treated in the same way as inclusions; however their interaction with dislocations is quite different and this must be taken into account

\section{REFERENCES;}

[1] Orowan E., A type of plastic deformation new in metals, Nature, 1942, vol.149, p.643.

[2] Bacon, D. J., Kocks, U. F. and Scattergood, R. O., 1973, Phil. Mag., 28, 1241.

[3] Scattergood, R. O., and Bacon, D. J., 1982, Acta metall., 30, 1665.

[4] Seeger A., Proc. 2nd UN Int. Conf. on Peaceful Uses of Atomic Energy (Geneva, Switzerland, September 1958), 1058, vol.6, p. 250.

[5] P. B. Hirsch, J. Inst. Metals 86, 7 (1957).

[6] F. J. Humphreys and P. B. Hirsch, Phil. Mag. 318, 73 (1970). 


\title{
8.2 PROPERTIES OF VACANCY-HELIUM-HYDROGEN COMPLEXES IN TUNGSTEN FROM FIRST PRINCIPLES
}

\author{
G.D.Samolyuk (samolyukgd@ornl.gov) and Y.N.Osetskiy
}

\section{OBJECTIVE}

The purpose of this research is to understand at the atomic level properties of defects created in tungsten by fusion irradiation conditions. W microstructure evolution depends strongly on kinetics of small complexes such as vacancies containing $\mathrm{H}$ and/or He atoms. Properties of such complexes including formation and binding energies and migration barriers are crucially important for understanding experimental results and predicting behavior of $\mathrm{W}$ alloys under irradiation. Accurate investigation of these properties is currently possible only by first principle modeling using density functional theory.

\section{SUMMARY}

We have studied the properties of vacancy clusters and their interaction with $\mathrm{H}$ and $\mathrm{He}$ in $\mathrm{W}$ using density functional theory (DFT). Convergence of calculation dependence on modeling cell size was investigated. It is demonstrated that vacancy cluster formation energy converges with small cells with size 6x6x6 (432 lattice sites) with enough accuracy to model a micro-void of size up to six vacancies. Most vacancy clusters containing less than six vacancies are unstable. Introducing $\mathrm{He}$ or $\mathrm{H}$ atoms increases their binding energy, potentially making gas-filled bubbles stable. The calculations show the $\mathrm{H}_{2}$ molecule is unstable in clusters containing six or fewer vacancies. This research is in collaboration with the Plasma Surface Interactions SciDAC project.

\section{PROGRESS AND STATUS}

Tungsten and its alloys are the primary candidate materials for plasma facing components in fusion reactors where they are exposed to high-energy neutrons and high flux of helium and hydrogen atoms [1]. During a plasma pulse hydrogen isotopes, deuterium and tritium, and helium ions will be implanted into tungsten and due to their high mobility diffuse through the bulk tungsten. Some will produce clusters with radiation induced defects, mainly of vacancy-type. The typical radiation damage observed in $\mathrm{W}$ after $\mathrm{H}$ and $\mathrm{He}$ ion implantation includes surface modification [2,3] (direct or due to blistering), and formation of craters, clusters and gas-filled bubbles [4-6]. Diffusion of $\mathrm{H}$ and $\mathrm{He}$ in tungsten, their interaction with radiation induced defects and nucleation and growth of gas bubbles are not fully understood. These processes affect the tungsten material properties and therefore attract attention in experimental, theoretical and modeling approaches. The main aim of atomic-scale modeling is to understand elementary properties and nucleation mechanisms of small clusters of $\mathrm{He}$ and $\mathrm{H}$ with radiation defects and their parameterization for use in higher level theoretical predictive modeling. A recent study [7] provides a detailed review of first principles based studies and results. Our current investigation is focused on obtaining density functional theory (DFT) based binding energies of $\mathrm{H}$ and $\mathrm{He}$ atoms with small vacancy clusters. Special attention is paid to the accuracy of calculated energies and convergence of the results with respect to the size of the modeling cell. To the author's best knowledge, the systematic investigation of small vacancy cluster (3-5 vacancies) formation and binding energies as well as binding energies of helium atoms with different types of di-vacancies has not been published previously. 


\section{DETAILS OF CALCULATIONS}

All calculations used the Vienna ab initio Simulation Package (VASP). The Brillouin zone (BZ) summations were carried out over a $4 \times 4 \times 4$ BZ grid for a modeling cell containing 6x6x6 cubic unit cells (432 atoms) and the grid was increased to keep the same k-point density in smaller modeling cells. The plane wave energy cut-off was $360 \mathrm{eV}$. These values of k-point mesh and energy cut-off are enough to reach convergence of the vacancy formation energy $\left(\mathrm{E}_{\mathrm{v}}\right)$ within $1 \%$. Simulation cells containing from 16 to 432 atoms were used to investigate the convergence of vacancy cluster binding energies. The atomic structure was optimized until the forces on all atoms dropped below $10^{-5} \mathrm{eV}$ per atom.

\section{RESULTS AND DISCUSSION}

Pressure effects and formation energy of a single vacancy as a function of modeling cell size are presented in Figure 56. The results were obtained using constant volumes of perfect W.

The formation energy, $3.16 \mathrm{eV}$, converged for the $4 \times 4 \times 4$ modeling cell containing 128 atoms. However, to keep the pressure in the system close to zero a minimum size $5 \times 5 \times 5$ modeling cell $(250$ atoms) is necessary. Another way to preserve zero pressure in the modeling cell is to change the lattice parameter. In this case the energies of the system with defects and without defects are calculated with different lattice parameters that can lead to uncontrolled errors. For this reason the authors believe that modeling of defects in tungsten should be executed in modeling cells $5 \times 5 \times 5$ or larger. A comparison with previous results is presented in Table 12 .
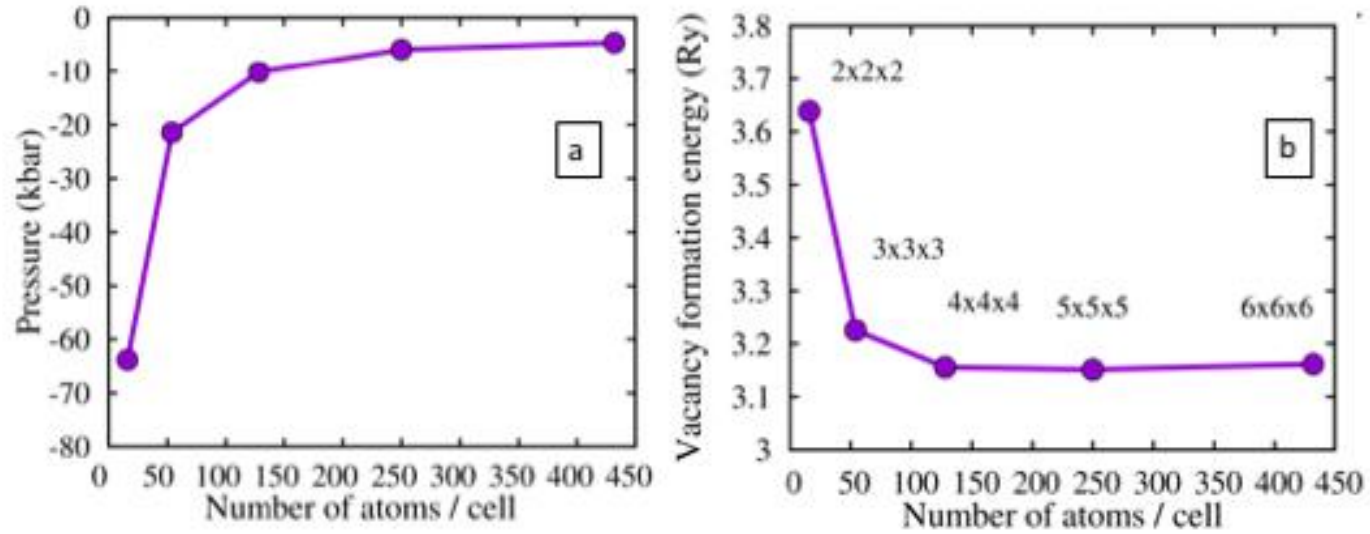

Figure 56. The total pressure (a) and vacancy formation energy (b) as a function of modeling cell size. The constant lattice parameter was used. The notation $\mathrm{NxNxN}_{\mathrm{N}}$ corresponds to the size of the modeling cell, where $\mathbf{N}$ is the number of repetitions of the original cubic cell.

Table 12. Single vacancy formation energy, in $\mathrm{eV}$, presented as a function of modeling cell size, $\mathrm{N}_{\mathrm{at}}$, together with previous results

\begin{tabular}{|c|c|c|c|c|}
\hline $\mathrm{N}_{\text {at }}$ & Current & {$[8]$} & {$[10]$} & {$[9]$} \\
\hline 54 & 3.23 & 3.23 & & \\
\hline 128 & 3.16 & & 3.56 & 3.17 \\
\hline 250 & 3.15 & & & \\
\hline 432 & 3.16 & & & \\
\hline
\end{tabular}


The results obtained are in good agreement with published DFT calculations [8,9] except for the formation energy obtained in [10]. Those authors obtained $3.58 \mathrm{eV}$ in a cell containing 250 atoms, which is inconsistent with all published DFT results. The possible reason for this disperancy is that all calculations in [10] were performed using a DFT approach implemented in the package of linear combination of atomic type orbitals, which has limited applicability in the case of metals.

The octahedral (OCT) and tetrahedral (TET) positions are the most stable configurations of $\mathrm{H}$ and He interstitial atoms in bcc tungsten. The ground state is the tetrahedral position. The difference between the interstitial formation energy in TET and OCT positions, obtained in the 432 atom modeling cell, is -0.37 and $-0.25 \mathrm{eV}$ for $\mathrm{H}$ and $\mathrm{He}$, respectively. These energy differences are in agreement with results obtained in [12]. Such a weak dependence on the modeling cell size is attributed to the small size of the $\mathrm{H}$ and $\mathrm{He}$ interstitial atoms. Although the vacancy formation energy converged in a modeling cell of 128 atoms (see Figure 56), at least 432 atoms are needed to maintain "zero" total pressure. Therefore inserting a He atom into one of the vacancies should lead to an increase of the binding energy for di-vacancies and larger vacancy clusters. The binding energy of one He atom with a vacancy is $4.64 \mathrm{eV}$, in agreement with previous results obtained in 128 atoms modeling cell [11]. In the presence of a vacancy, the hydrogen atom occupies a distorted OCT position. The calculated binding energy, which corresponds to the reaction $\mathrm{H}+\mathrm{V} \rightarrow \mathrm{HV}$, is equal to $1.2 \mathrm{eV}$. This value has a weak dependence on the modeling cell size and values obtained for a cell with 128 atoms are in agreement with the published results: $1.2 \mathrm{eV}$ in [11] and $1.28 \mathrm{eV}$ in [12]. Our results for the smaller modeling cells are also in agreement with published data: 54 atoms in [8] and 128 atoms in [9] for two vacancies placed in the nearest, $2 \mathrm{~V}(\mathrm{nn})$, and next nearest, $2 \mathrm{~V}(\mathrm{nnn})$, neighbor positions. The interaction in these cases is weakly repulsive (see [14] for details). The corresponding binding energies calculated here in the 432 atom modeling cell are -0.11 and $-0.46 \mathrm{eV}$, respectively, and are slightly below the values obtained in the smaller size cells (see Table 13). The interaction between vacancies in third nearest $(2 \mathrm{~V}(3)$ configuration) neighbor position is attractive with a binding energy equal to $0.05 \mathrm{eV}$. The attraction of vacancies in the $2 \mathrm{~V}(3)$ di-vacancy agrees with recent results in [9].

Table 13. Di-vacancy binding energy, in $\mathrm{eV}$, presented as a function of modeling cell size, $\mathbf{N}_{\mathrm{at}}$, together with existing results. For notations see text.

\begin{tabular}{|c|c|c|c|c|c|}
\hline Cell size, $\mathrm{N}_{\mathrm{at}}$ & 432 & 128 & 54 & $128[10]$ & $128[9]$ \\
\hline $2 \mathrm{~V}(\mathrm{nn})$ & -0.11 & -0.16 & -0.03 & 0.41 & -0.16 \\
\hline $2 \mathrm{~V}(\mathrm{nnn})$ & -0.46 & -0.48 & -0.47 & 0.19 & -0.47 \\
\hline $2 \mathrm{~V}(3)$ & 0.05 & & & & 0.13 \\
\hline
\end{tabular}

As for the single vacancy, a hydrogen atom added to a di-vacancy (2V) cluster occupies a distorted OCT position next to one of the vacancies. The presence of $\mathrm{H}$ makes 2-V stable with a binding energy of 1.33 and $1.38 \mathrm{eV}$ for the $2 \mathrm{~V}(\mathrm{nn})$ and $2 \mathrm{~V}(\mathrm{nnn})$, respectively (see Table 14). These energies correspond to decay of the $2 \mathrm{~V}+\mathrm{H}$ complex into two separate vacancies and one $\mathrm{H}$ atom $(2 \mathrm{~V}+\mathrm{H} \rightarrow 1 \mathrm{~V}+1 \mathrm{~V}+\mathrm{H}(\mathrm{TET}))$. This result is in reasonable agreement with previously obtained values in the smaller modeling cell containing 128 atoms [11]. The energy needed to separate a $\mathrm{H}$ atom from $2-\mathrm{V}: 2 \mathrm{~V}+\mathrm{H} \rightarrow 2 \mathrm{~V}+\mathrm{H}(\mathrm{TET})$, is even larger, 1.44 and $1.84 \mathrm{eV}$ for $2 \mathrm{~V}(\mathrm{nn})$ and $2 \mathrm{~V}(\mathrm{nnn})$, respectively. However, much less energy is needed to separate the cluster into one isolated vacancy and one vacancy with a hydrogen atom. This energy is equal to 0.12 and $0.17 \mathrm{eV}$ for $2 \mathrm{~V}(\mathrm{nn})$ and $2 \mathrm{~V}(\mathrm{nnn})$, respectively. In the presence of a He atom, both the $2 \mathrm{~V}(\mathrm{nn})$ and $2 \mathrm{~V}(\mathrm{nnn})$ di-vacancy binding energies become positive and equal to $\sim 4.5 \mathrm{eV}$ for both reaction $2 \mathrm{~V}+\mathrm{He} \rightarrow$ $1 \mathrm{~V}+1 \mathrm{~V}+\mathrm{He}$ (bulk) and $2 \mathrm{~V}+\mathrm{He} \rightarrow 2 \mathrm{~V}+\mathrm{He}$ (bulk). Similar to the case of hydrogen, the $2 \mathrm{~V}+\mathrm{He}$ cluster is 
weakly stable with respect to decay to one vacancy with helium and one isolated vacancy $(2 \mathrm{~V}+\mathrm{He} \rightarrow$ $(1 \mathrm{~V}+\mathrm{He})+1 \mathrm{~V})$ for $2 \mathrm{~V}(\mathrm{nn})$ and unstable for $2 \mathrm{~V}(\mathrm{nnn})$ di-vacancies.

Most small vacancy clusters studied were found to be unstable in pure tungsten. Following [13], we modeled the three possible configurations of $3 \mathrm{~V}$, four configurations of $4 \mathrm{~V}$ and one configuration of $5 \mathrm{~V}$ and $6 \mathrm{~V}$ clusters [14]. The binding energies are summarized in Table 15 . Only two (4V and 6V) have positive binding energy whereas all other configurations are unstable. A large energy, $2.94 \mathrm{eV}$, corresponds to the decay of $6 \mathrm{~V}(1)+\mathrm{H}$ into six separate vacancies and $\mathrm{H}$ atom (Table 16). The molecule $\mathrm{H}_{2}$ is unstable even in a $6 \mathrm{~V}$ cluster: the $\mathrm{H}_{2}$ molecule, initially placed in the center, during relaxation dissociates into $\mathrm{H}$ atoms and the highest binding energy, $1.9 \mathrm{eV}$, corresponds to the maximum separation distance. As shown in Table 16, He atoms have a positive binding energy with a $6 \mathrm{~V}$ cluster.

Table 14. Di-vacancy binding energy in presence of $\mathrm{H}$ or $\mathrm{He}$ atom, in $\mathrm{eV}$, presented as a function of modeling cell size, $\mathbf{N}_{\mathrm{a}}$, together with existing results. For notations see text. The second column specifies the decay of $2 \mathrm{~V} / \mathrm{H}$ of $2 \mathrm{~V} / \mathrm{He}$ clusters.

\begin{tabular}{|c|c|c|c|c|}
\hline $\mathrm{N}_{\mathrm{at}}$ & Cluster decay reaction & 432 & 128 & 128 [9] \\
\hline \multicolumn{5}{|c|}{$\mathrm{H}$} \\
\hline \multirow{3}{*}{$2 \mathrm{~V}(\mathrm{nn})$} & $2 \mathrm{~V}+\mathrm{H} \rightarrow(1 \mathrm{~V}+\mathrm{H})+(1 \mathrm{~V})$ & 0.12 & & \\
\hline & $2 \mathrm{~V}+\mathrm{H} \rightarrow 1 \mathrm{~V}+1 \mathrm{~V}+\mathrm{H}(\mathrm{TET})$ & 1.33 & 1.30 & 1.80 \\
\hline & $2 \mathrm{~V}+\mathrm{H} \rightarrow 2 \mathrm{~V}+\mathrm{H}(\mathrm{TET})$ & 1.44 & & \\
\hline \multirow{3}{*}{$2 \mathrm{~V}(\mathrm{nnn})$} & $2 \mathrm{~V}+\mathrm{H} \rightarrow(1 \mathrm{~V}+\mathrm{H})+(1 \mathrm{~V})$ & 0.17 & & \\
\hline & $2 \mathrm{~V}+\mathrm{H} \rightarrow 1 \mathrm{~V}+1 \mathrm{~V}+\mathrm{H}(\mathrm{TET})$ & 1.38 & 1.38 & 2.15 \\
\hline & $2 \mathrm{~V}+\mathrm{H} \rightarrow 2 \mathrm{~V}+\mathrm{H}(\mathrm{TET})$ & 1.84 & & \\
\hline \multicolumn{5}{|c|}{$\mathrm{He}$} \\
\hline \multirow{3}{*}{$2 \mathrm{~V}(\mathrm{nn})$} & $2 \mathrm{~V}+\mathrm{He} \rightarrow(1 \mathrm{~V}+\mathrm{He})+(1 \mathrm{~V})$ & 0.002 & & \\
\hline & $2 \mathrm{~V}+\mathrm{He} \rightarrow 1 \mathrm{~V}+1 \mathrm{~V}+\mathrm{He}(\mathrm{TET})$ & 4.65 & & \\
\hline & $2 \mathrm{~V}+\mathrm{He} \rightarrow 2 \mathrm{~V}+\mathrm{He}(\mathrm{TET})$ & 4.75 & & \\
\hline \multirow{3}{*}{$2 \mathrm{~V}(\mathrm{nnn})$} & $2 \mathrm{~V}+\mathrm{He} \rightarrow(1 \mathrm{~V}+\mathrm{He})+(1 \mathrm{~V})$ & -0.37 & & \\
\hline & $2 \mathrm{~V}+\mathrm{He} \rightarrow 1 \mathrm{~V}+1 \mathrm{~V}+\mathrm{He}(\mathrm{TET})$ & 4.28 & & \\
\hline & $2 \mathrm{~V}+\mathrm{He} \rightarrow 2 \mathrm{~V}+\mathrm{He}(\mathrm{TET})$ & 4.74 & & \\
\hline
\end{tabular}

\section{CONCLUSIONS}

$>$ Single vacancy formation energy and lattice pressure converge in a 5x5x5 (250 atoms) modeling cell. This size is large enough to produce accurate interaction and formation energies for $\mathrm{H}$ and $\mathrm{He}$.

$>\mathrm{H}$ and $\mathrm{He}$ atoms are strongly attracted to a vacancy and a substitutional $\mathrm{H}$ atom occupies a distorted octahedron position. 
Two vacancies are unstable at nn and nnn positions and weakly stable at the third neighbor position.

Adding $\mathrm{H}$ or $\mathrm{He}$ atoms stabilizes di-vacancies.

Compact three-dimensional 4-V and 6-V clusters are stable.

$>\mathrm{H}$ and $\mathrm{He}$ atoms are strongly attracted to a six-vacancy cluster.

$>\mathrm{H}$ occupies distorted octahedral positions at the edge of a 6-V cluster but will not occupy the center.

The $\mathrm{H}_{2}$ molecule is unstable in 6-V cluster and dissociates into two $\mathrm{H}$ atoms separated by $2.7 \mathrm{~A}$.

Table 15. Small vacancy cluster formation and binding energies. For notations see text. The modeling cell contains $4 \times 4 \times 4$ primitive cubic cells ( 250 atoms).

\begin{tabular}{|c|c|c|}
\hline Cluster & Formation (eV) & Binding (eV) \\
\hline $1 \mathrm{~V}$ & 3.15 & -0.11 \\
\hline $2 \mathrm{~V}(\mathrm{nn})$ & 6.43 & -0.46 \\
\hline $2 \mathrm{~V}(\mathrm{nnn})$ & 6.78 & 0.05 \\
\hline $2 \mathrm{~V}(3)$ & 6.28 & -0.38 \\
\hline $3 \mathrm{~V}(1)$ & 9.83 & -0.81 \\
\hline $3 \mathrm{~V}(2)$ & 10.27 & -0.17 \\
\hline $3 \mathrm{~V}(3)$ & 9.62 & -0.68 \\
\hline $4 \mathrm{~V}(1)$ & 13.28 & -1.12 \\
\hline $4 \mathrm{~V}(2)$ & 13.72 & -0.24 \\
\hline $4 \mathrm{~V}(3)$ & 12.85 & 0.42 \\
\hline $4 \mathrm{~V}(4)$ & 12.18 & -0.02 \\
\hline $5 \mathrm{~V}(1)$ & 15.78 & 1.98 \\
\hline $6 \mathrm{~V}(1)$ & 16.93 & \\
\hline
\end{tabular}


Table 16. Binding energy of 6-V cluster with $\mathrm{H}$ or $\mathrm{He}$ atom. For notations see text. The second column specifies the decay reaction. Modeling cell contains 250 sites ( $5 \times 5 \times 5$ unit cells).

\begin{tabular}{|c|c|c|}
\hline Cluster & Cluster decay reaction & Binding energy $(\mathrm{eV})$ \\
\hline $6 \mathrm{~V}$ & $6 \mathrm{~V} \rightarrow 6(1 \mathrm{~V})$ & 1.98 \\
\hline \multirow{2}{*}{$6 \mathrm{~V}+\mathrm{H}, \quad(\mathrm{H}$ in the center of cluster $)$} & $6 \mathrm{~V}+\mathrm{H} \rightarrow(6 \mathrm{~V})+\mathrm{H}(\mathrm{TET})$ & -1.02 \\
\hline & $6 \mathrm{~V}+\mathrm{H} \rightarrow 6(1 \mathrm{~V})+\mathrm{H}(\mathrm{TET})$ & 0.96 \\
\hline \multirow{2}{*}{$6 \mathrm{~V}+\mathrm{H},(\mathrm{H}$ in distorted OCT position $)$} & $6 \mathrm{~V}+\mathrm{H} \rightarrow(6 \mathrm{~V})+\mathrm{H}(\mathrm{TET})$ & 0.96 \\
\hline & $6 \mathrm{~V}+\mathrm{H} \rightarrow 6(1 \mathrm{~V})+\mathrm{H}(\mathrm{TET})$ & 2.94 \\
\hline \multirow{2}{*}{$6 \mathrm{~V}+\mathrm{He}$} & $6 \mathrm{~V}+\mathrm{He} \rightarrow(6 \mathrm{~V})+\mathrm{He}(\mathrm{TET})$ & 5.8 \\
\hline & $6 \mathrm{~V}+\mathrm{He} \rightarrow 6(1 \mathrm{~V})+\mathrm{He}(\mathrm{TET})$ & 7.78 \\
\hline $6 \mathrm{~V}+2 \mathrm{H},(\mathrm{H}$ in $\mathrm{TET}$ position $)$ & $6 \mathrm{~V}+2 \mathrm{H} \rightarrow(6 \mathrm{~V})+2 \mathrm{H}(\mathrm{TET})$ & 1.16 \\
\hline $6 \mathrm{~V}+2 \mathrm{H},(\mathrm{H}$ in distorted OCT position $)$ & $6 \mathrm{~V}+2 \mathrm{H} \rightarrow(6 \mathrm{~V})+2 \mathrm{H}(\mathrm{TET})$ & 1.9 \\
\hline $6 \mathrm{~V}+2 \mathrm{He}$ & $6 \mathrm{~V}+2 \mathrm{He} \rightarrow(6 \mathrm{~V})+2 \mathrm{He}(\mathrm{TET})$ & 11.27 \\
\hline
\end{tabular}

\section{FUTURE STUDIES}

1. Increase model size to study larger number of vacancies and $\mathrm{He}, \mathrm{H}$ atoms.

2. Complete the matrix of biding energies for $\mathrm{nVAC}-\mathrm{mHe}-\mathrm{kH}(\mathrm{n}, \mathrm{m}$, and $\mathrm{k}$ are number of vacancies, $\mathrm{He}$-atoms and $\mathrm{H}$-atoms correspondingly) to be used in cluster dynamics calculations.

3. Consider using a Bond Order Potential (BOP) approach to model W-based alloys.

\section{REFERENCES}

[1] S.T. Picraux, F.L. Vook, "Ion beam studies of H and He in metals," J. Nucl. Mater., 53, 246 (1974).

[2] H. Trinkaus and B.N. Singh, "Helium accumulation in metals during irradiation - where do we stand?” J. Nucl. Mater., 323, 229 (2003).

[3] Y. Dai, G.R. Odette, AND T. Yamamoto, "The effects of helium in irradiated structural alloys," Compr. Nucl. Mater., 1, 141 (2012).

[4] H.T. Lee, A.A. Haasz, J.W. Davis, R.G. Macaulay-Newcombe, D.G. Whyte, G.M. Wright," Hydrogen and helium trapping in tungsten under simultaneous irradiations," J. Nucl. Mater., 363-365, 898 (2007).

[5] O.V. Ogorodnikova, J. Roth, M. Mayer," Pre-implantation and pre-annealing effects on deuterium retention in tungsten," J. Nucl. Mater., 373, 254 (2008).

[6] M.Y. Ye, H. Kanehara, S. Fukuta, N. Ohno, S. Takamura, "Blister formation on tungsten surface under low energy and high flux hydrogen plasma irradiation in NAGDIS-I," J. Nucl. Mater., 313-316, 72 (2003).

[7] G.-H. Lu, H.-B. Zhou and C.S. Becquart, "A review of modeling and simulation of hydrogen behaviour in tungsten at different scales," Nucl. Fusion, 54, 86001 (2014).

[8] L. Ventelon, F. Willaime, C. -C. Fu, M. Heran, I. Ginoux, "Ab initio investigation of radiation defects in tungsten: Structure of self-interstitials and specificity of di-vacancies compared to other bcc transition metals," J. Nucl. Mat., 425, 16 (2012). 
[9] D. Kato, H. Iwakiri, K. Morishita, "Formation of vacancy clusters in tungsten crystals under hydrogen-rich condition," J. Nucl. Mat., 417, 1115 (2011).

[10] P. M. Derlet, D. Nguyen-Manh, and S. L. Dudarev, "Multiscale modeling of crowdion and vacancy defects in body-centered-cubic transition metals," Phys. Rev. B, 76, 54107 (2007).

[11] C. S. Becquart and C. Domain, "A density functional theory assessment of the clustering behavior of He and H in tungsten," J. of Nucl. Mat., 386-388, 109 (2009).

[12] K. Heinola, T. Ahlgren, K. Nordlund, and J. Keinonen, "Hydrogen interaction with point defects in tungsten," Phys. Rev. B, 82, 094102 (2010).

[13] K. Masuda, "Vacancies and small vacancy clusters in BCC transition metals," J. Physique, 43, 921 (1982).

[14] G.D. Samolyuk, Y.N. Osetsky and R.E. Stoller "Properties of Vacancy Complexes with Hydrogen and Helium Atoms in Tungsten from First Principles", Fusion Science and Technology., 2016, accepted. 


\section{INTERNATIONAL COLLABORATIONS}

\subsection{US-JAPAN COLLABORATIONS ON STRUCTURAL MATERIALS}

H. Sakasegawa (sakasegawah@ornl.gov), H. Tanigawa, T. Hirose, M. Ando, T. Nozawa, D. Hamaguchi (National Institutes for Quantum and Radiological Science and Technology, Japan), Y. Katoh, T. Koyanagi, and J.W. Geringer (Oak Ridge National Laboratory)

\section{OBJECTIVE}

This collaboration between the Department of Energy (DOE) and the National Institutes for Quantum and Radiological Science and Technology (QST, reorganized and transferred from Japan Atomic Energy Agency in April 2016) jointly pursues activities using the advanced capabilities for materials irradiation and post-irradiated examination at Oak Ridge National Laboratory, especially the High Flux Isotope Reactor (HFIR). The focus is on ferritic steels and other advanced materials, especially the development of the material database for the design of facilities beyond ITER. The goals include achieving DEMOrelevant performance data on structural materials neutron irradiated in HFIR to high levels of displacement damage (>30 dpa).

\section{SUMMARY}

The DOE-QST collaboration continues to make steady progress in building the materials data bases for the reduced activation ferritic martensitic (RAFM) F-82H steel and $\mathrm{SiC} / \mathrm{SiC}$ composites. Material properties of heavily irradiated, up to $87 \mathrm{dpa}$, were obtained and these results contribute to the materials data base for the blanket structural design of a fusion DEMO reactor. In addition, a new irradiation capsule (RB 19J) started to focus on the irradiation effects at low doses and low temperatures for the test blanket module of ITER.

\section{PROGRESS AND STATUS}

This DOE-QST (including DOE-JAEA) Project is the US-Japan long-running collaboration now in its 33rd year. The objective of this project is to perform irradiation and post-irradiation examination (PIE) of first wall and blanket structural materials for fusion reactors. Irradiation experiments for exposures up to 20 dpa were started for the RAFM steels and several BCC alloys in the HFIR Phase 3 program (19952000). In the Phase 4-5 programs of 2000-2009, three main tasks were conducted with goals: (1) To improve the irradiation resistance of RAFM, especially the fracture toughness, (2) To obtain data for high-dose irradiated RAFM and oxide dispersion strengthened steels, up to $80 \mathrm{dpa}$, and (3) To examine the effects of helium on mechanical properties and microstructures using boron and/or nickel-doped RAFM and/or Ni/Al coating techniques. Four HFIR target zone capsules (JP26, 27, 28 and 29), one RB capsule (RB15J) and several rabbit capsules were irradiated in these Phases. Irradiation of the high-dose JP28 and 29 capsules was completed in 2013. In the Phase 6 (2009-2014) program two additional target capsules (JP30 and 31) were irradiated to evaluate irradiation effects on joined sections of RAFM (TIG weldments, EB weldments and HIP joints). Several rabbit capsules (containing RAFM and SiC/SiC composites) were also irradiated to high doses and the target dose of F13A6 and F13B5 capsules was increased to $50 \mathrm{dpa}$. A new irradiation capsule for the reflector region of HFIR (RB 19J) started irradiation. It contains F-82H specimens for various tensile and toughness tests and the results are expected by 2019. The main objective of RB 19J is to create a database for ITER-TBM by obtaining material property data at low doses and low temperatures. 
For RAFM steel, Figure 57 shows the most representative results for F-82H. The materials were F82HIEA (Fe-8Cr-2W-0.2V-0.04Ta-0.1C), F82H-MOD3 (Fe-8Cr-2W-0.2V-0.09Ta-0.1C), and F82H-1.4 \% Ni (Fe-8Cr-2W-0.3V-0.02Ta-0.07C-1.4Ni58 or Ni60). These were irradiated up to about 87 dpa at 573, 673, and $773 \mathrm{~K}$ (in JP28 and 29). In all high temperature tensile tests, irradiation hardening and embrittlement were observed. However, for the irradiation temperatures of 673 and $773 \mathrm{~K}$, significant differences were observed between the planned temperatures and temperatures obtained by post irradiation measurements of silicon passive temperature monitors. Therefore, it is planned to supplement these results by future additional hardness tests and room temperature tensile tests.

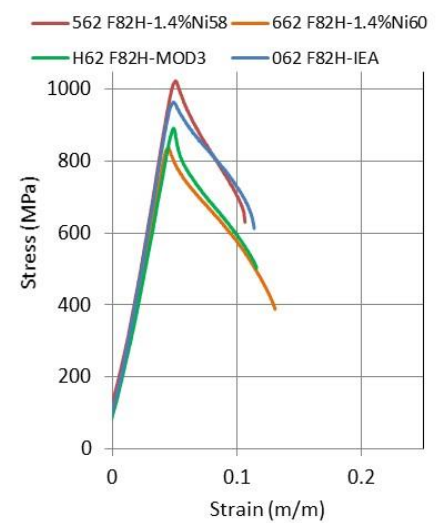

(a) $573 \mathrm{~K}$

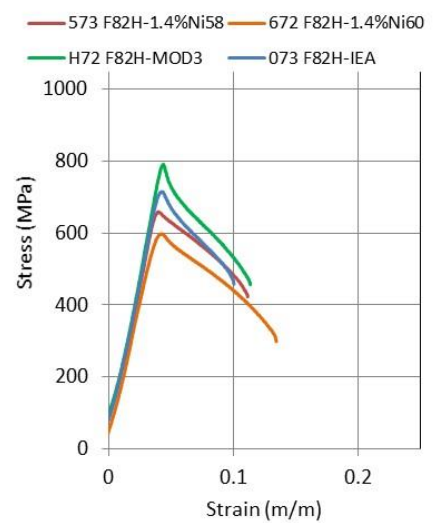

(b) $673 \mathrm{~K}$

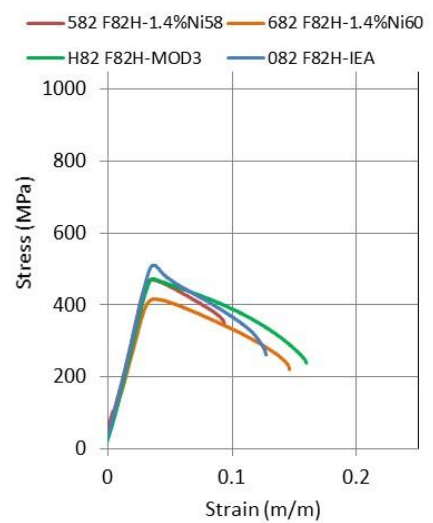

(c) $773 \mathrm{~K}$

Figure 57. High temperature tensile test results for several versions of F82H [1].

After the tensile tests of irradiated and unirradiated specimens, three dimensional fractography was performed. Representative fracture surfaces are shown in Figure 58 (F-82H IEA heat tested at $573 \mathrm{~K}$ ) [2]. Before irradiation, a few large and deep equiaxed dimples and small elongated dimples on the shear fracture surface were observed. For the irradiated specimen, a few small and shallow equiaxed dimples were visible. These results conform to the observed irradiation hardening and embrittlement shown in Figure 57. These observations can contribute to developing a tensile fracture mechanism model of the effects of irradiation on properties of the steels.

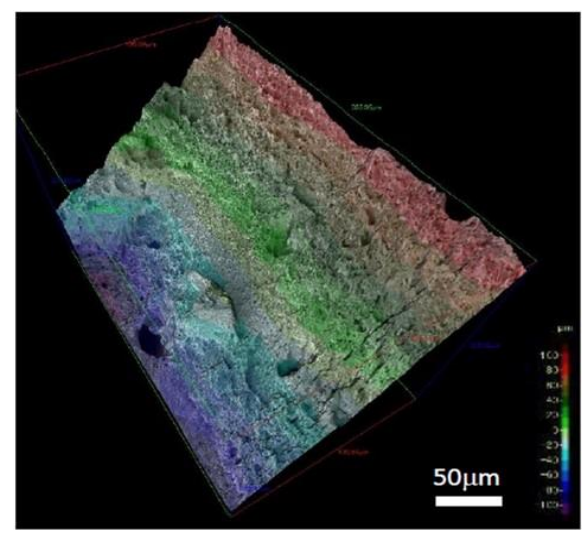

(a) Unirradiated

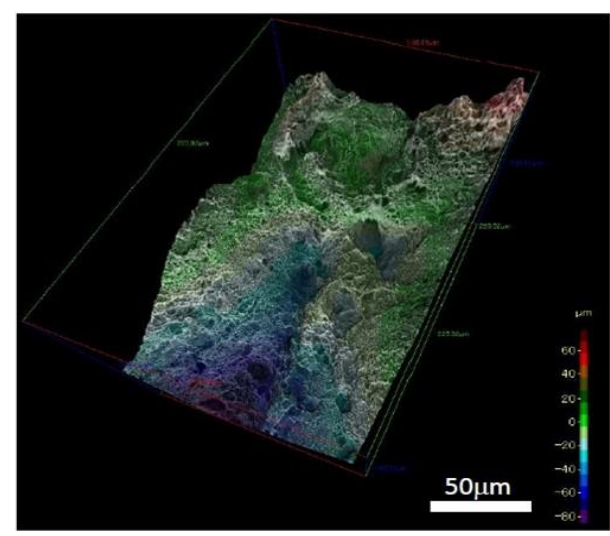

(b) $87 \mathrm{dpa}$

Figure 58. Fracture surface of F-82H, IEA heat tested at 573 K [2]. 
For $\mathrm{SiC} / \mathrm{SiC}$ composite work in the DOE-QST program, three irradiation campaigns are underway. First, high dose ( $100 \mathrm{dpa})$ irradiation of earlier generation of nuclear-grade Hi-Nicalon Type-S composites was finished and PIE is ongoing. With completion of flexural tests as reported in 2015, evaluation of irradiation-induced microstructure is being addressed. Second, the JCR-series of rabbit capsule irradiations at high temperature $(1223 \mathrm{~K})$ and high dose ( 100 dpa) of the latest $\mathrm{SiC} / \mathrm{SiC}$ composites with varied fibers and F/M interfaces continues. Third, another high dose irradiation campaigns (SCF-capsule series) are also ongoing with focus on the effect of irradiation temperature. Figure 59 summarizes the proportional limit stress (PLS) for irradiated $\mathrm{SiC} / \mathrm{SiC}$ composites with varied fiber/matrix interfaces. Significant reduction of the PLS was expected for carbon interface composites, while mild decrease was reported for multi-layer interface composites. The carbon interface thickness might affect the results but further investigation is required to support this tentative conclusion.

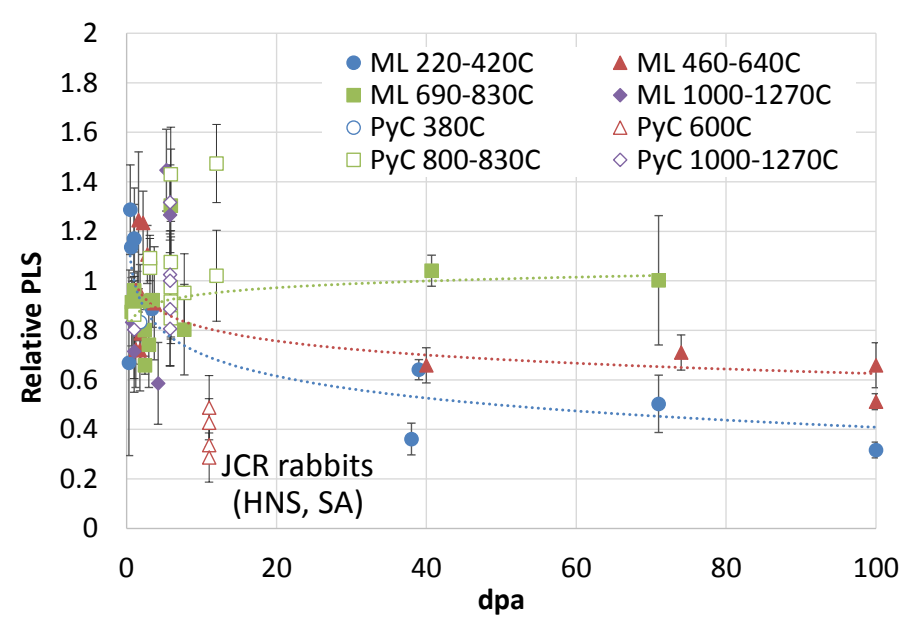

Figure 59. Neutron irradiation effect on the proportional limit stress (PLS) of $\mathrm{SiC} / \mathrm{SiC}$ composites with either pyrolytic carbon $(\mathrm{PyC})$ monolayer interface or multilayered $\mathrm{PyC} / \mathrm{SiC}$ interface.

\section{FUTURE PLANS}

Irradiations and PIE particularly focusing on JP28 and 29 will be continued for RAFM steels and SiC/SiC composites. In addition, a new irradiation campaign for pure-Cu and ITER-grade $\mathrm{CuCrZr}$ alloy produced for an ITER tungsten divertor prototype is planned. The $\mathrm{Cu}$ work includes alloys that were mechanically strengthened by Friction Stir Processing (FSP), to evaluate the response of their mechanical and physical properties to neutron irradiation. The $\mathrm{CuCrZr}$ alloy is a prime candidate for high heat flux applications in ITER and DEMO fusion reactors because of its high strength and high thermal conductivity. The issues with use of the $\mathrm{CuCrZr}$ alloy are on the drastic loss of plastic deformation capability during low temperature irradiation, below $100^{\circ} \mathrm{C}$. There are also questions on its suitability for high temperature applications. Most of the neutron irradiation data on $\mathrm{CuCrZr}$ were collected for ITER applications during the 1990s and there is a lack of comprehensive irradiation data, especially for temperatures above $200^{\circ} \mathrm{C}$ and for higher doses. The new irradiation campaign is directed at collecting data for higher temperatures, for higher doses, and for newly produced alloys. The work will also evaluate new strengthening methods for higher temperature applications. 


\section{REFERENCES}

[1] T. Hirose et al., Effects of high dose neutron irradiation on reduced-activation ferritic/martensitic steels, ICFRM-17, Aachen, Germany, 11-16 October (2015).

[2] H. Tanigawa et al., Impacts of inclusion on fracture process of reduced-activation ferritic/martensitic steels, ICFRM-17, Aachen, Germany, 11-16 October (2015). 


\subsection{US-JAPAN PHENIX PROGRAM}

\section{J.W. Geringer (geringerjw@ornl.gov), Y. Katoh, L.M. Garrison, A.S. Sabau,}

\section{OBJECTIVE}

The PHENIX Project on Technological Assessment of Plasma Facing Components for DEMO Reactors is a current US/Japan Fusion Research Collaboration Project that started in April 2013. The goal of the project is to evaluate critical issues on plasma-facing components (PFCs) under divertor conditions of fusion reactors, including: (1) heat transfer, (2) mechanical properties, (3) neutron irradiation effects, and (4) tritium retention and permeation. The project participants are ORNL, Idaho National Laboratory, Sandia National Laboratory, Georgia Institute of Technology, National Institute for Fusion Science of Japan, and various Japanese universities. The role of ORNL is to participate in Task 1 on high heat flux testing, Task 2 on neutron irradiation effects, and provide neutron irradiation in HFIR in support of all research tasks.

\section{IRRADIATION PROGRAM}

The RB19J instrumented irradiation capsule was completed and successfully inserted in HFIR for cycle 466 in June 2016. It houses 1100 tungsten specimens surrounded by gadolinium shielding to suppress the thermal neutron flux thus reducing transmutations. There are four different temperature zones of which the $800^{\circ} \mathrm{C}$ zone operated most consistent at design temperature. The $1200^{\circ} \mathrm{C}$ operated just below while the $500^{\circ} \mathrm{C}$ and $300^{\circ} \mathrm{C}$ operated just above designed temperatures. The experiment has completed three irradiation cycles in FY16. All thermocouples in the 300,800 and $1200^{\circ} \mathrm{C}$ regions have malfunctioned and been disconnected. Temperature for the next HFIR cycles will be controlled by setting the gas concentrations to the same historic conditions that achieved measured and recorded temperatures during the completed cycles.

The ORNL plasma arc lamp facility used for high heat flux testing is being upgraded. A new reflector is being fabricated that will maximize the heat flux for the existent facility to achieve a target heat flux of 16 $\mathrm{MW} / \mathrm{m}^{2}$ (incident) or $8 \mathrm{MW} / \mathrm{m}^{2}$ (absorbed in $\mathrm{W}$ ) over a $2 \times 15 \mathrm{~cm}^{2}$ area.

\section{PHENIX Task 1. High heat flux testing of W-based specimens}

Four W/SiC specimens where tested under high-heat flux (HHF) using the ORNL plasma-arc-lamps as part of the PHENIX program. Thermo-mechanical models for the simulations of entire HHFT were implemented in the ABAQUS ${ }^{\mathrm{TM}}$ software and numerical simulations were conducted for sample HHF testing. The progress and representative results of that work are reported in Section 6.3 of this report.

\section{PHENIX Task 2. Effects of neutron irradiation}

TEM microstructure analysis was performed on polycrystalline tungsten foils irradiated to doses of $\sim 4.5$ dpa. PHENIX assignees Makoto Fukuda and Taehyun Hwang collaborated on the analysis. For material irradiated above $\sim 1 \mathrm{dpa}$ and at irradiation temperatures above $400^{\circ} \mathrm{C}$, the dominate irradiation defect was precipitates of $\mathrm{Re}$ and $\mathrm{Os}$ from transmutation reactions. These transmutation reactions have a high cross section for thermal neutrons, so in HFIR there is significantly more transmutation per dpa than in fast reactors such as JOYO. One result is that the HIFIR irradiated materials have higher hardness for similar irradiation doses and temperature. Hardness measurements for material irradiated up to 4.5 dpa revealed no saturation of hardness up to this dose. The microstructure is similar to irradiated tungsten previously analyzed with a high density of small, needle-shaped precipitates throughout the material. An additional feature not seen in single crystal material is large precipitates on the grain boundaries. 
Additionally, in many cases voids were observed in close proximity to precipitates. Further analysis is required to determine if the voids or precipitates nucleated first in these instances. Additional details of this work are found in Sections 5.3 and 5.4.

Several new techniques are under development for testing irradiated tungsten. Tungsten fibers 36 to 40 $\mathrm{mm}$ long and $150 \mu \mathrm{m}$ diameters are included in RB-19J. A new tensile testing method for these fibers is being developed with ASTM C1557 as a guide. A three-point bend fixture has been designed that will be used for the tungsten bend bars included in RB-19J, with dimensions 4 x 2 x $10 \mathrm{~mm}$. The Netzsch LFA 467 HT HyperFlash instrument is undergoing trials to measure thermal conductivity on $3 \mathrm{~mm}$ diameter $0.5 \mathrm{~mm}$ thick samples. All of these techniques are intended to use less activated volume of material, thereby simplifying shielding and decreasing the cooldown time after irradiation before measurements can be conducted.

\section{FUTURE PLANS}

All technical tasks will continue through FY-19. In addition to participating in the continuing research in the areas planned for FY-17, ORNL will contribute to the project by providing project management, participating in personnel exchanges and workshops, and publishing and presenting the results. 


\section{MATERIALS ENGINEERING SUPPORTING THE FNSF STUDY}

\section{A. F.Rowcliffe (art.rowcliffe@gmail.com)}

\section{OBJECTIVE}

The primary objective of this task is to identify potential materials solutions for the Fusion Neutron Science Facility (FNSF) power core components, tritium containment and extraction systems and for lifetime components such as the vacuum vessel, structural ring and magnet shields.

\section{SUMMARY}

Information is provided on a wide range of structural and plasma facing materials properties including radiation damage tolerance, mechanical behavior, compatibility issues, and fabrication and joining including potential additive manufacturing technologies to ensure that FNSF concepts are developed with credible approaches to materials engineering issues. Feedback is provided to the Fusion Materials Program on proposed operating temperature windows, dpa and helium generation levels, thermomechanical loading and compatibility requirements and the component lifetimes needed to meet the staged series of FNSF mission goals

\section{PROGRESS AND STATUS}

Information was provided to the project on progress in the development of the advanced blanket structural materials including the nano-structured CNAs and ODS alloys which with their increased radiation damage tolerance and higher creep strengths will allow development of the power core components needed to meet the progressively challenging stages of FNSF operations. Updates were provided on the development of potential solutions to the development of tungsten-based alloys and composite systems for Plasma Facing Components, and on the development of low activation 3Cr-3W bainitic steels for vacuum vessel and structural ring applications. Discussions of the behavior of power core structural materials during potential Loss of Coolant Accidents (LOCAs) were initiated. While it appears that based on thermal stability considerations the Reduced Activation Ferritic Martensitic Steels (RAFMS) and bainitic steels would probably retain their essential properties under the LOCA conditions envisioned, the behavior of the radiation-induced components of the microstructure (helium bubbles, voids, precipitates etc.) will require experimental determination. The impact of temperature-time envelopes for off-normal events including LOCAs, disruptions, and transients on microstructural stability and post-event properties needs be included in the performance metrics for structural materials.

Information from the EU and Japan fusion materials programs indicates that the time- scale for the introduction of a $14 \mathrm{MeV}$ neutron source such as DONES implies that it would be 20 years from the start of construction before the US could expect to begin an irradiation program to establish a materials engineering design database to support FNSF/DEMO. However, the component lifetime neutron doses for the generation 1 (GEN1) RAFM base blanket for FNSF are relatively conservative (i.e. peak doses of 7, 19, 26, 37 dpa with maximum helium concentrations of 70, 190, 260 and 370 appm for phases 3-7). Another distinguishing feature of FNSF is that the selection of helium cooling for FNSF provides the option to maintain operating temperatures above the low temperature hardening regime. Recent modeling indicates that embrittlement characterized by the DBTT shifts related to matrix hardening at $50 \mathrm{dpa} / 500$ appm helium would be $<75^{\circ} \mathrm{C}$ for operation in the range $400-500^{\circ} \mathrm{C}$. Various radiation-induced mechanisms could contribute to interface weakening and creation of a regime of low ductility intergranular fracture with helium trapping and bubble formation being the major factor. Definition of the helium threshold for transition to the intergranular (IG) fracture regime in GEN-1 RAFMs in the 400$550^{\circ} \mathrm{C}$ regime could probably be established via judicious utilization of currently available and proposed irradiation sources such as STIP/SINQ, FMITS and compact cyclotron facilities. Mapping of the He- 
induced IG fracture regime via tensile, hardness and DBTT shift measurements and microstructural analysis could establish a more reliable assessment of the damage limits for RAFMS in the FNSF environment.

\section{FUTURE PLANS}

This activity will continue to provide support to the liquid metal PFC tokamak study in the areas of structural materials, materials interactions of substrate structural materials, and radiation effects in substrates. 


\section{EXPERIMENTAL TECHNIQUES AND LABORATORY SYSTEMS}

\subsection{IAEA ACTIVITY FOR STANDARDIZATION OF SMALL SPECIMEN TEST TECHNIQUES FOR FUSION}

\section{Mikhail A. Sokolov (sokolovma@ornl.gov)}

The use of small specimens becomes mandatory for the production of reliable and coherent data bases due to the limited volume available in Materials Test Reactors as well as in planned dedicated fusion neutron sources. The lack of standard procedures in this area is a major issue for the further development of coordinated testing and adequate database to be used by fusion system designers and regulators. Therefore, following the request of the Fusion materials community as well as system designers, an IAEA consultancy meeting on this subject was organized.

The overall objective of this meeting was to review the current status of the Small Specimen Test Techniques (SSTT) in terms of acceptance by regulators; identify critical points for the standardization procedures; and establish recommended actions that will enable the standardization process for SSTT. A long-term objective should be the inclusion of SSTT-based irradiated RAFM steel data in a DEMOrelevant design code.

The meeting was hosted by the Division of Physical and Chemical Sciences, Department of Nuclear Sciences and Applications of the IAEA at IAEA Headquarters in Vienna on July 4-6, 2016. Seven participants from Germany, Spain, Japan, France and USA decided to launch the IAEA Coordinated Research Program to harmonize and coordinate world-wide acceptance of small specimen test techniques for fusion applications. A program kick-off meeting is anticipated before spring, 2017. 


\subsection{MINIATURE TEST DEVELOPMENT FOR TUNGSTEN-BASED MATERIALS}

Lauren Garrison (garrisonlm@ornl.gov), Jeremy Moon (University of Nevada-Reno), Joseph Willenborg (University of Tennessee-Knoxville)

\section{OBJECTIVE}

The aim of this work is to develop miniature mechanical test methods that can be used to evaluate neutron-irradiated tungsten and tungsten composite samples in the LAMDA laboratory.

\section{SUMMARY}

Many tungsten based composites contain tungsten foils or tungsten fibers. Understanding the mechanical properties of the composite also requires understanding the mechanical properties of the constituent elements of the composite. While certain miniaturized mechanical tests, such as tensile testing SSJ size samples, is routinely accomplished in LAMDA, the requirements for testing foils and fibers is beyond the current capabilities in the laboratory. Three mechanical tests are being developed for the foils and fibers: a) shear punch test for foils, b) 3-point bend test for foils, and c) tensile test for fibers.

\section{PROGRESS AND STATUS}

This activity was covered in detail in the June 30, 2016 Fusion Materials Semiannual Progress Report, DOE-ER-0313/60, section 10.1 "Miniature Mechanical Test Development for Tungsten-Based Materials." The shear punch tests have been performed on unirradiated tungsten foils, steel foils, tungsten-copper composites, and tungsten-steel composites. Work is underway to develop a correlation between the shear punch and tensile data for these materials that would be used for future work with irradiated materials. A 3-point bend test fixture for foils with dimensions $16 \times 4 \times 0.1 \mathrm{~mm}$ was machined and initial tests completed on unirradiated tungsten foils. A 3-point bend fixture using the same design but smaller dimensions for testing $10 \times 4 \times 2 \mathrm{~mm}$ fracture toughness specimens will be machined for use at the hot cells. The tensile tests of fibers achieved some initial success with a modified version of the fixture used for foil tensile tests. A purpose built fixture specifically for the fibers is being designed.

\section{FUTURE PLANS}

The development of miniature mechanical tests for tungsten based materials continues. Once successful testing of unirradiated materials is achieved, the next step will be to utilize the new fixtures for tests of irradiated foils and fibers. 


\title{
11.3 NEW AND UPGRADED TESTING CAPABILITIES FOR IRRADIATED MATERIALS
}

\author{
K. Linton (lintonkd@ornl.gov), X. Hu, L Garrison, K.G. Field
}

\section{SUMMARY}

ORNL is home to two primary post-irradiation experimentation (PIE) facilities, Building 4508 which includes the Low Activation Materials Development and Analysis (LAMDA) lab and the Irradiated Materials Examination and Testing (IMET) hot-cell facility in Building 3025E, for performing systematic studies of the effects of neutron and/or ion irradiation on candidate materials for fusion and fission reactor applications. Typical PIE activities utilize both the IMET and LAMDA facility to conduct mechanical and physical property measurements and microstructural characterization. The unique set of capabilities in these facilities is shared by the Fusion Materials Program and other programs and is a keystone capability for irradiated materials research at ORNL. The equipment and capabilities are continually upgraded or added to keep these facilities at the forefront of irradiated materials research; the following briefly highlights FY2016 activities of this continuous improvement effort.

\section{LAB FACILITIES INCLUDING LAMDA - THE LOW ACTIVATION MATERIALS DEVELOPMENT AND ANALYSIS FACILITY}

The LAMDA facility in Building 4508 was established for materials science evaluation of irradiated materials that have low radiological threat $(<100 \mathrm{mR} / \mathrm{hr}$ at $30 \mathrm{~cm})$. The facility begins with a contamination-zone (C-zone) for possible radiological contamination work and expands to other labs within 4508 for "clean work" or work to be conducted on samples with limited to no threat of removable radioactive contamination. Both of these areas with the appropriate radiological controls allow work without the need for remote manipulation, which greatly expands the range of studies that can be conducted. The $\mathrm{C}$-zone is home to much of the mechanical testing equipment, including load frames and microhardness testers, as well as physical and thermophysical analysis equipment. These include Differential Scanning Calorimeters (DSC) and Thermogravimetric Analysis (TGA) units. Advanced optical and electron microscopy systems are housed just beyond the C-zone and have seen significant upgrades in the past couple years including installation of the FEI "Talos" F200X scanning/transmission electron microscope (S/TEM).

The most significant upgrade in the C-zone component of LAMDA is the fully functional Thermal Desorption Spectrometry (TDS) system coupled with an in situ $20 \mathrm{keV}$ ion gun. The TDS system is dedicated to investigating the gas-defect interactions in plasma facing materials and structural materials used in fusion reactors. It has successfully been used to study the neutron irradiation impacts on helium behavior in iron and to reveal the influence of pre-existing helium bubbles on deuterium behavior in tungsten. More details about these two projects could be found in Sections 3.6 and 5.4. The current heater in the system has a maximum temperature of $1200^{\circ} \mathrm{C}$, so is being upgraded to reach $1650^{\circ} \mathrm{C}$ to capture more features of helium behavior in tungsten. In parallel to the establishment of TDS system, a comprehensive gas permeation test station is being designed and constructed to investigate the hydrogen isotopes (i.e., $\mathrm{H}$ and $\mathrm{D}$ ) permeability in as-received and irradiated plasma facing materials and structural materials. Progress in construction of this system will be reported in FY2017.

Three operational FEI dual beam FIBs and two TEMs support irradiated materials research for the fusion materials program. One significant enhancement of capabilities is a heated tensile stage for the Versa 3D Dual Beam Microscope, shown in Figure 60 and Figure 61. The custom grip design and procurement were completed in FY16 for $2 \mathrm{kN}$ and $5 \mathrm{kN}$ load cells with high temp tensile test grips for SS-J3 tensile specimens. By December 2016 this system will provide up to $800^{\circ} \mathrm{C}$ heating during static or dynamic 
observations of surface changes under controlled mechanical load. This capability combined with EBSD will provide new input into the complex phenomena during all stages of plastic deformation.

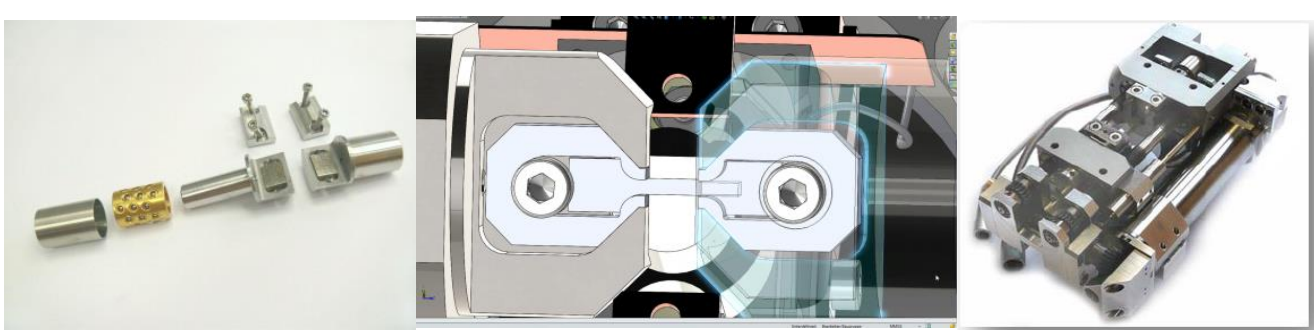

Figure 60. $5 \mathrm{kN}$ Tensile Testing Module for FEI Versa 3D Dual Beam Microscope. Images show grips, the placement of the shoulder loaded specimen relative to heater and, and the overall module design.

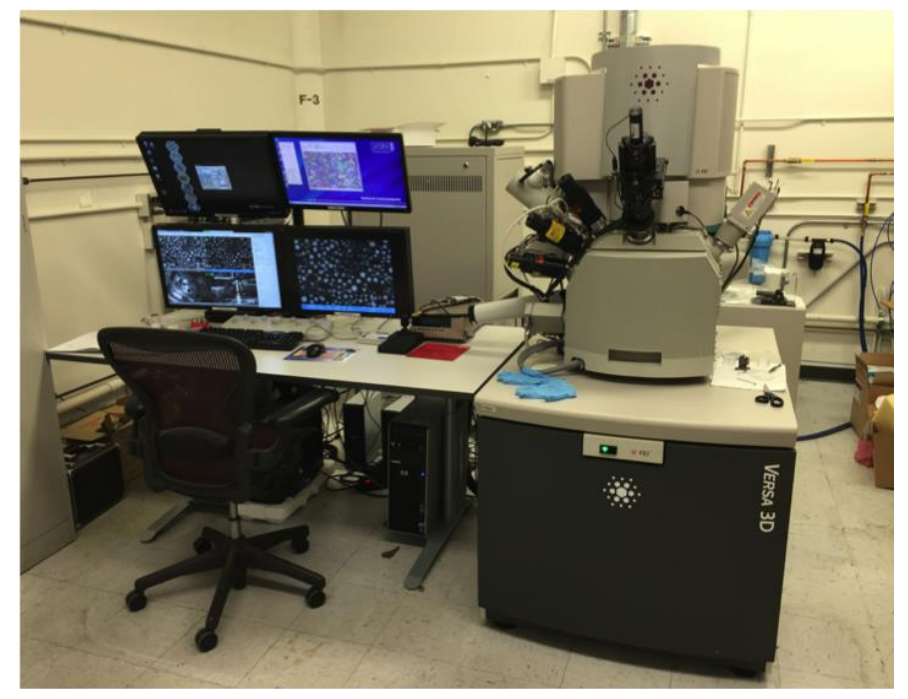

Figure 61. The FEI Versa 3D FIB-SEM, which will house the Tensile Testing Module.

Another significant addition to the suite of characterization equipment in LAMDA is the GD-Profiler 2 which arrived in September 2016, and is shown in Figure 62. A glow discharge coupled to an optical emission spectrometer will provide elemental analysis of bulk materials and surface compositions along with depth profiling. The GD-Profiler 2 features an RF plasma source for sputtering the target for analysis which allows both conductive and non-conductive materials to be analyzed. The instrument can simultaneously identify 40 elements in a $2 \mathrm{~mm}$ spot on the sample with depth profiling with accuracy on the order of nanometers and total depth of evaluation up to 150 microns. This combination of accuracy and ranges of sizes (from nano layers to bulk composition) analyzed is not matched by other elemental analysis techniques such as SIMs or EDS. While there are many experiments within the fusion program that will be aided by analysis with the GD-Profiler instrument, a unique one is the GD-Profiler's ability to distinguish $\mathrm{D}, \mathrm{H}$, and $\mathrm{He}$ signals. This capability will be important in understanding gas behavior in tungsten as a plasma-facing component for fusion reactors. The utility installations, NRTL certification and research safety summaries are on track to be completed by November 2017. 


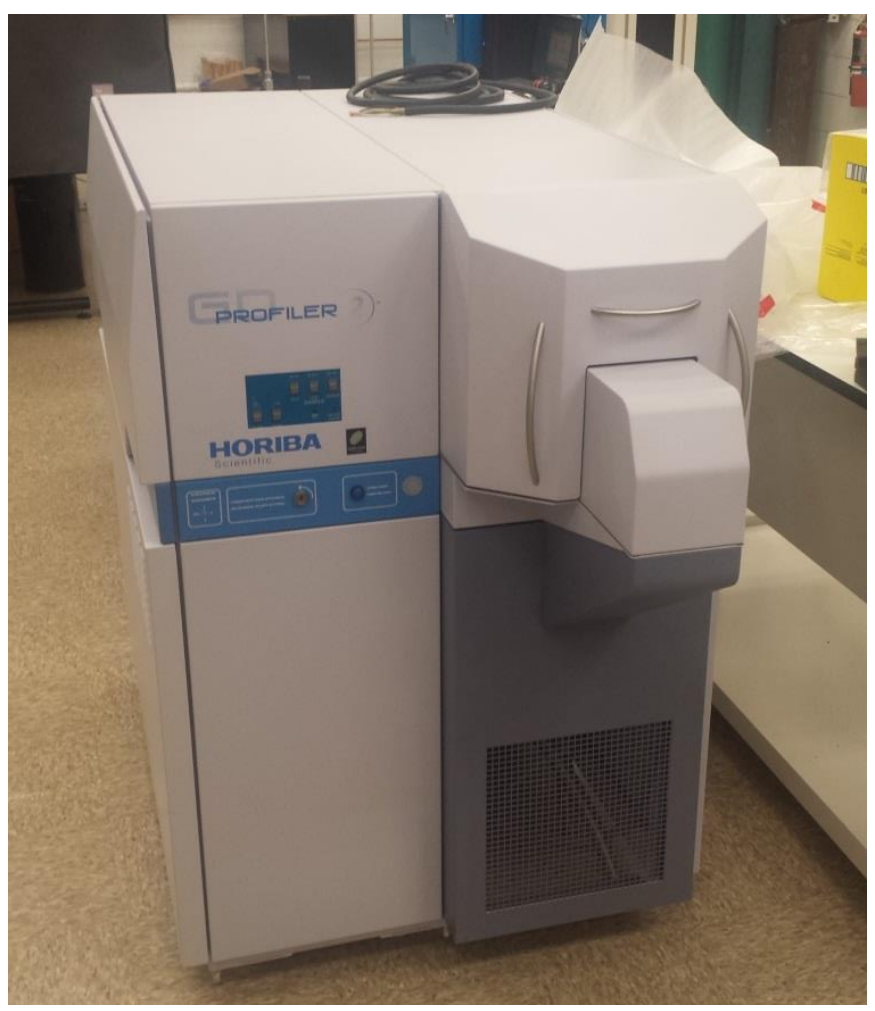

Figure 62. Uncrated GD-OES system in LAMDA. Installation anticipated by December 2016.

\section{IMET - IRRADIATED MATERIALS EXAMINATION AND TESTING LABORATORY}

The IMET in Building 3025E is the facility used for evaluations of irradiated materials with high radiological threat. This Class III nuclear facility includes a series of hot cells with remote manipulation. An example image of one of these cells in use is shown in Figure 63. The hot cells at IMET contain the primary mechanical testing and examination equipment for highly irradiated structural alloys and ceramics. The six interconnected steel-lined hot cells contain 320 square feet of workspace and are maintained for low alpha contamination to allow transfer of specimens to other radiological laboratories, such as LAMDA, after testing, segmenting or sorting. Functions that can be performed include capsule disassembly, laser profilometry, optical microscopic examination, grinding, polishing, welding, shearing, machining, sawing, photography, and video examination. Mechanical systems are also contained in the cells for tensile, creep, Charpy impact, fracture toughness, and fatigue testing. 


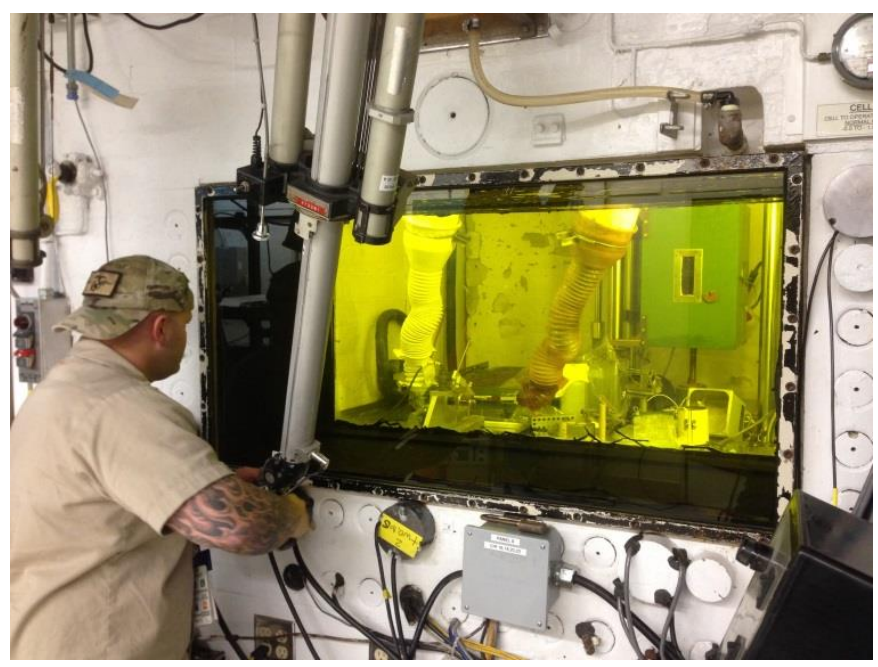

Figure 63. HFIR irradiation capsule disassembly by remote manipulation in the IMET Hot Cells in ORNL Building 3025E.

The increasing need for high temperature mechanical testing led to the procurement of a specialized load frame and furnace assembly for installation in the IMET facility. Purchase orders were placed in late FY15 for a new high temperature test frame including a custom vacuum chamber. In 2016, Oxy-Gon designed and manufactured the vacuum chamber and mounted the vacuum on an Instron Model 5967 Electromechanical Test Frame with a $30 \mathrm{kN}$ load capacity, show in Figure 64 and Figure 65. The system has been designed for ease of use with manipulators and provides sightlines for an optical extensometer to be added once placed Cell 1 of IMET. The load frame electronics have been separated and moved to the control area to avoid any need for radiation hardening.

The vacuum furnace on the test system will provide a maximum temperature of $1200^{\circ} \mathrm{C}$, ultimate vacuum of $1 \times 10^{-7}$ Torr, and the capability for mechanical testing in an inert environment. The addition of an optical extensometer will allow detailed strain measurements such as the use of digital image correlation (DIC) techniques. Samples tested using this new system then can be transferred to LAMDA for microstructural investigations to establish structure-property relationships for irradiated materials. The NRTL certification and Factory Acceptance Test are scheduled for October with delivery to ORNL IMET facility anticipated in mid-November. 

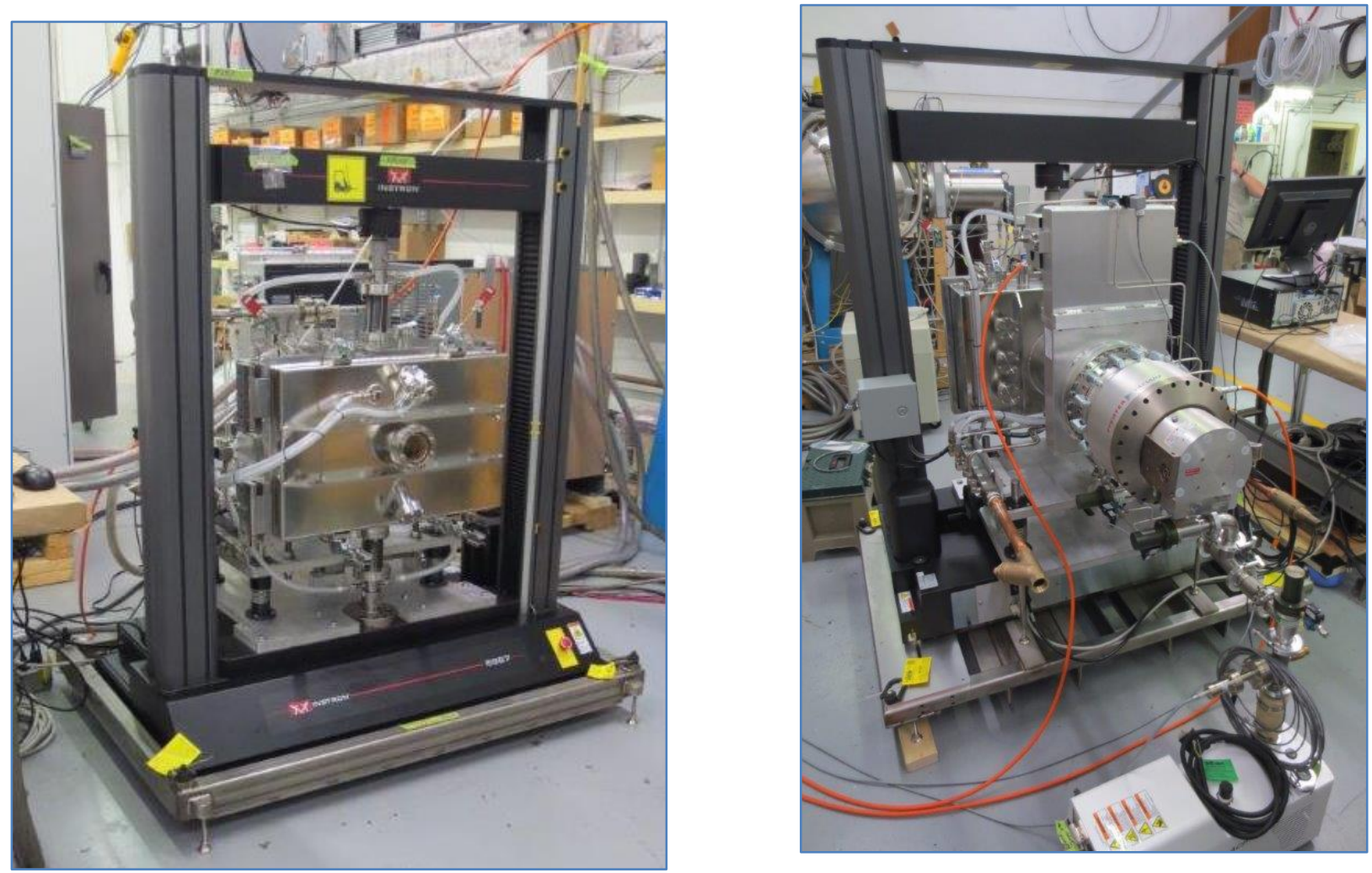

Figure 64. Front and Rear Views of Oxy-Gon Custom Vacuum Chamber on an Instron Load Frame Ready for NRTL Inspection and Factory Acceptance Test in October 2016.

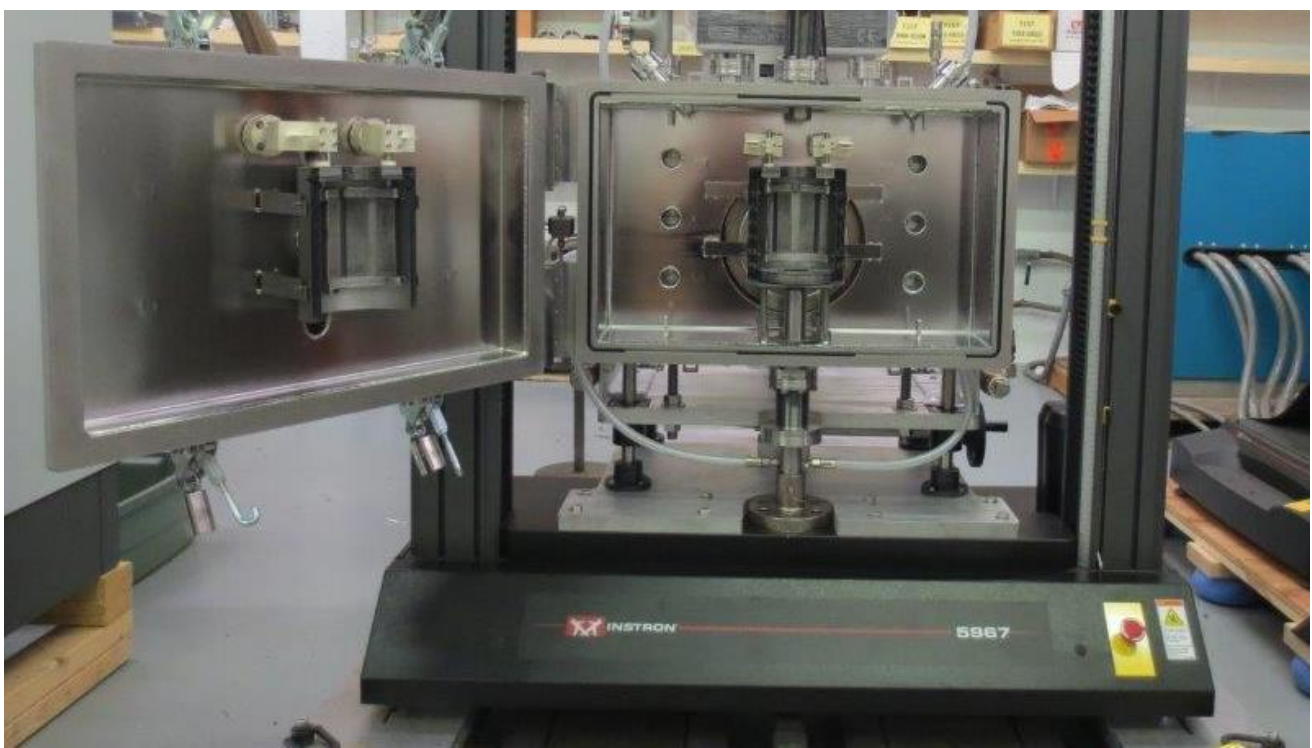

Figure 65. Interior View of the Chamber including Tungsten Mesh Resistance Heated Furnace. 


\title{
11.4 ORNL INVENTORY SYSTEM FOR MANAGEMENT OF RADIOACTIVE SPECIMENS
}

\author{
Linda Hulsey, Josh Schmidlin (schmidlinje@ornl.gov), Wilna Geringer
}

ORNL is developing a more efficient system for tracking the large and ever-growing inventory of irradiated material specimens. These specimens belong to several nuclear materials programs, come from irradiation experiments in HFIR, ATR and other reactors or accelerator-based sources, and reside in hot cells and other facilities shielded for storage of radioactive materials.

Currently the LAMDA (Low Activation Materials Development and Analysis) lab is tracking over 5000 specimens using a spreadsheet inventory system; we are transforming this spreadsheet tracking system into a relational database Laboratory Information Management System (LIMS). We will use bar coding to track the movement of the samples from the time they are received into LAMDA to track the location within LAMDA, for issuing and returns through shipping and disposal. LAMDA's inventory is similar to a library system. Like books, specimens are received, issued or checked-out, returned or discarded.

When a shipment is received in LAMDA, the specimens are entered into the inventory system. Once in the system the exact storage location of the samples can be tracked, including room, vault, shelf and cask (pig) identification. Specimens can then be issued or checked out to researchers and LIMS will track custodianship, date of issue and return. Then when the samples are returned, the condition will be noted in the system, daughters will be created as necessary (for example, if specimens are sectioned), and the specimens are returned to their storage location or new locations entered.

Information on the specimens can be searched and viewed by location, by custodian, by program, or any parameter captured in the system. It can be searched by the lab manager for operational integrity or by researchers for availability of samples. LabWare keeps an audit history for every sample including dates, movement and custodianship. LIMS helps to implement a systematic approach to maintaining sample location and custodianship.

We are using a commercial off the shelf LIMS called LabWare for the LAMDA specimen inventory. The implementation team consists of Project Owner Wilna Geringer, implementation lead and functional specialist Linda Hulsey, LabWare technical specialist Jim Dyke, SQA Documentation lead Shannon Byars, subroutine and coding developer David Correll, IT project schedule manager Lisa McCurry, and server administrator Matt Heid.

Future extension of LIMS to ORNL Building 3025E hot cells and other storage areas used by the fusion materials program is anticipated. 


\section{HFIR IRRADIATION PROGRAM}

\subsection{ARCHIVAL SAMPLES FOR THE FUSION MATERIALS COMMUNITY}

\section{Xunxiang Hu(huxl@ornl.gov)}

This project contributes to fusion materials research by testing and/or shipping ORNL archival samples to other members of the Fusion Materials community. Four different tasks are currently included.

There has been little activity, and no designated funding on this activity in FY 2016. This report documents the present status of the four tasks, mainly reflecting effort during FY 2014 and 2015.

\section{Shipment of specimens irradiated in JP28-31 to PNNL for PIE (PNNL/UCSB-Kurtz/Odette)}

The objective of the project proposed by PNNL/UCSB is to perform detailed microstructural characterization of in situ He implantation (ISHI) samples to answer three fundamental questions: 1) What are the basic interacting mechanisms controlling the transport of $\mathrm{He}$ and displacement induced defects, their fate and consequences? 2) How are the resulting cavity and other defect evolutions influenced by the starting microstructure and irradiation variables, including, displacements per atom (dpa), dpa rate, He/dpa ratio and irradiation temperature? and, 3) How can the detrimental effects of Hedpa synergisms be mitigated and managed by designing microstructures more resistant to these effects?

\section{PIE of neutron-irradiated BMG and HEA (UTK-Zinkle)}

The key objective of this work is to examine the microstructural and mechanical property changes produced by neutron irradiation of bulk metallic glass (BMG) and high entropy alloys (HEA), compared to conventional alloys, providing insight into the potential of these classes of materials for high temperature fusion structural applications.

\section{Micro-pillar compression of neutron-irradiated W(UCLA-Ghoniem)}

The objective of this project is to exam the mechanical deformation of irradiated tungsten and iron (or steel) micro-pillars using a coordinated modeling and experimental method. Compression and indentation tests require small material volumes, are relatively inexpensive for irradiated materials, and can be used as screening tests during the expensive phase of material development evaluating neutron damage effects. Discrete Dislocation Dynamics will be developed to directly compare with the experiments to provide insight into the physical mechanisms that govern plastic deformation and fracture phenomena.

\section{He-point defect interactions in neutron-irradiated $W$ and Fe (UTK-Wirth)}

The objective of this project is to expand current fundamental understanding of He-point defect/defectcluster interactions in neutron irradiated $\mathrm{W}$ and Fe. Positron annihilation spectroscopy will be used to characterize initial microstructure of as-irradiated samples, focusing on information on vacancy clusters. This will be followed by He implantation and thermal desorption measurements. The experimental results will be compared to similar He ion implantation and thermal desorption of non-irradiated specimens. The experimental measurements will provide data to validate the multiscale models of helium-defect interactions, thermal desorption and gas bubble nucleation in the fusion neutron environment.

The current status of these projects is listed in Table 17. 
Table 17. Status of Testing and Shipment of Archival Samples for FUSMAT Community

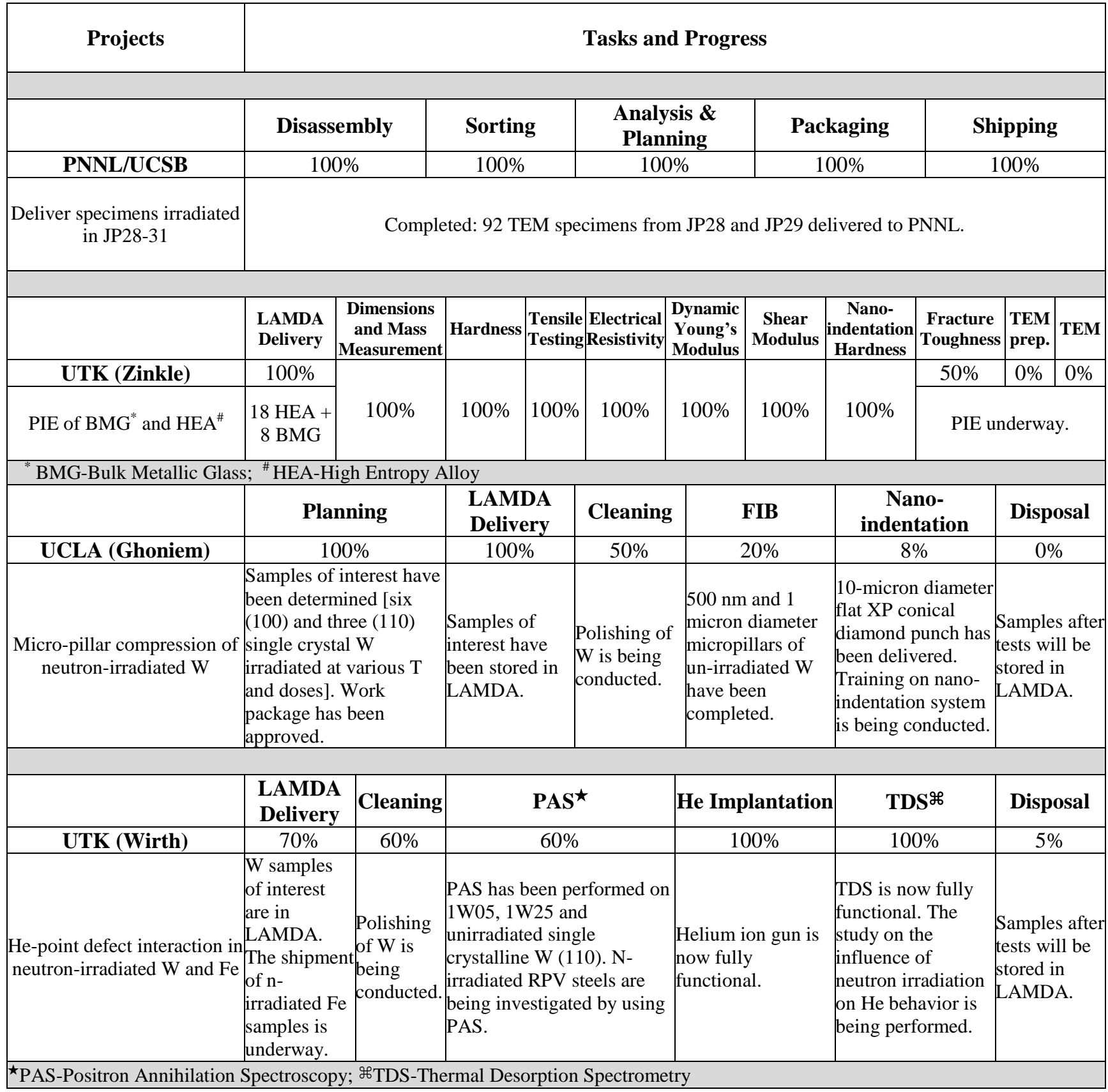




\subsection{THE MFE-RB-19J HFIR IRRADIATION EXPERIMENT}

\section{J.L.McDuffee (mcduffeej@ornl.gov), J.W.Geringer (geringerjw@ornl.gov)}

\section{OBJECTIVE}

The HFIR RB-19J irradiation experiment is a collaborative effort between the US and Japan Fusion Materials fusion programs to research tungsten for plasma facing components under divertor conditions and to evaluate blanket structural materials for DEMO and other fusion reactors.

The objective of this experiment is to irradiate tungsten and RAFM steel specimens at controlled temperatures of $300,500,800$ and $1200^{\circ} \mathrm{C}$ in the Removable Beryllium (RB) position of the High Flux Isotope Reactor (HFIR). The capsule has a gadolinium shield inside the capsule housing to reduce thermal neutron flux and thus reduce transmutation rates in specimen materials. The expected radiation damage levels for the steel and tungsten specimens for the originally planned six cycles of HFIR operation are $\sim 2.5$ to 3 dpa and $\sim 1.0$ to 1.5 dpa respectively.

\section{SUMMARY}

This experiment requires a thermal neutron shield to modify the fast/thermal neutron ratio over the life of the experiment. Previous experiments used an external $\mathrm{Eu}_{2} \mathrm{O}_{3}$ shield for thermal neutron suppression, but that design is no longer feasible due to both fabrication difficulties with the $\mathrm{Eu}_{2} \mathrm{O}_{3}$ inserts and HFIR management's decision not to allow the replacement of the RB experiment liners. Therefore, a new design has been established that uses a gadolinium metal cylinder encased between an inner aluminum sleeve and the outer experiment tube. During normal operation, differential thermal expansion will press the aluminum sleeve and gadolinium shield against the outer tube, minimizing the gaps between the parts and the temperature difference across those gaps. To minimize reductions in the HFIR cycle length (nominally 25 days), the current plan is to obtain 3 cycles in 2016 and 3 cycles in 2017, thereby splitting the "lost" days due to the presence of the neutron shield over two fiscal years.

The HFIR RB-19J irradiation experiment contains six cylindrical holders (four temperature zones) which houses 1300 tungsten and steel specimens. The capsule and shield is design to be centered about the HFIR mid-plane, but the holders are slightly shifted upward from the mid-plane. The assembly of the RB19J capsule was completed in May 2016 and installed in HFIR in June 2016. The first irradiation cycle, 466, started June 14 2016. Starting temperatures stabilized within design ranges for the $500^{\circ} \mathrm{C}$ and the $800^{\circ} \mathrm{C}$ holders. The $1200^{\circ} \mathrm{C}$ and the $300^{\circ} \mathrm{C}$ were lower and higher than designed by about $50^{\circ} \mathrm{C}$ and $100^{\circ} \mathrm{C}$ respectively.

\section{PROGRESS AND STATUS}

\section{Experiment Design and Specimen Matrices}

Thermal and Neutronics Analysis and Mechanical Design of the RB-19J experiment have been reported in detail in the Fusion Materials Semiannual Progress Report for the Period Ending June 30, 2016, report DOE-ER-0313/60, available in pages 205-214 in: (http://web.ornl.gov/sci/physical_sciences_directorate/mst/fusionreactor/Vol60.shtml).

The Specimen Matrices for the experiment are documented in the same Semiannual Progress Report in pages 215-233. 


\section{Operating History}

The capsule completed three irradiation cycles in FY16, cycle 466, 467 and 468. It remained in HFIR since installation in May 2016. Since the first cycle, thermocouples from the $300^{\circ} \mathrm{C}$ zone started to malfunction and at the end of the third cycle eleven of the fourteen thermocouples have been disconnected.

From data recording by the data acquisition system it is possible to analyze the controlling history of the first three cycles. The measured temperature is associated with the He/Ar gas concentrations in each zone. There is a direct correlation between the gas mixture ratio and the expected temperature.

For the fourth and any subsequent cycles, temperatures in each zone will be controlled based on the recorded temperature history from the earlier cycles, using this history to set the He/Ar gas concentrations to replicate the earlier temperature control. More detail on this history and the zone behavior will be documented in future reports after irradiation of the $19 \mathrm{~J}$ experiment is completed.

Figure 66 shows the cycle comparison of the HFIR control plate positions in terms of Reactor Power Days. It is being compared to cycle 465 which was the cycle before capsule insertion. Current trending shows that the cycle length improves by $\sim 0.4$ days with each irradiation cycle, perhaps indicating burnout of the $\mathrm{Gd}$ shield. Detailed analysis is being performed to evaluate the local shielding effect on the specimens as exposure of the experiment continues. A decision on any additional irradiation cycles will be made after completion of cycle 469.

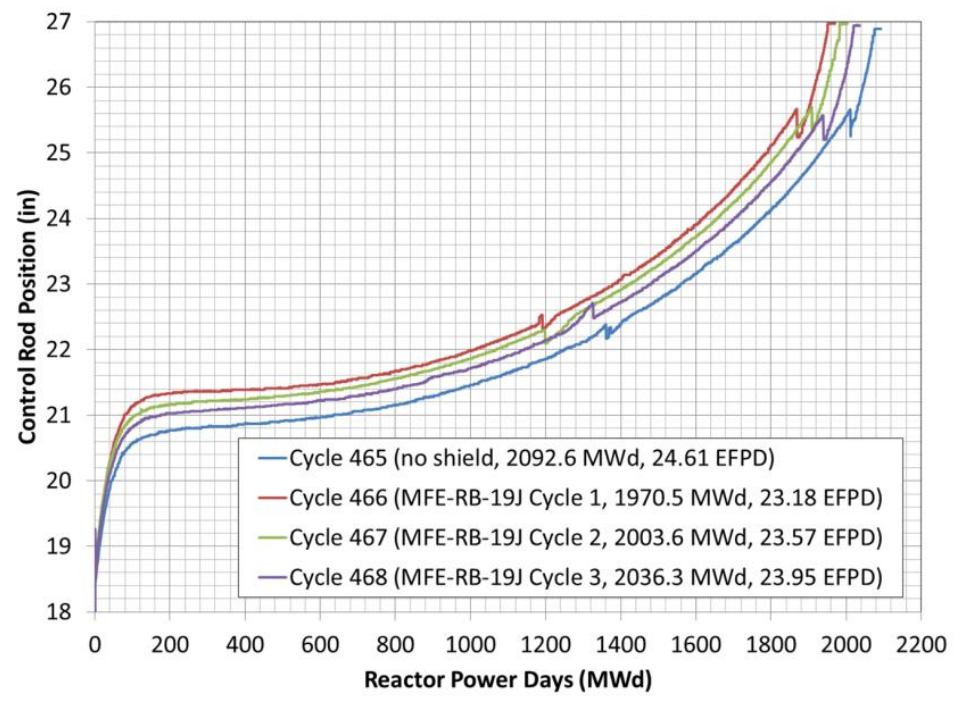

Figure 66. Cycle comparison for Control Plate Position as a function of Reactor Power Days in the cycle.

\section{FUTURE PLANS}

The irradiation of RB-19J will continue with the recommended temperature control method. The tentative plan now is to complete the irradiation after a total of either four or five HFIR cycles. Decision on the removal of the capsule will depend on the best estimate of the burnout status of the Gd shield. Shipping and disassembly activities will commence soon after the experiment is removed and a short decay period is completed. 


\subsection{HFIR IRRADIATION EXPERIMENTS}

\section{Y.Katoh(katohy@ornl.gov), J.L.McDuffee, C.Bryan, J.P. Robertson}

\section{SUMMARY}

Neutron irradiation experiments performed in support of the research and development of fusion reactor materials use various materials irradiation facilities in the High Flux Isotope Reactor (HFIR). The HFIR reactor operated for seven cycles in FY2016, cycles 462 through 468, accumulating a total of 14,423 MWD.

During FY2016, 8 target zone rabbit capsules completed HFIR irradiation, achieving the target neutron fluences. Those capsules are listed in Table 18 along with condensed information on material, specimen type, temperature, fluence, and period of irradiation. At the end of FY2016, 10 target zone rabbit capsules are continuing irradiation in HFIR toward their target neutron fluences. Those capsules are listed in Table 19 along with the information on materials, specimen types, and irradiation parameters. Included in these two tables are the 7 target zone rabbit capsules that started irradiation in HFIR during FY2016. Table 20 lists 5 program rabbits that were removed from the reactor at the end of cycle 465 for damage inspection.

The full length instrumented, flux tailored capsule RB-19J was installed in the removable beryllium of the reactor with the start of Cycle 466, in June 2016. It contains tungsten and F82H alloys in various specimen configurations, with four zones operating at $250 / 300,500,800$, or $1200^{\circ} \mathrm{C}$. The experiment uses a Gd thermal neutron shield. It is scheduled to run for six reactor cycles, for maximum exposures of 1.5 dpa in $\mathrm{W}$ and about 3 dpa in steel.

Table 18. Fusion materials program capsules that completed HFIR irradiation in FY2016. These were all target zone rabbit capsules.

\begin{tabular}{|c|c|c|c|c|c|c|c|c|}
\hline $\begin{array}{l}\text { Experiment } \\
\text { Designation }\end{array}$ & $\begin{array}{l}\text { Primary } \\
\text { Materials }\end{array}$ & $\begin{array}{l}\text { Specimen } \\
\text { Types }\end{array}$ & $\begin{array}{l}\text { Irradiation } \\
\text { Temperature } \\
\left({ }^{\circ} \mathrm{C}\right)\end{array}$ & $\begin{array}{l}\text { Maximum } \\
\text { Exposure } \\
\text { (dpa) }\end{array}$ & $\begin{array}{l}\text { Number of } \\
\text { Reactor } \\
\text { Cycles }\end{array}$ & \multicolumn{3}{|c|}{$\begin{array}{l}\text { HFIR Cycles } \\
\text { Start - End }\end{array}$} \\
\hline IMR4 & various & $\begin{array}{l}\text { MD } \\
\text { specimens }\end{array}$ & 200 & 2 & 1 & 466 & - & 466 \\
\hline IMR5 & various & $\begin{array}{l}\text { MD } \\
\text { specimens }\end{array}$ & 200 & 10 & 5 & 460 & - & 464 \\
\hline IMR6 & various & $\begin{array}{l}\text { MD } \\
\text { specimens }\end{array}$ & 600 & 2 & 1 & 466 & - & 466 \\
\hline IMR7 & various & $\begin{array}{l}\text { MD } \\
\text { specimens }\end{array}$ & 600 & 6 & 3 & 466 & - & 468 \\
\hline IMR9 & various & $\begin{array}{l}\text { MD } \\
\text { specimens }\end{array}$ & 1000 & 2 & 1 & 466 & - & 466 \\
\hline FTS3 & $\mathrm{SiC}$ & $\begin{array}{l}\text { Joint } \\
\text { specimens }\end{array}$ & 500 & 10 & 14 & 453 & 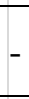 & 466 \\
\hline SCF6 & $\mathrm{SiC} / \mathrm{SiC}$ & bend bars & 600 & 10 & 6 & 457 & - & 462 \\
\hline SCF10 & $\mathrm{SiC} / \mathrm{SiC}$ & bend bars & 950 & 10 & 5 & 458 & - & 462 \\
\hline
\end{tabular}


Table 19. HFIR fusion materials program rabbit capsules continuing irradiation beyond FY2016

\begin{tabular}{|c|c|c|c|c|c|c|c|c|}
\hline $\begin{array}{l}\text { Experiment } \\
\text { Designation }\end{array}$ & $\begin{array}{l}\text { Primary } \\
\text { Materials }\end{array}$ & $\begin{array}{l}\text { Specimen } \\
\text { Types }\end{array}$ & $\begin{array}{l}\text { Irradiation } \\
\text { Temperature } \\
\left({ }^{\circ} \mathrm{C}\right)\end{array}$ & $\begin{array}{l}\text { Maximum } \\
\text { Exposure } \\
\text { (dpa) }\end{array}$ & $\begin{array}{l}\text { Number of } \\
\text { Reactor } \\
\text { Cycles }\end{array}$ & \multicolumn{3}{|c|}{$\begin{array}{l}\text { HFIR Cycles } \\
\text { Start - End }\end{array}$} \\
\hline F13A6 & $\begin{array}{l}\text { FeCrAlY } \\
\text { Steel }\end{array}$ & Bend bar & 300 & 47 & 28 & 451 & & 478 \\
\hline IMR8 & various & $\begin{array}{l}\text { MD } \\
\text { specimens }\end{array}$ & 600 & 10 & 5 & 466 & - & 470 \\
\hline IMR10 & various & $\begin{array}{l}\text { MD } \\
\text { specimens }\end{array}$ & 1000 & 10 & 5 & 466 & - & 470 \\
\hline IMR11 & various & $\begin{array}{l}\text { MD } \\
\text { specimens }\end{array}$ & 1000 & 10 & 5 & 466 & & 470 \\
\hline JCR11-07 & $\mathrm{SiC} / \mathrm{SiC}$ & $\begin{array}{l}\text { Mini bend } \\
\text { bars }\end{array}$ & 950 & 100 & 47 & 444 & - & 490 \\
\hline JCR11-08 & $\mathrm{SiC} / \mathrm{SiC}$ & $\begin{array}{l}\text { Mini bend } \\
\text { bars }\end{array}$ & 950 & 200 & 85 & 444 & - & 528 \\
\hline SCF7 & $\mathrm{SiC} / \mathrm{SiC}$ & Bend bars & 600 & 30 & 14 & 457 & - & 470 \\
\hline SCF8 & $\mathrm{SiC} / \mathrm{SiC}$ & Bend bars & 600 & 100 & 45 & 457 & - & 501 \\
\hline SCF9 & $\mathrm{SiC} / \mathrm{SiC}$ & Bend bars & 600 & 200 & 90 & 457 & - & 546 \\
\hline SCF11 & $\mathrm{SiC} / \mathrm{SiC}$ & Bend bars & 950 & 30 & 14 & 458 & - & 471 \\
\hline
\end{tabular}

Table 20. Fusion materials program capsules removed from HFIR at the end of Cycle 465 for damage inspection

\begin{tabular}{|l|l|l|l|l|l|l|l|}
\hline $\begin{array}{l}\text { Experiment } \\
\text { Designation }\end{array}$ & $\begin{array}{l}\text { Primary } \\
\text { Materials }\end{array}$ & $\begin{array}{l}\text { Specimen } \\
\text { Types }\end{array}$ & $\begin{array}{l}\text { Irradiation } \\
\text { Temperature } \\
\left({ }^{\circ} \mathrm{C}\right)\end{array}$ & $\begin{array}{l}\text { Maximum } \\
\text { Exposure } \\
(\mathrm{dpa})\end{array}$ & $\begin{array}{l}\text { Number of } \\
\text { Reactor } \\
\text { Cycles }\end{array}$ & $\begin{array}{l}\text { HFIR Cycles } \\
\text { Start - End }\end{array}$ \\
\hline JCR11-01 & $\mathrm{SiC/SiC}$ & bend bars & 950 & 200 & 101 & 445 & 547 \\
\hline JCR11-05 & $\mathrm{SiC/SiC}$ & bend bars & 950 & 50 & 25 & 444 & 470 \\
\hline JCR11-12 & SiC/SiC & $\begin{array}{l}\text { Mini- } \\
\text { composites }\end{array}$ & 950 & 100 & 45 & 448 & 494 \\
\hline F13B5 & $\begin{array}{l}\text { FeCrAlY } \\
\text { Steel }\end{array}$ & Tensile & 300 & 20 & 18 & 451 & 470 \\
\hline SCF12 & SiC/SiC & bend bars & 950 & 100 & 45 & 458 & 484 \\
\hline
\end{tabular}




\section{PUBLICATION AND PRESENTATION RECORD}

\subsection{PAPERS PUBLISHED IN FY2016 (Alphabetical by first ORNL author)}

C. Ang, C. Silva, C. Shih, T. Koyanagi, Y. Katoh, and S. J. Zinkle. "Anisotropic swelling and microcracking of neutron irradiated $\mathrm{Ti}_{3} \mathrm{AlC}_{2}-\mathrm{Ti}_{5} \mathrm{Al}_{2} \mathrm{C}_{3}$ materials," Scripta Materialia 114 (2016) 74-78.

M. Bannister, F. Meyer, H. Hijazi, K. Unocic, L. Garrison, C. Parish, "Surface morphologies of Heimplanted tungsten," Nuclear Instruments and Methods in Physics Research Section B: Beam Interactions with Materials and Atoms 382 (2016) 76-81. doi: 10.1016/j.nimb.2016.05.003.

D.W. Clark, S.J. Zinkle, M.K. Patel, C.M. Parish, "High temperature ion irradiation effects in MAX phase ceramics," Acta Materialia 105 (2016) 130-146.

L.M. Garrison, Y. Katoh, L.L. Snead, T.S. Byun, J. Reiser, M. Rieth "Irradiation Effects in TungstenCopper Laminate Composite,” Journal of Nuclear Materials 481 (2016) 134-146.

Xunxiang Hu, Takaaki Koyanagi, Makoto Fukuda, Yutai Katoh, Lance L. Snead, and Brian D. Wirth, "Defect evolution in single crystalline tungsten following low temperature and low dose neutron irradiation," Journal of Nuclear Materials 470 (2016) 278-289.

Xunxiang Hu, Takaaki Koyanagi, Makoto Fukuda, N.A.P. Kiran Kumar, Lance L. Snead, Brian D. Wirth, Yutai Katoh, "Irradiation hardening of pure tungsten exposed to neutron irradiation," Journal of Nuclear Materials 480 (2016) 235-243.

N.A.P. Kiran Kumar, C. Li, K.J. Leonard, H. Bei and S.J. Zinkle, "Microstructural Stability and Mechanical Behavior of FeMnNiCr High Entropy Alloy under Ion Irradiation," Acta Materialia 113 (2016) 230-244. doi:10.1016/j.actamat.2016.05.007.

T. Koyanagi, Y. Katoh, K. Ozawa, K. Shimoda, T. Hinoki, L.L. Snead, "Neutron-irradiation creep of silicon carbide materials beyond the initial transient," Journal of Nuclear Materials 478 (2016) 97-111.

T. Koyanagi, M.J. Lance, Y. Katoh, "Quantification of irradiation defects in beta-silicon carbide using Raman spectroscopy,” Scripta Materialia 125 (2016) 58-62.

M. Fukuda, N.A.P.K. Kumar, T. Koyanagi, L.M. Garrison, L.L. Snead, Y. Katoh, A. Hasegawa, "Neutron energy spectrum influence on irradiation hardening and microstructural development of tungsten," Journal of Nuclear Materials 479 (2016) 249-254.

B. Mazumder, X. Yu, P.D. Edmondson, C.M. Parish, M.K. Miller, H.M. Meyer III, Z. Feng, "Effect of friction stir welding and post-weld heat treatment on a nanostructured ferritic alloy," Journal of Nuclear Materials 469 (2016) 200-208. 
F. Meyer, H. Hijazi, M. Bannister, K. Unocic, L. Garrison, C. Parish, "Flux threshold measurements of He-ion beam induced nanofuzz formation on hot tungsten surfaces," Physica Scripta T167 (2016) 014019 (doi: 10.1088/0031-8949/T167/1/014019).

Laila El-Guebaly, Arthur Rowcliffe, Jonathan Menard, Tomas Brown, "An Innovative Strategy to Qualify/Validate Fusion Technologies for U.S.DEMO,” Energies 9 (2016) 632-646.

G.D. Samolyuk, Y.N. Osetsky, and R.E. Stoller, "Molecular dynamics modeling of atomic displacement cascades in 3C-SiC: Comparison of interatomic potentials," Journal of Nuclear Materials 465 (2015) 8388.

C.M. Silva, L.L. Snead, J.D. Hunn, E.D. Specht, K.A. Terrani and Y. Katoh "Application of X-ray microcomputed tomography in the characterization of irradiated nuclear fuel and material specimens," Journal of Microscopy 260-2 (2015) 163-174.

L. L. Snead, Y. Katoh, T. Koyanagi, K. A. Terrani, and E. D. Specht, "Dimensional isotropy of 6H and 3C SiC under neutron irradiation," Journal of Nuclear Materials 471 (2016) 92-96.

L. Tan, Y. Katoh, A.-A.F. Tavassoli, J. Henry, M. Rieth, H. Sakasegawa, H. Tanigawa, Q. Huang, "Recent status and improvement of reduced-activation ferritic-martensitic steels for high-temperature service,” Journal of Nuclear Materials 479 (2016) 515-523.

L. Tan, L.L. Snead, Y. Katoh, "Development of new generation reduced activation ferritic-martensitic steels for advanced fusion reactors," Journal of Nuclear Materials 478 (2016) 42-49 (doi:10.1016/j.jnucmat.2016.05.037.).

K.A. Unocic and D.T. Hoelzer, "Evaluation of Pb-17Li Compatibility of ODS Fe-12Cr-5Al Alloys," Journal of Nuclear Materials 479 (2016) 357-364.

K.A. Unocic, B.A. Pint, and D.T. Hoelzer, "Advanced TEM characterization of oxide nanoparticles in ODS Fe-12Cr-5Al alloys," Journal of Materials Science 51 (2016) 9190-9206, (DOI 10.1007/s 10853016-0111-5).

Z. Yu, Z. Feng, D. Hoelzer, L. Tan, and M. Sokolov, "Friction Stir Welding of ODS and RAFM Steels," Metallurgical and Materials Transactions E 2 (2015) 164-172 (doi:10.1007/s40553-015-0054-9).

Steven J Zinkle, “Applicability of copper alloys for DEMO high heat flux components," Physica Scripta T167 (2016) 014004 (doi:10.1088/0031-8949/2015/T167/014004). 


\subsection{PAPERS SUBMITTED IN FY 2016 (Currently awaiting publication)}

C. Ang, C. Shih, C. Silva, S. Zinkle, N. Cetiner, Y. Katoh, "Phase stability, swelling, microstructure and strength of $\mathrm{Ti}_{3} \mathrm{SiC}_{2}-\mathrm{TiC}$ ceramics after low dose neutron irradiation," accepted by Journal of Nuclear Materials.

C. Ang, C. Shih, C. Parish, Y. Katoh, "Microstructure and mechanical properties of neutron irradiated titanium aluminum carbides at elevated temperatures," accepted by Journal of the European Ceramic Society.

L.M. Garrison, Y. Katoh, L.L. Snead, T.S. Byun, J. Reiser, M. Rieth, "Irradiation Effects in TungstenCopper Laminate Composite," submitted to Journal of Nuclear Materials.

D.T. Hoelzer and K.A. Unocic, "Influence of Microstructure on the Tensile Strength of ODS Fe-12Cr5Al Ferritic Alloys," submitted to Journal of Materials Science.

Chad M. Parish, Kinga Unocic, Lizhen Tan, Steven Zinkle, Sosuke Kondo, Lance Snead, David Hoelzer, Yutai Katoh, "Sequestration of cavities at nanoparticle-matrix interfaces in helium + heavy ion irradiated nanostructured ferritic alloys," submitted to Journal of Nuclear Materials.

Chad M. Parish, Kun Wang, Russel P. Doerner, and Matthew J. Baldwin, "Grain orientations and grain boundaries in tungsten nanotendril fuzz grown under divertor-like conditions," accepted by Scripta Materialia.

S. J. Pawel and K. A. Unocic, "Compatibility of an FeCrAl Alloy with Flowing Pb-Li in a Thermal Convection Loop," submitted to Journal of Nuclear Materials.

L. El-Guebaly, L. Mynsberge, A.Davis, C.D'Angelo, A. F. Rowcliffe, B.Pint, and the ARIES-ACT Team, "Design and Evaluation of Nuclear System for ARIES-ACT2 Power Plant with DCLL Blanket," submitted to Fusion Science and Technology.

G. D. Samolyuk, Y. N. Osetskiy and R. E. Stoller, "Properties of Vacancy Complexes with Hydrogen and Helium Atoms in Tungsten from First Principles," accepted for a special issue of Fusion Science and Technology.

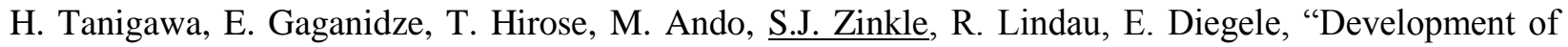
Benchmark Reduced Activation Ferritic/Martensitic Steels for Fusion Energy Applications," accepted for Nuclear Fusion, Special Issue on Materials for a Fusion Reactor.

S.J. Zinkle, J-L. Boutard, D.T. Hoelzer, A. Kimura, R. Lindau, G.R. Odette, M. Rieth, L. Tan, H. Tanigawa, "Development of Next Generation Tempered and ODS Reduced Activation Ferritic/Martensitic Steels for Fusion Energy Applications," accepted for Nuclear Fusion, Special Issue on Materials for a Fusion Reactor. 
S. M. González de Vicente, J.-L. Boutard, S. J. Zinkle, H. Tanigawa, "Materials Testing Facilities and Programmes for Fission and Ion implantation damage," accepted for Nuclear Fusion, Special Issue on Materials for a Fusion Reactor. 


\subsection{PRESENTATIONS (Includes only OFES-funded ORNL Presenting Authors, by date presented)}

Plenary, Invited and Oral Presentations at ICFRM 17, October 11-16, 2015, Aachen, Germany

L.M. Garrison, L.L. Snead, N.A.P. Kiran Kumar, T.S. Byun, J. Reiser, M. Rieth, "Irradiation effects in copper-tungsten laminate composite”.

X. Hu, T. Koyanagi, M. Fukuda, Y. Katoh, L. L. Snead, B. Wirth, "Defect Evolution in single crystal tungsten following low temperature and low dose neutron irradiation”.

Y. Katoh, T. Koyanagi, J.O. Kiggans, C.H. Henager, S.T. Gonczy, T. Hinoki, M. Ferraris, "Development and evaluation of silicon carbide joining technologies for fusion".

B.K. Kim, C.M. Parish, H. Sakasegawa, L. Tan, Y. Katoh, "Effect of helium on microstructure and properties of nickel-doped ferritic/martensitic steels".

T. Koyanagi, Y. Katoh, K. Ozawa, K. Shimoda, T. Hinoki, L. L. Snead, "High dose neutron irradiation creep of silicon carbide materials".

Y.Osetsky and R.Stoller, "He-vacancy defects in Fe: equilibrium and hardening mechanisms".

C. M. Parish, K. A. Unocic, L. Tan, B.-K. Kim, S. J. Zinkle, S. Kondo, L. L. Snead, D. T. Hoelzer, M. E. Bannister, and Y. Katoh, "Comparing helium mitigation in nanostructured steels".

L.L. Snead, L.M. Garrison, N.A.P. Kiran Kumar, Y. Katoh, M. R. McAlister, W. D. Lewis, T.S. Byun, M. Fukuda, and A. Hasegawa. "Mechanical properties and microstructures of neutronirradiated tungsten".

L. Tan, "RAFM steels: status and enhancement for high temperature performance".

Y. Yamamoto, P.J. Maziasz, A.F. Rowcliffe, and L.L. Snead, 'Development of 'Advanced' 3Cr3WV(Ta) Bainitic Steels for Fusion Structural Applications”.

S.J. Zinkle, M. Eldrup, S.A. Fabritsiev, N.M. Ghoniem, S.I. Golubov, H.L. Heinisch, S. Ishino, Yu.N. Osetsky and M. Victoria, "Bachu Narain Singh: Enduring Impact on Radiation Damage Physics".

\section{Poster Presentations at ICFRM 17, October 11-16, 2015, Aachen, Germany}

C. Ang, Y. Katoh, T. Toyama, T. Shikama and S.J. Zinkle, "Mechanical and microstructural effects of neutron irradiation on Ti-Si-C and Ti-Al-C MAX phase ceramics".

P. D. Edmondson, N.A.P. Kiran Kumar, L. L. Snead, Y. Katoh, “Atom probe tomography study of neutron-irradiation-induced sigma phases in tungsten". 
L. Garrison and E. Ohriner, "Fabrication of functionally graded tungsten-steel laminate plasmafacing material”.

D. Hoelzer, L. Tan, W. Tang, Z. Feng, "Solid-state mixing between the ODS 14YWT alloy and 9 Cr steel along a friction stir welded butt joint”.

C.H. Henager, B.N. Nguyen, R.J. Kurtz, T. Roosendaal, B. Borlaug, M. Ferraris, A. Ventrella, Y.

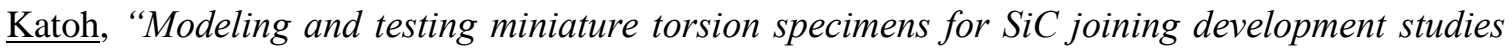
for fusion”.

Takaaki Koyanagi, Caen Ang, Chinthaka Silva, Anne Campbell, Yutai Katoh and Steve Zinkle, "Properties of commercial $M_{n+1} A X_{n}(M A X)$ phases after neutron irradiation".

C. Li, D.W. Clark, J. Brechtl, N.A.P. Kiran Kumar, C. Ang, A.G. Perez-Bergquist, H. Bei, C.M. Parish and S.J. Zinkle, "Investigation of radiation resistance of several novel potential fusion structural materials systems".

K. Nordlund, A. E. Sand, F. Granberg, S.J. Zinkle, R. Stoller, R.S. Averback, T. Suzudo, L. Malerba, F. Banhart, W.J. Weber, F. Willaime, S. Dudarev and D. Simeone, "Improving the DPA equation to account for athermal defect recombination and radiation mixing: ARC-DPA and RPA".

C. M. Parish, N. A. P. Kiran Kumar, P. D. Edmondson, K. G. Field, C. Silva, A. M. Williams, K. Linton, and K. J. Leonard, "Irradiated materials microscopy in the ORNL LAMDA facility".

C. M. Parish, T. Koyanagi, T. J. Gerczak, D. N. Leonard, X. Sang, J. M. LeBeau, G. Samolyuk, M. P. Oxley, S. Kondo, and Y. Katoh, "Advanced electron microscopy of irradiated ceramics".

S. Pawel and Y. Yamamoto, "Compatibility assessment of Fe21Cr5Al in a thermal convection loop with flowing Pb-Li eutectic”.

G. D. Samolyuk and Y. N. Osetsky, "Thermodynamic approach to the stability of multiphase systems: application to the $\mathrm{Y}_{2} \mathrm{O}_{3}-\mathrm{Fe}$ system”.

G. D. Samolyuk, Y. N. Osetsky, X. Hu, and R.E. Stoller, "DFT study of vacancy - H/He complexes in tungsten".

Roger. E. Stoller, Yuri Osetskiy, and Beau Wesh, "Dispersed barrier hardening parameters from atomistic simulations".

L. Tan, L.L. Snead, Y. Katoh, "Development of cast nanostructured alloys for fusion reactors". 
Y. Yamamoto, J.K. Thomson, J.R. Keiser, L.L. Snead, and M. Rieth, "Fabrication of low activation ferritic-martensitic steels containing ${ }^{54} \mathrm{Fe}$ isotope".

X. Yu, B. Mazumder, M. K. Miller, W. Tang, D. T. Hoelzer, and Z. Feng, "Characterization of friction stir welded ODS ferritic alloys".

Invited Tutorial Lecture at Preconference Symposium Associated with ICFRM 17

Roger. E. Stoller, "Computational theory and modeling relevant to fusion reactor materials," Special Tutorial Lecture, Seventeenth International Conference on Fusion Reactor Materials, 1116 October 2015, Aachen, Germany.

Materials Science \& Technology 2015, Columbus, OH, Oct. 4-8, 2015

M. R. McAlister, L. M. Garrison, R. K. Nanstad, M. A. Sokolov, E. T. Manneschmidt, C. M. Silva, B. D. Eckhart, "Irradiated materials mechanical testing capability in the ORNL LAMDA facility".

J. Brechtl, N.A.P. Kiran Kumar, X. Xie, P. Liaw, S.J. Zinkle, "Effects of ion irradiation on the serration behavior of Zr52.5Cu17.9Ni14.6Al10Ti5 (BAM-11) bulk metallic glass," Symposium on Large Fluctuations and Collective Phenomena in Materials II.

L.M. Garrison, Y. Katoh, L.L. Snead, N. A. P. Kiran Kumar, P. Edmondson, C. Parish, T. Colling, T.S. Byun, b, J. Reiser, M. Rieth, "FNSF challenges and new directions for tungsten PFCs," FNSF meeting, October 27-30, 2015, Denver, Colorado.

S.J. Zinkle, "Research synergies for development of high performance materials," Invited keynote, Workshop on Cross-cutting Issues in Structural Materials R\&D for Future Energy Systems, European Commission Joint Research Center, Institute for Energy and Transport, Petten, The Netherlands, Nov. 2526, 2015.

American Physical Society, Division of Plasma Physics (APS-DPP), Savannah, Georgia, Nov. 16-20, 2015

C. M. Parish, P. D. Edmondson, F. W. Meyer, M. E. Bannister, L. M. Garrison, K. A. Unocic, X. $\mathrm{Hu}$, and Y. Katoh, "Materials research for PMI at Oak Ridge National Laboratory".

F. W. Meyer, H. Hijazi, M. E. Bannister, L. M. Garrison, C. M. Parish, and K. A. Unocic, "Flux threshold measurements of nano-fuzz formation by He-ion beam impact on hot tungsten surfaces".

Fusion Power Associates 36th Annual Meeting: Strategies to Fusion Power, Washington DC, Dec. 1516, 2015.

S.J. Zinkle, "Materials Prospects for Fusion Power Plants" (invited). 
40th International Conference and Expo on Advanced Ceramics and Composites, Daytona Beach, FL, January 24-29, 2016

D.J. Sprouster, S.K. Ghose, E. Dooryhee, L.E Ecker, T. Koyanagi, Y. Katoh, "Quantifying radiation damage in silicon carbide with high-energy $x$-rays".

J. Fellows, C. Lewinsohn, Y. Katoh, T. Koyanagi, "Low temperature air braze process for joining silicon carbide composites used in heat exchangers, fusion and fission reactors, and other energy production and chemical synthesis systems".

TMS Annual Meeting, Nashville, TN, February 14-18, 2016

J. Brechtl, N.A.P. Kiran Kumar, H. Bei, S.J. Zinkle, "Effects of Neutron Irradiation on BAM-11 Bulk Metallic Glass, ”Symposium on Accelerated Materials Evaluation for Nuclear Application Utilizing Test Reactors, Ion Beam Facilities and Integrated Modeling.

L. Garrison, E. Ohriner, and Y. Katoh, "Fabrication of Functionally Graded Tungsten-Steel Laminate Plasma-Facing Material".

N.A.P. Kiran Kumar, C. Li, H. Bei, K.J. Leonard and S.J. Zinkle, "Ion Irradiation Effects on Microstructure and Mechanical Properties of High Entropy Alloy," Symposium on High Entropy Alloys IV.

C. Li, A. Tamm, G.M. Stocks, A. Alvo, K. Mattias, A. Caro, B.D. Wirth, and S.J. Zinkle, "Vacancy formation and migration energy of high entropy alloy," Symposium on High Entropy Alloys IV.

C. Li, N.A.P. Kiran Kumar, H. Bei, B.D. Wirth, G.M. Stocks and S.J. Zinkle, "Evaluation of Radiation Effects in FeMnNiCr High Entropy Alloy", Symposium on Accelerated Materials Evaluation for Nuclear Application Utilizing Test Reactors, Ion Beam Facilities and Integrated Modeling.

Chinthaka M. Silva, Yutai Katoh, Eliot Specht, Joh Hun, Kurt Terrani, Keith Leonard, "X-ray tomography for nondestructive examination of nuclear materials".

S.J. Zinkle, C.M. Parish and D.W. Clark, "Spatial Scales for Designing Radiation-Resistant Materials," Symposium on Nanostructured Materials for Nuclear Application.

Materials Research Society (MRS) 2016 Spring Meeting, Phoenix, AZ, March 28-April 1, 2016

Xunxiang Hu, Takaaki Koyanagi, Makoto Fukuda, Lauren M. Garrison, Philip D. Edmondson, Chad M. Parish, Yutai Katoh, and Lance L. Snead, "Irradiation hardening of single crystal tungsten exposed to neutron irradiation”. 
R.E. Stoller and Y.N. Osetsky, "Determining Local Defect Hardening via Atomistic Simulations".

Y.N. Osetsky and R.E. Stoller, "Temperature and strain rate effects in modeling nanoscale plasticity".

A.F. Rowcliffe, "Recent Progress on Materials Issues," FNSF Project Meeting, Denver CO, April 5-7, 2016.

Materials Challenges in Alternative \& Renewable Energy 2016, Clearwater FL, April 17-21, 2016

Caen Ang, C. Shih, C. Silva, C. Parish, T. Koyanagi, S. J. Zinkle, Y. Katoh, "Properties of commercial $M_{n+1} A X_{n}$ phase materials after neutron irradiation: Assessment for current and advanced nuclear reactors".

Y. Katoh, T. Koyanagi, M. Ferraris, "Radiation Tolerance of Pressurelessly Processed Silicon Carbide Joints".

A.S. Sabau, Y. Katoh, S. Zinkle, J. O. Kiggans, and C.R. Schaich, "Plasma-Arc Lamp Facility for Testing Li-based Divertor Concepts", a webinar presentation to Princeton Plasma Physics Laboratory Seminar Series "Liquid Metal PFC Strategy," May 17, 2016.

Xunxiang Hu, "Multiscale Investigation of Gas Behavior in Structural Materials in Fusion and Fission Energy Environments: A Combined Experimental and Modeling Approach," Invited talk presented at:

- Shanghai University, Shanghai, China, May 09, 2016,

- Shanghai Jiao Tong University, Shanghai, China, May 11, 2016.

S.J. Zinkle, "Foundations of Fusion Materials Science," Institute of Plasma Physics, Chinese Academy of Sciences, Hefei, China, May 16, 2016.

S.J. Zinkle, "Structural Materials for Nuclear Energy: Challenges and Recent Results, ” Phoenix Science and Technology Lecture, Institute of Nuclear Energy Safety Technology, Chinese Academy of Sciences, Hefei, China, May 17, 2016.

3rd China Fusion Materials Conference, Chengdu, China, May 19, 2016

S.J. Zinkle, "Frontiers of Fusion Materials Research \& Development".

C.M. Parish, M. Gussev, P.D. Edmondson, T. Koyanagi, and T. Gerczak, "EBSD of Nuclear and Irradiated Materials," invited presentation at Electron Backscatter Diffraction 2016, Tuscaloosa, AL, May 2016. 
22nd International Conference on Plasma-Surface Interactions in Controlled Fusion Devices (PSI), Rome, Italy, May-June 2016

C.M. Parish, K. Wang, K.G. Field, Y. Katoh, F.W. Meyer, M.E. Bannister, R.P. Doerner, M.J. Baldwin, and D. Donovan, "The microstructure of plasma-exposed tungsten and tungsten nanotendrils".

L. Garrison, Y. Katoh, W. Geringer, T. Koyanagi, X. Hu, C. Parish, P. Edmondson, J.L. McDuffee, C. Petrie, R. Howard, N.A.P. Kiran Kumar, M. Fukuda, T. Hwang. "Research on Tungsten for Fusion Reactors at Oak Ridge National Laboratory,” Tohoku University, Japan, June 13, 2016.

L. M. Garrison, Y. Katoh, T. Koyanagi, X. Hu, C. Parish, P. Edmondson, N.A.P. Kiran Kumar, G.L. Kulcinski. "Research on Tungsten for Fusion Reactors at Oak Ridge National Laboratory," Nagoya University, Japan, June 15, 2016.

L.M. Garrison, Y. Katoh, W. Geringer, T. Koyanagi, X. Hu, C. Parish, P. Edmondson, J.L. McDuffee, C. Petrie, R. Howard, N.A.P. Kiran Kumar, "Research on Tungsten for Fusion Reactors at Oak Ridge National Laboratory, ” National Institute for Fusion Science, Japan, June 16, 2016.

L.M. Garrison, Y. Katoh, W. Geringer, T. Koyanagi, X. Hu, C. Parish, P. Edmondson, J.L. McDuffee, C. Petrie, R. Howard, N.A.P. Kiran Kumar, M. Fukuda, T. Hwang, "Research on Tungsten for Fusion Reactors at Oak Ridge National Laboratory, ” Kyoto University, Japan, June 17, 2016.

Topical Meeting on Nuclear Fuels and Structural Materials, American Nuclear Society Annual Meeting, New Orleans, June 12-16, 2016

C.M. Parish, P.D. Edmondson, K.G. Field, K. Terrani, R.L. Seibert, and Y. Katoh, "Recent Advances in Analytical Electron Microscopy for Irradiated Materials".

S.J. Zinkle, C.K. Ang, N.A.P. Kiran Kumar, C. Li, J. Brechtl, H. Bei, "Radiation Effects in Innovative Structural Materials".

S.J. Zinkle, "Next Generation Steels for Fission and Fusion Energy Applications," Northwest Polytechnic University, Xian, China, June 21, 2016.

Fourth International Workshop on Structural Materials for Innovative Nuclear Systems (SMINS-4), Manchester, United Kingdom, July 11-14, 2016

S.J. Zinkle, C. Ang, N.A.P. Kiran Kumar, A.G. Perez-Bergquist, C. Li, D.W. Clark, J. Brechtl, H. Bei, and C.M. Parish, (keynote), "Radiation Resistance of Several Novel Potential Fusion Structural Materials Systems".

S.J. Zinkle, "Roles and limitations of ion irradiation studies for understanding neutron irradiation behavior," invited panelist, discussion on ion vs. neutron irradiation. 
ORNL summer school: Modeling, experiment, and validation (MeV), Oak Ridge, TN, July 18, 2016

C. M. Parish, "Characterization of Radiation Damage".

S.J. Zinkle, "Structural Materials for Fusion Energy Applications".

Microscopy and Microanalysis 2016, Columbus, OH, USA, July 2016

C.M. Parish, R.P. Doerner, M.J. Baldwin, D. Donovan, K.G. Field, and Y. Katoh, "Microscopy of Plasma-Materials Interactions in Tungsten for Fusion Power".

American Nuclear Society, 22nd Topical Meeting on the Technology of Fusion Energy (TOFE), Philadelphia, PA, August 23, 2016

L.M. Garrison, Y. Katoh, J. Reiser, M. Rieth "Microstructural Changes and Mechanical Behavior of Tungsten-Copper Laminate Composite after Neutron Irradiation".

L.M. Garrison, F.W. Meyer, M.E. Bannister, "The Influence of Microstructure on Deuterium Retention in Polycrystalline Tungsten".

Xunxiang Hu, Takaaki Koyanagi, Yutai Katoh, "Positron annihilation spectroscopy investigation of vacancy clusters in neutron-irradiated $3 C$-SiC".

Yutai Katoh, Daniel Clark, Yoshio Ueda, Yuji Hatano, Minami Yoda, Adrian S. Sabau, Takehiko Yokomine, Lauren M. Garrison, Wilna Geringer, Akira Hasegawa, Tatsuya Hinoki, Masashi Shimada, Dean Buchenauer, Yasuhisa Oya, Takeo Muroga, "Progress in the US/Japan PHENIX Project for the Technological Assessment of Plasma Facing Components for DEMO Reactors".

B.A. Pint, S.J. Pawel, "Thermal Convection Loop Testing of an FeCrAlMo Alloy at 550 and $600^{\circ} \mathrm{C}$, .

S.J. Zinkle, L.L. Snead and B.D. Wirth, "Pathways for Fusion Energy: Impact of Materials Options".

29th Symposium of Fusion Technology (SOFT 2016), Prague, Czech Republic, September 5-9, 2016

S.J. Zinkle, Y. Yang and L.L. Snead, "Design of high-strength, high-conductivity, creep-resistant Cu alloys for fusion high heat flux structures". 